\title{
EFFECTS OF COAGULATION ON THE REMOVAL OF NATURAL ORGANIC MATTER, GENOTOXICITY, AND PRECURSORS TO HALOGENATED FURANONES
}

by

Dana Zheng

A thesis submitted in conformity with the requirements

for the degree of Master of Applied Science

Graduate Department of Civil Engineering

University of Toronto

C Copyright by Dana Zheng 2013 


\title{
EFFECTS OF COAGULATION ON THE REMOVAL OF NATURAL ORGANIC MATTER, GENOTOXICITY, AND PRECURSORS TO HALOGENATED FURANONES
}

\author{
Dana Zheng \\ Master of Applied Science, 2013 \\ Department of Civil Engineering \\ University of Toronto
}

\begin{abstract}
Disinfectants in drinking water can interact with natural organic matter (NOM) to form disinfection by-products (DBPs). Halogenated furanones (including MX and MCA) are a group of emerging DBPs that can account for a significant amount of the total mutagenicity found in drinking water. Source water characteristics and NOM removal capabilities of coagulation can greatly influence the formation of DBPs. This project examines the effects of bench scale coagulation and chlorination tests on NOM removal, DBP formation, and genotoxicity. NOM was characterized using liquid chromatography-organic carbon detection (LC-OCD).
\end{abstract}

Experiments with Ottawa River, Otonabee River, and Lake Simcoe waters show that DBPs decreased with increases in coagulant dosage, due to the removal of NOM during coagulation. DBP formation and speciation was then compared with NOM content to identify specific fractions that contribute to the formation of these DBPs. Genotoxicity was directly linked to MX presence in chlorinated waters. 


\section{ACKNOWLEDGEMENTS}

This work was funded in part by the Natural Sciences and Engineering Research Council of Canada (NSERC) Chair in Drinking Water Research and through the Ontario Graduate Scholarship in Science and Technology.

I would like to thank my co-supervisors, Professor Robert C. Andrews and Professor Susan A. Andrews, for their support and guidance throughout this journey. Their expertise and encouragement were immensely helpful not only to my research, but also in my academic and professional life.

I am indebted to Jim Wang and Liz Taylor-Edmonds for their many hours of help with lab experiments. Similarly, the collaborative efforts of Sabrina Diemert, Nicolas Peleato, Alex Balmus, and Chunkei Tang over the course of the summer months truly cannot be overlooked. Thanks to John Armour at the Peterborough Utilities Commission, Laura Meteer at the Regional Municipality of York, and Ian Douglas \& colleagues at the City of Ottawa for providing and shipping the carboys upon carboys of water. As well, thanks to Dr. Monica Tudorancea \& colleagues at the University of Waterloo for processing the LC-OCD samples. Big thanks to everyone in the Drinking Water Research Group, GB $4^{\text {th }}$ floor/lunch room friends, and the GB431 crew for always being there with words of encouragement and helping hands. Your friendship and camaraderie got me through many long lab days/nights.

Finally, I would like to thank my parents, Geoff, and my amazing friends for their support, encouragement, and guidance. I couldn't have done it without you! 


\section{TABLE OF CONTENTS}

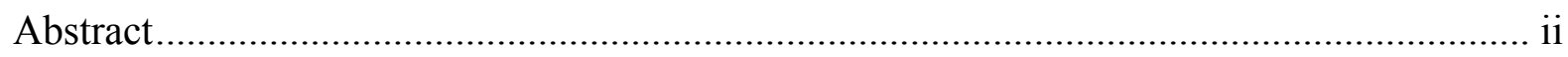

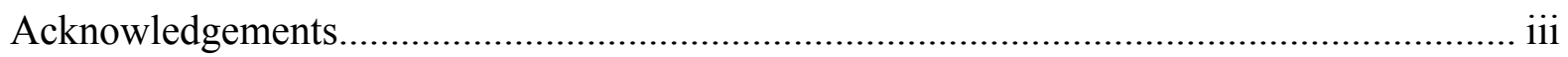

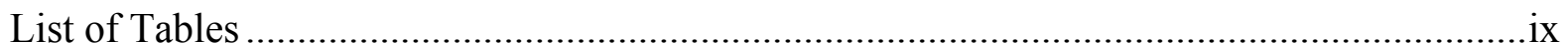

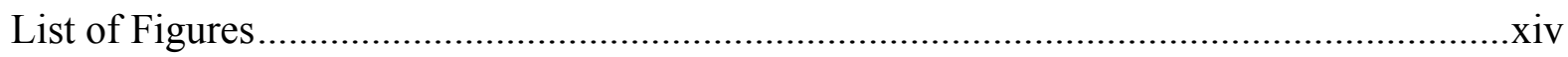

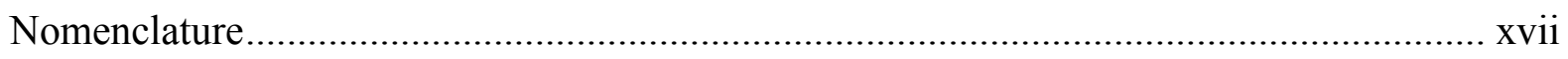

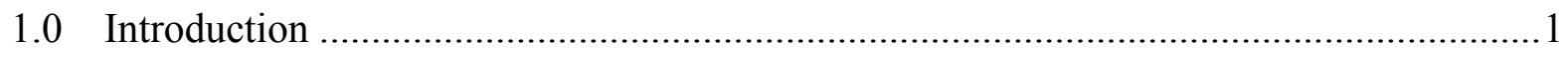

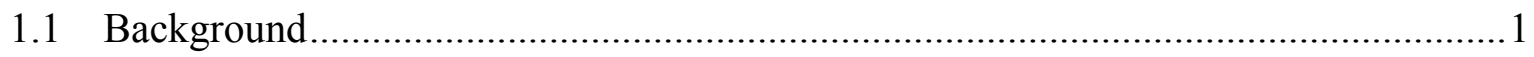

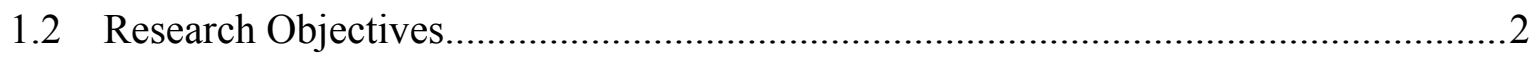

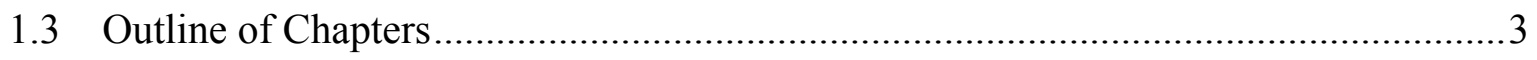

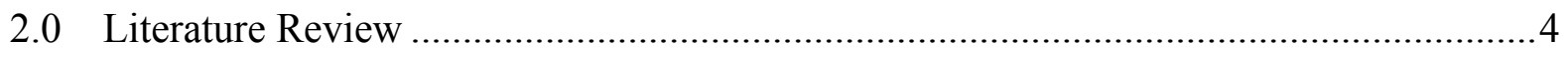

2.1 Disinfection By-Products ……………………............................................

2.2 Halogenated Furanones ………………………...........................................

2.2.1 Chemical Properties of MX Analogues ...........................................................6

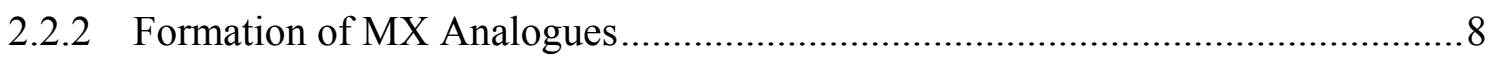

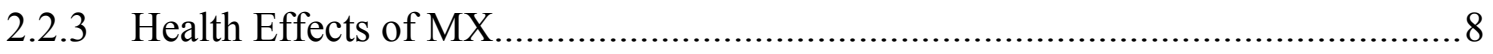

2.3 Toxicological Evaluation of Drinking Water ……….............................................10

2.4 Natural Organic Matter (NOM) ......................................................................11

2.5 Conventional Water Treatment.........................................................................12

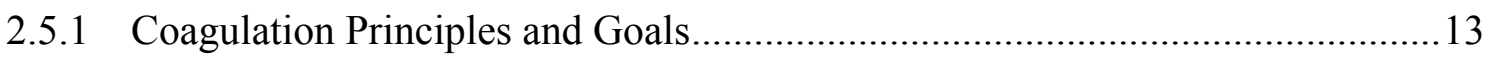




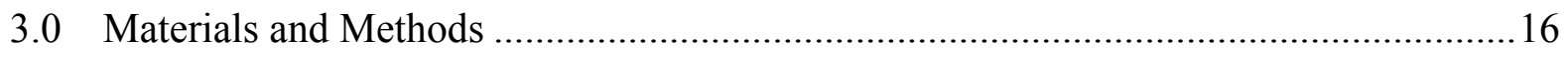

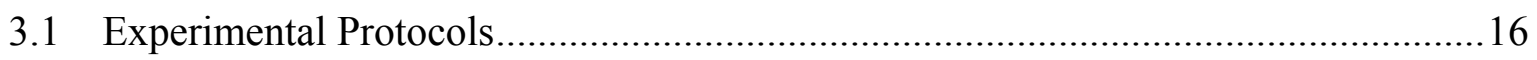

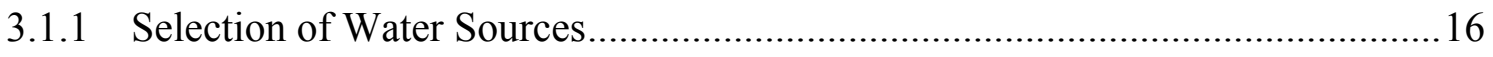

3.1.2 Bench-Scale Treatment Sequence ................................................................ 18

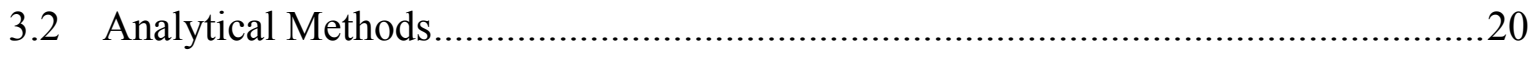

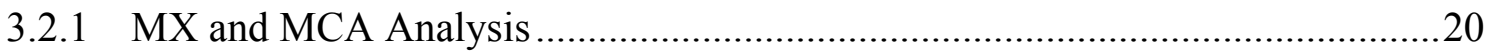

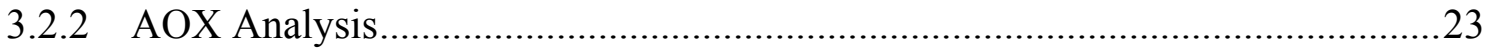

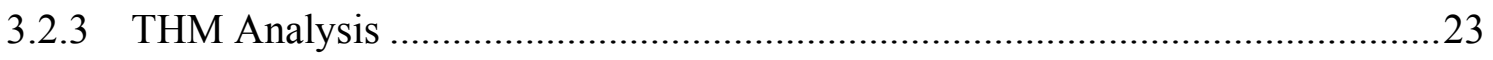

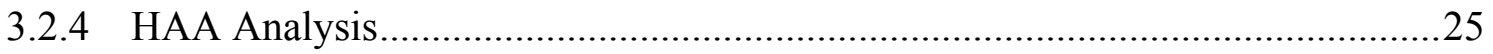

3.2.5 Genotoxicity Analysis with the SOS Chromotest .......................................2

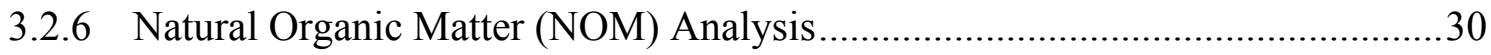

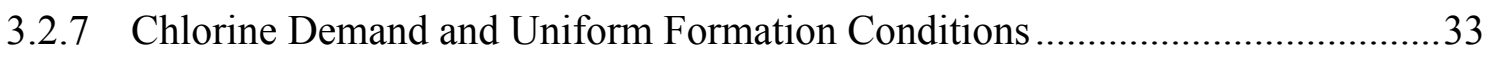

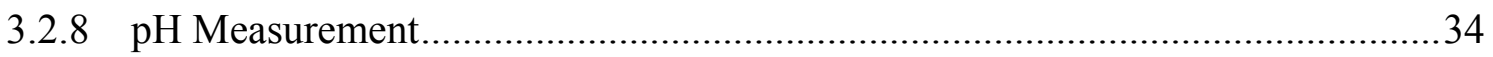

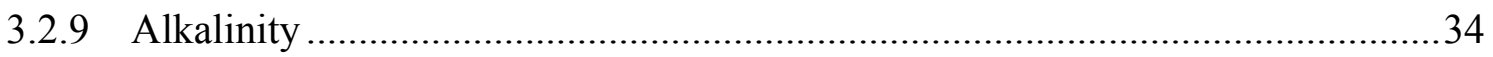

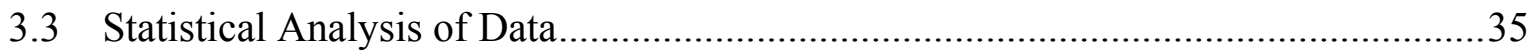

3.3.1 Determination of Chlorine Residual Influence on DBP Formation ....................35

3.3.2 Hypothesis Testing for Correlation Significance ......................................... 37

3.3.3 Determination of Source Water Effect on DBP Formation Modeling ................37 
4.0 MCA and MX Method Development

4.1 Sample Preparation and Extraction for Analysis.

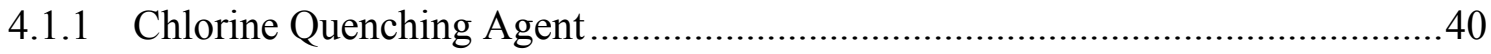

4.1.2 Acidification of Water Samples.............................................................. 40

4.1.3 Mucobromic Acid as a Surrogate Standard ................................................ 41

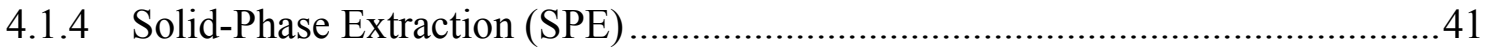

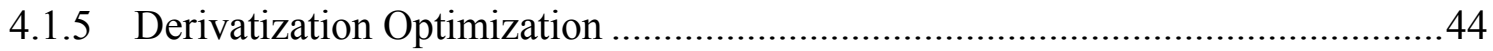

4.1.6 Final Concentration of Sample .......................................................... 46

4.2 Gas Chromatography with Election Capture Detection (GC-ECD) .......................46

4.2.1 Selection of Internal Standard for GC-ECD Analysis ..................................48

4.2.2 Analysis of Chlorinated Water Samples ...................................................48

4.3 Gas Chromatography Tandem Mass Spectrometry (GC/MS/MS) .........................49

4.3.1 Calibration Curves for MX Compounds .................................................52

5.0 Evaluation of Precursors to MX and Other DBPs, Genotoxicity - Effect of

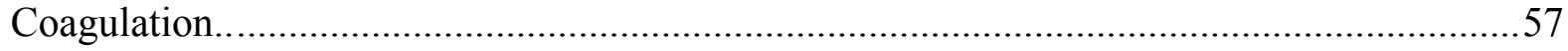

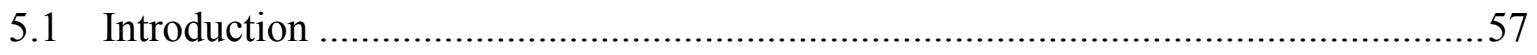

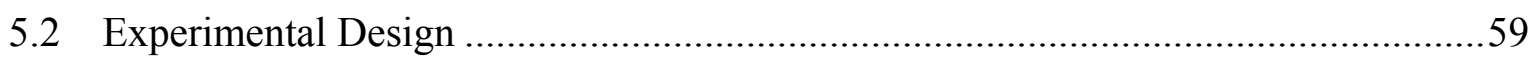

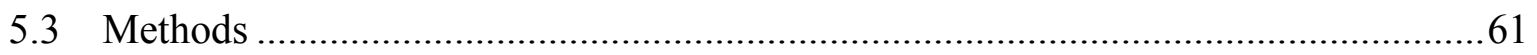

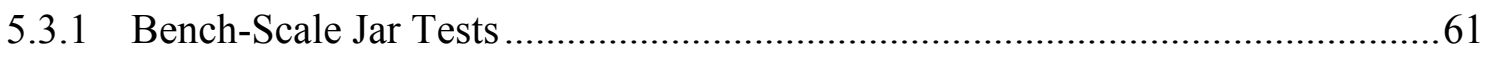

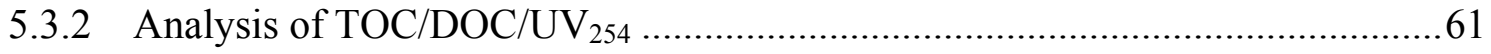


5.3.5 Analysis of Genotoxicity.....

5.4 Evaluation of Coagulation for Minimizing DBP Formation and Genotoxicity

Potential .66

5.5 NOM Content and DBP Formation 76

5.6 Comparison of Established DBPs (AOX/THMs/HAAs) with MX Compounds and Genotoxicity

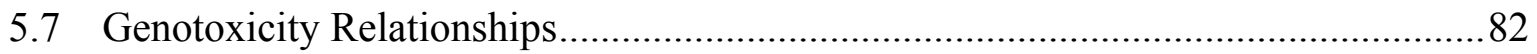

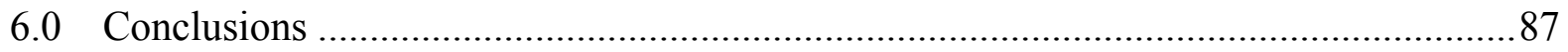

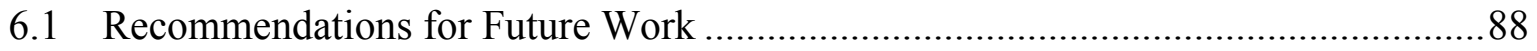

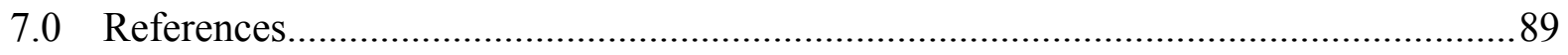

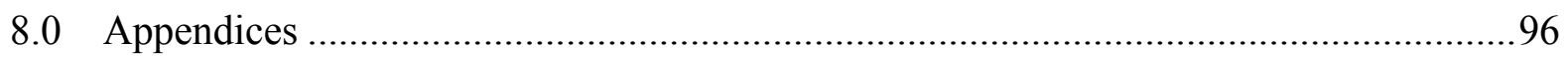

8.1 Alum Concentration Conversion Data.........................................................96

8.2 Ottawa River Experiment Data............................................................... 97

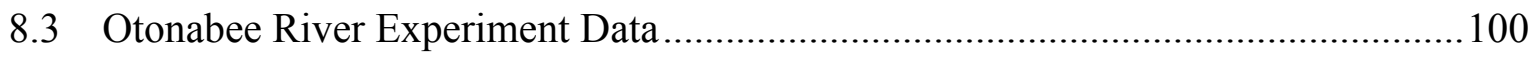

8.4 Lake Simcoe Experiment Data ........................................................................ 103

8.5 Contribution of Measured DBPs to AOX - Sample Calculations .......................... 106

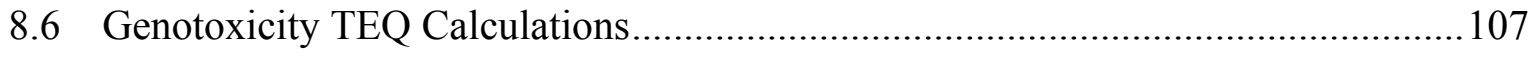

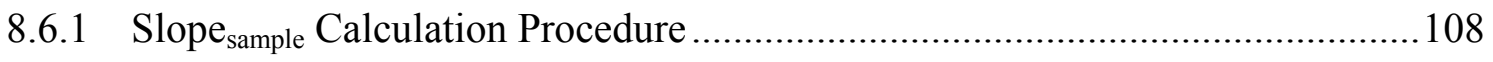


8.6.2 Slope 4 -NQO sosiP Calculation Procedure.

8.6.3 TEQ 4 -NQO Calculations.

8.7 Statistical Analyses Data and Sample Calculations.

8.7.1 Two-way ANOVA for the Determination of Chlorine Residual Influence on DBP Formation.

8.7.2 Hypothesis Testing for Correlation Significance between NOM and DBP Formation. 115

8.7.3 Determination of Source Water Effect on DBP Formation Modeling 


\section{LIST OF TABLES}

Table 2.1 - Chemical Structures of halogenated furanones (MX analogues) ........................ 6

Table 2.2 - Optimal TOC removal percentages by enhanced coagulation for plants using conventional treatment: Step 1 Disinfection By-Product Rule (USEPA, 1999)

Table 3.1 - Raw water characteristics of three Ontario source waters

Table 3.2 - SUVA as an indicator of NOM composition and coagulation efficacy (adapted

from Edzwald \& Tobiason, 1999)

Table 3.3 - Summary of sample collection after jar testing and filtration

Table 3.4 - GC/MS instrument conditions for MCA/MX analysis

Table 3.5 - MS/MS conditions and monitored ions

Table 3.6 - GC-ECD operating conditions for THM analysis

Table 3.7 - GC-ECD operating conditions for HAA analysis .26

Table 3.8 - TOC/DOC reagents .31

Table 3.9 - TOC instrument conditions

Table 4.1 - Percent recovery of MX in SPE with HLB cartridges.

Table 4.2 - GC-ECD instrument conditions for MX analysis .46

Table 4.3 - Peaks and retention times in this analysis compared with USEPA (2008)

Table 4.4 - GC/MS operating conditions for the analysis of MX analogues.....

Table 4.5 - MS/MS optimized conditions........

Table 4.6 - Concentrations of MX compounds found in Otonabee River water samples .55 
Table 5.1 - Raw water characteristics of the three Ontario, Canada source waters

Table 5.2 - SUVA as an indicator of NOM composition and coagulation efficacy (adapted from Edzwald \& Tobiason, 1999)

Table 5.3 - Optimal TOC removal percentages by enhanced coagulation for plants using conventional treatment: Step 1 Disinfection By-Product Rule (USEPA, 1999)

Table 5.4 - Enhanced coagulation target alum doses $(\mathrm{mg} / \mathrm{L})$ for each source water .68

Table 5.5 - Comparison of DBP formation to Krasner et al. (2006). .70

Table 5.6 - Correlations $\left(\mathrm{R}^{2}\right)$ between DBP formation and water quality parameters - Ottawa River water. .77

Table 5.7 - Correlations $\left(\mathrm{R}^{2}\right)$ between DBP formation and water quality parameters Otonabee River water .78

Table 5.8 - Correlations $\left(\mathrm{R}^{2}\right)$ between DBP formation and water quality parameters - Lake Simcoe water .78

Table 5.9 - Correlations (R) between specific DBPs formed - Ottawa River water .81

Table 5.10 - Correlations (R) between species of DBPs formed - Otonabee River water.....81

Table 5.11 - Correlations (R) between species of DBPs formed - Lake Simcoe water

Table 5.12 - Percent contributions of MX and unknown portions to toxicity equivalent concentration (TEQ4-NQO) and AOX in Ottawa River water

Table 5.13 - Percent contributions of MX and unknown portions to toxicity equivalent concentration $\left(\mathrm{TEQ}_{4-\mathrm{NQO}}\right)$ and $\mathrm{AOX}$ in Lake Simcoe water. .86

Table 8.1 - Conversion of alum concentrations for dosages used in jar tests ...... .97

Table 8.2 - Ottawa River jar test results - TOC/DOC/UV/SUVA/NOM fractions .97 
Table 8.3 - Ottawa River chlorination results

Table 8.4 - Ottawa River DBP formation results - AOX/THMs/HAAs/AOX/MCA/MX .....98

Table 8.5 - Ottawa River - TTHM by specific compounds ......................................... 99

Table 8.6 - Ottawa River - HAA, by specific compounds............................................99

Table 8.7 - Ottawa River - SOS Chromotest IF values for water samples .......................... 100

Table 8.8 - Otonabee River jar test results - TOC/DOC/UV/SUVA/NOM fractions........... 100

Table 8.9 - Otonabee River chlorination results ...................................................... 101

Table 8.10 - Otonabee River DBP formation results - AOX/THMs/HAAs/AOX/MCA/MX

Table 8.11 - Otonabee River - TTHM by specific compounds ....................................... 102

Table 8.12 - Otonabee River - HAA 9 by specific compounds ....................................... 102

Table 8.13 - Otonabee River - SOS Chromotest IF values ........................................ 103

Table 8.14 - Lake Simcoe jar test results - TOC/DOC/UV/SUVA/NOM fractions..............103

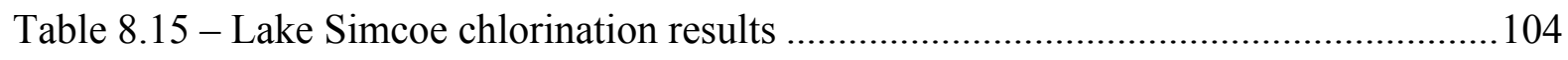

Table 8.16 - Lake Simcoe DBP formation results - AOX/THMs/HAAs/AOX/MCA/MX..104

Table 8.17 - Lake Simcoe - TTHM by specific compounds.......................................... 105

Table 8.18 - Lake Simcoe - HAA, by specific compounds ........................................... 105

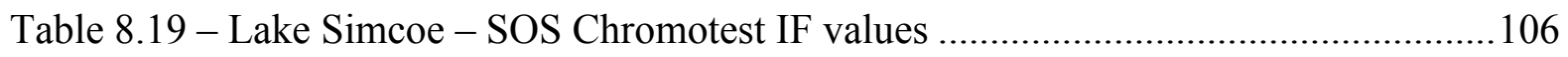

Table 8.20 - Conversion of equivalent volumes (eqmL) to relative enrichment factors (REF)

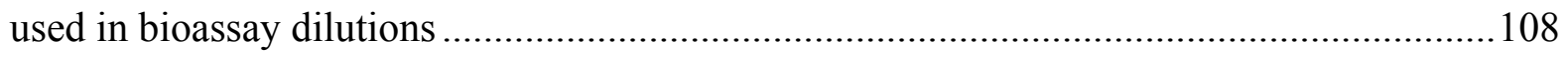


Table 8.21 - IF values for each dilution in SOS Chromotest bioassays on the three source waters

Table 8.22 - Concentrations of 4-NQO added to SOS Chromotest bioassay

Table 8.23 - IF values for 4-NQO at each dilution in SOS Chromotest bioassays on the three source waters

Table 8.24 - Slope $_{\text {samples }}$ for coagulated and chlorinated water samples used for the calculation of $\mathrm{TEQ}_{4-\mathrm{NQO}}$ values

Table 8.25 - SOSIP correction factors and Slope 4 -NQO SOSIP for 4-NQO samples used for the calculation of $\mathrm{TEQ}_{4-\mathrm{NQO}}$ values

Table 8.26 - TEQ 4 -NQO values....

Table 8.27 - Two-way ANOVA for Ottawa River water

Table 8.28 - Two-way ANOVA for Otonabee River water.

Table 8.29 - Two-way ANOVA for Lake Simcoe water.

Table 8.30 - Correlations in Ottawa River water between DBP formation and water quality parameters

Table 8.31 - Correlations in Ottawa River water between specific DBPs formed

Table 8.32 - Correlations in Otonabee River water between DBP formation and water quality parameters

Table 8.33 - Correlations in Otonabee River water between species of DBPs formed ...... 118

Table 8.34 - Correlations in Lake Simcoe water between DBP formation and water quality parameters.

Table 8.35 - Correlations in Lake Simcoe water between species of DBPs formed 120 


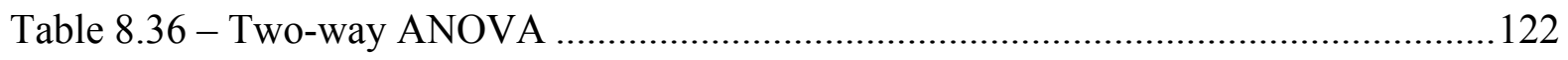

Table 8.37 - Tukey's HSD - LS means of water sources ............................................. 122

Table 8.38 - Tukey's HSD - Difference between LS means ...........................................122 


\section{LIST OF FIGURES}

Figure $2.1-\mathrm{pH}$ dependency of MX speciation (Adapted from USEPA, 2008) .................... 7

Figure 3.1 - Generalized bench-scale testing schematic ............................................ 16

Figure 3.2 - QC/QA of MCA/MX spike and recovery samples (prepared at $100 \mathrm{ng} / \mathrm{L}$ in raw water)

Figure 3.3 - Typical calibration curves for MCA and MX analysis

Figure $3.4-\mathrm{QC} / \mathrm{QA}$ of THM spike and recovery samples (prepared at $40 \mu \mathrm{g} / \mathrm{L}$ ).

Figure 3.5 - Typical calibration curves for THM analysis.

Figure 3.6 - QC/QA of HAA spike and recovery samples (prepared at $40 \mu \mathrm{g} / \mathrm{L}$ ) .26

Figure 3.7 - Example calibration curves for HAA analysis.

Figure 3.8 - Example calibration curve for the determination of TOC.

Figure 3.9-Quality control chart for TOC/DOC analysis (check standards prepared at 3.0 $\mathrm{mg} / \mathrm{L})$

Figure 4.1 - Structure of $L$-ascorbic acid

Figure 4.2 - Comparison of recovery of MX compounds using HLB cartridge vs. tC18/HLB (tandem SPE) cartridges .

Figure 4.3 - Comparison of MX recoveries for different derivatization times

Figure 4.4 - Sample chromatogram of chlorinated Lake Simcoe water extracted and analyzed using GC-ECD.

Figure 4.5 - Total ion chromatogram of $2500 \mathrm{ng} / \mathrm{L}$ spiked MX mix analyzed on GC/MS using EI full scan $(50-400 \mathrm{~m} / \mathrm{z})$ 
Figure 4.6 - CID of BMX1.

Figure 4.7 - Calibration curves for MX compounds spiked directly into solvent and analyzed with $\mathrm{GC} / \mathrm{MS} / \mathrm{MS}$

Figure 4.8 - Calibration curves for MX compounds (area relative to MBA sum) analyzed with GC-MS/MS.

Figure 4.9 - Calibration curves for MX compounds (area relative to MBA sum) analyzed with GC-MS/MS with a hollow liner

Figure 5.1 - DOC and $\mathrm{UV}_{254}$ results for three source waters. .66

Figure 5.2 - Chlorine demand for three source waters.

Figure 5.3 - NOM fractions (from LC-OCD) following alum coagulation in Ottawa River water

Figure 5.4 - NOM fractions (from LC-OCD) following alum coagulation in Otonabee River water

Figure 5.5 - NOM fractions (from LC-OCD) following alum coagulation in Lake Simcoe water

Figure 5.6 - Average concentration of TTHM, chlorinated under UFC.

Figure 5.7 - Average concentration of $\mathrm{HAA}_{9}$, chlorinated under UFC.

Figure 5.8 - Average concentration of MCA, chlorinated under UFC.

Figure 5.9 - Average concentration of MX, chlorinated under UFC

Figure 5.10 - Average concentration of AOX, chlorinated under UFC

Figure 5.11 - Contributions to AOX: TTHM, HAA9, MCA, and MX in Ottawa River water 
Figure 5.12 - Contributions to AOX: TTHM, HAA9, MCA, and MX in Otonabee River water

Figure 5.13 - Contributions to AOX: TTHM, HAA, MCA, and MX in Lake Simcoe water75

Figure 5.14 - SOS Chromotest IF values for three coagulated and chlorinated waters at an equivalent concentration of $16.5 \mathrm{eqmL} / \mathrm{well}$

Figure 5.15 - Genotoxicity $\left(\mathrm{TEQ}_{4-\mathrm{NQO}}\right)$ of coagulated and chlorinated samples for three source waters. (1 TEQ 4 -NQO is equivalent to toxicity of positive control 4-NQO at an equivalent concentration)

Figure 8.1 - IF vs. REF for Ottawa River samples 108

Figure 8.2 - IF vs. pmol/well for 4-NQO sample used in Ottawa River bioassays 110

Figure 8.3 - IF vs. nmol/well for the determination of SOSIP 4 -NQO ..................................111 


\section{NOMENCLATURE}

$\begin{array}{ll}{ }^{\circ} \mathrm{C} & \text { Degrees Celsius } \\ \text { Alum } & \text { Aluminum sulphate }\left(\mathrm{Al}_{2}\left(\mathrm{SO}_{4}\right)_{3} \bullet 14 \mathrm{H}_{2} \mathrm{O}\right) \\ \text { ANOVA } & \text { Analysis of variance } \\ \text { AOX } & \text { Absorbable organic halides } \\ \text { APHA } & \text { American Public Health Association } \\ \text { AWWA } & \text { American Water Works Association } \\ \text { BCAA } & \text { Bromochloroacetic acid } \\ \text { BDCAA } & \text { Bromodichloroacetic acid } \\ \text { BDCM } & \text { Bromodichloromethane } \\ \text { BMX1 } & \text { 3-chloro-4-(bromochloromethyl)-5-hydroxy-2(5H)-furanone } \\ \text { BEMX1 } & \text { (E)-2-chloro-3-(bromochloromethyl)-4-oxobutenoic acid } \\ \text { BMX2 } & \text { 3-chloro-4-(dibromomethyl)-5-hydroxy-2(5H)-furanone } \\ \text { BEMX2 } & \text { (E)-2-chloro-3-(dibromomethyl)-4-oxobutenoic acid } \\ \text { BMX3 } & \text { 3-bromo-4-(dibromomethyl)-5-hydroxy-2(5H)-furanone } \\ \text { BEMX3 } & \text { (E)-2-bromo-3-(dibromomethyl)-4-oxobutenoic acid } \\ \text { CDBM } & \text { Chlorodibromomethane } \\ \text { CPDB } & \text { The Berkeley Lab Carcinogenic Potency Database } \\ \text { D/DBP } & \text { Disinfectants/Disinfection By-Product Rule (USEPA) } \\ \text { DBAA } & \text { Dibromoacetic acid } \\ \text { DBCAA } & \text { Dibromochloroacetic acid } \\ \text { DBP } & \text { Disinfection by-product } \\ \text { DCAA } & \text { Dichloroacetic acid } \\ \text { DOC } & \end{array}$


DWRG

EI

EMX

g

GC-ECD

GC/MS/MS

$\mathrm{H}_{0}$

$\mathrm{H}_{2} \mathrm{SO}_{4}$

HAA

$\mathrm{HAA}_{5}$

$\mathrm{HAA}_{9}$

HLB

HMW

HPSEC

$\mathrm{hr}$

HSD

IARC

$\mathrm{K}_{\mathrm{ow}}$

L

LC-OCD

LMW

MBAA

MCAA
Drinking Water Research Group

Electron Impact

(E)-2-chloro-3-(dochloromethyl)-4-oxobutenoic acid

$\operatorname{Gram}(\mathrm{s})$

Gas chromatography with electron capture detection

Gas chromatography - tandem mass spectrometry

Null hypothesis

Sulphuric acid

Haloacetic acid

Group of five haloacetic acids

Group of nine haloacetic acids (sum of monochloroacetic acid, monobromoacetic acid, dichloroacetic acid, trichloroacetic acid, dibromoacetic acid, tribromoacetic acid, bromochloroacetic acid, bromodichloroacetic acid, and dibromochloroacetic acid)

Hydrophilic-lipophilic balance

high molecular weight

High performance size exclusion chromatography

$\operatorname{Hour}(\mathrm{s})$

Tukey's Honestly Significant Difference

International Agency for Research on Cancer

Octanol-water partition coefficient

Litre(s)

Liquid chromatography - organic carbon detection

Low molecular weight

Monobromoacetic acid

Monochloroacetic acid 


\begin{tabular}{|c|c|}
\hline MCL & Maximum contaminant level \\
\hline MDL & Method detection limit \\
\hline MTBE & methyl-tert-butyl-ether \\
\hline $\min$ & Minute(s) \\
\hline $\mathrm{mg}$ & Milligram(s) \\
\hline$\mu \mathrm{g}$ & Microgram(s) \\
\hline $\mathrm{mL}$ & Millilitre(s) \\
\hline$\mu \mathrm{L}$ & Mirolitre(s) \\
\hline $\mathrm{MCA}$ & Mucochloric acid, 2,3-dichloromalealdehydic acid \\
\hline MOE & Ministry of the Environment \\
\hline MSE & Mean squared error \\
\hline MW & Molecular weight \\
\hline MX & 3-Chloro-4-(dichloromethyl)-2(5H)-furanone \\
\hline $\mathrm{n}$ & Number of replicates \\
\hline $\mathrm{N} / \mathrm{A}$ & Not applicable \\
\hline ng & Nanogram(s) \\
\hline $\mathrm{nm}$ & Nanometer(s) \\
\hline n.d. & Not detected \\
\hline n.m. & Not measured \\
\hline NOM & Natural organic matter \\
\hline OCD & Organic carbon detection \\
\hline OEHHA & Office of Environmental Health Hazard Assessment (CA, USA) \\
\hline OND & Organic nitrogen detection \\
\hline p-value & Statistical significance \\
\hline PCA & Principle component analysis \\
\hline
\end{tabular}




\begin{tabular}{|c|c|}
\hline $\mathrm{R}$ & Correlation coefficient \\
\hline $\mathrm{R}^{2}$ & Coefficient of determination \\
\hline rpm & Revolutions per minute \\
\hline SEC & Size exclusion chromatography \\
\hline SPE & Solid phase extraction \\
\hline SUVA & Specific ultraviolet absorbance (at $254 \mathrm{~nm}$ ) \\
\hline TBAA & Tribromoacetic acid \\
\hline TBM & Tribromomethane (bromoform) \\
\hline TCAA & Trichloroacetic acid \\
\hline TCM & Trichloromethane (chloroform) \\
\hline THM & trihalomethane \\
\hline TTHM & $\begin{array}{l}\text { Total trihalomethanes, group of four trihalomethanes (sum of } \\
\text { trichloromethane, bromodichloromethane, dibromochloromethane, and } \\
\text { tribromomethane) }\end{array}$ \\
\hline TOC & Total organic carbon \\
\hline USEPA & United States Environmental Protection Agency \\
\hline UFC & Uniform Formation Conditions \\
\hline UV & Ultraviolet \\
\hline $\mathrm{UV}_{254}$ & UV absorbance at $254 \mathrm{~nm}$ \\
\hline UVD & Ultraviolet detection (at $254 \mathrm{~nm}$ ) \\
\hline $\mathrm{v} / \mathrm{v}$ & Volume to volume ratio \\
\hline $\mathrm{w} / \mathrm{w}$ & weight to weight ratio \\
\hline $\mathrm{w} / \mathrm{v}$ & weight to volume ratio \\
\hline WTP & Water treatment plant \\
\hline ZMX & (Z)-2-chloro-3-(dichloromethyl)-4-oxobutenoic acid \\
\hline
\end{tabular}




\section{$1 . \mathrm{O}$ INTRODUCTION}

\subsection{Background}

Disinfection by-products (DBPs) are formed through the reaction of oxidating disinfection agents with natural organic matter (NOM). Since the discovery of trihalomethanes (THMs) in 1974 (Rook, 1974), DBP research has largely focused on THMs and haloacetic acids (HAAs), the two largest groups of DBPs by weight, with regulated maximum contaminant levels (MCLs) promulgated in the US and Canada (Karanfil et al., 2008; Health Canada, 2006; Health Canada, 2008). However, recent reports indicate that potential health risks due to THMs and HAAs exposure are relatively low (Hrudey, 2009). Non-regulated DBPs, such as halogenated furanones (MX analogues), may be more cytotoxic and genotoxic than many regulated DBPs (Krasner, 2009).

In a study of pulp mill chlorination stage effluent, a highly mutagenic compound 3-chloro-4(dichloromethyl)-2(5H)-furanone, initially named Mutagen $\mathrm{X}$ and now known as MX, was discovered (Holmbom et al., 1984). Subsequent studies have found MX and 12 similar analogues in chlorinated drinking waters (Kronberg et al., 1988; Andrews et al., 1990; Simpson \& Hayes, 1993; Krasner et al., 2006), primarily those disinfected with free chlorine (Kubwabo et al., 2009). MX has been shown to be highly genotoxic (Tikkanen \& Kronberg, 1990) and mutagenic with observed ng/L concentrations of MX (typically 1000 fold less than THMs or HAAs) accounting for up to $60 \%$ of the total mutagenicity of treated drinking waters (Onstad \& Weinberg, 2005). The cancer potency of MX has been estimated by several studies, and in 2000, the state of California formally designated MX as a carcinogen (OEHHA, 2001). Many other DBPs have also been linked to genotoxicity, mutagenicity, and/or carcinogenicity (Onstad et al., 2008). To examine complex mixture of DBPs found in drinking water following disinfection, in vitro toxicological bioassays can be used alongside analytical techniques for DBP analysis. One such in vitro bioassay, the SOS Chromotest, can provide qualitative and quantitative determination of DNA damaging agents to help elucidate human health risks due to exposure (Kocak et al., 2010). 
NOM composition can be characterized based on hydrophobicity/polarity and size of fractions. NOM's reactivity with chlorine is dependent on the fractions present (Edzwald \& Tobiason, 1999; Hua \& Reckhow, 2007; Wassink, 2010), and thus the speciation and concentration of DBPs formed is also dependent on NOM fractions. Coagulation is the most common treatment process used at water utilities and its optimization can greatly reduce NOM content and effectively limit disinfection by-product formation (USEPA, 1999). Hydrophobic and high molecular weight (HMW) fractions of NOM are more readliy removed through coagulation (Chow et al, 2008; Bond et al., 2009) and traditionally these two components of NOM were thought to be the main DBP precursors (Hua \& Reckhow, 2007). However, recent studies have shown that hydrophilic and low molecular weight (LMW) fractions can act as DBP precursors as well (Matilainen et al., 2010).

A recently developed liquid chromatography - organic carbon detection (LC-OCD) technique for the analysis of NOM can provide detailed information about its characterization. The LC-OCD can identify five fractions of DOC: biopolymers, humic substances, building blocks, LMW acids, and LMW neutrals. The identification and quantification of NOM fractions in conjunction to DBP analysis may reveal further relationships between NOM fractions and specific DBPs formed. When these analysis are combined with bench-scale coagulation tests, the effects of coagulation on NOM removal and subsequent reduction in DBP formation can be examined.

\subsection{Research Objectives}

This study was aimed at examining the effects of chemical coagulation followed by chlorination on NOM removal by specific fraction and DBP formation, focusing on the formation of halogenated furanones. The specific objectives were:

1. To examine NOM fraction removal and DBP formation with bench-scale coagulation and chlorination studies of three natural source waters (Ottawa River, Otonabee River, and Lake Simcoe). 
2. To explore the correlations between NOM fraction and DBP formation in chlorinated waters. Secondly, to compare the formation of halogenated furanones to monitored DBPs.

3. To assess to use of genotoxicity testing on chlorinated waters and to examine the relationship between genotoxicity and halogenated furanones.

\subsection{Outline of Chapters}

Chapter 2 - literature review on DBPs (with focus on halogenated furanones), the toxicological evaluation of chlorinated drinking waters, NOM, and coagulation and its effects on NOM removal

Chapter 3 - description of the methodology followed for coagulation and chlorination for the analysis of NOM, DBP formation, and genotoxicity evaluation. Procedures for the statistical analysis of data are outlined.

Chapter 4 - details on method development for the analysis of MX and MCA, describing the sample extraction procedure and analytical procedures developed for GCECD and GC-MS

Chapter 5 - results of coagulation bench-scale tests with the evaluation of NOM removal and DBP formation. Statistical correlations between NOM content and DBP formation are presented. The relationship of chlorinated waters with genotoxicity is examined.

Chapter 6 - summary and conclusions of the study, with recommendations for future work

Chapter 7 - appendices, including raw data from jar tests, NOM and DBP concentrations, and sample calculations 


\section{O LITERATURE REVIEW}

\subsection{Disinfection By-Products}

Disinfection of distributed drinking water has, since the early $20^{\text {th }}$ century, effectively reduced the risk of infections due to waterborne pathogens (Richardson 2005). Disinfectants (e.g. chlorine, chloramines, chlorine dioxide, etc) are successful in inactivating microorganisms and preventing the spread of waterborne diseases. However, the use of these powerful oxidants can inadvertently react with natural organic matter (NOM), a mixture of organic materials dependent on biogeochemical cycles and ubiquitous to source waters (Matilainen et al., 2010), to form halogenated disinfection by-products (DBPs). The occurrence and speciation of DBPs is dictated by the NOM content of the water, as well as the type of disinfectant used.

DBP formation was discovered in 1974, with the identification of chloroform and trihalomethanes (THMs) formed in chlorinated drinking water (Rook, 1974). Subsequent studies on DBPs over the years have led to the identification of more than 600 DBPs (Krasner et al., 2006), as well as the toxicological properties of certain DBPs to cause cancer and reproductive/developmental problems (Krasner, 2009). The rise of DBPs as a public health issue has led to regulations around the world to address the risk of DBP exposure with maintaining sufficient disinfection for pathogen control. Currently in the U.S., the Stage 2 Disinfectants (D)/DBP Rule regulates two major classes of DBPs (largest based on weight), total trihalomethanes (TTHM) and five haloacetic acids $\left(\mathrm{HAA}_{5}\right)$ at maximum contaminant levels (MCLs) of $80 \mu \mathrm{g} / \mathrm{L}$ and $60 \mu \mathrm{g} / \mathrm{L}$ respectively (Karanfil et al., 2008). In Canada, TTHM are regulated at an MCL of $100 \mu \mathrm{g} / \mathrm{L}$ and $\mathrm{HAA}_{5}$ at an MCL of $80 \mu \mathrm{g} / \mathrm{L}$ (Health Canada, 2008). Although THMs and HAAs are monitored and regulated, they can account for less than $50 \%$ of the total organic halide (TOX) produced in chlorinated drinking water. Furthermore, recent studies have highlighted the relatively low health concerns of THMs/HAAs exposure, which questions the effectiveness of these DBPs as indicators of overall DBP presence and toxicology (Hrudey, 2009). Studies have indicated that non- 
regulated emerging DBPs, such as halogenated furanones (MX analogues), may be more cytotoxic and genotoxic than many regulated DBPs (Krasner, 2009).

\subsection{Halogenated Furanones}

In the 1980s, an unknown and extremely mutagenic compound was discovered during a study of pulp mill chlorination stage effluents from four paper mills in Canada. This compound was initially named Mutagen X or MX, before it was isolated and identified as 3chloro-4-(dichloromethyl)-5-hydroxy-2(5H)-furanone (Holmbom et al., 1984). Further studies revealed the presence of this same mutagen in chlorinated humic and drinking waters (Hemming et al., 1986). In addition, more research led to the identification of similar compounds - analogues of MX - such as its geometric isomer (E)-2-chloro-3(dichloromethyl)-4-oxobutenoic acid (EMX) (Kronberg et al., 1988). In total, 12 analogues of MX have been identified and collectively categorized as halogenated furanones (Table 2.1). Halogenated furanones have been detected in treated drinking waters across the world, in countries including Canada (Andrews, et al. 1990), the US (Krasner et al., 2006; Onstad et al., 2008), Finland (Holmbom et al., 1981; Hemming et al., 1986), Australia (Simpson \& Hayes, 1993), China (Zou et al., 2000), and Japan (Suzuki \& Nakanishi, 1995). In past occurrence studies, the average concentrations of MX in drinking waters ranged from 0.1 to 90 ng/L (Kubwabo et al., 2009). However, in a recent US study by Krasner et al. (2006), MX concentrations were found to be as high as $310 \mathrm{ng} / \mathrm{L}$. Similarly, Onstad et al. (2008) conducted a survey of MX in treated water from 12 water treatment plants across the US and the highest concentration of MX found was $850 \mathrm{ng} / \mathrm{L}$. Richardson (2005) noted that the levels of halogenated furanones remained stable in distribution system and simulated distribution system tests. Although concentrations of halogenated furanones in drinking waters are at trace levels (up to 1000 fold lower than THMs) it has been hypothesized that MX may be associated with increased cancer risks related to consumption of and exposure to drinking water (McDonald \& Komulainen, 2005) 


\subsubsection{Chemical Properties of MX Analogues}

Table 2.1 - Chemical Structures of halogenated furanones (MX analogues)

\begin{tabular}{|c|c|c|c|}
\hline Name & Structure & Name & Structure \\
\hline $\begin{array}{c}\text { MX: 3-chloro-4- } \\
\text { (dichloromethyl)-5- } \\
\text { hydroxy-2(5H)-furanone }\end{array}$ & & $\begin{array}{c}\text { BMX3: 3-bromo-4- } \\
\text { (dibromomethyl)-5- } \\
\text { hydroxy-2(5H)-furanone }\end{array}$ & \\
\hline $\begin{array}{l}\text { red-MX: 3-chloro-4- } \\
\text { (dichloromethyl)-2- } \\
\quad(5 \mathrm{H}) \text {-furanone }\end{array}$ & & $\begin{array}{l}\text { BEMX1: (E)-2-chloro- } \\
\text { 3-(bromochloromethyl)- } \\
\text { 4-oxobutenoic acid }\end{array}$ & \\
\hline $\begin{array}{l}\text { ox-MX: (E)-2-chloro-3- } \\
\text { (dichloromethyl) } \\
\text { butenedioic acid }\end{array}$ & & $\begin{array}{l}\text { BEMX2: (E)-2-chloro- } \\
\text { 3-(dibromomethyl)-4- } \\
\text { oxobutenoic acid }\end{array}$ & \\
\hline $\begin{array}{l}\text { EMX: (E)-2-chloro-3- } \\
\text { (dichloromethyl)-4- } \\
\text { oxobutenoic acid }\end{array}$ & & $\begin{array}{l}\text { BEMX3: (E)-2-bromo- } \\
\text { 3-(dibromomethyl)-4- } \\
\text { oxobutenoic acid }\end{array}$ & \\
\hline $\begin{array}{l}\text { ZMX: (Z)-2-chloro-3- } \\
\text { (dichloromethyl)-4- } \\
\text { oxobutenoic acid }\end{array}$ & & $\begin{array}{c}\text { MCA }_{\text {ring: }} \text { 2,3- } \\
\text { dichloromalealdehydic } \\
\text { acid }\end{array}$ & \\
\hline $\begin{array}{l}\text { BMX1: 3-chloro-4- } \\
\text { (bromochloromethyl)-5- } \\
\text { hydroxy-2(5H)-furanone }\end{array}$ & & $\begin{array}{l}\text { MCA }_{\text {open }}: 2,3 \text {-dichloro- } \\
\text { 4-oxobutenoic acid }\end{array}$ & \\
\hline $\begin{array}{c}\text { BMX2: 3-chloro-4- } \\
\text { (dibromomethyl)-5- } \\
\text { hydroxy-2(5H)-furanone }\end{array}$ & & & \\
\hline
\end{tabular}

MX and its 12 analogues can undergo reversible cyclization, based on pH changes (Onstad et al., 2008). $\mathrm{MX}$, in a ring form, is predominant at low $\mathrm{pH}$ values $(\sim \mathrm{pH} 2)$, but as $\mathrm{pH}$ rises $(\geq$ $\mathrm{pH}$ 4) the ring opens to ZMX, which then dissociates (tautomerizes) to EMX and degrades at higher $\mathrm{pH}$ levels $(\geq \mathrm{pH}$ 8) (USEPA, 2008). At $\mathrm{pH}$ levels above 6.5, the ring opening and 


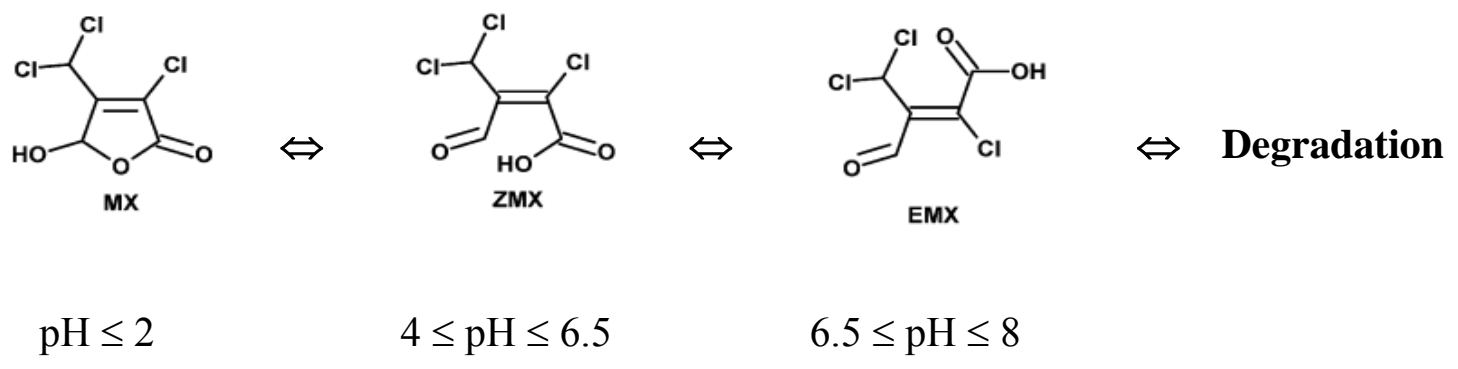

Figure 2.1 - pH dependency of MX speciation (Adapted from USEPA, 2008)

tautomerization causes MX water solubility to increase rapidly, as determined by the extraction of MX in aqueous solutions with ethyl acetate at varying $\mathrm{pH}$ values by Holmbom (1984). Between pH 5 and 7, the degradation of MX directly correlates with the formation of EMX (Simpson and Hayes, 1993) - Figure 2.1. The partitioning characteristics of MX also vary with $\mathrm{pH}$. At $\mathrm{pH} 2, \mathrm{MX}$ is fairly hydrophilic with a $\mathrm{K}_{\mathrm{ow}}$ of $11.9(\mathrm{mg} / \mathrm{L}$ octanol/ $\mathrm{mg} / \mathrm{L}$ water) (Holmbom et al., 1984). This $\mathrm{K}_{\mathrm{ow}}$ value decreases with increasing $\mathrm{pH}$, and thus should be lower in neutral $\mathrm{pH}$ and drinking waters.

The same relationship with $\mathrm{pH}$ is observed for brominated forms of MX (BMX1, BMX2, BMX3) as well as mucochloric acid (MCA). At acidic conditions $(\mathrm{pH} \leq 7)$, the ring forms of BMXs are predominant, while at above $\mathrm{pH} 7$ BMXs tautomerize to their open forms (BEMXs) (Onstad et al., 2008).

The $\mathrm{pH}$ dependent cyclization properties of $\mathrm{MX}$ analogues can be used advantageously during the detection of halogenated furanones. Onstad et al. (2008) used concentration summations of similar analogues to track the formation and removal of halogenated furanones:

$$
\begin{gathered}
M X_{\text {sum }}=M X+Z M X+E M X \\
M C A_{\text {sum }}=M C A_{\text {ring }}+M C A_{\text {open }} \\
B M X_{\text {sum }}=B M X 1+B E M X 1+B M X 2+B E M X 2+B M X 3+B E M X 3
\end{gathered}
$$


Rezemini et al. (2008) reported the relevance of an acidification step for studies on the health effects of MX, since the $\mathrm{pH}$ of gastric fluid is approximately 1.2 and thus the closed MX form is assumed to be predominant in the human body.

\subsubsection{Formation of MX Analogues}

MX analogues have been primarily observed in waters treated with free chlorine, compared to with chlorine dioxide or chloramines. MX is usually formed from the reaction of chlorine with humic acids in raw water (Kubwabo et al., 2009). In the presence of excess chlorine, MX has been shown to degrade at increasing concentrations of 10-100 mg/ $\mathrm{L} \mathrm{Cl}_{2}$ (Schenck et al., 1990; Simpson and Hayes, 1993). At lower concentrations, similar to those found as chlorine residuals in distribution systems, of $0.5-3.0 \mathrm{mg} / \mathrm{L} \mathrm{Cl}_{2} \mathrm{MX}$ degradation was also observed. This effect is hypothesized to be the conversion of MX to EMX, ox-MX, and/or ox-EMX in the presence of chlorine (USEPA, 2008). Schenck et al. (1990) found an approximate 5:1 molar ratio for reaction of chlorine and $\mathrm{MX}$, with reaction completion achieved within one day.

\subsubsection{Health Effects of MX}

In 2000, the state of California designated MX as a carcinogen, with a cancer potency value of $6.37\left(\mathrm{mg} / \mathrm{kg}_{\text {-day }}\right)^{-1}$ based on carcinogenicity studies on rats (Komulainen et al., 1997) and used this value to promulgate a risk-specific intake level of $0.11 \mu \mathrm{g} /$ day associated with a 1 in 100,000 lifetime cancer risk (OEHHA, 2001). In 2004, The International Agency for Research on Cancer (IARC) designated MX as a group 2B carcinogen, indicating that it is classified as possibly carcinogenic to humans (IARC, 2004).

In two separate studies on drinking waters in Finland and the US, a significant linear correlation $\left(\mathrm{R}^{2}=0.73\right.$ and 0.74 respectively) was found between MX concentrations and the drinking water sample's mutagenic potential in Salmonella typhimurim TA100 (Vartiainen et al., 1990 \& Wright et al., 2002). At 5000 - 13000 revertants/nmol, MX was reported as the most mutagenic DBP identified to date (DeMarini et al., 1995). Typical concentrations of MX in drinking waters have been reported in the order of $\mathrm{ng} / \mathrm{L}$, however even these trace amounts account for $20-60 \%$ of the total mutagenicity of drinking water samples (Onstad 
and Weinberg, 2005). The structural components, $\mathrm{CHCl}_{2}$ and $\mathrm{Cl}$ substituents in a cis arrangement on a carbon-carbon double bond within the hydroxyfuranone ring structure of MX, are thought to be responsible for its mutagenicity (USEPA, 2008). Mutagenicity is enhanced by incorporation into the 5-hydroxy-2(5H)-furanone ring system or an open structure that is readily transformed to the ring system under mutagenic testing conditions (Ishiguro et al., 1987). As such, EMX, ox-EMX, and MCA are less mutagenic than other MX-analogues. Mutagenicity also enhanced by the presence of the C-5 hydroxyl group, making red-MX is less mutagenic than MX (Kronberg \& Franzen, 1993).

Using a variety of bacterial strains and bioassays, many in vitro genotoxicity studies have shown that MX induces mutations, sometimes with high potency (Holmbom et al., 1981; Ishiguro et al., 1987; Tikkanen \& Kronberg, 1990; and DeMarini et al., 1995). In genotoxicity studies performed in vivo, some researchers have observed clear increases in DNA damage (Fekadu et al., 1994; Sasaki et al., 1997), while others did not (Brunborg et al., 1991; Holme et al., 1999). Komulainen et al. (1997) were the first to administer MX in drinking water to male and female rates during a two year long-term carcinogenicity study. They observed increases in the frequency of tumors in the thyroid gland, liver, and adrenal gland for both sexes and the mammary gland for only female rats, indicating MX to be a multisite carcinogen in rats. Combining all available data at the time, McDonald \& Komulainen (2005) derived a combined potency estimate for all treatment-related tumor sites and reported a mean cancer potency value of $3.2(\mathrm{mg} / \mathrm{kg} \text { day })^{-1}$. This value represents an arithmetic mean estimate obtained from a Monte Carlo distribution of cancer potency estimates. The Berkeley Lab Carcinogenic Potency Database (CPDB) calculated for MX a carcinogenic potency value $\mathrm{TD}_{50}$ of $1.72(\mathrm{mg} / \mathrm{kg} \text { day })^{-1}$ (Gold et al., 2010). $\mathrm{TD}_{50}$ is defined as the chronic dose-rate that induces tumors in half the test animals at the end of a standard lifespan. Both of these published cancer potency estimates differ from the $6.37(\mathrm{mg} / \mathrm{kg} \text { day })^{-1}$ value derived by OEHHA (2001). The differences in published cancer potency values for MX are due to methodological and estimation distinctions, and provide some indication of the discrepancies involved with extrapolated data. Additional difficulties lie in the application of cancer potency values of MX from animal studies to human health risks associated with the consumption of chlorinated drinking waters. Currently, MX is the only 
halogenated furanone to be extensively researched for carcinogenicity. More research is required to investigate the effects of other halogenated furanones, as well as possible additive or synergistic effects.

\subsection{Toxicological Evaluation of Drinking Water}

The genotoxic, mutagenic, and/or carcinogenic potentials of individual DBPs shed some light on which specific compounds contribute to toxicity; however there is still a significant undetermined portion that contributes to overall toxicity in drinking water (Richardson et al., 2008). Complex mixtures of DBPs found in drinking water following disinfection make it difficult to assess potential health risks. In addition, complex mixtures may have synergistic and/or antagonistic effects that are not fully understood (Simmons et al., 2002). In vitro toxicological tests can be used as a complimentary tool to analytical techniques, to tease out the possible mechanisms of toxic action of an unknown mixture, without requiring the identification and quantification of individual constituents (Kocak et al., 2010). These results may help to elucidate the human health risks due to exposure and can complement conventional water quality indices and chemical analyses (Wang et al., 2011). Furthermore, in vitro toxicological tests are sensitive, cost effective, and simple methods that may enhance existing water quality monitoring and provide a more robust evaluation (Zegura et al., 2009). Because of these qualities, they are well suited for monitoring studies and/or initial screenings for genotoxic potential. One such in vitro bioassay is the SOS Chromotest, for the evaluation of genotoxicity. Genotoxic agents are defined as substances that interact with DNA to induce transmissible mutations that could lead to cancerous transformations of functioning cells (Quillardet et al., 1982). Wang et al. (2011) examined the genotoxic potential of finished water (with chlorine disinfection) from seven utilities in China using the SOS Chromotest. Most finished waters (induction factor, IF $\geq 2.0$, indicating genotoxicity in samples) had much higher genotoxic effects compared to raw waters (IF $<2.0$ ) for exposures with equivalent concentrations of $300 \mathrm{~mL}$. Many other studies have also indicated the contribution of chlorine disinfection to drinking water genotoxicity (Vartiainen et al., 1990; Takanashi et al., 2009). Notably, many of these studies attributed up to $70 \%$ of observed genotoxic potentials to MX presence (Myllykangas et al., 2003; Richardson et al., 2007). 
Thus, the detection and quantification of genotoxic potential via the SOS Chromotest is an effective means of monitoring complex environmental samples (Kocak et al., 2010), such as chlorinated drinking waters, for toxicological activity.

\subsection{Natural Organic Matter (NOM)}

Natural organic matter (NOM) is ubiquitous to all waters and consists of a complex mixture of compounds. It is derived of biomass from the interaction of the hydrological cycle with biogeochemical activity (Matilainen et al., 2010). Consequently, NOM composition and quantity in water can vary spatially, seasonally, and temporally (Fabris et al., 2008). NOM composition can be characterized based on fractionation, separating NOM by the polarity and hydrophobicity of individual compounds. The hydrophilic portions (or fractions) of NOM are mainly composed on compounds such as carboxylic acids, carbohydrates, and proteins aliphatic carbonaceous and nitrogenous compounds (Matilainen et al., 2010). The hydrophobic fractions are primarily humic substances (humic and fulvic acids), which can account for about half of the dissolved organic carbon (DOC) content of water (Nikolaou \& Lekkas, 2001). NOM composition can also be characterized by molecular weight distribution, separating low molecular weight (LMW) compounds from high molecular weight (HMW) compounds (Chow et al., 2008). Past research has shown that of the NOM fractions, hydrophobic HMW compounds are the most reactive with oxidating agents, functioning as main precursors for DBP formation (Hua \& Reckhow, 2007). Hydrophilic NOM compounds have also been found to contribute to DBP formation (often in low humic waters) as well as highly react with bromine and iodine to form brominated and iodinated DBPs (Matilainen et al., 2010). Apart from the formation of DBPs, NOM affects practically all other aspects of water treatment, with impacts on colour, taste and odour, interference with removal of contaminants, membrane fouling, contribution to biological substrate, and decrease of activated carbon adsorption sites (Fabris et al., 2008). Because NOM significantly affects the processes of water treatment and drinking water quality itself, optimized control and removal of NOM is of upmost importance.

Since NOM encompasses such a broad range of compounds that differ in size, polarity, and hydrophobicity, the quantification methods of NOM in water are diverse. Many common 
parameters for the determination of NOM such as total organic carbon (TOC), dissolved organic carbon (DOC), UV absorbance at 254nm $\left(\mathrm{UV}_{254}\right)$, turbidity, and colour are parameters used for quantification of overall water quality in water treatment facilities. The issue with these conventional NOM parameters is that they do not provide information about the specific characterization of NOM, instead giving only an overall 'lump sum' NOM surrogate value. However, these techniques can be of great value, as they have relatively easy to perform and can offer rapid (and often on-line) determination of NOM. The methods for analyses are standardized (APHA, 2005), allowing for easy comparisons between sources and providing reliability in the results. Most previous studies on DBP occurrence and formation have reported NOM content in terms of the conventional NOM parameters of TOC/DOC/UV 254 (van Leeuwen et al., 2005; Krasner et al., 2006; Karanfil et al., 2008). Thus, to relate occurrence and formation patterns to past studies, the analysis of conventional NOM parameters still can provide invaluable insight.

To determine the individual constituents of NOM, other techniques are necessary. NOM can be characterized by size exclusion chromatography (SEC), which separates NOM compounds based on molecular weight (Chow et al., 2008). Another method is fractionation with resins, which divides NOM based on polarity and hydrophobicity (Sharp et al., 2006). A new, emerging method for the detection and characterization of NOM is liquid chromatography with organic carbon detection (LC-OCD), developed by Huber et al. (2011). The LC-OCD first separates NOM in water samples by size with a SEC column, which then leads to an online fixed wavelength UV detector (at 254nm), an organic carbon detector (OCD), and an organic nitrogen detector (OND). The LC-OCD is able to divide and identify six specific fractions of NOM in water samples: biopolymers, humic substances, building blocks, LMW acids, LMW neutrals, and hydrophobic organic carbon. The LC-OCD offers robust and sensitive detection of NOM fractions, allowing the direct analysis of low NOM waters (Huber et al., 2011).

\subsection{Conventional Water Treatment}

Treatment of water with coagulation-flocculation/sedimentation/filtration is the most commonly used by utilities for the reduction of NOM (AWWA, 2000). Optimization of the 
coagulation NOM removal process can significantly improve water quality and minimize DBP formation (Jacangelo et al., 1995). For existing conventional treatment plants, this optimization can be the most economically feasible method for better NOM control (Matilainen et al., 2010).

\subsection{Coagulation Principles and Goals}

Coagulation is achieved with the addition of chemical coagulants, most commonly in the form of hydrolyzing metal salts such as aluminum sulphate (alum), ferric chloride, and ferric sulphate (Duan \& Gregory, 2003). Jarvis et al. (2004) defined four mechanisms for the removal of NOM through aggregation during coagulation: 1) charge neutralization through destabilization of ions, 2) entrapment of NOM within metal complexes, 3) adsorption of NOM to metal complexes, and 4) complexation reactions between NOM and hydrolyzed metal species. The traditional motivation for NOM removal via coagulation was to reduce turbidity levels, remove suspended and colloidal particles, and improve downstream processes (Edzwald, 1993). With USEPA's Stage 1 and 2 Disinfectants/Disinfection ByProducts (D/DBP) Rules, coagulation has evolved to optimize NOM removal for DBP reduction (USEPA, 1999). In general, coagulation is most effective at removing organics from waters with high initial DOC, while low DOC waters contain larger portions of nonremovable organics (Chow et al., 2008).

The majority of colloidal matter are negatively charged, thus electrostatic repulsion allows for their stable suspension in water. In addition, bound water at particle surfaces may introduce hydrophilic effects and adsorbed macromolecules may cause steric effects (Edzwald, 1993). The addition of alum or ferric coagulant to water allows for the metal salts added to hydrolyze to form a range of charged cations (e.g. $\mathrm{Al}^{3+}, \mathrm{Al}^{2+}$ ) with varying solubility levels, depending on coagulant dosage and $\mathrm{pH}$ of water (Duan \& Gregory, 2003). These cations then interact with the negative colloids, allowing for destabilization under the correct conditions. Sweep flocculation can occur concurrent to destabilization, removing particles as they are sorbed to growing precipitates. At $\mathrm{pH}$ values slightly lower than minimum solubility of the coagulants (usually $\mathrm{pH}<7$ ), cation species most efficient for DOC removal are formed (Matilainen et al., 2010). Furthermore, lower pH levels increase the hydrophobicity of humic 
substances (Chow et al., 2008). Thus, coagulation for NOM removal may be optimized by reducing $\mathrm{pH}$ to 5-6 prior to coagulation (Edzwald \& Tobiason, 1999). The alum and ferric coagulants are acidic in nature and many treatment plants rely on this alone for $\mathrm{pH}$ adjustment (Budd et al., 2004). Alkalinity of waters and the buffering capacity should also be taken into account when optimizing $\mathrm{pH}$ for coagulation (Matilainen et al., 2010).

\subsubsection{Coagulation and NOM Removal for DBP Reduction}

Enhanced coagulation is the optimization of coagulant type, dose, and water $\mathrm{pH}$ to achieve maximum NOM removal (for DBP formation reduction) while maintaining sufficient reduction in turbidity (Mesdaghinia et al., 2006). As per the USEPA D/DBP Rule, all surface and groundwater under the direct influence of surface water (GUDI) must comply with enhanced coagulation guidelines for sufficient removal of DBP precursors (USEPA, 1999). Optimal coagulant dose is selected based on TOC removal (\%) and is dictated by source water alkalinity and TOC (see Table 2.2).

Table 2.2 - Optimal TOC removal percentages by enhanced coagulation for plants using conventional treatment: Step 1 Disinfection By-Product Rule (USEPA, 1999)

\begin{tabular}{|c|c|c|c|}
\hline \multirow{2}{*}{ Raw water TOC (mg/L) } & \multicolumn{3}{|c|}{ Raw water alkalinity (mg/L as CaCO $\mathbf{~})$} \\
\cline { 2 - 4 } & $\mathbf{0 - 6 0}$ & $\mathbf{6 0}-\mathbf{1 2 0}$ & $>\mathbf{1 2 0}$ \\
\hline $\mathbf{2 . 0}-\mathbf{4 . 0}$ & $35.0 \%$ & $25.0 \%$ & $15.0 \%$ \\
\hline $\mathbf{4 . 0}-\mathbf{8 . 0}$ & $45.0 \%$ & $35.0 \%$ & $25.0 \%$ \\
\hline $\mathbf{8 . 0}$ & $50.0 \%$ & $40.0 \%$ & $30.0 \%$ \\
\hline
\end{tabular}

Enhanced coagulation can provide sufficient removal of DBP precursors at a relatively low cost of treatment. However, several disadvantages of enhanced coagulation include increased sludge production due to increased coagulant dosages, a need for facilities upgrades in regards to chemical storage and feed systems, non-optimal turbidity removal, and increased costs due to increase coagulant use and possible $\mathrm{pH}$ adjustment (Jiang \& Graham, 1996). Furthermore, the use of TOC as a measure of NOM may not be sufficient for indicating the presence of DBP precursors. Many past studies have shown that NOM reactivity with chlorine is highly variable based on the fractions present. Hydrophobic, high molecular water (HMW) components of NOM were traditionally regarded as main DBP precursors, however recent studies have shown the ability of hydrophilic and low molecular weight (LMW) 
fractions to act as DBP precursors (Matilainen et al., 2010). Hua and Reckhow (2007) found that the majority of the DBPs formed from hydrophilic and LMW compounds reacting with chlorine were THMs and HAAs. However, in this same study, unknown DBPs (calculated by the difference between AOX and sum of THMs, HAAs, dihaloacetonitriles, haloketones, chloropicrin detected) were formed mainly from hydrophobic and HMW NOM. Typically, hydrophobic and high molecular weight (HMW) fractions of NOM are more readily removed through coagulation (Bond et al., 2009). Chow et al. (2008) found through alum coagulation jar tests that non-polar humics, inorganic colloids, and biological residues were easily removed (even with the lowest coagulant dose) while low molecular weight (LMW) humics could only be partially removed through enhanced coagulation. Building blocks and Ncontaining aromatics were largely unaffected by coagulation in their experiments. 


\section{O MATERIALS AND METHODS}

\subsection{Experimental Protocols}

A bench-scale treatment method was developed to simulate the typical coagulation/flocculation/disinfection scheme used at conventional water treatment plants. A flow diagram of the general testing method is shown in Figure 3.1.

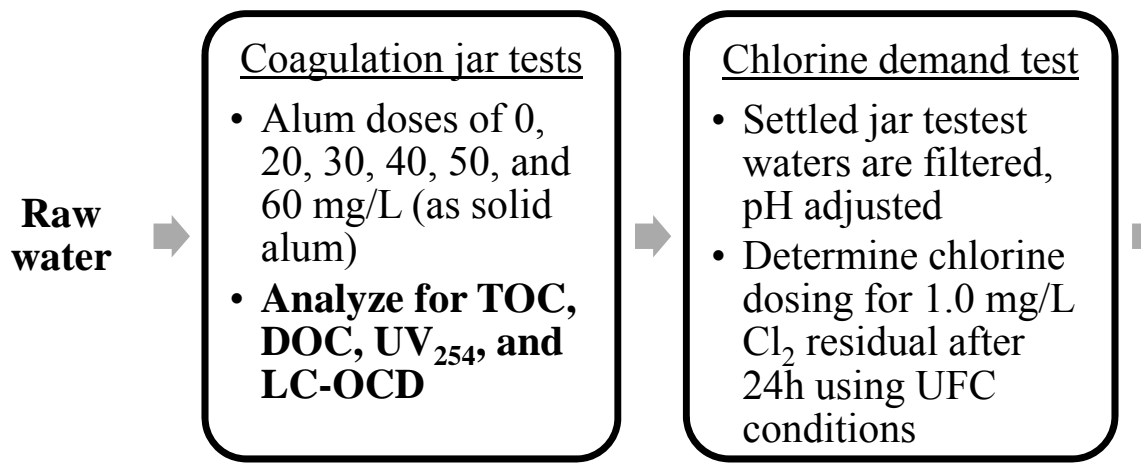
Formation tests
- Samples
chlorinated at
UFC dose
- Analyze for
AOX, THMs, HAAs, MX,
MCA,
genotoxicity

\section{Figure 3.1 - Generalized bench-scale testing schematic}

Raw water was collected from various sources in Ontario, Canada (see Section 3.1.1). The water was stored in the dark at $4^{\circ} \mathrm{C}$, then combined and brought to room temperature $\left(22^{\circ} \mathrm{C}\right)$ before conducting any tests. Multiple carboys of water were mixed in a $100 \mathrm{~L}$ stainless steel container (Royal Industries Inc., Chicago, IL) at $100 \mathrm{rpm}$ using a Cafrano BDC 2002 electric stirrer (VWR International, Mississauga, ON).

\subsubsection{Selection of Water Sources}

Three source waters of differing initial total organic carbon (TOC) and dissolved organic carbon (DOC) were chosen, for replicated bench-scale coagulation jar tests. Raw, untreated water was collected from the following utilities in Ontario, Canada: Britannia Water Treatment Plant (Ottawa River water), Peterborough Water Treatment Plant (Otonabee River water), and Keswick Water Treatment Plant (Lake Simcoe water). Table 3.1 shows the raw water characteristics from each source, as determined using the analytical methods described in Sections 3.2.6.1, 3.2.6.2, 3.2.8, and 3.2.9. In the measured samples, TOC and DOC measurements were within $\pm 0.2 \mathrm{mg} / \mathrm{L}$ (as C) and DOC was primarily used in data analyses. 
Ottawa River raw water had the highest DOC $(5.85 \mathrm{mg} / \mathrm{L})$, with very low alkalinity $(23.5$ $\mathrm{mg} / \mathrm{L}$ as $\mathrm{CaCO}_{3}$ ) and about neutral $\mathrm{pH}$ (7.36). Lake Simcoe raw water had the lowest DOC (4.14), with the highest alkalinity value $\left(115.0 \mathrm{mg} / \mathrm{L}\right.$ as $\left.\mathrm{CaCO}_{3}\right)$ and the highest $\mathrm{pH}(8.47)$. Otonabee River raw water had DOC $(5.03 \mathrm{mg} / \mathrm{L})$, alkalinity $\left(90.5 \mathrm{mg} / \mathrm{L}\right.$ as $\left.\mathrm{CaCO}_{3}\right)$, and $\mathrm{pH}$ (8.38) values that were in between the other two water sources. All analyses were performed within two weeks of water collection, with the exception of LC-OCD (samples preserved at $4^{\circ} \mathrm{C}$ and analyzed on Nov 21-26, 2012).

Table 3.1 - Raw water characteristics of three Ontario source waters

\begin{tabular}{|c|c|c|c|c|c|c|c|}
\hline & $\begin{array}{c}\text { Date of } \\
\text { collection }\end{array}$ & $\begin{array}{c}\text { DOC } \\
(\mathrm{mg} / \mathrm{L})\end{array}$ & $\begin{array}{c}\text { TOC } \\
(\mathrm{mg} / \mathrm{L})\end{array}$ & pH & $\begin{array}{c}\text { Alkalinity } \\
\text { (mg/L } \\
\left.\mathrm{CaCO}_{3}\right)\end{array}$ & $\begin{array}{l}\mathrm{UV}_{254} \\
\left(\mathrm{~cm}^{-1}\right)\end{array}$ & $\begin{array}{c}\text { SUVA } \\
(\mathrm{L} / \mathrm{mg} / \mathrm{m})\end{array}$ \\
\hline $\begin{array}{c}\text { Ottawa } \\
\text { River }\end{array}$ & $9 / 17 / 12$ & 5.85 & 6.06 & 7.36 & 23.5 & 0.202 & 3.45 \\
\hline $\begin{array}{c}\text { Otonabee } \\
\text { River }\end{array}$ & $10 / 2 / 12$ & 5.03 & 4.92 & 8.38 & 90.5 & 0.103 & 2.05 \\
\hline $\begin{array}{c}\text { Lake } \\
\text { Simcoe }\end{array}$ & $10 / 24 / 12$ & 4.14 & 4.23 & 8.47 & 115.0 & 0.0545 & 1.32 \\
\hline
\end{tabular}

Table 3.2 - SUVA as an indicator of NOM composition and coagulation efficacy (adapted from Edzwald \& Tobiason, 1999)

\begin{tabular}{ccccc}
$\begin{array}{c}\text { Water } \\
\text { Source }\end{array}$ & $\begin{array}{c}\text { SUVA } \\
\text { category }\end{array}$ & Predicted composition & $\begin{array}{c}\text { Predicted } \\
\text { effect of } \\
\text { coagulation }\end{array}$ & $\begin{array}{c}\text { Predicted } \\
\text { DOC removal } \\
\text { using alum }\end{array}$ \\
\hline N/A & $>4$ & $\begin{array}{c}\text { High molecular weight (HMW) } \\
\text { compounds; mostly humics; high } \\
\text { hydrophobicity }\end{array}$ & $\begin{array}{c}\text { Coagulation } \\
\text { controlled } \\
\text { by NOM }\end{array}$ & $>50 \%$ \\
\hline $\begin{array}{c}\text { Ottawa } \\
\text { River \& } \\
\text { Otonabee } \\
\text { River }\end{array}$ & $2-4$ & $\begin{array}{c}\text { Mixture of molecular weights; } \\
\text { humics and other NOMs (such as } \\
\text { fulvic acids); varying hydrophobicity }\end{array}$ & $\begin{array}{c}\text { Some NOM } \\
\text { influence }\end{array}$ & $25-50 \%$ \\
\hline $\begin{array}{c}\text { Lake } \\
\text { Simcoe }\end{array}$ & $<2$ & $\begin{array}{c}\text { Low molecular weight (LMW) } \\
\text { compounds; mostly non-humics; low } \\
\text { hydrophobicity }\end{array}$ & $\begin{array}{c}\text { Little NOM } \\
\text { influence }\end{array}$ & $<25 \%$ \\
\hline \multicolumn{5}{c}{} \\
\hline
\end{tabular}

A relationship between specific UV absorbance (SUVA, calculated as $\mathrm{UV}_{254} / \mathrm{DOC}$ in $\mathrm{L} / \mathrm{mg} / \mathrm{m}$ ), NOM composition and coagulation removal has been identified by many researchers (Edzwald \& Tobiason, 1999; Chow et al., 2008; Matilainen et al., 2010). This 
relationship, and how it pertains to the three source waters examined in this study, is summarized in Table 3.2.

\subsubsection{Bench-Scale Treatment Sequence}

Four replicates of jar tests were performed for each experimental sequence (each source water), to provide a sufficient quantity of sample water for the subsequent formation tests and DBP analyses. A broad range of coagulant doses was chosen $(0,20,30,40,50$, and $60 \mathrm{mg} / \mathrm{L})$ to maximize the range of DBP formation levels and ensure their detection. Jar testing was completed with a bench-scale stirrer (Phipps and Bird, Richmond, VA) and six square, acrylic 2-L jars (B-ker², Phipps and Bird). For jar tests, each jar was filled with 2-L of raw water and placed under the stirrer. Appropriate dosages of alum coagulant were added to each jar using a micropipette. In the commercial alum used $\left(\mathrm{Al}_{2}\left(\mathrm{SO}_{4}\right)_{3} \bullet 14 \mathrm{H}_{2} \mathrm{O}\right.$ Liquid Alum, General Chemical, Parsippany, NJ), solid alum content was $48.5 \%$, aluminum content made up $4.3 \%$ of the solution. For alum doses of $0-60 \mathrm{mg} / \mathrm{L}$ (given as solid alum), this corresponds to aluminum concentrations of $0-5.45 \mathrm{mg} / \mathrm{L}$ as $\mathrm{Al}$ (sample calculations in Appendix 8.1). After the addition of coagulant, the jars were subjected to 90 seconds of rapid mix (100 rpm), 15 minutes of slow mixing or flocculation $(30 \mathrm{rpm})$, followed by 30 minutes of settling. This jar testing protocol differs slightly from the Enhanced Coagulation Guidance Manual (USEPA, 1999), which recommends 1 of minute rapid mix, 30 minutes of flocculation, and 60 minutes of settling. The shorter times were chosen to better reflect the residence times at the Peterborough WTP and to increase the number of tests that could be performed per day (Wassink, 2011). The settled water was filtered using $1.2 \mu \mathrm{m}$ pore size glass microfiber filters (42.5 mm diameter, Whatman Inc., Florham Park, NJ). Filtration mimicked the effects of settling basins in full-scale treatment operations and removed particulate organic matter that could contribute to chlorine demand and interfere with sample extractions for subsequent analyses.

Sample water for each coagulant dose from the four jar tests was mixed in stainless steel containers after jar testing, to eliminate the impact of the replicate jar tests. The final volume of each sample corresponding to a given coagulant dose was approximately 7 L. The samples 
were then filtered (to mimic settling basins) and adjusted to $\mathrm{pH} 7.0$ with sulphuric acid. At this stage, aliquots were collected for TOC, DOC, UV, LC-OCD, chlorine demand tests, AOX/THMs/HAAs, MCA/MX, and genotoxicity analysis. Chlorine demand tests were conducted, to determine an optimal initial chlorine dose is calculated for each water sample to maintain a consistent $24 \mathrm{~h}$ chlorine residual of $1.0 \mathrm{mg} / \mathrm{L} \mathrm{Cl}_{2}$. More information about chlorination procedures can be found in Section 3.2.7. DBP formation and genotoxicity samples were chlorinated according to the calculated optimal dose, and incubated for $24 \mathrm{~h}$ at $20^{\circ} \mathrm{C}$. Chlorine residual was measured after $24 \mathrm{~h}$ and the samples were then quenched, acidified to $\mathrm{pH} 2$ (for $\mathrm{MX}$ and genotoxicity samples only), and stored at $4^{\circ} \mathrm{C}$ until analysis. DBP and genotoxicity analysis procedures are found in Sections 3.2.1, 3.2.2, 3.2.3, 3.2.4, and 3.2.5. A summary of sample collection and preparation is provided in Table 3.3.

Table 3.3 - Summary of sample collection after jar testing and filtration

\begin{tabular}{|c|c|c|c|}
\hline Sample type & $\begin{array}{l}\text { Volume } \\
\text { collected }\end{array}$ & $\begin{array}{c}\text { \# of } \\
\text { samples/jar }\end{array}$ & Preparation steps for analysis \\
\hline TOC & $40 \mathrm{~mL}$ & 2 & - Acidify with 2 drops of $\mathrm{H}_{2} \mathrm{SO}_{4}$ \\
\hline $\begin{array}{l}\text { DOC and } \\
\mathrm{UV}_{254}\end{array}$ & $40 \mathrm{~mL}$ & 2 & $\begin{array}{l}\text { - Filter with } 0.45 \mu \mathrm{m} \text { membrane filter } \\
\text { - Acidify with } 2 \text { drops of } \mathrm{H}_{2} \mathrm{SO}_{4}\end{array}$ \\
\hline LC-OCD & $40 \mathrm{~mL}$ & 2 & - Filter with $0.45 \mu \mathrm{m}$ membrane filter \\
\hline $\begin{array}{l}\text { Chlorine } \\
\text { demand }\end{array}$ & $125 \mathrm{~mL}$ & 1 & $\begin{array}{l}\text { - Neutralize to } \mathrm{pH} 7 \text { with } 0.1 \mathrm{M} \mathrm{H}_{2} \mathrm{SO}_{4} \\
\text { - Chlorinate at } 4.0 \mathrm{mg} / \mathrm{L} \mathrm{Cl}_{2} \text { for } 24 \mathrm{~h} \\
\text { - Determine UFC dose }\end{array}$ \\
\hline $\begin{array}{l}\text { AOX/THMs/ } \\
\text { HAAs }\end{array}$ & $500 \mathrm{~mL}$ & 1 & $\begin{array}{l}\text { - Neutralize to } \mathrm{pH} 7 \text { with } 0.1 \mathrm{M} \mathrm{H}_{2} \mathrm{SO}_{4} \\
\text { - Chlorinate at UFC dose for } 24 \mathrm{~h} \\
\text { - Quench with } 3 \text { micro-scoops L-ascorbic acid }\end{array}$ \\
\hline $\mathrm{MCA} / \mathrm{MX}$ & $1 \mathrm{~L}$ & 2 & $\begin{array}{l}\text { - Neutralize to } \mathrm{pH} 7 \text { with } 0.1 \mathrm{M} \mathrm{H}_{2} \mathrm{SO}_{4} \\
\text { - Chlorinate at UFC dose for } 24 \mathrm{~h}\end{array}$ \\
\hline Genotoxicity & $1 \mathrm{~L}$ & 2 & $\begin{array}{l}\text { - Quench with } 5 \text { micro-scoops L-ascorbic acid } \\
\text { - Acidify to pH } 2 \text { with } 20 \text { drops of } \mathrm{H}_{2} \mathrm{SO}_{4}\end{array}$ \\
\hline
\end{tabular}

Glassware (amber vials and bottles) used was purchased from Systems Plus (Edmonton, AB). Cleaning of glassware was completed using a Miele Disinfektor G7736 dishwasher using detergent water (LaboClean FT, Dr. Weigert, Germany) and an acid rinse (Neodisher acid, Dr. Weigert). After the dishwasher cycle, glassware was then rinsed three times with distilled water and dried at $300^{\circ} \mathrm{C}$ for 3 hours in the oven. Glassware used for chlorination tests (both 
chlorine demand and formation tests) was pre-treated to be chlorine demand free by soaking overnight in a dilute bleach solution (approximately $1 \mathrm{~mL}$ of commercial bleach to $1 \mathrm{~L}$ of deionized water). Bottles were then rinsed three times with distilled water. Chlorine demand free bottles were not placed in the oven for drying, as heat will re-activate chlorine demand sites.

\subsection{Analytical Methods}

\subsubsection{MX and MCA Analysis}

\subsubsection{Sample Preparation}

For 3-chloro-4-(dichloromethyl)-5-hydroxy-2(5H)-furanone (Mutagen X, MX) and 2,3dichloromalealdehydic acid (mucochloric acid, MCA) analysis, water from the jar tests were collected in $1 \mathrm{~L}$ amber bottles and chlorinated under UFC conditions. After 24h of chlorination, chlorine residuals were determined and samples were quenched with L-ascorbic acid ( $20 \mathrm{mg}$ or 5 micro-scoops per 1L sample). The bottles were acidified to $\mathrm{pH} 2$ with 20 drops of $\mathrm{H}_{2} \mathrm{SO}_{4}$ and stored in the dark at $4^{\circ} \mathrm{C}$ until extraction. Surrogate standard 2,3dibromoalealdehydic acid (mucobromic acid, MBA) was spiked at $100 \mathrm{ng} / \mathrm{L}$ into all samples and calibration standards (prepared in raw water, see Section 3.2.1.2). Duplicate samples were extracted and analyzed for MCA and MX.

Solid phase extraction was completed using a tandem SPE setup, with a trifunctional C18 (tC18) cartridge (Sep Pak 6cc, 1g, Waters Corporation, Mississauga, ON) for humics removal placed in-line on top of an Oasis HLB cartridge (12cc, 500mg, Waters Corporation). With a Visiprep SPE vacuum manifold (Supelco), flow rate through the cartridges was maintained at under $20 \mathrm{~mL} / \mathrm{min}$ (to maintain a linear velocity of $0.17 \mathrm{~cm} / \mathrm{s}$ ). After sample loading, cartridges were dried under vacuum for approximately 1 hour. HLB cartridges were eluted by gravity with $2 \times 5 \mathrm{~mL}$ of acetone into $15 \mathrm{~mL}$ polypropylene BD Falcon ${ }^{\circledR}$ tubes (VWR International), which was then evaporated to dryness under a gentle stream of nitrogen. Samples were transferred to $2 \mathrm{~mL}$ amber GC vials when the volume reached approximately $0.5 \mathrm{~mL}$, with additional acetone being provided intermittently to rinse sides of 
Falcon ${ }^{\circledR}$ tubes). Samples were reconstituted in $300 \mu \mathrm{L}$ of $2 \% \mathrm{H}_{2} \mathrm{SO}_{4}$ in methanol (v/v), capped, vortexed, and derivatized at $70^{\circ} \mathrm{C}$ for $1 \mathrm{hr}$. After cooling to room temperature, 750 $\mu \mathrm{L}$ of $2 \% \mathrm{NaHCO}_{3}\left(\mathrm{w} / \mathrm{v}\right.$ in Milli-Q ${ }^{\circledR}$ water) was added to each sample to neutralize the acid. Back extraction was performed twice with $600 \mu \mathrm{L}$ of hexane. The final extract was then concentrated to approximately $0.1 \mathrm{~mL}$ under a gentle stream of nitrogen. GC/MS analysis was performed immediately. Final MCA/MX extracts were stored at $-20^{\circ} \mathrm{C}$.

\subsubsection{Gas Chromatography/Mass Spectrometry}

Quantification of MX compounds in the derivatized extracts (method development described in Section 4.0) was achieved using gas chromatography/mass spectrometry. Samples were analyzed using a Varian GC/MS system (Mississauga, ON) equipped with a Varian 3800 GC, $4000 \mathrm{MS}$, and CombiPAL autosampler. The column used was a J \& W Scientific DB-1701 column $(30 \mathrm{~m}, 0.25 \mathrm{~mm}$ ID, $0.25 \mu \mathrm{m}$ film thickness). The GC/MS method was developed based on methodology described in Zwiener \& Kronberg (2001); specifics are given in Table 3.4. MS/MS specifications are provided in Table 3.5.

Table 3.4 - GC/MS instrument conditions for MCA/MX analysis

\begin{tabular}{|c|c|}
\hline Parameter & Conditions \\
\hline System & Varian 3800 GC with $4000 \mathrm{MS}$ and CombiPAL autosampler \\
\hline Column & DB-1701 (30m x 0.25mm OD x $0.25 \mu \mathrm{m}$ ID, Agilent J \& W) \\
\hline Injection volume & $8 \mu \mathrm{L}$ \\
\hline Injection mode & $\begin{array}{l}\text { Initial splitless injection } \\
\text { Split on at } 0.10 \mathrm{~min} \text { at } 5: 1 \\
\text { Split off at } 0.8 \mathrm{~min} \\
\text { Split on at } 6.0 \mathrm{~min} \text { at } 30: 1\end{array}$ \\
\hline Injector temperature & $\begin{array}{l}50^{\circ} \mathrm{C} \text { hold for } 0.8 \mathrm{~min} \\
200^{\circ} \mathrm{C} / \mathrm{min} \text { to } 200^{\circ} \mathrm{C} \text {, hold for } 20 \mathrm{~min}\end{array}$ \\
\hline Oven temperature & $\begin{array}{l}40^{\circ} \mathrm{C} \text {, hold for } 2 \mathrm{~min} \\
20^{\circ} \mathrm{C} / \mathrm{min} \text { to } 100^{\circ} \mathrm{C} \\
6^{\circ} \mathrm{C} / \mathrm{min} \text { to } 170^{\circ} \mathrm{C} \\
15^{\circ} \mathrm{C} / \mathrm{min} \text { to } 260^{\circ} \mathrm{C} \text {, hold for } 3 \mathrm{~min}\end{array}$ \\
\hline Carrier gas & Helium, constant flow at $1.2 \mathrm{~mL} / \mathrm{min}$ \\
\hline Transfer line temperature & $275^{\circ} \mathrm{C}$ \\
\hline Ion source temperature & $150^{\circ} \mathrm{C}$ \\
\hline Ionization mode & Electron impact (EI) \\
\hline Scan range & $50-400 \mathrm{amu}$ \\
\hline MS scan mode & $\mathrm{MS} / \mathrm{MS}$ \\
\hline
\end{tabular}


Table 3.5 - MS/MS conditions and monitored ions

\begin{tabular}{|c|c|c|c|c|c|c|}
\hline 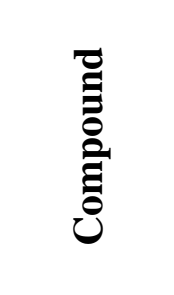 & 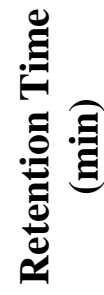 & 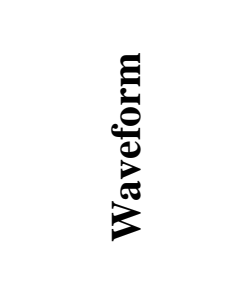 & 这 & 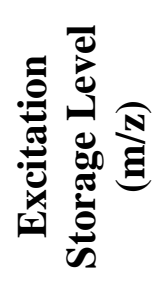 & 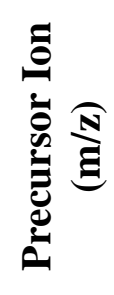 & 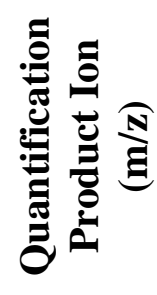 \\
\hline MCA & 10.88 & Resonant & 0.37 & 64.8 & 147 & 119 \\
\hline $\mathrm{MBA}_{\text {ring }}$ & 14.75 & Non-resonant & 96 & 106.2 & 241 & 185 \\
\hline MX & 16.21 & Non-resonant & 70 & 88.5 & 201 & 173 \\
\hline $\mathrm{MBA}_{\text {open }}$ & 16.31 & Non-resonant & 80 & 105.3 & 239 & 157 \\
\hline
\end{tabular}

A standard of 3-chloro-4-(dichloromethyl)-5-hydroxy-2(5H)-furanone (MX) was obtained from Toronto Research Chemicals Inc. (North York, ON). Mucochloric acid (MCA) and mucobromic acid (MBA) standards were obtained from Sigma-Aldrich Inc (Oakville, ON). A six-point calibration of MX and MCA at $0,10,25,50,100$, and $200 \mathrm{ng} / \mathrm{L}$ was prepared alongside spike and recovery standards (1 per 6 samples) in 1L raw water samples for each water source and extracted alongside chlorinated water samples, to account for sample matrix effects. The relative peak area of MCA and $\mathrm{MX}$ to the sum of $\mathrm{MBA}_{\text {ring }}$ and $\mathrm{MBA}_{\text {open }}$ $\left(\mathrm{MBA}_{\text {sum }}\right)$ peak areas was used for determination of concentration. Spike and recovery sample concentrations (spiked to a nominal concentration of $100 \mathrm{ng} / \mathrm{L}$ for MX and MCA) for QC/QA are given in Figure 3.2. Typical calibration curves for MCA and MX are given in Figure 3.3.

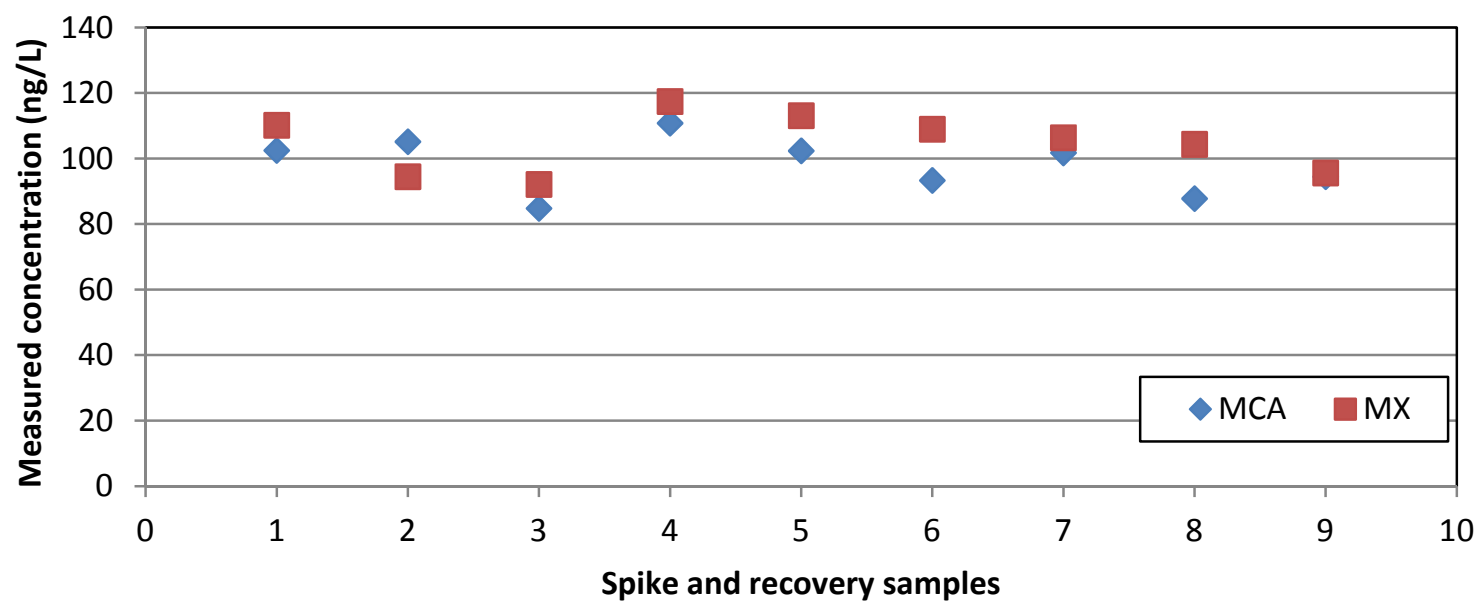

Figure 3.2 - QC/QA of MCA/MX spike and recovery samples (prepared at $100 \mathrm{ng} / \mathrm{L}$ in raw water) 


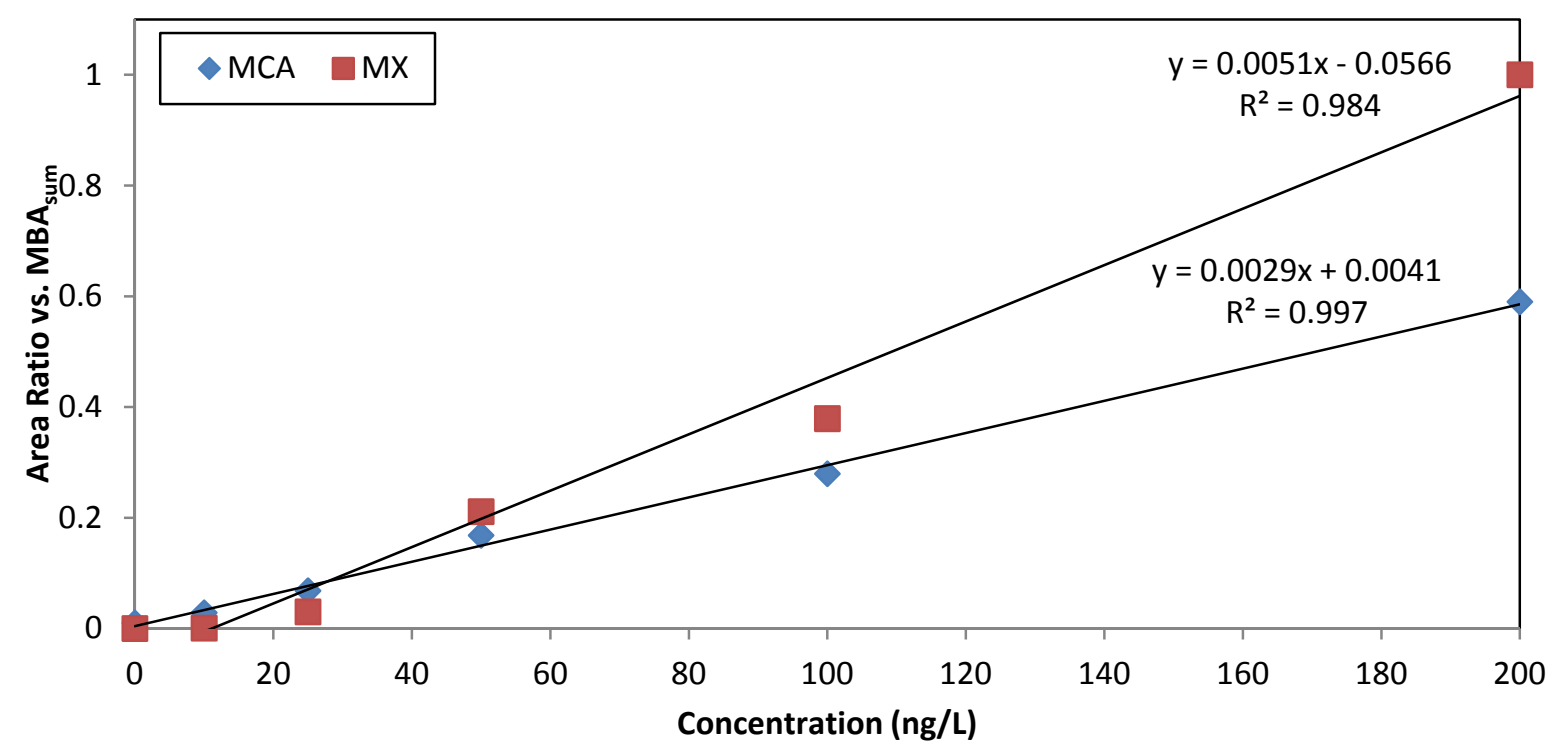

Figure 3.3 - Typical calibration curves for MCA and MX analysis

\subsubsection{AOX Analysis}

Absorbable organic halides (AOX) content was analyzed by the batch method using the Trace Elemental Instruments Xplorer Analyzer (TE Instruments, Delft, the Netherlands). 50 mg activated carbon, which adsorbs the organic halogens, was mixed with $100 \mathrm{~mL}$ water samples for 1 hour on an orbital shaker (BiggerBill, Thermolyne). The sample was then filtered through a quartz frit to recover the carbon particles. A combustion process followed by coulometric titration of the released halogens determined AOX in the sample. Duplicate samples were analyzed.

\subsubsection{THM Analysis}

The liquid-liquid extraction, gas chromatographic method described in Standard Method 6232B (APHA, 2005) was used for TTHM analysis. The four THM compounds (chloroform (trichloromethane, TCM), bromodichloromethane (BDCM), dibromochloromethane (DBCM), and bromoform (tribromomethane, TBM) in chlorinated samples were extracted by adding $4 \mathrm{~mL}$ of methyl-tert-butyl-ether (MTBE) to a $25 \mathrm{~mL}$ sample in $40 \mathrm{~mL}$ glass vials. 1 tsp of sodium sulphate $\left(\mathrm{Na}_{2} \mathrm{SO}_{4}\right)$ is also added, to increase extraction efficiency. The vials 
were capped and manually shaken for 2 minutes. The organic layer was transferred into GC vials and analyzed on a Hewlett Packard 5890 Series II Plus Gas Chromatograph (Mississauga, ON) with electron capture detection (GC-ECD), equipped with a DB 5.625 capillary column (Agilent Technologies Canada Inc., Mississauga, ON). GC-ECD instrument operating conditions are provided in Table 3.6.

Table 3.6 - GC-ECD operating conditions for THM analysis

\begin{tabular}{|l|l|}
\hline Parameter & Conditions \\
\hline System & HP5890 Series II Plus \\
\hline Column & DB 5.625 capillary column $(30 \mathrm{~m} \times 0.25 \mathrm{~mm}$ OD x $0.25 \mu \mathrm{m} \mathrm{ID})$ \\
\hline Injector Temperature & $200^{\circ} \mathrm{C}$ \\
\hline Detector Temperature & $300^{\circ} \mathrm{C}$ \\
\hline Temperature Program & $40^{\circ} \mathrm{C}$ for 4.0 min \\
& $4^{\circ} \mathrm{C} / \mathrm{min}$ temperature ramp to $95^{\circ} \mathrm{C}$ \\
& $60^{\circ} \mathrm{C} / \mathrm{min}$ temperature ramp to $200^{\circ} \mathrm{C}$ \\
\hline Carrier Gas & $\mathrm{Helium}$ \\
\hline Flow Rate & $1.2 \mathrm{~mL} / \mathrm{min}$ at $35^{\circ} \mathrm{C}$ \\
\hline
\end{tabular}

A stock standard containing all four THMs (Supelco, 48140-U) was used to make an eightpoint calibration at concentrations of $0,5,10,20,40,60,80$, and $100 \mu \mathrm{g} / \mathrm{L}$ spiked in Milli$\mathrm{Q}^{\circledR}$ water. Check standards made at nominal concentrations of $40 \mu \mathrm{g} / \mathrm{L}$ in Milli-Q ${ }^{\circledR}$ water were analyzed every 12 samples and used for QA/QC of the THM analysis (Figure 3.4). 1,2dibromopropane (1,2-DBP, Supelco) was added as an internal standard in all samples and calibration standards. Relative area responses (area ratios) of each THM compound peak area to internal standard peak area were used for concentration determination. Typical calibration curves for the four THM species are provided in Figure 3.5.

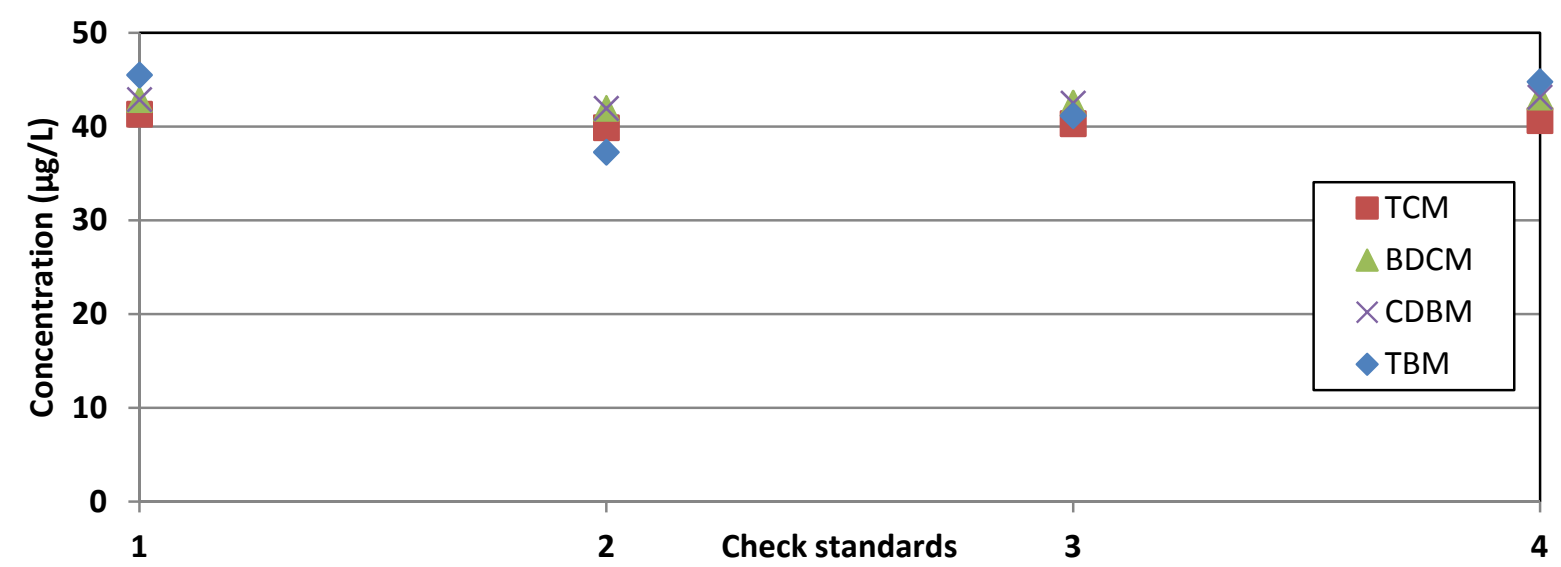

Figure 3.4 - QC/QA of THM spike and recovery samples (prepared at $40 \mu \mathrm{g} / \mathrm{L}$ ) 


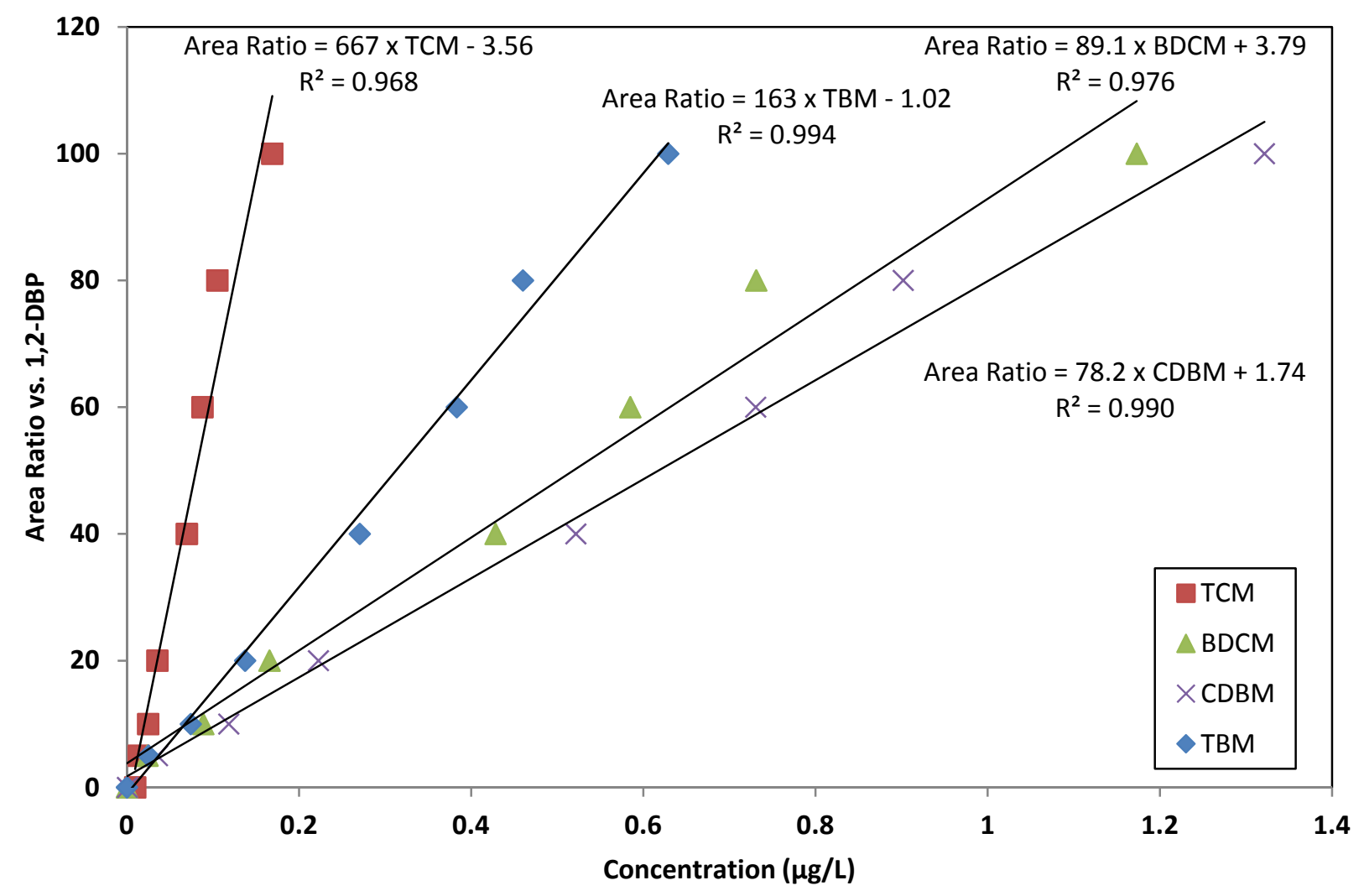

Figure 3.5 - Typical calibration curves for THM analysis

\subsubsection{HAA Analysis}

The liquid-liquid extraction, gas chromatographic Standard Method 6251B (APHA, 2005) was used for $\mathrm{HAA}_{9}$ analysis. The nine HAA species: monochloroacetic acid (MCAA), monobromoacetic acid (MBAA), dichloroacetic acid (DCAA), trichloroacetic acid (TCAA), bromochloroacetic acid (BCAA), dibromoacetic acid (DBAA), bromodichloroacetic acid (BDCAA), dibromochloroacetic acid (DBCAA), and tribromoacetic acid (TBAA) in chlorinated samples were extracted by adding $4 \mathrm{~mL}$ of methyl-tert-butyl-ether (MTBE) to a $25 \mathrm{~mL}$ sample in $40 \mathrm{~mL}$ glass vials. 1 tsp of sodium sulphate $\left(\mathrm{Na}_{2} \mathrm{SO}_{4}\right)$ is also added, to increase extraction efficiency. The vials were capped and manually shaken for 2 minutes. The organic layer was transferred into GC vials, with $100 \mu \mathrm{L}$ of diazomethane added into each vial. Extracted samples were analyzed on a Hewlett Packard 5890 Series II Plus Gas Chromatograph (Mississauga, ON) with electron capture detection (GC-ECD), equipped with 
a DB 5.625 capillary column (Agilent Technologies Canada Inc., Mississauga, ON). GCECD instrument conditions are provided in Table 3.7.

Table 3.7 - GC-ECD operating conditions for HAA analysis

\begin{tabular}{|l|l|}
\hline Parameter & Conditions \\
\hline System & HP5890 Series II Plus \\
\hline Column & DB 5.625 capillary column $(30 \mathrm{~m} \times 0.25 \mathrm{~mm}$ OD x $0.25 \mu \mathrm{m}$ ID) \\
\hline Injector Temperature & $200^{\circ} \mathrm{C}$ \\
\hline Detector Temperature & $300^{\circ} \mathrm{C}$ \\
\hline Temperature Program & $35^{\circ} \mathrm{C}$ for 10.0 min \\
& $2.5^{\circ} \mathrm{C} /$ min temperature ramp to $65^{\circ} \mathrm{C}$ \\
& $10^{\circ} \mathrm{C} /$ min temperature ramp to $85^{\circ} \mathrm{C}$ \\
& $20^{\circ} \mathrm{C} /$ min temperature ramp to $205^{\circ} \mathrm{C}$ \\
\hline Carrier Gas & Hold for 7 min \\
\hline Flow Rate & Helium \\
\hline
\end{tabular}

A stock standard containing all nine HAAs (Supelco, 47787) was used to make a six-point calibration at concentrations of $0,5,10,20,40$, and $60 \mu \mathrm{g} / \mathrm{L}$ spiked in Milli-Q ${ }^{\circledR}$ water. Check standards made at nominal concentrations of $40 \mu \mathrm{g} / \mathrm{L}$ in Milli-Q® water were analyzed every 12 samples and used for QA/QC of the THM analysis (Figure 3.6). 2,3,5,6tetrafluorobenzoic acid (TFBA, Supelco) was added as an internal standard in all samples and calibration standards. Relative area responses (area ratios) of each HAA compound peak area to internal standard peak area were used for concentration determination. Typical calibration curves for the nine HAA species are provided in Figure 3.7.

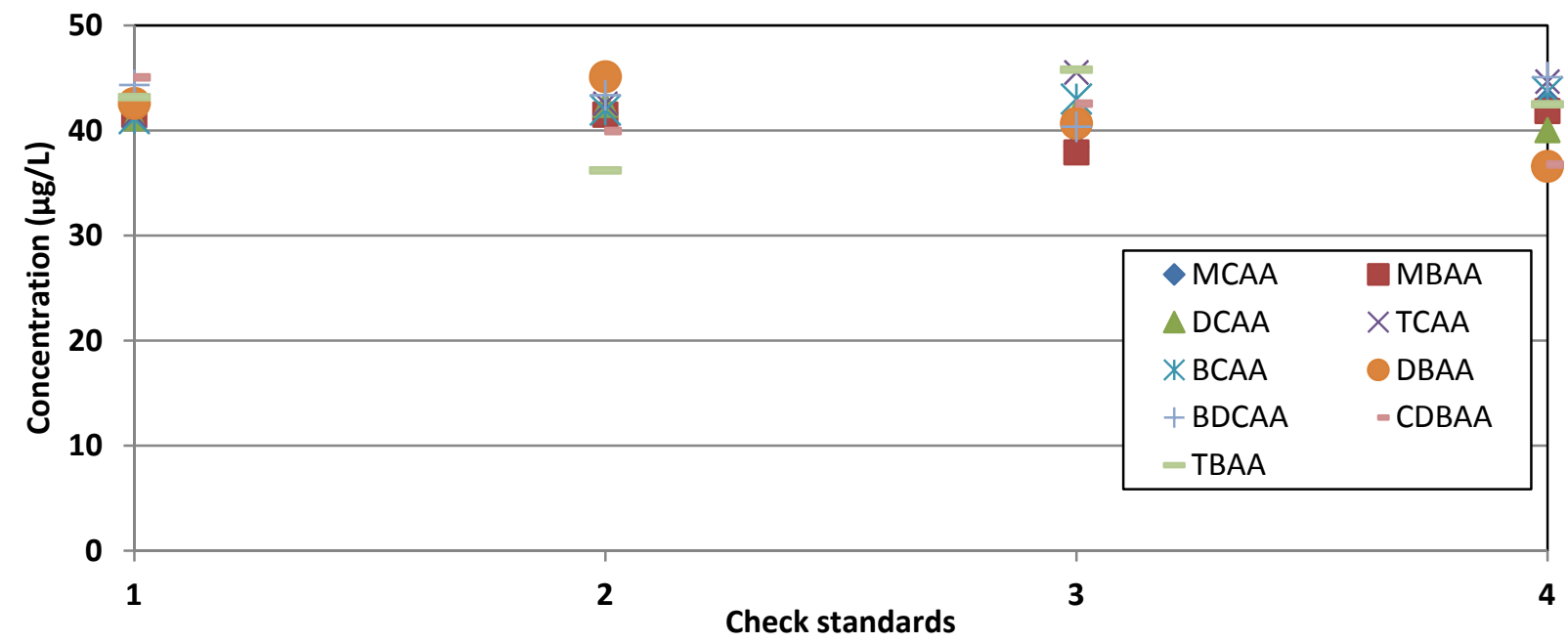

Figure 3.6 - QC/QA of HAA spike and recovery samples (prepared at $40 \mu \mathrm{g} / \mathrm{L}$ ) 


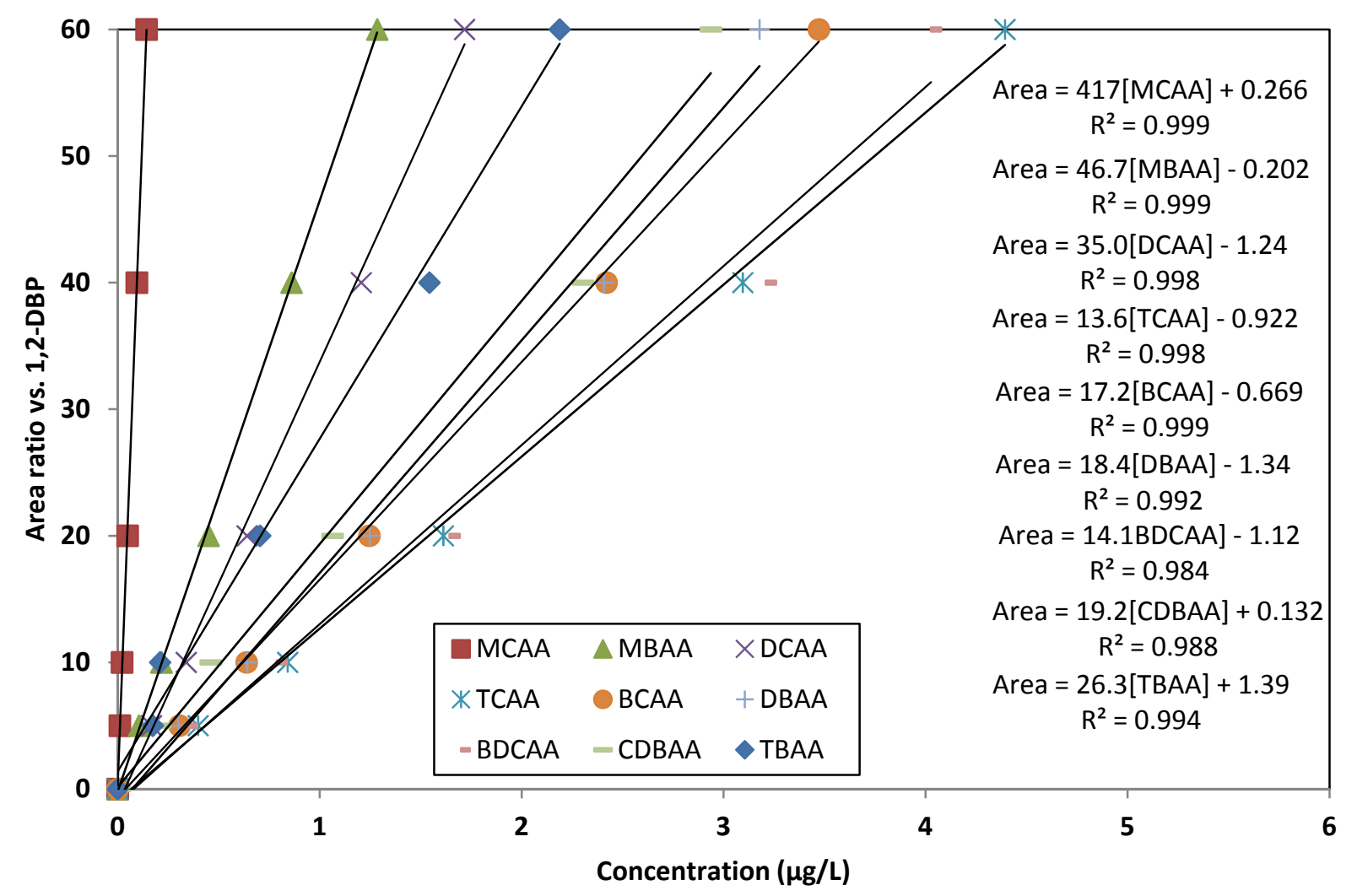

Figure 3.7 - Example calibration curves for HAA analysis

\subsubsection{Genotoxicity Analysis with the SOS Chromotest}

The SOS Chromotest can detect DNA damaging agents by utilizing the inherent mechanism in living cells that detects lesions created in their genetic material and then activates the DNA repair mechanism. In Escherichia coli (E. coli), the SOS repair system is activated in response to DNA damage (EBPI, 2011). The SOS-reporter gene in E. coli was first developed in 1982 by Quillardet et al. and then miniaturized into kit form by Fish et al. (1987). The SOS Chromotest kit employed in this research project was supplied by EBPI (Environmental Bio-Detection Products Inc, Mississauga, Ontario, Canada).

For the colorimetric SOS Chromotest assay, the $\beta$-galactosidase ( $\beta$-gal) gene (lacZ) is fused to the bacterial sfiA SOS operon in a genetically engineered strain of E. coli PQ37. This means that the SOS repair system of PQ37 is engineered such that sfiA, SOS promoter induces lac $Z$ expression and the synthesis of $\beta$-gal. The degree of induction of $\beta$-gal can be 
quantified photometrically using a chromogenic substrate to form a blue colour. The amount of $\beta$-gal induction is representative of SOS induction and hence, bacterial genotoxicity (Kocak et al., 2010). The endogenous SOS repair is altered to effectively inactivate the DNA repair mechanism of excision repair ( $u v r A$ ) to increase the sensitivity to DNA damaging agents. In addition, the outer membrane of the cell is lipopolysaccharide deficient $(r f a)$ to increase permeability, allowing for greater chemical diffusion into the cell (Quillardet et al., 1982). General protein synthesis is also measured in order to correct for inhibition of protein synthesis due to mixture exposure, which could result in the underestimation of $\beta$-gal induction. This is accomplished by making the strain constitutive for alkaline phosphatase (AP) synthesis. Hence, the induction of $\beta$-gal is measured by the ratio of $\beta$-gal activity to AP activity (referred to as the induction factor).

The assay consists of the introduction of the tester PQ37 strain to serial dilutions of the test agent. After incubation and addition of chromogen solution, the induction factor ( $\beta$-gal/AP activity ratio) is determined colorimetrically. Dose-response curves of the induction factor vs. equivalent concentration must show linearity, where the slope quantitatively expresses the genotoxicity of that particular chemical mixture. A well-known carcinogen and mutagen, 4nitroquinonline 1-oxide (4-NQO), is included in each assay as a positive control.

SOS Chromotest procedures were provided by EBPI. First to prepare jar tested, chlorinated water samples for the SOS Chromotest bioassay, $2 \mathrm{~L}$ samples were quenched with L-ascorbic acid and acidified to $\mathrm{pH} 2$ with sulphuric acid. Extraction via SPE was performed, using Oasis HLB cartridges (500 mg, Waters Corporation, Mississauga, Ontario, Canada). Prior to extraction, the columns were conditioned using $10 \mathrm{~mL}$ of acetone, $10 \mathrm{~mL}$ of methanol, and $10 \mathrm{~mL}$ of Milli-Q ${ }^{\circledR}$ water. Samples were loaded onto the columns at a flow rate of approximately $20 \mathrm{~mL} / \mathrm{min}$, to maintain a linear velocity of $0.17 \mathrm{~cm} / \mathrm{s}$. After loading of samples, cartridges were dried under vacuum and eluted with two aliquots of $4.5 \mathrm{~mL}$ of acetone into falcon tubes. The acetone was evaporated under a gentle stream of nitrogen and reconstituted in $30 \mu \mathrm{L}$ of dimethyl sulfoxide (DMSO). 
On a 96 well microplate, $1 \mu \mathrm{L}$ of extracted water sample (in DMSO) was added to $4 \mu \mathrm{L}$ of 10\% DMSO saline solution. Each sample was then diluted two-fold into five respective wells, for a total of six test concentrations. Positive control substance 4-NQO was tested on every plate, alongside samples. A $100 \mu \mathrm{L}$ of diluted bacterial suspension (prepared overnight and diluted to 0.5 final optical density at $600 \mathrm{~nm}, \mathrm{OD}_{600}$, prior to use) was added to each well and the bioassay was incubated at $37^{\circ} \mathrm{C}$ for $2 \mathrm{~h}$. After incubation, $100 \mu \mathrm{L}$ of chromogen for $\beta$ gal and AP was added to each well and plates were incubated at $37^{\circ} \mathrm{C}$ for an additional hour. A microplate reader (Infinite 200, Tecan, Morrisville, NC) was used to read the activity of $\beta$ gal (at $\left.\mathrm{OD}_{605}\right)$ and $\mathrm{AP}\left(\right.$ at $\left.\mathrm{OD}_{420}\right)$.

The specific equations for the determination of $\beta$-gal specific activity $\left(R_{c}\right)$, AP reduction specific activity $\left(\mathrm{R}_{0}\right)$, and the induction factor (IF) are given below:

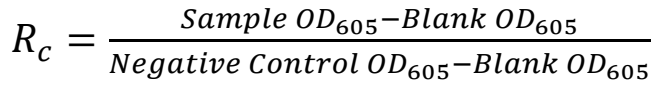

$$
\begin{aligned}
& R_{0}=\frac{\text { Sample } O D_{420}-\text { Blank } O D_{420}}{\text { Negative Control } O D_{420}-B \text { Blank } O D_{420}} \\
& I F=\frac{R_{C}}{R_{0}}
\end{aligned}
$$

A serial, step-wise dilution (total of six dilutions for each sample) was used in the SOS Chromotest bioassay. For each dilution, the amount of sample is quantified with a unitless relative enrichment factor (REF) defined by Escher \& Leusch (2011):

$$
R E F=\frac{\text { enrichment }_{\text {factor }} \text { extraction }}{\text { dilution } \text { factor }_{\text {bioassay }}}
$$

where the enrichment factor is the concentration achieved during sample extraction (i.e. with SPE) and the dilution factor is the dilution amount for each step in the bioassay.

With the IF and REF values for each dilution in each sample, the slope of the linear portion of IF vs. REF can be found (use one dilution after an observed IF $>2.0$, indicating a genotoxic level). For the known carcinogenic positive control, 4-NQO, instead of REF a mass in pmol is used (since exact concentration added is known). The 4-NQO slopes are 
corrected with the SOSIP factor, to normalize out the mass unit. SOSIP is defined by Quillardet et al. (1982) as the potency of IF per nmol per assay. For known genotoxic compounds, this SOSIP value is consistent and reported.

Finally, each sample's IF vs. REF slope value is quantified relative to 4-NQO SOSIP with the toxic equivalent concentration $\left(\mathrm{TEQ}_{4-\mathrm{NQO}}\right)$ :

$$
T E Q_{\text {sample }}=\frac{\text { Slope }_{\text {sample }}}{\text { Slope }_{4-N Q O S O S I P}}
$$

The TEQ value represents the genotoxicity of each sample, relative to the genotoxicity of carcinogen 4-NQO. For example, if a sample was as genotoxic as 4-NQO, it would have a TEQ value of 1.0. Sample calculations for the entire SOS Chromotest are available in the Appendix 8.6.

\subsubsection{Natural Organic Matter (NOM) Analysis}

\subsubsection{Total Organic Carbon (TOC), Total Dissolved Carbon (DOC)}

An O-I Corporation Model 1030 Analytical TOC Analyzer and Model 1051 Vial MultiSampler (College Station, Texas) was used for total organic carbon (TOC) and dissolved organic carbon (DOC) analyses. Measurements were made according to the wet oxidation method described in Standard Method 5310D (APHA, 2005).

Samples were collected in $40 \mathrm{~mL}$ amber vials, acidified to $\mathrm{pH}<2$ with 3 drops of concentrated sulphuric acid $\left(\mathrm{H}_{2} \mathrm{SO}_{4}\right)$, capped with Teflon ${ }^{\circledR}$-lined septum screw caps, and stored in the dark at $4^{\circ} \mathrm{C}$ until analysis. TOC samples were pre-filtered using $1.2 \mu \mathrm{m}$ pore size glass microfiber filters (42.5 mm diameter, Whatman Inc., Florham Park, NJ) and DOC samples were pre-filtered using $0.45 \mu \mathrm{m}$ pore size membrane filters (Supor-450 $47 \mathrm{~mm}$ diameter, Pall Corporation, Ann Arbor, MI). Calibration solutions were prepared with anhydrous potassium phthalate in Milli-Q ${ }^{\circledR}$ water and run with each sample set. Blanks of Milli-Q ${ }^{\circledR}$ water and check standards (prepared with anhydrous potassium phthalate) were run between every 10 samples. A list of reagents used and the instrument conditions are provided 
in Table 3.8 and Table 3.9, respectively. A typical calibration curve for TOC is given in Figure 3.8.

Table 3.8 - TOC/DOC reagents

\begin{tabular}{|l|l|}
\hline Reagent & Supplier and Purity \\
\hline Milli-Q ${ }^{\circledR}$ water & Prepared in laboratory \\
\hline Nitrogen gas, $\mathrm{N}_{2}$ & Praxair, Ultra high purity \\
\hline Phosphoric acid, $\mathrm{H}_{3} \mathrm{PO}_{4}$ & Caledon Laboratory Chemicals, 85+\% \\
\hline Potassium hydrogen phthalate, $\mathrm{C}_{8} \mathrm{H}_{5} \mathrm{KO}_{4}$ & Sigma Aldrich, 98+\% \\
\hline Sodium persulphate, $\mathrm{Na}_{2} \mathrm{~S}_{2} \mathrm{O}_{8}$ & Sigma Aldrich, 98+\% \\
\hline Sulphuric acid, $\mathrm{H}_{2} \mathrm{SO}_{4}$ & VWR International, 98+\% \\
\hline
\end{tabular}

Table 3.9 - TOC instrument conditions

\begin{tabular}{|l|l|}
\hline Parameter & Description \\
\hline Acid volume & $200 \mu \mathrm{L}$ of $5 \%$ phosphoric acid \\
\hline Oxidant volume & $1000 \mu \mathrm{L}$ of $100 \mathrm{~g} / \mathrm{L}$ sodium persulphate \\
\hline Sample volume & $15 \mathrm{~mL}$ \\
\hline Rinses per sample & 1 \\
\hline Volume per rinse & $15 \mathrm{~mL}$ \\
\hline Reaction time (min:sec) & $2: 30$ \\
\hline Detection time (min:sec) & $2: 00$ \\
\hline Purge gas & Nitrogen \\
\hline Loop size & $5 \mathrm{~mL}$ \\
\hline
\end{tabular}

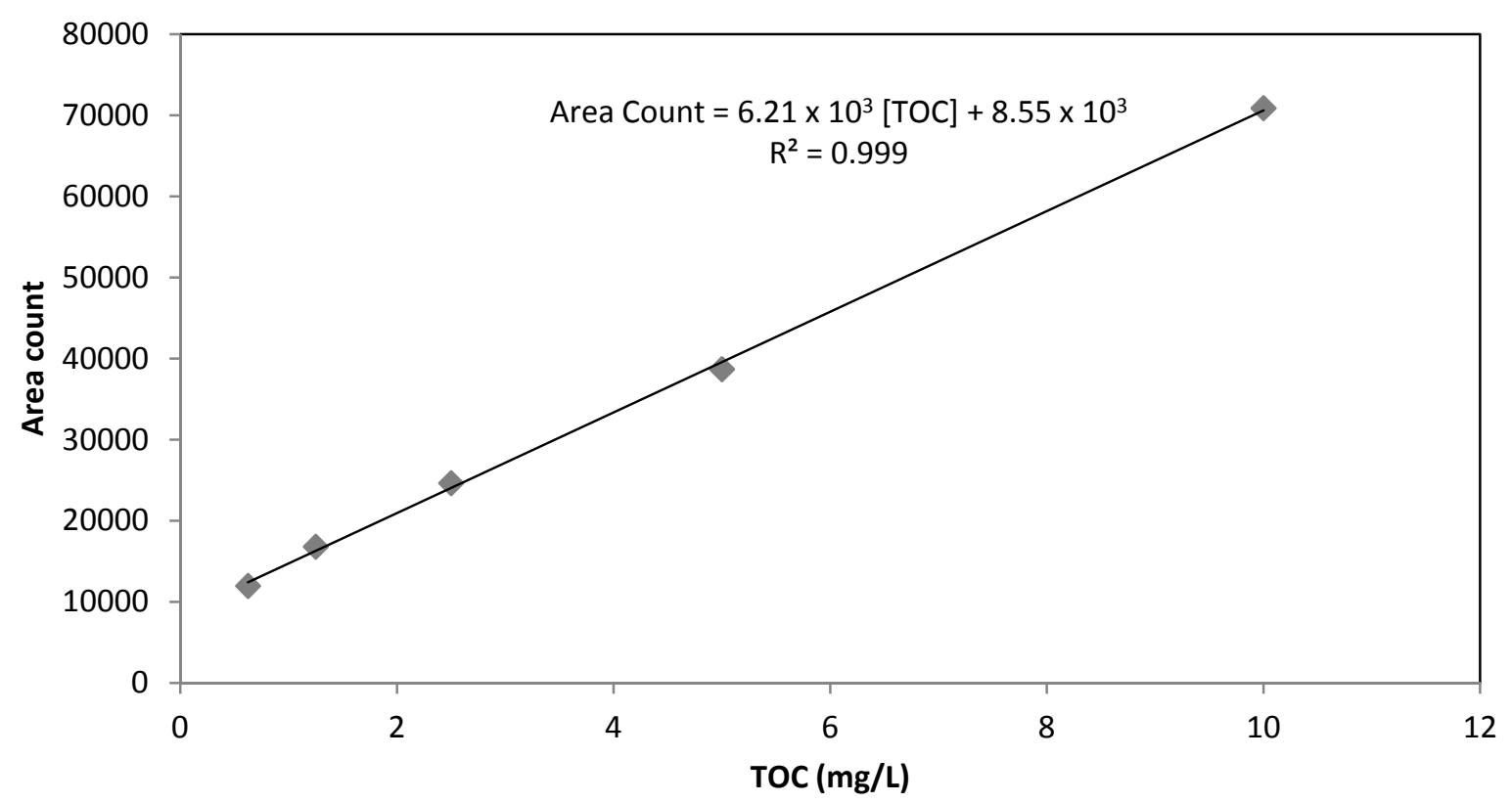

Figure 3.8 - Example calibration curve for the determination of TOC 


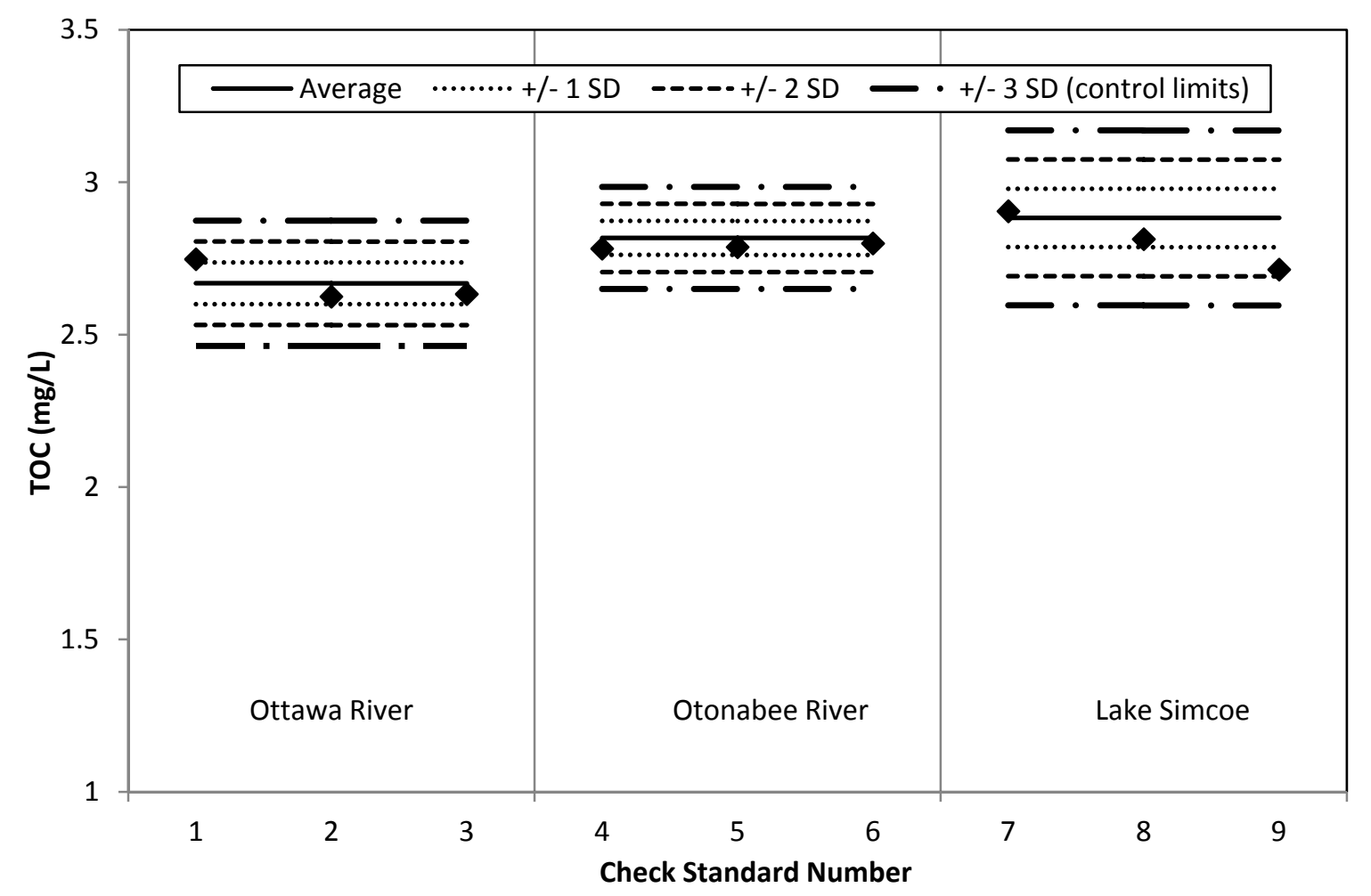

Figure 3.9 - Quality control chart for TOC/DOC analysis (check standards prepared at $3.0 \mathrm{mg} / \mathrm{L})$

Control charts and quality control of TOC data to maintain proper method performance was completed based on Standard Methods 1020 (APHA, 2005). QA/QC samples (eight samples per calibration) and check standards at $3.0 \mathrm{mg} / \mathrm{L}$ (run in between every ten samples) were prepared with potassium hydrogen phthalate in Milli-Q ${ }^{\circledR}$ water. The quality control chart is given in Figure 3.9. Standard Method 1020 (APHA, 2005) guidelines for quality control using check standards were used, which state that a calibration is deemed unacceptable if:

- 2 consecutive measurements were greater than mean $\pm 3 \times$ standard deviation (3 SD)

- 3 out of 4 consecutive measurements were greater than mean $\pm 2 \times$ standard deviation (2 SD) 


\subsubsection{Ultraviolet Absorbance at $254 \mathrm{~nm}$}

Ultraviolet absorbance was measured with a CE 3055 Single Beam Cecil UV/Visible Spectrophotometer (Cambridge, England). UV absorbance at $254 \mathrm{~nm}\left(\mathrm{UV}_{254}\right)$ was determined using $1 \mathrm{~cm}$ quartz cells (Hewlett Packard, Mississauga), following Standard Method 5910B (APHA, 2005). The spectrophotometer was blanked with Milli-Q ${ }^{\circledR}$ water; cells were rinsed with Milli-Q ${ }^{\circledR}$ water, followed by a rinse with sample water prior to measurement.

\subsubsection{LC-OCD}

A size exclusion liquid chromatography with organic carbon detection (LC-OCD) system was used to analyze NOM composition in water samples. The LC-OCD characterized NOM into five fractions: biopolymers, humics, building blocks, low molecular weight (LMW) acids, and LMW neutrals. The method by Huber et al. (2011) was followed. After the bench scale coagulation/filtration experiments, samples for LC-OCD were filtered a second time with a $0.45 \mu \mathrm{m}$ filter (Supor-450 47mm, Pall Corporation, Ann Arbor, MI) and collected in $40 \mathrm{~mL}$ amber vials. The samples were shipped to the University of Waterloo, where the organic components were chromatographically separated using a size exclusion, weak cation exchange column (250 mm x $20 \mathrm{~mm}$, TSK HW 50S, Toso, Japan) with a phosphate buffer (purified in an annular UV reactor) at $1.1 \mathrm{~mL} / \mathrm{min}$ as the mobile phase. After separation in the column, samples were analyzed with a non-destructive UV detector $\left(\mathrm{UV}_{254 \mathrm{~nm}}\right)$ followed by the organic carbon detector (OCD) that acidified samples to convert carbonates to carbonic acid. A bypass stream in the system around the column determines DOC. Data acquisition and analysis was completed with a customized software package ChromCALC (DOC-LABOR, Karlsruhe, Germany).

\subsubsection{Chlorine Demand and Uniform Formation Conditions}

The uniform formation conditions (UFC) test (Summers et al., 1996) was generally followed for DBP formation and genotoxicity tests. The appropriate chlorine dose for each DBP and genotoxicity analysis sample was estimated from chlorine demand tests that were conducted 
on separate $250 \mathrm{~mL}$ aliquots of each sample. Samples were chlorinated at a uniform dose of 4 $\mathrm{mg} / \mathrm{L} \mathrm{Cl}_{2}$ and chlorine residual was measured after $24 \mathrm{~h}$ of incubation. Using this measured residual, an optimal initial chlorine dose was calculated for each water sample to maintain a consistent $24 \mathrm{~h}$ chlorine residual of $1.0 \pm 0.4 \mathrm{mg} / \mathrm{L} \mathrm{Cl}_{2}$. UFC stipulates that chlorinated samples are incubated at $20.0 \pm 1.0^{\circ} \mathrm{C}$ for $24 \pm 1$ hours at a $\mathrm{pH}$ of $8.0 \pm 0.2$ (Summers et al., 1996). However, in these experiments, the $\mathrm{pH}$ was adjusted to $7.0 \pm 0.1$ to allow for disinfection with primarily hypochlorous acid (hypochlorous acid dissociates to hypochlorite ion, a weaker disinfectant, with increasing $\mathrm{pH}$ ). All other parameters of the UFC test were followed as provided.

Chlorination of chlorine demand, DBP and genotoxicity formation samples was accomplished with the addition of sodium hypochlorite solution (12\% NaOCl stock, BioShop Canada Inc., Burlington, ON). Chlorine concentrations were measured using the DPD colorimetric Standard Method 4500-Cl G (APHA, 2005). A HACH chlorine kit (DR2010, Mississauga, ON) was used and blanked using Milli-Q ${ }^{\circledR}$ water prior to sample analysis. For higher chlorine concentration samples $\left(>3.0 \mathrm{mg} / \mathrm{L} \mathrm{Cl}_{2}\right)$, samples were diluted with Milli-Q ${ }^{\circledR}$ water to a known volume prior to analysis (resulting concentrations were multiplied by the dilution factor).

\subsection{8 pH Measurement}

A Model 8015 pH meter (VWR Scientific Inc., Mississauga) was used to determine the pH of water samples. Calibration was accomplished with standard $\mathrm{pH}$ buffer solutions at $\mathrm{pH} \mathrm{4,} \mathrm{7,}$ and 10 (VWR International) prior to each use. During measurement, samples were mixed using a magnetic stir device and a stir bar.

\subsubsection{Alkalinity}

Alkalinity of raw water samples was determined following the end-point colorimetric titration method described in Standard Method 2320B (APHA, 2005). A $100 \mathrm{~mL}$ water sample at room temperature was transferred to a $250 \mathrm{~mL}$ beaker with 5 drops of bromocresol 
green indicator (VWR International). A $0.02 \mathrm{~N}$ sulphuric acid titrant solution (VWR International, 98+\%) prepared in Milli-Q ${ }^{\circledR}$ water was added drop wise, until the sample colour changed from blue to yellow. The alkalinity of the sample was calculated by:

$$
\text { Alkalinity }\left(\frac{m g}{L} \mathrm{CaCO}_{3}\right)=\frac{A \times N \times 50000}{V}
$$

where:

$$
\begin{aligned}
& \mathrm{A}=\text { volume of } \mathrm{H}_{2} \mathrm{SO}_{4} \text { titrated (in } \mathrm{mL} \text { ) } \\
& \mathrm{N}=\text { normality of } \mathrm{H}_{2} \mathrm{SO}_{4} \text { (in these experiments, } \mathrm{N}=0.02 \text { ) } \\
& \mathrm{V}=\text { volume of sample (in these experiments, } \mathrm{V}=100 \mathrm{~mL} \text { ) }
\end{aligned}
$$

The alkalinity of each sample was determined in duplicate and an average was taken as the final value.

\subsection{Statistical Analysis of Data}

All statistical calculations and analyses were performed using JMP 9.0.1 software (SAS Institute Inc., Cary, NC). The alum dosage order in jar tests was randomized and duplicate samples were collected and analyzed for all parameters except LC-OCD (single samples) and genotoxicity (single sample collected with triplicate analysis).

\subsection{Determination of Chlorine Residual Influence on DBP Formation}

DBP formation was achieved by under UFC conditions, which stipulates a $24 \mathrm{~h}$ chlorine residual of $1.0 \pm 0.4 \mathrm{mg} / \mathrm{L} \mathrm{Cl}_{2}$. Doses that theoretically provide this residual were calculated based upon chlorine demand tests. The actual measured chlorine residuals after $24 \mathrm{~h}$ varied from $1.0 \pm 0.5 \mathrm{mg} / \mathrm{L} \mathrm{Cl}_{2}$. Since the variation of chlorine residuals is quite large (even under UFC guidelines), a two-way analysis of variance (ANOVA) test was applied to determine whether actual chlorine residuals had an influence on the observed DBP formation results.

For each measured DBP, the following ANOVA test was applied. Using alum dose as the main effect for DBP formation and measured chlorine residual as a secondary effect, the twoway ANOVA model is given by: 


$$
y_{i j}=\mu+A_{i j}+B_{i j}+(A B)_{i j}+\varepsilon_{i j}
$$

where: $\quad \mu=$ the grand mean of the observations

$\mathrm{A}=$ the effect of alum dose

$\mathrm{B}=$ the effect of measured chlorine residual

$\mathrm{AB}=$ the effect of interaction between $\mathrm{A}$ and $\mathrm{B}$

$\varepsilon=$ normally distributed random error (zero mean)

$\mathrm{i}=$ index of experimental units $(1,2)$

$\mathrm{j}=$ level of alum doses (1-6)

The three null hypotheses tested to assess statistical significance were:

1. $\mathrm{H}_{0}$ : all $\mathrm{A}_{\mathrm{ij}}$ are zero (i.e. alum dose has no significant influence on DBP formation)

2. $\mathrm{H}_{0}$ : all $\mathrm{B}_{\mathrm{ij}}$ are zero (i.e. chlorine residual has no significant influence on DBP formation)

3. $\mathrm{H}_{0}$ : all $(\mathrm{AB})_{\mathrm{ij}}$ are zero (i.e. the interaction between applied alum dose and measured chlorine residual has no significant influence on DBP formation)

A confidence level of $99 \%(\alpha=0.01)$ was chosen to be more restrictive on Type I errors (the false rejection of null hypotheses). This was to prevent compounding of error due to the different sources (e.g. error in each analytical technique).

For every measured DBP, the first null hypothesis was rejected (i.e. alum has a significant effect on all DBP formation), while the second and third null hypotheses were accepted (chlorine residual and the alum-chlorine residual interaction factor did not have a significant effect on DBP formation). Although the chlorine residual effect term did not have a statistically significant impact on DBP formation ( $\mathrm{p}$-value $>0.01$ ), the inclusion of this term improved the overall fit of the multiple regression models. Thus, it was included in the final, simplified model. The interaction factor was removed because its contribution to model fit was deemed insignificant. The final model for effect on DBP formation becomes:

$$
y_{i j}=\mu+A_{i j}+B_{i j}+\varepsilon_{i j}
$$




\subsubsection{Hypothesis Testing for Correlation Significance}

The A term in Equation 3.8 (representing alum dose in the previous model) was then changed to represent NOM parameters (TOC, DOC, $\mathrm{UV}_{254}$ ) as well as the individual NOM fractions determined by LC-OCD in subsequent modeling tests. The goals of these models were:

1. To statistically determine correlations between the NOM content of the water (measured by NOM parameters and individual NOM fraction concentrations) and DBP formation

2. To compare correlations to investigate which portions of NOM have the greatest impact on DBP formation

For each model, the $\mathrm{R}^{2}$ value was used as a measure of correlation, with $\mathrm{R}^{2}=1$ representing the best possible fit and $R^{2}=0$ as no measured correlation. This $R^{2}$ value was supplemented by the p-value, to determine consistency with the rejection of the null hypothesis. A confidence level of $99 \%$ was maintained. For each NOM parameter, the effect term B (chlorine residual) was statistically insignificant but included in the model for fit improvement. Effectively, chlorine residual was implemented in models as a covariate in a multiple regression of NOM effect on DBP formation.

\subsubsection{Determination of Source Water Effect on DBP Formation Modeling}

Concentrations if individual NOM fractions in water samples were determined with LC$\mathrm{OCD}$, and the correlations of these individual fractions with DBP formation were modeled. If the interactions of fractions within the complex water matrices are relatively small (compared to the main effects), it is possible that sample data from all the sources can be pooled to increase the robustness of the models. This is investigated in an analysis of variance (ANOVA) test to determine effect of source waters on DBP formation. Tukey's Honestly Significant Difference (HSD) post-hoc testing was applied to determine if the sample sets (defined by source water) vary significantly from each other. 
The three fractions of NOM determined to be most correlated with DBP formation: humics, biopolymers, and building blocks, are implemented as effects, as well as water source, in models of individual DBP formation (for each DBP measured). Tukey's HSD at a 95\% confidence interval was determined by comparing the Least Squares Means (LS Means) of each sample set (defined by source water). If difference in LS Means between sample sets exceeds the HSD (defined in Equation 3.9), then the sample sets are defined as significantly different from each other.

$$
H S D=q_{0.05,6} \sqrt{\frac{M S E}{n}}
$$

Where: $\quad q=$ the studentized range statistic (table value)

$\mathrm{MSE}=$ mean square error (from ANCOVA)

$\mathrm{n}=$ number of replicates in means 


\section{O MCA AND MX METHOD DEVELOPMENT}

The detection and analysis of halogenated furanones required development of methods for the extraction of MX and its 12 analogues from water samples and their subsequent analytical detection. At the trace $\mathrm{ppb}(\mathrm{ng} / \mathrm{L})$ levels found in drinking waters, the identification and quantification of MX is especially challenging. Current analytical methods that are reported in the literature for MX involve difficult clean up and concentration steps due to the complexities of natural water matrices. As well, MX speciation (between open and ring forms of MX, MCA, BMX1-3) varies and degrades with $\mathrm{pH}$ changes, which must be taken into account during analysis. Various analytical methods for the determination of MX in drinking water have been outlined in previous studies (Hemming et al., 1986; Kronberg et al., 1988; Zou et al., 2000; Onstad et al., 2008; USEPA, 2008; Kubwabo et al., 2009). The general procedure is as follows. If water samples contain chlorine (or other oxidating agent) residual, a quenching agent is added to stop excess oxidation reactions. From there, MX in the water samples must be concentrated either by adsorption onto XAD columns and liquidliquid extraction (LLE) or alternatively, using solid-phase extraction (SPE). This extraction step is followed by a derivatization step, back-extraction, and analysis with either gas chromatography/electron capture detection (GC-ECD) or gas chromatography/mass spectrometry (GC/MS).

MX extraction from water samples was completed using solid phase extraction (SPE) cartridges, followed by elution and then derivatization of the compounds, a liquid-liquid back-extraction, and a final concentration step. Analytical detection of the compounds was first achieved using gas chromatography with electron capture detection (GC-ECD) but was later switched to gas chromatography tandem mass spectrometry (GC-MS/MS) for better selectivity, isolation, and minimization of sample matrix effects. The final method allowed for the extraction and detection of MCA and MX simultaneously. The original intent was to develop a method that included the detection of BMX1-3; however there was too much water matrix interference to enable reliably accurate determination of the BMXs at the low ng/L concentrations that are expected in drinking water. Descriptions of the methods that were 
developed during this research are included here for the benefit of researchers who are interested in samples with higher $\mathrm{ng} / \mathrm{L}$ to $\mu \mathrm{g} / \mathrm{L}$ levels of brominated analogues.

\subsection{Sample Preparation and Extraction for Analysis}

\subsubsection{Chlorine Quenching Agent}

Chlorinated water samples were quenched with $L$-ascorbic acid, identified by Simpson and Hayes (1993) as the best quenching agent for MX, due to its similar furanone structure to MX (see Figure 4.1). Other quenching agents that are commonly used for DBP analysis, such as sodium thiosulphate and sodium sulfite, were found to destroy MX by removing chlorine atoms (USEPA, 2008).

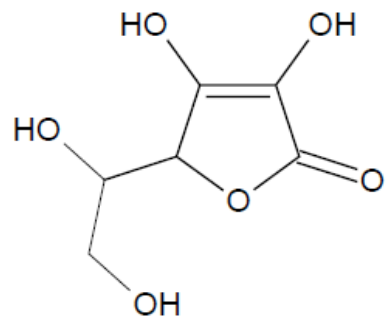

\section{Figure 4.1 - Structure of $L$-ascorbic acid}

Water samples chlorinated at $4 \mathrm{mg} / \mathrm{L}$ free $\mathrm{Cl}_{2}$ for $24 \mathrm{~h}$ were used to determine the dose of quenching agent required, to ensure complete chlorine quenching in samples. $L$-ascorbic acid was added to the sample at incremented amounts and the chlorine residual was measured. It was determined that $20 \mathrm{mg}$ (5 micro-scoops) of $L$-ascorbic acid was sufficient to quench residual chlorine for samples with chlorine residuals up to $1 \mathrm{mg} / \mathrm{L}$ free $\mathrm{Cl}_{2}$.

\subsubsection{Acidification of Water Samples}

The $\mathrm{pH}$ dependent speciation of MX analogues is described in Section 2.2.1. This cyclization property of the compounds with regards to $\mathrm{pH}$ was taken advantage of during analysis. For controlled experiments of MX occurrence and concentration, samples were acidified to a $\mathrm{pH}$ value of 2 in order to stabilize the analogues in their ring forms and ensure the predominance 
of MX (Hemming et al, 1986; Kronberg et al., 1988). Thus, at a $\mathrm{pH}$ of 2, the summations for MX analogues (Equations 2.1-2.3 defined in Section 2.2.1) became as follows:

$$
\begin{gathered}
M X_{\text {sum }}(\text { at } p H 2) \cong M X \\
M C A_{\text {sum }}(\text { at } p H 2) \cong M C A_{\text {ring }} \\
B M X_{\text {sum }}(\text { at } p H 2) \cong B M X 1+B M X 2+B M X 3
\end{gathered}
$$

As well, by controlling the $\mathrm{pH}$ of samples with acidification to $\mathrm{pH} 2$, the number of $\mathrm{MX}$ analogues needed to be detected was reduced and the experimental analysis was simplified. Therefore, water samples were acidified immediately after the quenching of chlorine residuals, by adding 20 drops of concentrated sulphuric acid $\left(\mathrm{H}_{2} \mathrm{SO}_{4}\right)$ to each $1 \mathrm{~L}$ sample.

\subsubsection{Mucobromic Acid as a Surrogate Standard}

Mucobromic acid (MBA) has been extensively used as a surrogate standard in the analysis of MX. In this study, MBA was added to acidified samples just prior to extraction. MBA was spiked into each sample at a concentration of $100 \mathrm{ng} / \mathrm{L}$, to reflect a mid-range occurrence concentration.

\subsubsection{Solid-Phase Extraction (SPE)}

Concentration of MX analogues in water samples was accomplished using SPE, due to the simplicity of the SPE method, its use by other researchers, and a lack of equipment for performing LLE on large sample volumes. Two commercially available SPE cartridges were tested for applicability, Waters C18 and Oasis HLB cartridges (Waters Corporation). USEPA (2008) tested the applicability of a variety of C18 cartridges for the SPE concentration of MX analogues and found only a 25\% recovery of MX. C18 cartridges were initially evaluated in this study as well; however, in the extractions performed on MX compounds spiked into Milli-Q ${ }^{\circledR}$ water at concentrations of up to $2500 \mathrm{ng} / \mathrm{L}$, there appeared to be no recovery of MX compounds. Subsequently, it was learned that Kubwabo et al. (2009) found a relatively high recovery of MX using Waters Oasis HLB cartridges. HLB cartridges were then 
investigated and were ultimately selected as the optimal cartridges for extraction of the MX compounds.

During early tests, samples of $200 \mathrm{ng} / \mathrm{L}$ MX were spiked into $1 \mathrm{~L}$ of Milli-Q ${ }^{\circledR}$ water, extracted with HLB cartridges, then derivatized. These extracted samples were compared with samples of $200 \mathrm{ng} / \mathrm{L} \mathrm{MX}$ spiked directly in ethyl acetate and derivatized. The percent recovery of extraction was calculated by comparing the relative area response of the MX peak to the internal standard 1,2-dibromopropane (1,2-DBP) peak in the two types of samples using GC-ECD analysis. Three replicates of spiked and extracted samples and spiked solvent samples were prepared and the responses were averaged. The calculated percent recovery is given in Table 4.1 .

Table 4.1 - Percent recovery of MX in SPE with HLB cartridges

\begin{tabular}{|c|c|c|c|}
\hline & \multicolumn{2}{|c|}{ Average Area of MX/Area of 1,2-DBP } & \multirow{2}{*}{$\begin{array}{c}\text { Percent } \\
\text { Recovery }\end{array}$} \\
\hline MX concentration (ng/L) & SPE & Solvent & $\mathbf{8 5 . 4 \%}$ \\
\hline 200 & 0.461 & 0.540 & \\
\hline
\end{tabular}

At later stages of method development, a trifunctional C18 cartridge ( $\mathrm{tC} 18)$ was added before the HLB cartridge, to remove humic components and other interfering compounds. This method was adapted from Rantakokko et al. (2004), who found no adsorption of MX compounds by the tC18 pre-filter cartridge. This was supported by comparisons of tC18/HLB-extracted samples with HLB-extracted samples, which revealed no losses of analytes due to introducing the $\mathrm{tC} 18$ cartridge. In fact, the relative peak response was increased for some analytes in this test. The comparison of tC18/HLB vs. HLB recovery is shown in Figure 4.2. This increase in recovery is hypothesized to be due to improved derivatization and back-extraction from the reduction of interfering compounds in the extracts. 


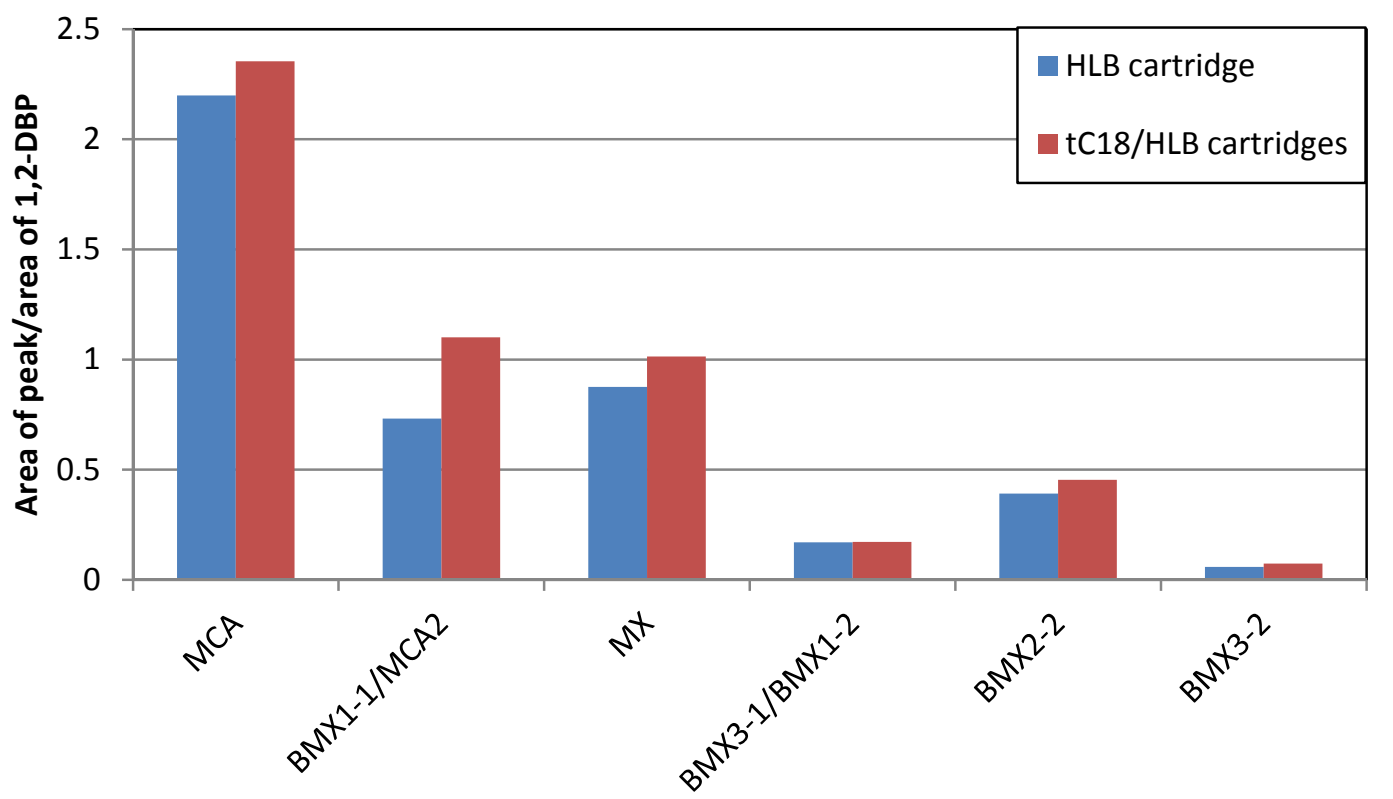

Figure 4.2 - Comparison of recovery of MX compounds using HLB cartridge vs. tC18/HLB (tandem SPE) cartridges

Calibration samples were prepared by spiking known concentrations of MX compounds into $1 \mathrm{~L}$ of acidified raw water. By preparing matrix matched calibration samples, any losses incurred during extraction will be taken into account. Any matrix interferences will also be accounted for.

Prior to sample loading, all SPE cartridges required some pre-conditioning. The Oasis HLB cartridges were rinsed with $10 \mathrm{~mL}$ of acetone (pre-conditioning), $10 \mathrm{~mL}$ of methanol (conditioning), and $10 \mathrm{~mL}$ of Milli-Q ${ }^{\circledR}$ water (rinsing). The tC18 cartridges were preconditioned with successive applications of $5 \mathrm{~mL}$ of acetone, methanol, and Milli-Q ${ }^{\circledR}$ water. Conditioning was completed under gravity flow and carefully monitored to avoid the cartridges from going dry. Cartridges were filled and maintained with Milli- ${ }^{\circledR}$ water throughout the extraction procedure. All samples were extracted with the tandem SPE cartridges by passing them through at a loading flow rate under $20 \mathrm{~mL} / \mathrm{min}$ (to maintain a linear velocity of $0.17 \mathrm{~cm} / \mathrm{s}$ ) with a Visiprep vacuum manifold (Supelco). After loading of 1L samples is complete, sample vessels were rinsed with $100 \mathrm{~mL}$ of acidified Milli-Q ${ }^{\circledR}$ water, to transfer any remaining MX to the cartridges. The cartridges were dried under vacuum for upwards of 1 hour, to minimize the quantity of water that remained on the cartridge, and then 
eluted with 2 x $5 \mathrm{~mL}$ of acetone into BD Falcon ${ }^{\circledR}$ tubes (VWR International). The extracts were then dried under a gentle stream of nitrogen to a volume of approximately $0.5 \mathrm{~mL}$. The extracts were transferred to GC vials with additional acetone (approximately $0.5 \mathrm{~mL}$ for rinsing the Falcon ${ }^{\circledR}$ tube walls) and dried to completeness under nitrogen. The isolated compounds were then derivatized as described in Section 4.1.5 to make them analyzable using either GC-ECD (Section 4.2) or GC/MS/MS (Section 4.3).

\subsubsection{Derivatization Optimization}

Derivatization of MX compounds is necessary before analysis by gas chromatography, to increase the volatility of the compounds. The methylation derivatization method using acidic methanol that was first outlined by Holmbom et al. (1984) and Hemming et al. (1986) was optimized for use in this study.

After complete drying of extracted samples in GC vials (4.1.4), samples were reconstituted in $300 \mu \mathrm{L} 2 \% \mathrm{H}_{2} \mathrm{SO}_{4}$ in methanol (v/v) added as a derivatization agent. The sample vials were capped and vortexed, then placed in an oven at $70^{\circ} \mathrm{C}$ for 1 hour. After cooling to room temperature, $750 \mu \mathrm{L}$ of $2 \% \mathrm{NaHCO}_{3}$ (w/v in Milli-Q ${ }^{\circledR}$ water) was added to each sample to neutralize the acid. The volume of this neutralizing agent was increased from the $450 \mu \mathrm{L}$ stipulated by previous methods (Hemming et al., 1986) because $\mathrm{pH}$ testing of samples after adding the neutralizing agent revealed an incomplete neutralization of the final solution. After neutralization, a liquid-liquid back-extraction into hexane solution containing 0.25 $\mathrm{mg} / \mathrm{L}$ of internal standard 1,2-dibromopropane (1,2-DBP) was performed with $2 \times 600 \mu \mathrm{L}$ hexane, manual shaking of capped GC vials for 2 minutes, and transfer of the hexane layer into new GC vials. Care was necessary to avoid transfer of any aqueous subnatant. A final extract of approximately $1 \mathrm{~mL}$ in hexane was obtained.

Derivatization time was tested, to explore the flexibility of experiment scheduling. Samples of $200 \mathrm{ng} / \mathrm{L}$ MX mix (MX, MCA, BMX1, BMX2, and BMX3) spiked into solvent were prepared and tested with derivatization times of 1, 2, 4, 7, and 24 hours. A comparison of the recoveries indicated a loss of analytes with time (particularly BMX compounds). This may 
have been due to evaporation of sample in the oven (from the loosening of the plastic GC vial caps) since, theoretically, a longer derivatization time should increase recovery.

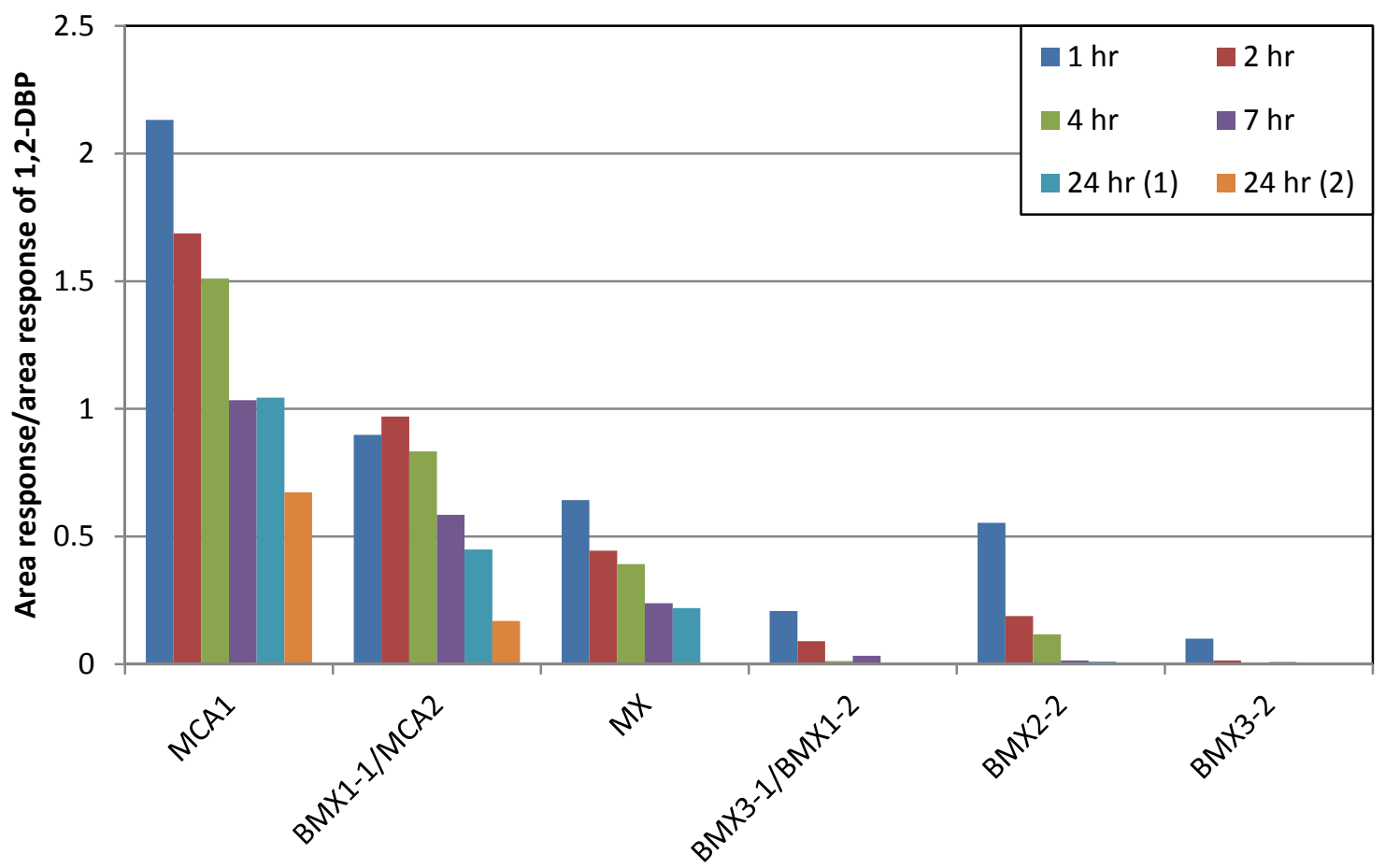

Figure 4.3 - Comparison of MX recoveries for different derivatization times

Kubwabo et al. (2009) noted some issues associated with this methylation method. A low relative abundance of the characteristic ions for GC/MS analysis may decrease the sensitivity of the analysis. As well, it was speculated that methylation might have caused the formation of acetals, which may cause an underestimation of MX. Kuwabo et al. were also concerned that the neutralization and back-extraction steps might introduce opportunities for analyte loss. They suggested a one-step derivatization procedure using $N$-methyl-bistrifluoroacetamide (MBTFA). This derivatization method was initially tested for use in this study; however MX was not detected in preliminary tests. While these results do not necessarily confirm poor derivatization of MX with MBTFA, this method was not tested further due to ease of use of methylation and the achievement of adequate sensitivity for the 
proposed research. Further investigation of Kubwabo et al.'s derivatization method may improve the sensitivity of MX analysis and is worthwhile to examine in future work.

\subsubsection{Final Concentration of Sample}

To improve the detection sensitivity, the $1 \mathrm{~mL}$ "final" hexane extract was further concentrated to approximately $0.1 \mathrm{~mL}$ under a very gentle stream of nitrogen. This 10 -fold final concentration of the extract translates directly into a 10-fold increase in sensitivity during analysis, and was required for detection of $\mathrm{MX}$ at trace levels.

Extreme caution was required, to avoid complete evaporation of the final hexane extract. Final samples were transferred into glass inserts and placed back into GC vials for analysis with GC-ECD or GC/MS/MS. Samples may be stored in the freezer $\left(-14^{\circ} \mathrm{C}\right)$ for up to two weeks.

\subsection{Gas Chromatography with Election Capture Detection (GC-ECD)}

Analysis of MX compounds was initially performed using a Hewlett Packard 5890 Series II Plus Gas Chromatograph (Mississauga, ON) with electron capture detection (GC-ECD), equipped with a DB 5.625 capillary column $(30 \mathrm{~m}$ x $0.25 \mathrm{~mm}$ OD x $0.25 \mu \mathrm{m}$ ID, Agilent Technologies Canada Inc., Mississauga, ON). The GC-ECD operating conditions are listed in Table 4.2.

Table 4.2 - GC-ECD instrument conditions for MX analysis

\begin{tabular}{|l|l|}
\hline Parameter & Description \\
\hline System & HP5890 Series II Plus \\
\hline Column & DB 5.625 capillary column $(30 \mathrm{~m} \times 0.25 \mathrm{~mm}$ OD x $0.25 \mu \mathrm{m}$ ID) \\
\hline Injection volume & $1 \mu \mathrm{L}$ \\
\hline Injector Temperature & $220^{\circ} \mathrm{C}$ \\
\hline Detector Temperature & $300^{\circ} \mathrm{C}$ \\
\hline Oven Temperature & $100^{\circ} \mathrm{C}$ \\
Program & $4^{\circ} \mathrm{C} / \mathrm{min}$ temperature ramp to $200^{\circ} \mathrm{C}$ \\
& $10^{\circ} \mathrm{C} / \mathrm{min}$ temperature ramp to $300^{\circ} \mathrm{C}$ \\
\hline Carrier Gas & $\mathrm{Helium}\left(1.2 \mathrm{~mL} / \mathrm{min}\right.$ at $\left.35^{\circ} \mathrm{C}\right)$ \\
\hline Makeup gas & $5 \% \mathrm{CH}_{4}, 95 \% \mathrm{Ar}(23.1 \mathrm{~mL} / \mathrm{min})$ \\
\hline
\end{tabular}


Samples containing MX, MCA, and BMX1-3 were prepared and analyzed to identify compound peaks based on retention time. The elution order found for all compounds analyzed simultaneously was then compared with retention times from USEPA (2008) to confirm their identity (see Table 4.3).

Table 4.3 - Peaks and retention times in this analysis compared with USEPA (2008)

\begin{tabular}{|c|c|}
\hline This study (retention time) & EPA study (retention time) \\
\hline $\begin{array}{c}\text { Internal standard 1,2-DBP (5.39 } \\
\text { min) }\end{array}$ & Int. std 3-bromochlorobenzene (10.022 min) \\
\hline MCA - peak 1 (10.6 min) & - \\
\hline BMX1 - peak 1 (15.26 min) & Unknown component of BMX1 (17.372 min) \\
\hline MCA - peak $2(15.3 \mathrm{~min})$ & - \\
\hline $\mathrm{MX}(18.00 \mathrm{~min})$ & MX (21.143 min) \\
\hline BMX2 - peak 1 (not detected) & Unknown component of BMX2 (21.143) \\
\hline BMX3 - peak 1 (21.14 min) & Unknown component of BMX3 (25.087 min) \\
\hline BMX1 - peak 2 (21.15 min) & BMX1 ring A $(25.158 \mathrm{~min})$ \\
\hline- & BMX1 ring B (25.399 min) \\
\hline MX - peak $2(21.35 \mathrm{~min})$ & - \\
\hline BMX2 - peak 2 (24.14 min) & BMX2 ring (29.428 min) \\
\hline- & BMX1 open (29.719 min) \\
\hline- & BMX2 open (33.391 min) \\
\hline BMX3 - peak 2 (26.93 min) & BMX3 ring (33.461 min) \\
\hline- & BMX3 open (36.641 min) \\
\hline
\end{tabular}

The overall order of elution for MX compounds in this study matched the order provided in USEPA (2008). Unfortunately, the open forms of BMX1-3 were not detected in this study. However, the "unknown" components of BMXs found in USEPA (2008) were also present in the standards used in this study.

The oven temperature program was optimized to provide maximum peak separation. However, as shown in Table 4.3, several peak overlaps still occurred between BMX1-peak 1/MCA-peak 2 and BMX3-peak 1/BMX1-peak 2. This presented a problem for quantification of the individual compounds, especially BMX1, whose two identifying peaks were both overlapped by other peaks. 


\subsubsection{Selection of Internal Standard for GC-ECD Analysis}

1,2-dibromopropane (1,2-DBP) is the internal standard described in Standard Method 6232B (APHA, 2005) for trihalomethanes (THMs) analysis. Because of its availability in the lab, 1,2-DBP was evaluated and adopted for use as an internal standard for MX analysis. 1,2-DBP was added to samples in the hexane back-extraction solution, made at a concentration of 0.25 $\mathrm{mg} / \mathrm{L}$ 1,2-DBP.

\subsubsection{Analysis of Chlorinated Water Samples}

While GC-ECD was suitable for the detection of spiked MX compounds in non-chlorinated water matrices, chlorinated water samples introduced the presence of too many interfering compounds. A sample chromatogram of a chlorinated sample of Lake Simcoe water is shown in Figure 4.4. Ultimately, GC-ECD's sensitivity towards halogenated compounds was found to make it unsuitable for MX detection in chlorinated samples, as the levels of MX analogues present are too trace $(\mathrm{ng} / \mathrm{L})$ to be differentiated from other halogenated byproducts $(\mu \mathrm{g} / \mathrm{L})$.

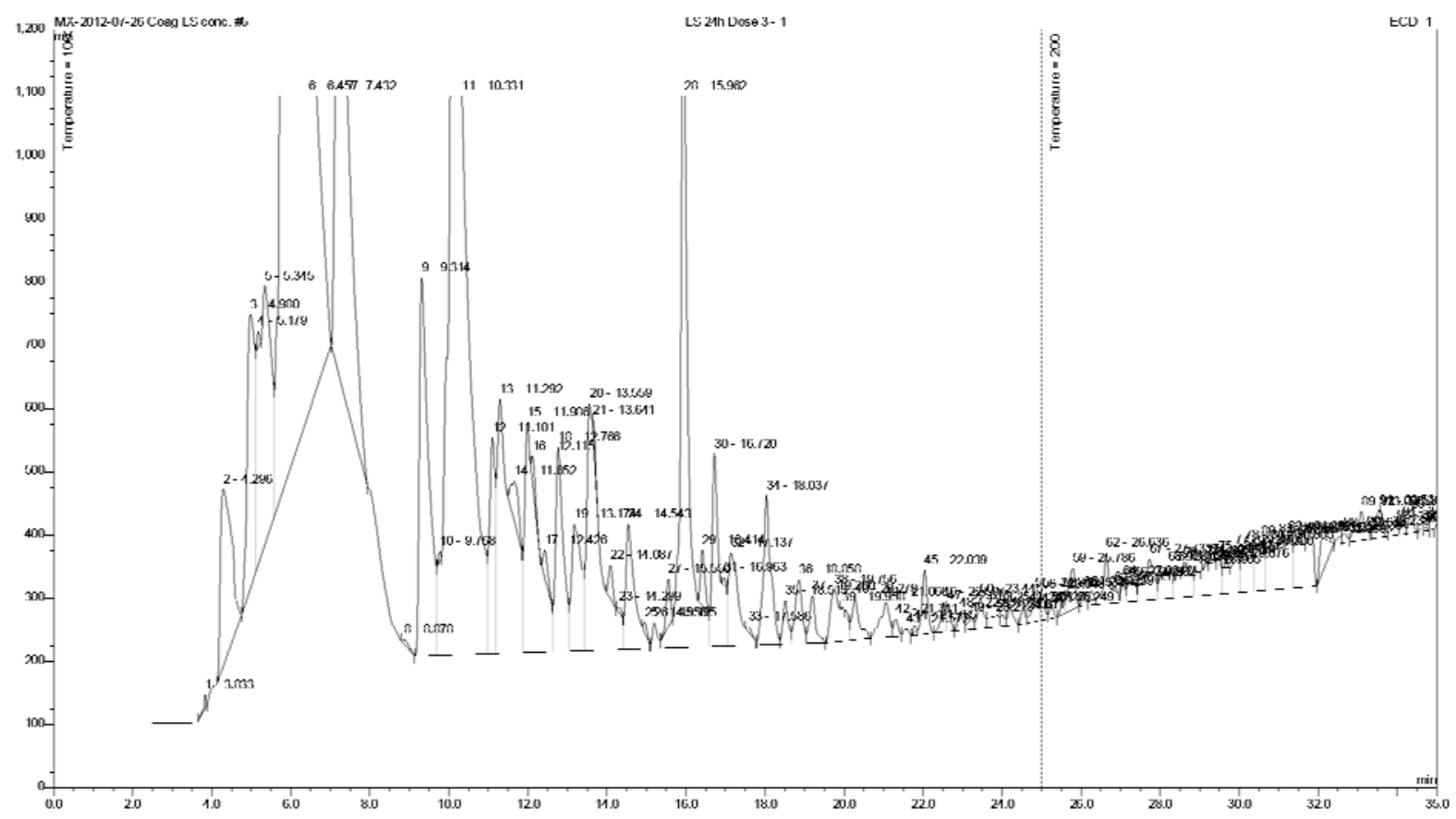

Figure 4.4 - Sample chromatogram of chlorinated Lake Simcoe water extracted and analyzed using GC-ECD 


\subsection{Gas Chromatography Tandem Mass Spectrometry (GC/MS/MS)}

For the simultaneous analysis of $5 \mathrm{MX}$ analogues (MCA, MX, BMX1-3) and a surrogate standard (MBA), GC/MS/MS was used to provide high selectivity and sensitivity. GC/MS EI was initially used, but the surrogate standard peak co-eluted with the MX peak. Since they share common ions, a detection method with a higher selectivity was needed to quantify each of the three compounds.

A spiked sample with $2500 \mathrm{ng} / \mathrm{L}$ of MX mix (MCA, MX, BMX1, BMX2, and BMX3) was derivatized (Section 4.1.5) and analyzed using EI full scan $(50-400 \mathrm{~m} / \mathrm{z})$ to match the EI mass spectra of each analyte peak with the mass spectra provided by Zwiener \& Kronberg (2001) and to determine the retention times of each compound. The total ion chromatogram of this spiked sample is shown in Figure 4.5.

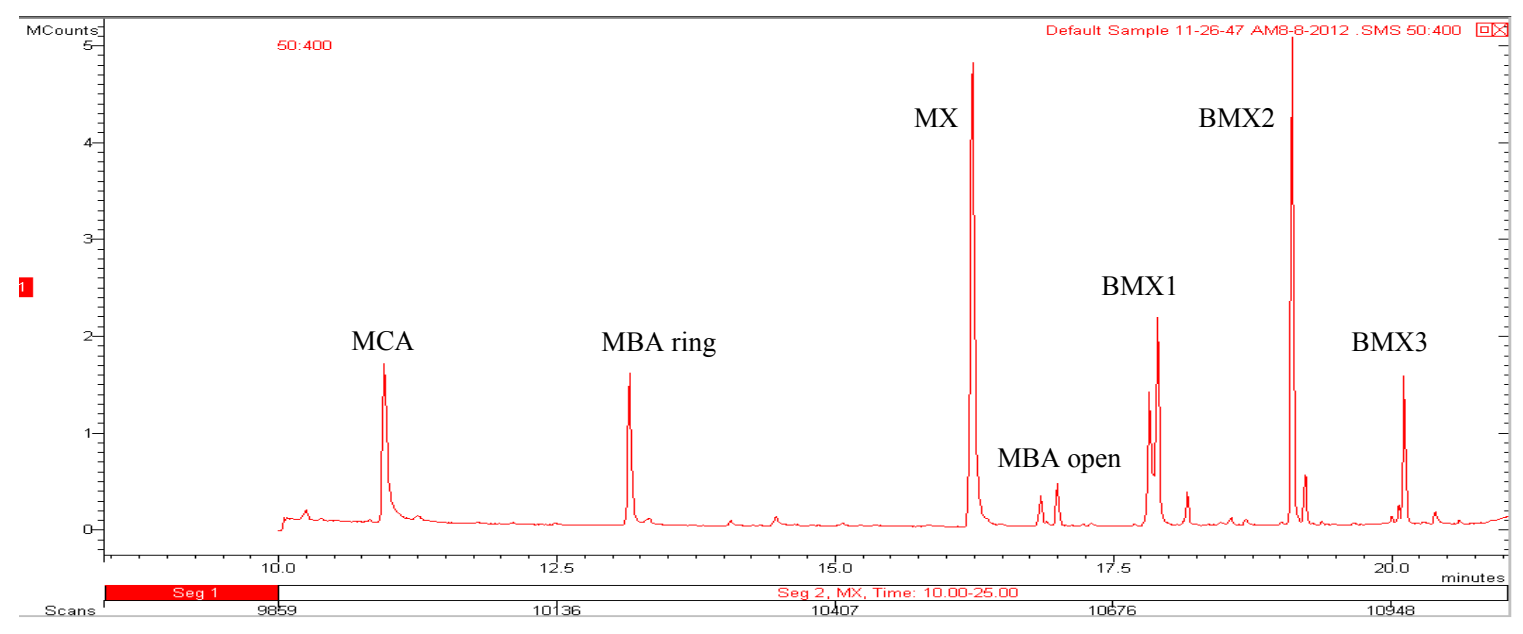

Figure 4.5 - Total ion chromatogram of $2500 \mathrm{ng} / \mathrm{L}$ spiked MX mix analyzed on GC/MS using EI full scan $(50-400 \mathrm{~m} / \mathrm{z})$

The surrogate standard, MBA, eluted as two distinct peaks, representing the ring and open forms of the compound. Each form was analyzed individually and the sum of their area responses was used for subsequent calculations.

A new sample containing MX analogues and the surrogate standard was then prepared and analyzed using MS/MS. Precursor ions and quantification product ions were provided by Zwiener and Kronberg (2001) for each analyte (Table 4.5). These were selected by the 
authors for being abundant and unique to each analyte. Zwiener and Kronberg also provided secondary product ions for each compound, but these were not used in this method because the primary quantification product ions were adequate for identification and quantification.

Using the Automated Method Development (AMD) setting on the GC/MS, collision induced dissociation (CID) conditions were optimized for product ion formation in the MS/MS method. AMD allows for the scanning of the same precursor ion under 10 different sets of conditions. The optimum excitation amplitude was determined using AMD. The excitation amplitude was set to $0-90 \mathrm{~V}$ (for non-resonant excitation, at $10 \mathrm{~V}$ increments) for the scan of each ion. At each excitation amplitude, the ion intensity $(\mathrm{m} / \mathrm{z})$ of the parent ion and two product ions are recorded. The optimum amplitude is defined as the amplitude that forms the maximum intensity of the primary product ion, while ensuring that there is still some precursor ion present. This is determined by plotting the ion intensities as a function of excitation amplitude, as seen in Figure 4.6 for BMX1.

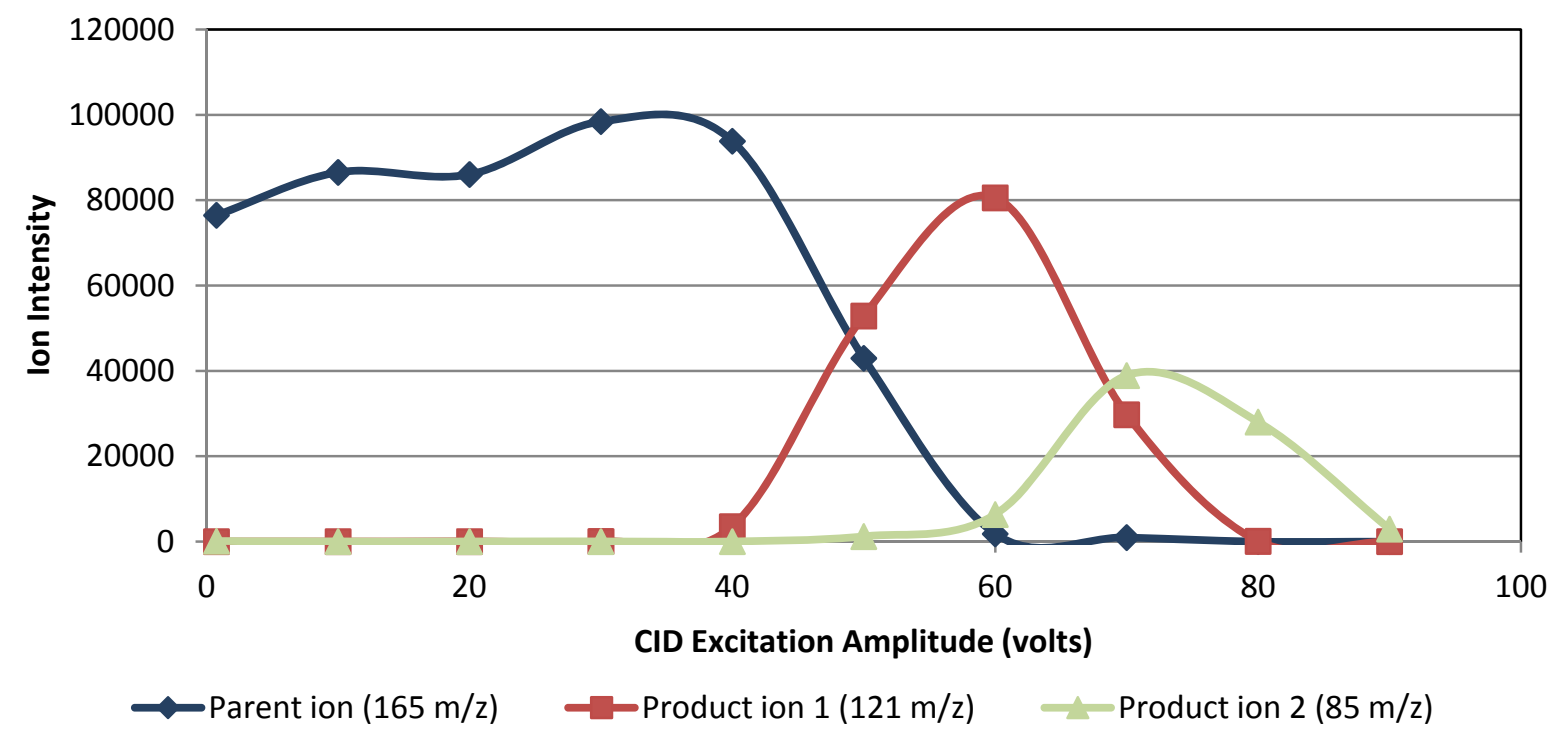

Figure 4.6 - CID of BMX1.

Optimum excitation amplitude for the production of product ion 1 is around $60 \mathrm{~V}$.

Using these results, AMD was repeated a second time at smaller increments of excitation amplitude to further refine estimates for the optimum amplitude. 
This process was repeated for all analytes using resonant excitation (as opposed to nonresonant) because there was not a satisfactory number of product ions found for MCA. After both resonant and non-resonant excitation was performed, it was determined that only the dissociation of ions for MCA was optimized using resonant excitation.

The excitation storage level $(\mathrm{m} / \mathrm{z})$ for each precursor ion was first calculated using the builtin " $q$ " calculator. These values were used when conducting AMD to determine optimum excitation amplitude. Afterwards, the storage level was calculated based on the highest recommended excitation storage level - the lowest product ion mass divided by 1.4. The new storage level values were applied to scans, but the "q" calculated values produced a higher intensity of ions for quantification. Overall, an optimized set of MS/MS parameters was determined (Table 4.5).

Table 4.4 - GC/MS operating conditions for the analysis of MX analogues

\begin{tabular}{|c|c|}
\hline Parameter & Conditions \\
\hline System & Varian 3800 GC with $4000 \mathrm{MS}$ and CombiPAL autosampler \\
\hline Column & DB-1701 (30m x $0.25 \mathrm{~mm}$ OD x $0.25 \mu \mathrm{m}$ ID, Agilent J \& W) \\
\hline Injection volume & $8 \mu \mathrm{L}$ \\
\hline Injection mode & $\begin{array}{l}\text { Initial splitless injection } \\
\text { Split on at } 0.10 \mathrm{~min} \text { at } 5: 1 \\
\text { Split off at } 0.8 \mathrm{~min} \\
\text { Split on at } 6.0 \mathrm{~min} \text { at } 30: 1\end{array}$ \\
\hline Injector temperature & $\begin{array}{l}50^{\circ} \mathrm{C} \text { hold for } 0.8 \mathrm{~min} \\
200^{\circ} \mathrm{C} / \mathrm{min} \text { to } 200^{\circ} \mathrm{C} \text {, hold for } 20 \mathrm{~min}\end{array}$ \\
\hline Oven temperature & $\begin{array}{l}40^{\circ} \mathrm{C} \text {, hold for } 2 \mathrm{~min} \\
20^{\circ} \mathrm{C} / \mathrm{min} \text { to } 100^{\circ} \mathrm{C} \\
6^{\circ} \mathrm{C} / \mathrm{min} \text { to } 170^{\circ} \mathrm{C} \\
15^{\circ} \mathrm{C} / \mathrm{min} \text { to } 260^{\circ} \mathrm{C} \text {, hold for } 3 \mathrm{~min}\end{array}$ \\
\hline Carrier gas & Helium, constant flow at $1.2 \mathrm{~mL} / \mathrm{min}$ \\
\hline Transfer line temperature & $275^{\circ} \mathrm{C}$ \\
\hline Ion source temperature & $150^{\circ} \mathrm{C}$ \\
\hline Ionization mode & Electron impact (EI) \\
\hline Scan range & $50-400 \mathrm{amu}$ \\
\hline MS scan mode & $\mathrm{MS} / \mathrm{MS}$ \\
\hline
\end{tabular}


Table 4.5 - MS/MS optimized conditions

\begin{tabular}{|c|c|c|c|c|c|c|}
\hline 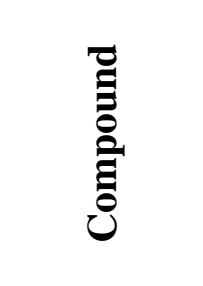 & 兽 & 章 & 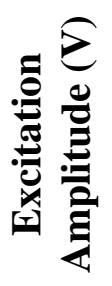 & 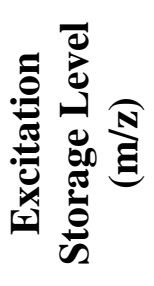 & 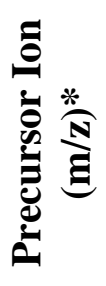 & 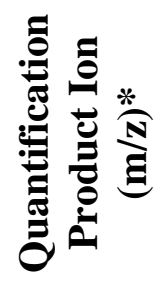 \\
\hline MCA & 10.88 & Resonant & 0.37 & 64.8 & 147 & 119 \\
\hline MBA ring & 14.75 & Non-resonant & 96 & 106.2 & 241 & 185 \\
\hline MX & 16.21 & Non-resonant & 70 & 88.5 & 201 & 173 \\
\hline MBA open & 16.31 & Non-resonant & 80 & 105.3 & 239 & 157 \\
\hline BMX1 & 17.89 & Non-resonant & 63 & 72.7 & 165 & 121 \\
\hline BMX2 & 19.10 & Non-resonant & 72 & 93.0 & 211 & 167 \\
\hline BMX3 & 20.11 & Non-resonant & 92 & 112.3 & 255 & 211 \\
\hline
\end{tabular}

*provided by Zwiener and Kronberg (2001)

\subsubsection{Calibration Curves for MX Compounds}

Calibration standards of MX compounds were spiked into solvent, derivatized, and analyzed using the optimized GC/MS/MS method. The standards were prepared with a concentration range of $10-200 \mathrm{ng} / \mathrm{L}$ (equivalent in 1L water samples). Each standard was also spiked with $100 \mathrm{ng} / \mathrm{L}$ of MBA as a surrogate standard. After derivatization, the samples were backextracted and concentrated in hexane.

Area responses of the analytes were taken relative to the sum of area responses of the two forms of MBA (ring and open). The calibration curves using standards prepared in solvent are shown in Figure 4.7. These standards showed good linearity, with $\mathrm{R}^{2}>0.9$. 


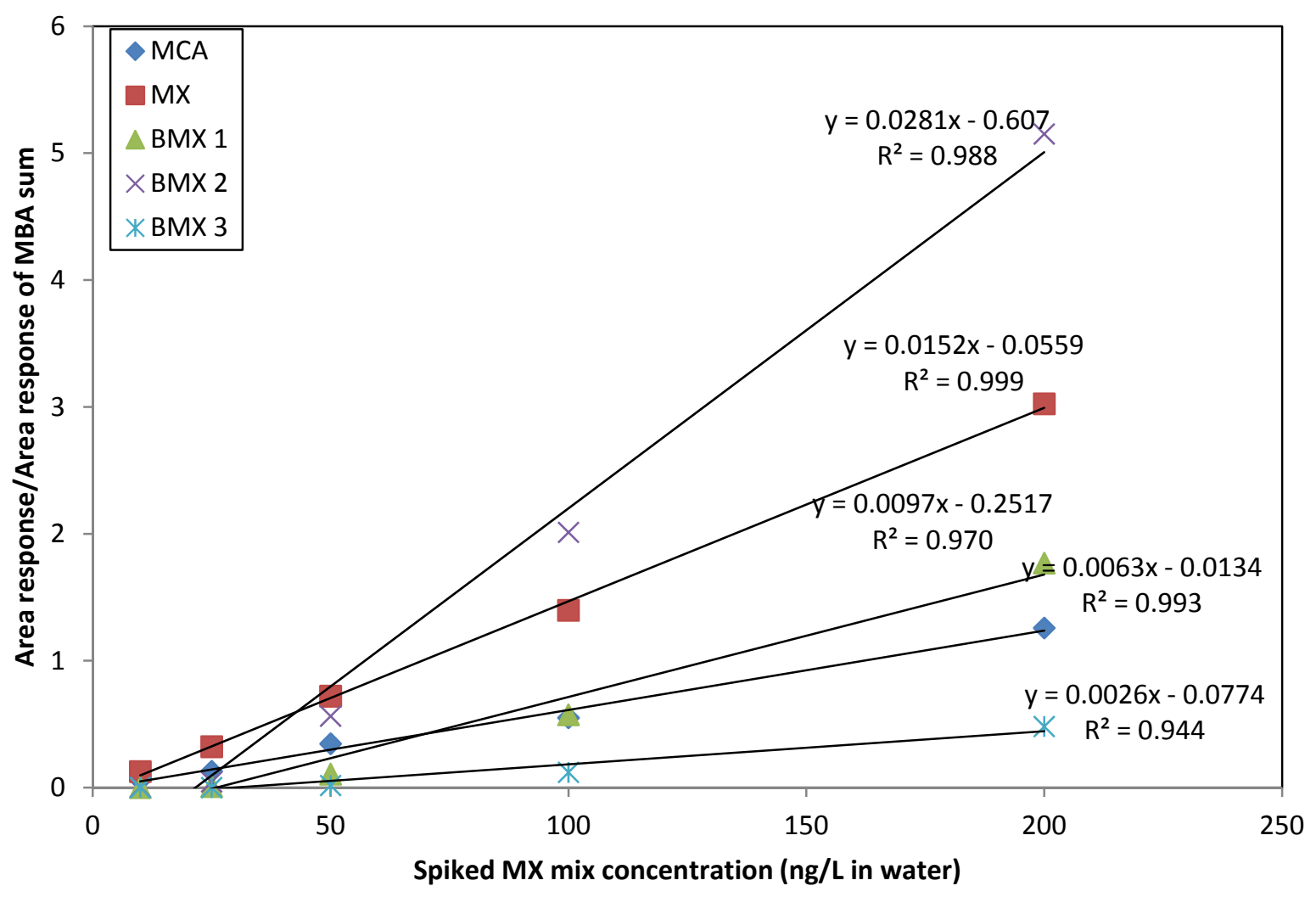

Figure 4.7 - Calibration curves for MX compounds spiked directly into solvent and analyzed with GC/MS/MS

Since there were expected to be measured losses due to the extraction process (previously shown in Section 4.1.4), matrix-matched calibration samples were preferred for quantification use. Therefore, calibration samples were also prepared in water, extracted, then analyzed with GC/MS/MS. For this test, 1L filtered (1.2um pore size) Otonabee River raw water samples were spiked with MX mix (MCA, MX, BMX1, BMX2, and BMX3) at 0, 10, $25,50,100$, and $200 \mathrm{ng} / \mathrm{L}$ for calibration standards. In addition, three spike and recovery samples at $100 \mathrm{ng} / \mathrm{L}$ were prepared using the same standards. MBA was added to all calibration and spike and recover samples at $100 \mathrm{ng} / \mathrm{L}$. 


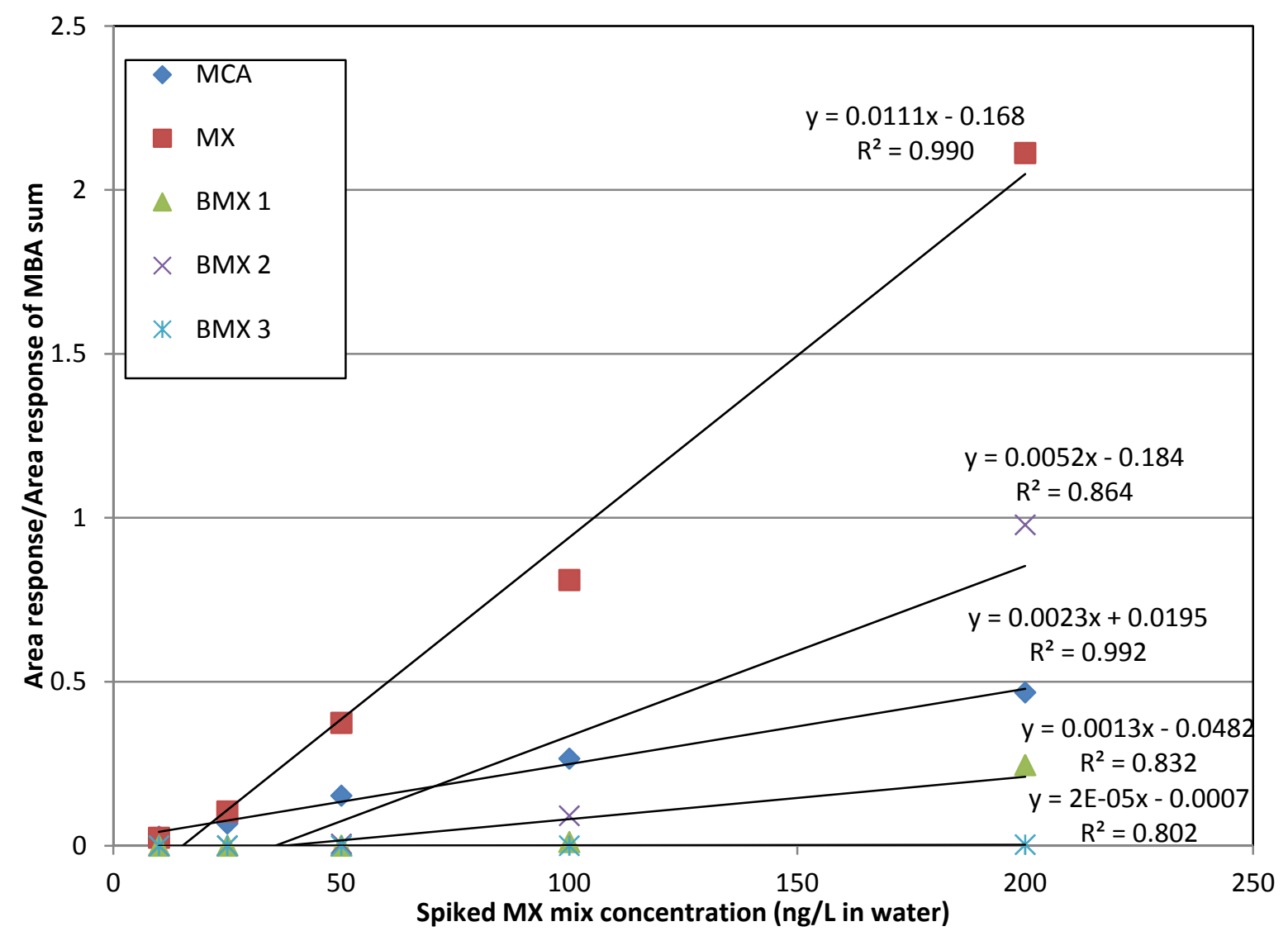

Figure 4.8 - Calibration curves for MX compounds (area relative to MBA sum) analyzed with GC-MS/MS

The detection of BMX compounds in water matrix calibration samples was poor, with BMX1 only detected in samples spiked with $100 \mathrm{ng} / \mathrm{L}$ and higher, BMX2 in $50 \mathrm{ng} / \mathrm{L}$ and higher, and BMX3 in $200 \mathrm{ng} / \mathrm{L}$. Comparatively, MCA and MX were detected in all spiked water samples above $10 \mathrm{ng} / \mathrm{L}$.

Analyte recovery with the spike and recovery samples was then tested using the calibration curves above (see Table 4.6). These samples (excluding S\&R 1) showed a generally consistent recovery of MCA and MX at $100-120 \%$, while the recovery of BMX1 was approximately $50 \%$ and the recovery of BMX2 was approximately $65 \%$. BMX3 was not detected in these samples. 
Table 4.6 - Concentrations of MX compounds found in Otonabee River water samples

\begin{tabular}{|c|c|c|c|c|c|}
\hline & \multicolumn{5}{|c|}{ Concentrations (ng/L in water) } \\
Sample ID & MCA & MX & BMX 1 & BMX 2 & BMX 3 \\
\hline S\&R 1 & 152 & 122 & 89.7 & 112 & n.d. \\
S\&R 2 & 111 & 101 & 47.2 & 64.1 & n.d. \\
S\&R 3 & 120 & 104 & 57.1 & 66.5 & n.d. \\
\hline
\end{tabular}

n.d. $=$ not detected

Rantakokko et al. (2004) looked at matrix effects during the analysis of MX and BMX compounds. According to the authors, BMXs are very sensitive to active sites in the GC, making trace detection and accurate quantification difficult. Factors such as injection liners with deactivated glass wool and degradation of GC columns can affect detection of BMXs.

Since the responses of BMXs were much lower than that of MCA and MX, it was hypothesized that the factors mentioned by Rantakokko et al. may have played a role in this experiment. To investigate this further, the injection liner on the GC (packed with carbon beads for NDMA analysis) was replaced with a hollow liner. The calibration samples from Otonabee River water were re-analyzed using this new liner.

Figure 4.9 shows the calibration curves generated using the new liner. Responses for MCA and MX increased by about a factor of 3, MCA remained fairly unchanged, but the BMXs lost some sensitivity (BMX2 at $50 \mathrm{ng} / \mathrm{L}$ was no longer detected and BMX3 was not detected in any of the calibration samples).

Since there was no measured improvement in the detection of BMX compounds, the initial liner was re-installed. At this point in the method development, the detection of BMX compounds was taken out of the experimental design. Since the source waters to be analyzed (from Lake and River sources in Southern Ontario) have low bromide content and monitoring has shown a lack of brominated THMs and HAAs presence, it was postulated that brominated MX compounds occurrence would also be of little significance to overall DBP content. However, for future research on MX compounds, the inclusion of BMX compounds is recommended. 


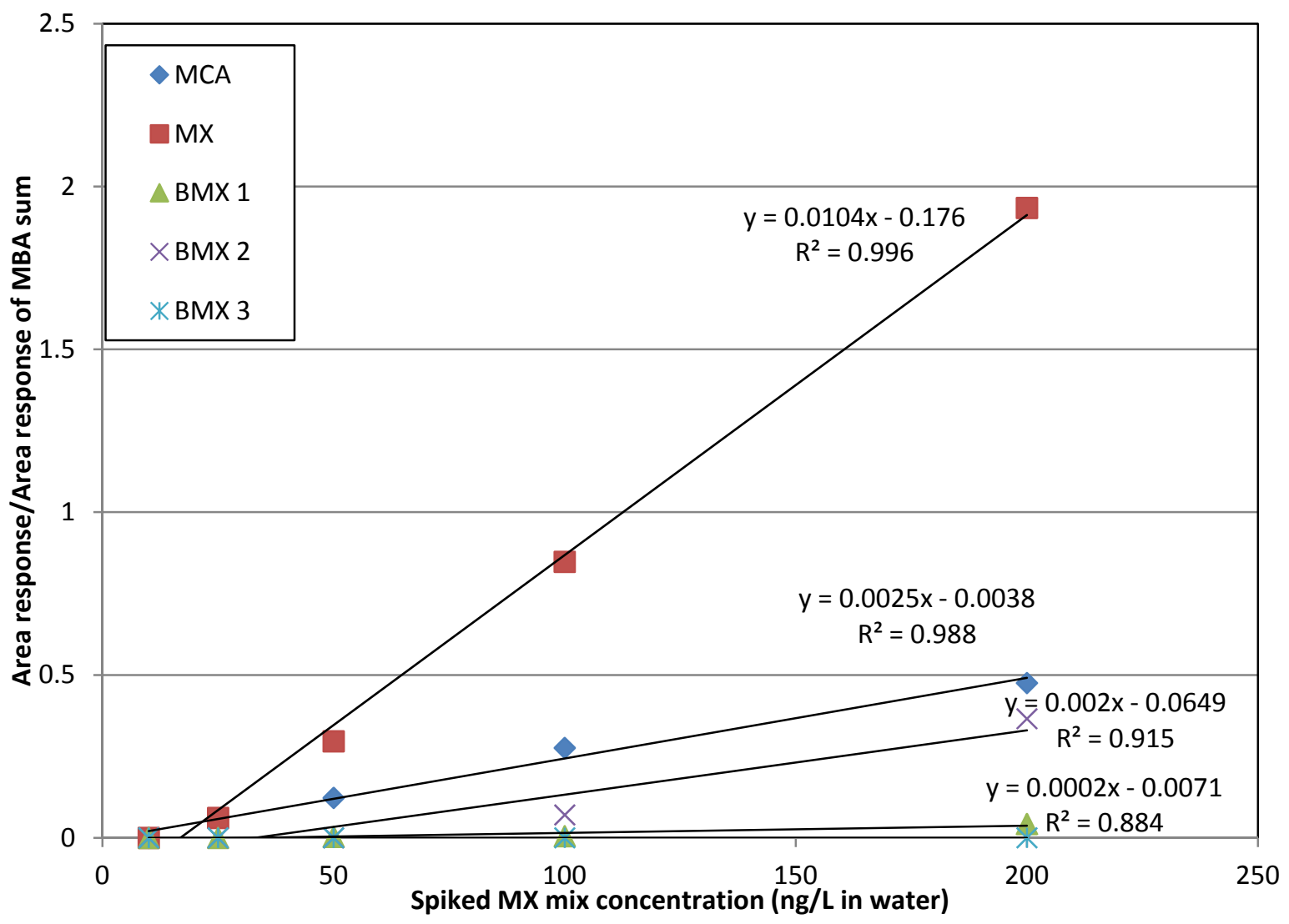

Figure 4.9 - Calibration curves for MX compounds (area relative to MBA sum) analyzed with GC-MS/MS with a hollow liner 


\section{O EVALUATION OF PRECURSORS TO MX AND OTHER DBPS, GENOTOXICITY - EFFECT OF COAGULATION}

\subsection{Introduction}

Natural organic matter (NOM), a mixture of organic materials dependent on biogeochemical cycles, is ubiquitous in natural waters (Matilainen et al., 2010). NOM influences practically all components of water treatment, with impacts on colour, taste and odour, interference with removal of contaminants, membrane fouling, contribution to biological substrate, and decrease of activated carbon capacity (Fabris et al., 2008). Because of this impact, optimized control and removal of NOM is of upmost importance. Optimization of coagulation for NOM removal is the most economical means to improve drinking water quality and limit disinfection by-product (DBP) formation.

A consequence of disinfection is the interaction of oxidative disinfecting agents with NOM to produce halogenated DBPs, which may be of concern due to potential health risks associated with consumption and exposure (Richardson \& Postigo, 2012). Of the identified DBPs, the two major classes are trihalomethanes (THMs) and haloacetic acids (HAAs). Although these two classes of DBPs are systematically monitored and routinely regulated, monitored DBPs typically account for less than $50 \%$ of the total organic halides (AOX) produced in chlorinated drinking waters (Krasner et al., 2006). In addition, recent reports have highlighted the relatively low health concerns of THMs/HAAs exposure, which questions the effectiveness of these DBPs to serve as surrogates (Hrudey, 2009). Recent studies have also indicated that non-regulated DBPs, such as halogenated furanones (MX analogues), may be more cytotoxic and genotoxic than many of the regulated DBPs (Krasner, 2009).

Halogenated furanones gained prominence with the discovery of the highly mutagenic compound 3-chloro-4-(dichloromethyl)-5-hydroxy-2(5H)-furanone, commonly known as Mutagen $\mathrm{X}$ or MX, from an examination of pulp mill chlorination stage effluent by Holmbom et al. (1984). Subsequent studies have identified 12 analogues of MX, collectively referred to as halogenated furanones, and have reported the presence of MX and its analogues 
in a wide range of chlorinated drinking waters (Kronberg et al., 1988; Andrews et al., 1990; Simpson \& Hayes, 1993; Krasner et al., 2006). Halogenated furanones have been detected primarily in waters treated with free chlorine, and are usually formed from the reaction of chlorine with humic acid components of NOM (Kubwabo et al., 2009). Typical observed concentrations of MX (ng/L) are 1000 fold lower than THMs or HAAs, however even these levels have been shown to account for $20-60 \%$ of the total mutagenicity of treated drinking water (Onstad and Weinberg, 2005). MX has also been shown to be highly genotoxic (Tikkanen \& Kronberg, 1990). Many other DBPs in chlorinated drinking water have also been linked to genotoxicity, mutagenicity, and/or carcinogenicity activity (Onstad et al., 2008), however a significant portion of the genotoxic potential remains unaccounted for. In vitro tests, or bioassays, provide an attractive means of assessing toxicity as they are sensitive, easy to perform, and do not require prior knowledge of the individual constituents in the tested mixture (Kocak et al., 2010). One such in vitro bioassay used for the evaluation of genotoxicity is the SOS Chromotest. Genotoxic agents interact with DNA to induce transmissible mutations which may lead to cancerous transformation of functioning cells (Quillardet et al., 1982). Tests such as the SOS Chromotest offer rapid determination of qualitative and quantitative detection of DNA damaging agents (Wang et al., 2011). Due to these qualities, they are well suited for monitoring studies and/or initial screenings of toxicological potential.

Halogenated furanones are currently unregulated, in part due to the complex analytical detection techniques required as well as their presence at trace concentrations (typically low $\mathrm{ng} / \mathrm{L}$ ) in drinking waters. While many studies have reported the presence of MX analogues in drinking waters, few have examined how drinking water treatment processes impact MX formation. Andrews et al. (1990) reported very good removal of MX by activated carbon. Zou et al. (2000) suggested that some aromatic aldehydes and amino acids associated with NOM (humic and fulvic acid fractions) may serve as precursors for MX. No research has been identified that explicitly explores the link between NOM removal, the reduction in MX formation, and its genotoxic potential. Since NOM is a complex matrix of organics, its composition can vary from source to source and vary seasonally (Sharp et al., 2006). This 
study investigates the relationship between specific NOM compounds and MX formation, to elucidate MX reduction via NOM removal.

\subsection{Experimental Design}

Three source waters of differing NOM composition were selected for use in replicated benchscale coagulation jar tests. Raw, untreated water was collected from the following water utilities located in Ontario, Canada: Britannia Water Treatment Plant (Ottawa River), Peterborough Water Treatment Plant (Otonabee River), and the Keswick Water Treatment Plant (Lake Simcoe). Typical raw water characteristics associated with each source are shown in Table 5.1. All analyses were performed within two weeks of water collection, with the exception of NOM characterization by Liquid Chromatography with Organic Carbon Detection, LC-OCD (samples preserved at $4^{\circ} \mathrm{C}$ and analyzed within 8 weeks).

Table 5.1 - Raw water characteristics of the three Ontario, Canada source waters

\begin{tabular}{ccccccc}
\hline & $\begin{array}{c}\text { DOC } \\
(\mathbf{m g} / \mathbf{L})\end{array}$ & $\begin{array}{c}\text { TOC } \\
(\mathbf{m g} / \mathbf{L})\end{array}$ & $\mathbf{p H}$ & $\begin{array}{c}\text { Alkalinity } \\
\left(\mathbf{m g} / \mathbf{L C a C O}_{3}\right)\end{array}$ & $\begin{array}{c}\mathbf{U V}_{\mathbf{2 5 4}} \\
\left.\mathbf{( c m}^{-1}\right)\end{array}$ & $\begin{array}{c}\text { SUVA } \\
(\mathbf{L} / \mathbf{m g} / \mathbf{m})\end{array}$ \\
\hline Ottawa River & 5.85 & 6.06 & 7.36 & 23.5 & 0.202 & 3.45 \\
\hline Otonabee River & 5.03 & 4.92 & 8.38 & 90.5 & 0.103 & 2.05 \\
\hline Lake Simcoe & 4.14 & 4.23 & 8.47 & 115.0 & 0.0545 & 1.32 \\
\hline
\end{tabular}

Relationships between specific UV absorbance (SUVA, calculated as $\mathrm{UV}_{254} / \mathrm{DOC}$ in $\mathrm{L} / \mathrm{mg} / \mathrm{m}$ ) and NOM removal via coagulation has been reported by many researchers (Edzwald \& Tobiason, 1999; Chow et al., 2008; Matilainen et al., 2010). This relationship and data regarding the three source waters examined in this study, is summarized in Table 5.2 . 
Table 5.2 - SUVA as an indicator of NOM composition and coagulation efficacy (adapted from Edzwald \& Tobiason, 1999)

\begin{tabular}{ccccc}
\hline $\begin{array}{c}\text { Water } \\
\text { Source }\end{array}$ & SUVA & Predicted composition & $\begin{array}{c}\text { Predicted } \\
\text { effect of } \\
\text { coagulation }\end{array}$ & $\begin{array}{c}\text { Predicted } \\
\text { DOC } \\
\text { removal } \\
\text { using alum }\end{array}$ \\
\hline- & $>4$ & $\begin{array}{c}\text { High molecular weight (HMW) } \\
\text { compounds; mostly humics; high } \\
\text { hydrophobicity }\end{array}$ & $\begin{array}{c}\text { Coagulation } \\
\text { controlled } \\
\text { by NOM }\end{array}$ & $>50 \%$ \\
\hline $\begin{array}{c}\text { Ottawa } \\
\text { River \& }\end{array}$ & $2-4$ & $\begin{array}{c}\text { Mixture of molecular weights; humics } \\
\text { and other NOMs (such as fulvic acids); } \\
\text { Otonabee } \\
\text { River }\end{array}$ & $\begin{array}{c}\text { Some NOM } \\
\text { influence }\end{array}$ & $25-50 \%$ \\
\hline $\begin{array}{c}\text { Lake } \\
\text { Simcoe }\end{array}$ & $<2$ & $\begin{array}{c}\text { Low molecular weight (LMW) } \\
\text { compounds; mostly non-humics; low } \\
\text { hydrophobicity }\end{array}$ & $\begin{array}{c}\text { Little NOM } \\
\text { influence }\end{array}$ & $<25 \%$ \\
\hline
\end{tabular}

Aluminum sulphate coagulant was selected for coagulation optimization as it represents the most prevalently used chemical coagulant in North America (Matilainen et al., 2010). Alum dosages of $0,20,30,40,50$, and $60 \mathrm{mg} / \mathrm{L}$ were used (jar tests for Ottawa River water were also supplemented by the inclusion of 5 and $10 \mathrm{mg} / \mathrm{L}$ doses), to assess a potential maximum range of DBP formation. In the commercial alum used $\left(\mathrm{Al}_{2}\left(\mathrm{SO}_{4}\right)_{3} \bullet 14 \mathrm{H}_{2} \mathrm{O}\right.$ Liquid Alum, General Chemical, Parsippany, NJ), solid alum content was $48.5 \%$, aluminum content made up $4.3 \%$ of the solution. For alum doses of $0-60 \mathrm{mg} / \mathrm{L}$ (expressed as solid alum), this corresponds to aluminum concentrations of $0-5.45 \mathrm{mg} / \mathrm{L}$ as $\mathrm{Al}$ (sample calculations shown in Appendix 8.1). In raw and coagulated waters, NOM was characterized using LC-OCD, along with total organic carbon (TOC), dissolved organic carbon (DOC), and UV absorbance at $254 \mathrm{~nm}\left(\mathrm{UV}_{254}\right)$. Aliquots of the waters were then chlorinated under uniform formation conditions (UFC), which stipulate chlorine dosing at an adjusted $\mathrm{pH}$ and controlled temperature to obtain a $1.0 \mathrm{mg} / \mathrm{L} \mathrm{Cl}_{2}$ residual following $24 \mathrm{~h}$ of incubation (Summers et al., 1996). This technique allows for the direct comparison of DBP formation potential between source waters with varying water quality. Following 24 hours of chlorination, the residual was quenched by the addition of $L$-ascorbic acid, followed by the determination of DBPs and genotoxicity. 


\subsection{Methods}

Replicated jar tests were performed for alum coagulation on the three source waters. Water quality parameters measured included $\mathrm{pH}$, TOC/DOC, $\mathrm{UV}_{254}, \mathrm{NOM}$ characterization using LC-OCD, and UFC chlorine demand. Following coagulation, samples were then analyzed for the formation of TTHM, HAA 9 , MX, MCA and the determination of genotoxicity. Detailed descriptions of experimental methods are presented in Section 3.0.

\subsection{Bench-Scale Jar Tests}

Prior to conducting jar tests a raw water volume of approximately $75 \mathrm{~L}$ was allowed to equilibrate to room temperature $\left(22^{\circ} \mathrm{C}\right)$ in a $100 \mathrm{~L}$ stainless steel container (Royal Industries Inc., Chicago, IL) while mixing at 100 rpm using a Cafrano BDC 2002 electric stirrer (VWR International, Mississauga, ON). Four replicates were performed, in order to provide sufficient amounts of sample water for all subsequent UFC and DBP testing analyses. Each jar test consisted of six $2 \mathrm{~L}$ water samples into which $0,20,30,40,50$, and $60 \mathrm{mg} / \mathrm{L}$ of alum coagulant $\left(\mathrm{Al}_{2}\left(\mathrm{SO}_{4}\right)_{3} \bullet 14 \mathrm{H}_{2} \mathrm{O}\right.$ Liquid Alum, General Chemical, Parsippany, NJ) were added. An initial 90 seconds of rapid mix (100 rpm) was followed by 15 minutes of slow mix/flocculation $(30 \mathrm{rpm})$, and 30 minutes of settling. The supernatant from each jar was collected and filtered using $1.2 \mu \mathrm{m}$ glass microfiber filters (42.5 mm diameter, Whatman Inc., Florham Park, NJ) to mimic the effects of granular media filtration. All replicates of jar tested and filtered water at each dose were then combined to eliminate any variation associated with a single jar test.

\subsubsection{Analysis of TOC/DOC/UV 254}

Samples for TOC and $\mathrm{UV}_{254}$ were collected in $40 \mathrm{~mL}$ amber vials. Samples for DOC were first filtered using a $0.45 \mu \mathrm{m}$ pore size membrane filter (Supor-450 47mm, Pall Corporation, Ann Arbor, MI). Both TOC and DOC samples were acidified to $\mathrm{pH} 2$ using concentrated sulphuric acid and stored in the dark at $4^{\circ} \mathrm{C}$ prior to analysis. TOC and DOC were analyzed using a Model 1030 Analytical TOC Analyzer equipped with a Model 1051 Vial MultiSampler (O-I Corporation, College Station, Texas). Standard Method 5310D incorporating wet oxidation method was used (APHA, 2005). $\mathrm{UV}_{254}$ was measured using a $1 \mathrm{~cm}$ quartz cell 
(Hewlett Packard, Mississauga) on a CE 3055 spectrophotometer (Cecil Instruments, Cambridge, England) following Standard Method 5910B (APHA, 2005). Duplicate TOC, DOC, and $\mathrm{UV}_{254}$ samples were collected for each coagulation dose.

\subsubsection{Analysis of NOM using LC-OCD}

NOM was analyzed via liquid chromatography with organic carbon detection (LC-OCD) using the method described by Huber et al. (2011). All samples were filtered using a $0.45 \mu \mathrm{m}$ filter (Supor-450 47mm, Pall Corporation, Ann Arbor, MI) prior to analysis. NOM fractions in the samples were chromatographically separately by a size exclusion weak cation exchange column (250 mm x $20 \mathrm{~mm}$, TSK HW 50S, Toso, Japan). A phosphate buffer (purified in an annular UV reactor) was used as the mobile phase at a flow rate of 1.1 $\mathrm{mL} / \mathrm{min}$. After separation, injected samples were subjected to non-destructive UV detection $\left(\mathrm{UV}_{254 \mathrm{~nm}}\right)$ followed by organic carbon detection (OCD), which converted carbonates to carbonic acid $\left(\mathrm{H}_{2} \mathrm{CO}_{3}\right)$. A bypass stream around the size exclusion column allowed the determination of DOC. Five NOM fractions were characterized: biopolymers, humics, building blocks, low molecular weight (LMW) acids, and LMW neutrals. Data acquisition and analysis was completed using customized software (ChromCALC, DOC-LABOR, Karlsruhe, Germany).

\subsubsection{Analysis of DBPs: TTHM/HAA9/AOX and MCA/MX}

Samples were chlorinated using sodium hypochlorite dosing solution under uniform formation conditions (UFC) as described by Summers et al. (1996). DBP formation was measured following a $24 \mathrm{~h}$ chlorination period, at which time the chlorine residual was measured and samples were quenched using $L$-ascorbic acid.

Each sample for THMs and HAAs analysis was collected in a $25 \mathrm{~mL}$ amber vial. TTHM analyses followed Standard Method 6232B (APHA, 2005); HAA9 analyses followed Standard Method 6251 B (APHA, 2005). Both analyses were conducted using a 5890 Series II Plus Gas Chromatograph (Hewlett Packard, Mississauga, ON) equipped with an election capture detector (GC-ECD) and a DB 5.625 capillary column (Agilent Technologies Canada, Inc., Mississauga, ON). Standards were obtained from Sigma Aldrich for THMs (Supelco, 
48140-U) and HAAs (Supelco, 49107-U). Calibration samples were prepared in Milli-Q ${ }^{\circledR}$ water. Duplicate samples were analyzed for both TTHM and HAA9.

AOX was analyzed using a batch adsorption method and a Trace Elemental Instruments Xplorer Analyzer (TE Instruments, Delft, the Netherlands). $100 \mathrm{~mL}$ water samples were shaken with $50 \mathrm{mg}$ activated carbon to absorb the organic halogens, then filtered through a quartz frit to remove the carbon. Duplicate samples were analyzed for AOX by combustion and coulometric titration of released halogens in the analyzer.

MCA and MX were extracted from $1 \mathrm{~L}$ by solid phase extraction (SPE), chlorinated and quenched samples, acidified to $\mathrm{pH} 2$ with concentrated sulphuric acid. Mucobromic acid (MBA) was added to each sample at $100 \mathrm{ng} / \mathrm{L}$ to serve as a surrogate standard. Extraction was completed using a tandem SPE setup, with a tC18 cartridge (Sep Pak 6cc, 1g, Waters Corporation, Mississauga, ON) placed in-line prior to an Oasis HLB cartridge (12cc, 500mg, Waters Corporation). HLB cartridges were eluted using $2 \times 5 \mathrm{~mL}$ of acetone, and then evaporated to dryness under nitrogen. Samples were reconstituted in $300 \mu \mathrm{L}$ of $2 \% \mathrm{H}_{2} \mathrm{SO}_{4}$ in methanol $(\mathrm{v} / \mathrm{v})$ and derivatized at $70^{\circ} \mathrm{C}$ for $1 \mathrm{hr}$. After cooling to room temperature, $750 \mu \mathrm{L}$ of $2 \% \mathrm{NaHCO}_{3}$ (w/v in Milli-Q ${ }^{\circledR}$ water) was added to neutralize the acid. Back extraction was performed twice with $600 \mu \mathrm{L}$ of hexane. The final extract was then concentrated to approximately $0.1 \mathrm{~mL}$ under a gentle stream of nitrogen. MCA and MX were analyzed by GC/MS/MS using a Varian GC/MS system (Mississauga, ON) equipped with a Varian 3800 GC, 4000 MS, and CombiPAL autosampler. The column used was a J \& W Scientific DB1701 column $(30 \mathrm{~m}, 0.25 \mathrm{~mm}$ ID, $0.25 \mu \mathrm{m}$ film thickness). All samples were analyzed in duplicate.

\subsubsection{Analysis of Genotoxicity}

Genotoxicity tests were conducted using a SOS Chromotest kit supplied by EBPI (Environmental Bio-Detection Products Inc., Mississauga, Ontario, Canada). The test was originally developed by Quillardet et al. (1982) and is used to colorimetrically determine SOS response, an inherent mechanism in living cells that detects lesions created in genetic material and triggers a subsequent DNA repair mechanism. 
In the SOS Chromotest bioassay, a strain of Escherichia coli (E. coli), PQ37, was genetically modified with a $\beta$-galactosidase ( $\beta$-gal) gene fused to the bacterial SOS operon (Quillardet et al., 1982). The indogenous SOS repair is altered to effectively inactivate the DNA repair mechanism and instead, $\beta$-gal is synthesized. The amount of $\beta$-gal induction, which can be quantified photometrically using a chromogenic substrate, is thus representative of SOS induction and bacterial genotoxicity (Kocak et al., 2010). General protein synthesis is also measured and corrected for using the photometric quantification of alkaline phosphatase (AP). The induction of $\beta$-gal is determined by the ratio of $\beta$-gal activity to AP activity (referred to as the induction factor). A more detailed description of the SOS Chromotest can be found in Section 3.0.

Chlorinated water samples (2L) were quenched and acidified to $\mathrm{pH} 2$ with concentrated sulphuric acid, then extracted via SPE using Oasis HLB cartridges (12cc, 500mg, Waters Corporation). Samples were eluted with $2 \times 5 \mathrm{~mL}$ of acetone, which was then evaporated under nitrogen, with $30 \mu \mathrm{L}$ of dimethyl sulfoxide (DMSO) added before complete evaporation of acetone. Drying was stopped when a final volume of approximately $10 \mu \mathrm{L}$ was reached. Samples were then supplemented with DMSO to obtain a final volume of 30 $\mu \mathrm{L}$. SOS Chromotest procedures provided by EBPI were observed. Briefly, $1 \mu \mathrm{L}$ of extracted water sample (in DMSO) was added to $4 \mu \mathrm{L}$ of $10 \%$ DMSO saline solution on a 96 well microplate. Each sample was then diluted two-fold into five respective wells, for a total of six test concentrations. A positive control (4-NQO) was tested on every plate, alongside samples. $100 \mu \mathrm{L}$ of diluted bacterial suspension (prepared overnight and diluted to 0.5 optical density at $600 \mathrm{~nm}$ ) was added to each well and the bioassay was incubated at $37^{\circ} \mathrm{C}$ for $2 \mathrm{~h}$. Following incubation, $100 \mu \mathrm{L}$ of chromogen for $\beta$-galactosidase ( $\beta$-gal) and alkaline phosphatase (AP) was added to each well and plates were incubated at $37^{\circ} \mathrm{C}$ for an additional hour. A microplate reader (Infinite 200, Tecan, Morrisville, NC) was used to read the activity of $\beta$-gal $\left(\mathrm{OD}_{605}\right)$ and $\mathrm{AP}\left(\mathrm{OD}_{420}\right)$.

Equations used for the determination of $\beta$-gal activity $\left(\mathrm{R}_{\mathrm{c}}\right)$, AP reduction activity $\left(\mathrm{R}_{0}\right)$, and induction factor (IF) are shown below: 


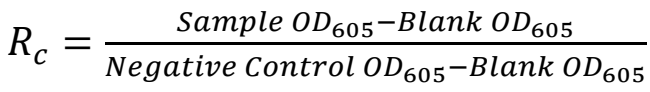

$$
\begin{aligned}
& R_{0}=\frac{\text { Sample } O D_{420}-\text { Blank } O D_{420}}{\text { Negative Control } O D_{420}-B \text { Blank } O D_{420}} \\
& I F=\frac{R_{C}}{R_{0}}
\end{aligned}
$$

A serial, step-wise dilution (total of six dilutions for each sample) was used in the SOS Chromotest bioassay. For each dilution, the amount of sample was quantified with a unitless relative enrichment factor (REF) as defined by Escher \& Leusch (2011):

$$
R E F=\frac{\text { enrichment } \text { factor }_{\text {extraction }}}{\text { dilution } \text { factor }_{\text {bioassay }}}
$$

where the enrichment factor is the concentration achieved during sample extraction (i.e. with SPE) and the dilution factor is the dilution amount for each step in the bioassay.

Using the IF and REF values obtained for each dilution in each sample, the slope of the linear portion of IF versus REF was determined. For the known carcinogenic positive control, 4NQO, a mass in pmol was used instead of REF (since the exact concentration added is known). 4-NQO slopes were corrected using the SOSIP factor, to normalize the mass units. SOSIP has been defined by Quillardet et al. (1982) as the potency of IF per nmol per assay. For known genotoxic compounds, this SOSIP value is consistent and reported.

Finally, for each sample the IF vs. REF slope value was quantified relative to 4-NQO SOSIP with the toxic equivalent concentration (TEQ4-NQO), adapted from Wang et al. (2011):

$$
T E Q_{\text {sample }}=\frac{\text { Slope }_{\text {sample }}}{\text { Slope }_{4-N Q O \text { SOSIP }}}
$$

The TEQ 4 -NQO value represents the genotoxicity of each sample, relative to the genotoxicity of carcinogen 4-NQO. For example, if a sample was as genotoxic as 4-NQO, it would have a $\mathrm{TEQ}_{4-\mathrm{NQO}}$ value of 1.0. A sample calculation is available in Appendix 8.6. 


\subsection{Evaluation of Coagulation for Minimizing DBP Formation and Genotoxicity Potential}

Bench-scale coagulation and filtration tests were used to examine the three source waters. TOC, DOC, $\mathrm{UV}_{254}$, and NOM fractions (using LC-OCD) were measured. In addition to providing information regarding the concentration and characterization of NOM in the samples, these parameters provided an indication of the level of coagulation treatment. DOC and $\mathrm{UV}_{254}$ (conventionally used as NOM surrogates) measured following jar tests are shown in Figure 5.1. for each of the three source waters experiments. The decreasing trends for all three parameters indicate overall NOM removal, consistent with previously published benchscale coagulation results (Wassink, 2010). Chlorine demand was also observed to decrease with increasing alum dosages (Figure 5.2).

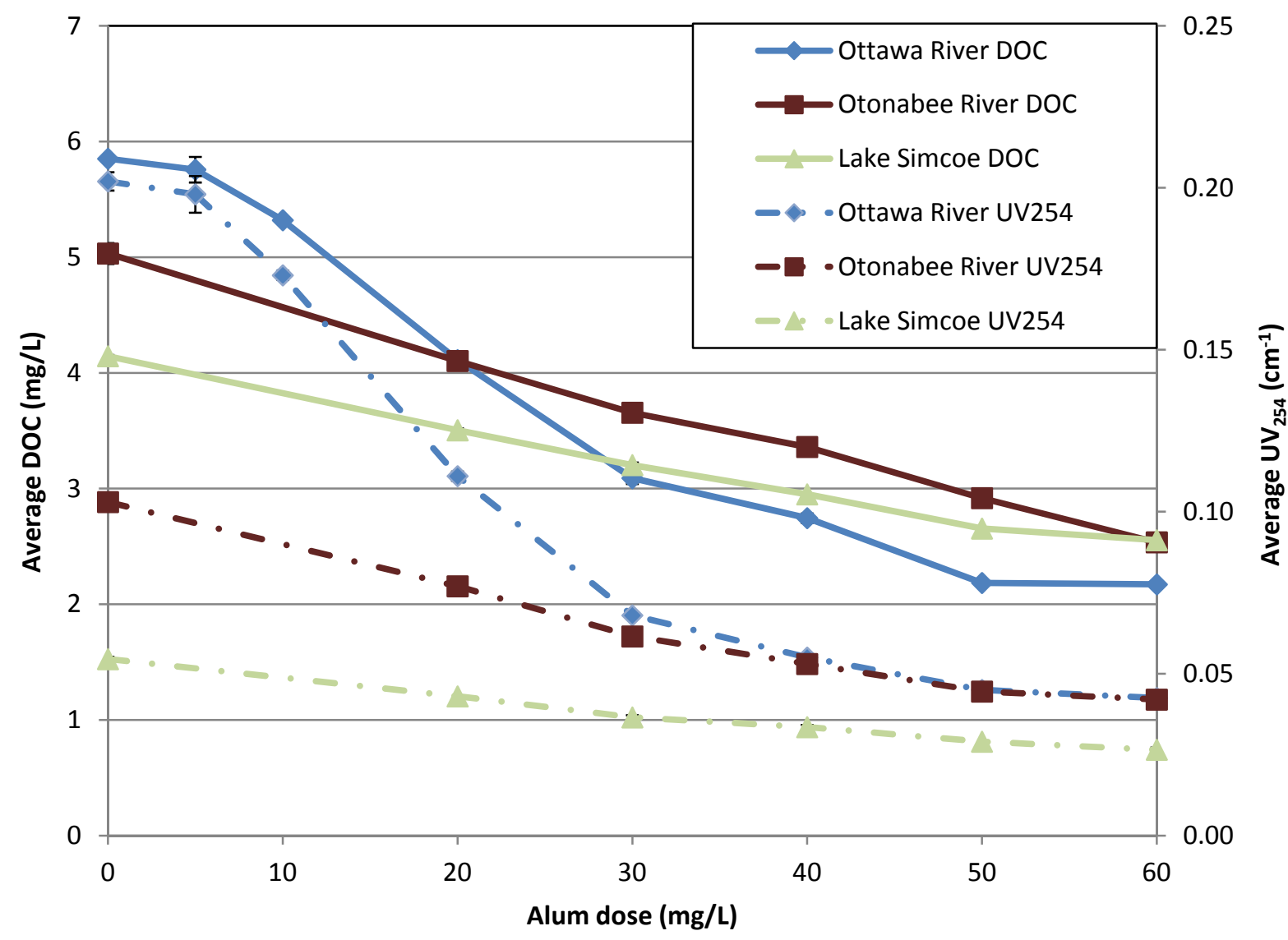

Figure 5.1 - DOC and $\mathrm{UV}_{254}$ results for three source waters

Samples were analyzed in duplicate; error bars represent the maximum and minimum of duplicate samples. 


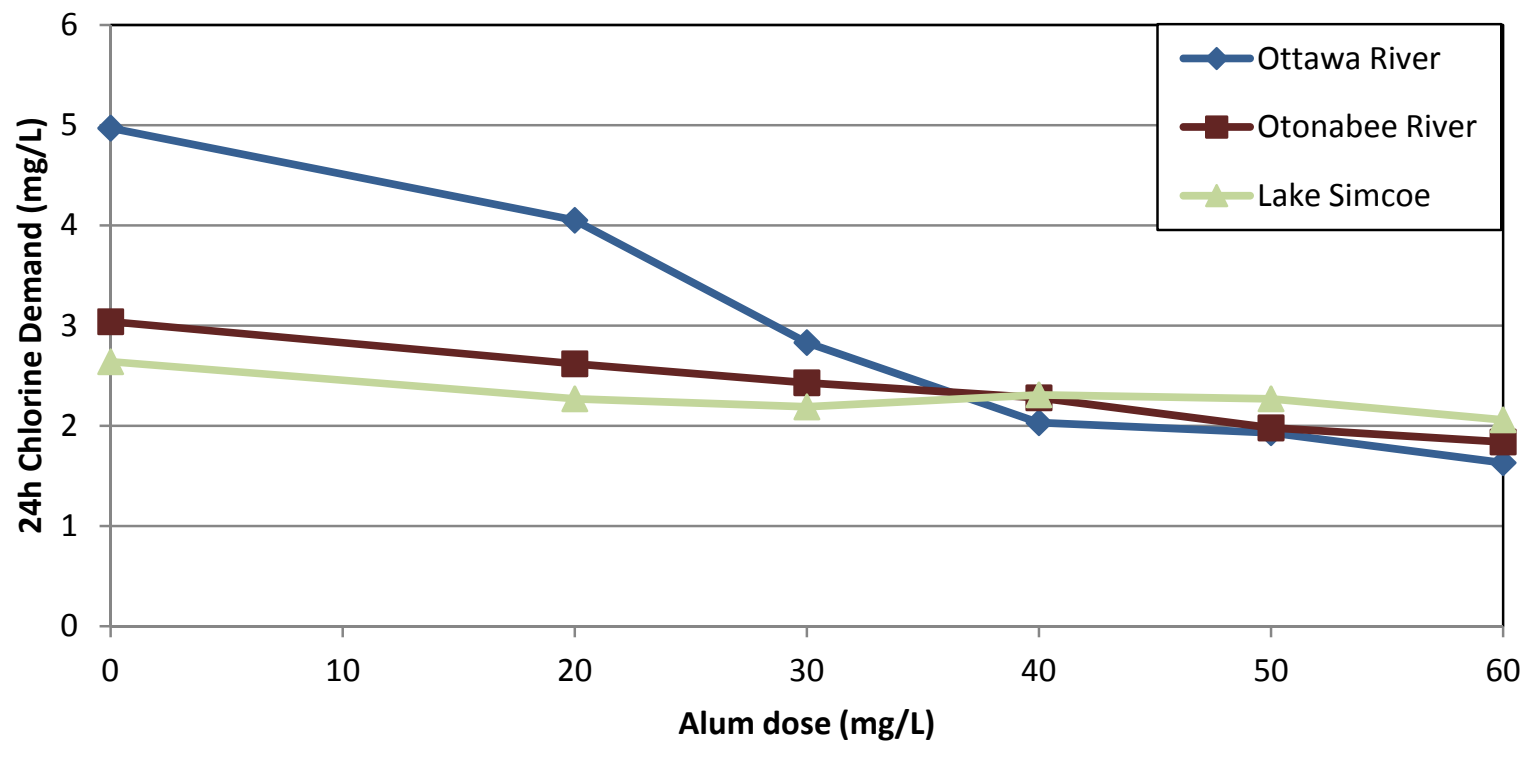

Figure 5.2 - Chlorine demand for three source waters

Coagulation results were compared with USEPA requirements for TOC removal via enhanced coagulation. The TOC reduction targets are defined based on raw water TOC and alkalinity values and presented in Table 5.3 (USEPA, 1999).

Table 5.3 - Optimal TOC removal percentages by enhanced coagulation for plants using conventional treatment: Step 1 Disinfection By-Product Rule (USEPA, 1999)

\begin{tabular}{|c|c|c|c|}
\hline \multirow{2}{*}{$\begin{array}{c}\text { Raw water TOC } \\
\text { (mg/L) }\end{array}$} & \multicolumn{3}{|c|}{ Raw water alkalinity (mg/L as $\left.\mathbf{C a C O}_{3}\right)$} \\
\cline { 2 - 4 } ) & $\mathbf{0 - 6 0}$ & $\mathbf{6 0}-\mathbf{1 2 0}$ & $>\mathbf{1 2 0}$ \\
\hline $\mathbf{2 . 0}-\mathbf{4 . 0}$ & $35.0 \%$ & $25.0 \%$ & $15.0 \%$ \\
\hline $\mathbf{4 . 0 - 8 . 0}$ & $45.0 \%$ & $35.0 \%$ & $25.0 \%$ \\
\hline$>\mathbf{8 . 0}$ & $50.0 \%$ & $40.0 \%$ & $30.0 \%$ \\
\hline
\end{tabular}

DOC values are used as a substitute to TOC (since DOC accounted for $>90 \%$ of TOC in all samples). According to Edzwald \& Tobiason (1999) DOC is a more reliable measure, since TOC may be impacted by scale-dependent factors such as settling. Furthermore, jar test optimization using TOC may lead to overdosing of coagulant (Edzwald \& Tobiason, 1999). The calculated target alum dose for each water based on DOC removal is shown in Table 5.4. Target alum doses for each source water were well within the jar test range, thereby reflecting the potential applicability of DBP formation and genotoxicity results to full-scale scenarios. 
Table 5.4 - Enhanced coagulation target alum doses (mg/L) for each source water

\begin{tabular}{|c|c|c|c|c|c|}
\hline \multirow[b]{2}{*}{ Water source } & \multicolumn{3}{|c|}{ Raw water characteristics } & \multirow{2}{*}{$\begin{array}{l}\text { Target DOC } \\
\text { reduction }\end{array}$} & \multirow{2}{*}{$\begin{array}{l}\text { Calculated } \\
\text { target alum } \\
\text { dose }(\mathrm{mg} / \mathrm{L})\end{array}$} \\
\hline & $\begin{array}{c}\text { SUVA } \\
(\mathrm{L} / \mathbf{m g} / \mathbf{c m})\end{array}$ & $\begin{array}{c}\text { DOC } \\
(\mathrm{mg} / \mathrm{L})\end{array}$ & $\begin{array}{c}\text { Alkalinity } \\
\left(\mathrm{mg} / \mathrm{L} \mathrm{CaCO}_{3}\right)\end{array}$ & & \\
\hline Ottawa River & 3.45 & 5.85 & 23.5 & $45.0 \%$ & 28.7 \\
\hline Otonabee River & 2.05 & 5.03 & 90.5 & $35.0 \%$ & 42.0 \\
\hline Lake Simcoe & 1.32 & 4.14 & 115.0 & $25-35.0 \%$ & 48.7 \\
\hline
\end{tabular}

Alkalinity is an important factor during coagulation, as waters undergo $\mathrm{pH}$ depression more readily when alkalinity levels are low, thus improving coagulation, as it is more effective at lower $\mathrm{pH}$ levels. This phenomenon is observed when comparing Ottawa River and Otonabee River waters. Both raw waters had mid-range SUVA values and comparable DOC; however Ottawa River water exhibited a low alkalinity while Otonabee River water had relatively high alkalinity (Table 5.4). As such, jar test results show a greater DOC reduction at a lower alum dose for Ottawa River water (Table 5.4). As well, Figure 5.1 shows a steeper decrease in DOC and $\mathrm{UV}_{254}$ with increasing alum doses for Ottawa River jar tests when compared to both Otonabee River and Lake Simcoe. The applicability of SUVA for the prediction of NOM removal via coagulation (see Section 5.2) can also be examined using the results of this study. According to Edzwald \& Tobiason (1999), coagulation efficacy decreases with decreasing SUVA, which is also supported by these results. In addition, SUVA may be used as an indicator for the distribution of NOM compounds based on molecular weight (Chow et al., 2008). NOM fractions as determined using LC-OCD are shown in Figure 5.3 to Figure 5.5 . 


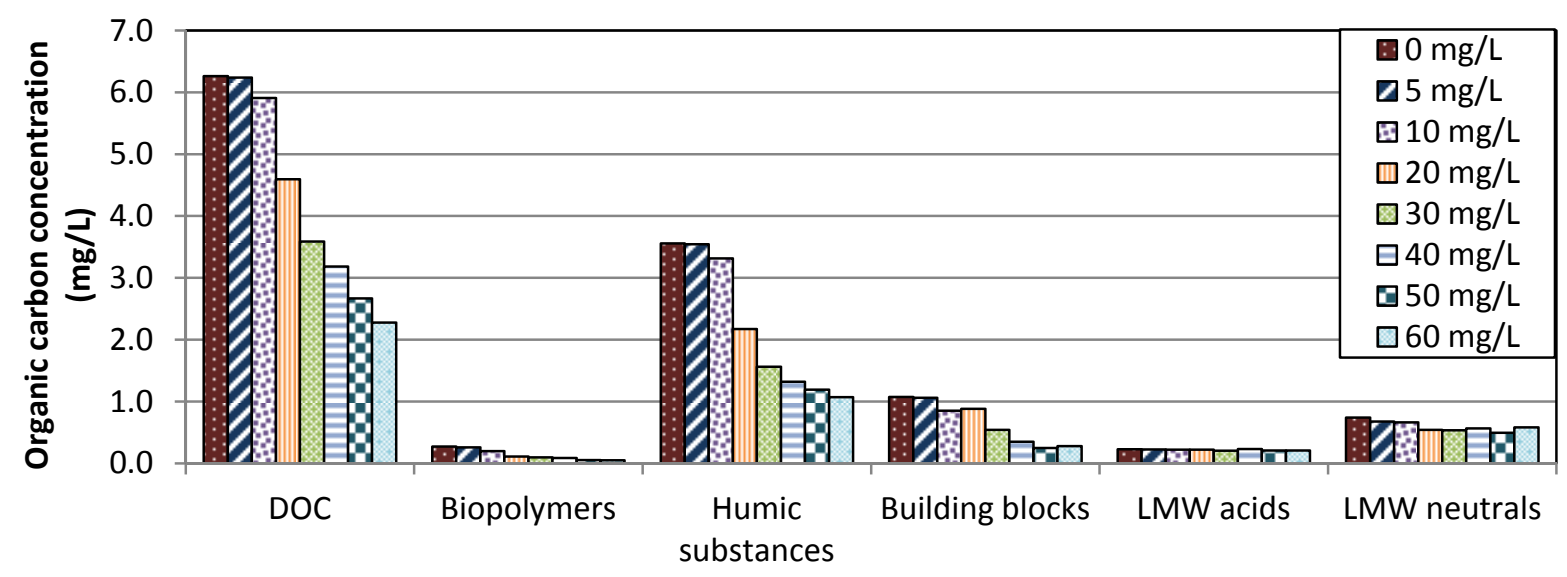

Figure 5.3 - NOM fractions (from LC-OCD) following alum coagulation in Ottawa River water

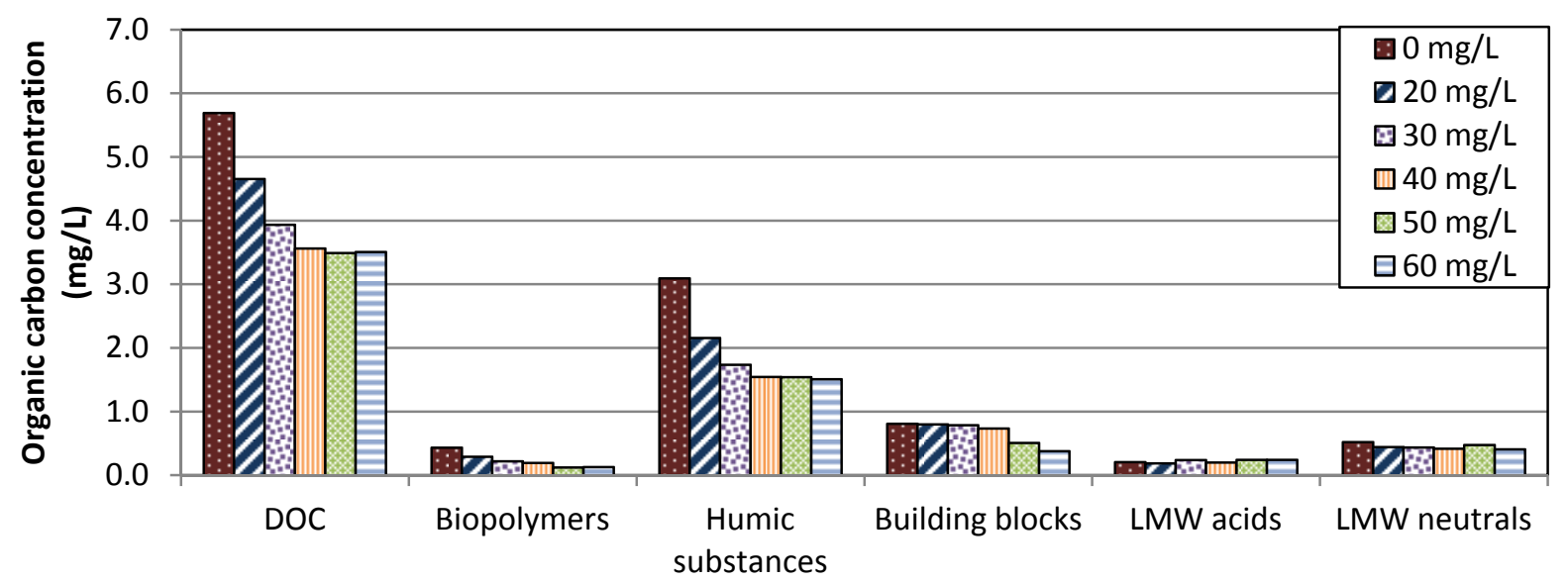

Figure 5.4 - NOM fractions (from LC-OCD) following alum coagulation in Otonabee River water

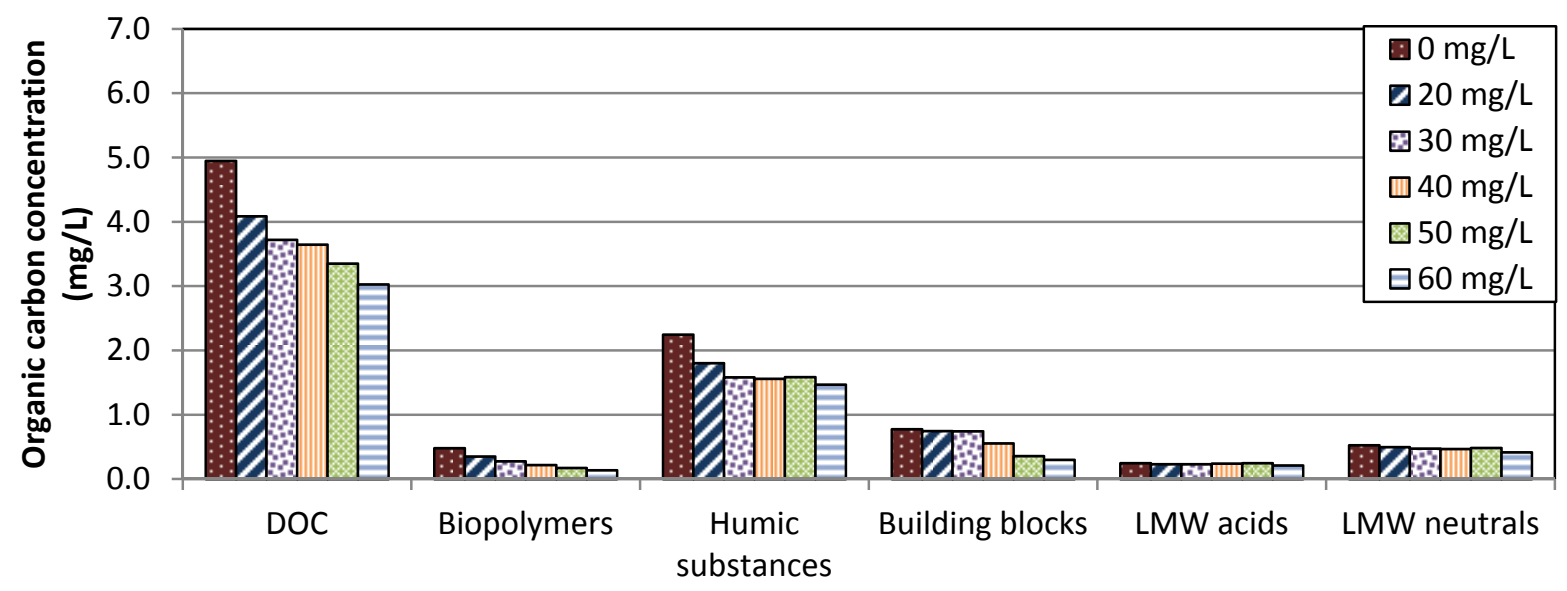

Figure 5.5 - NOM fractions (from LC-OCD) following alum coagulation in Lake Simcoe water 
DBP formation potential was assessed using AOX, TTHM, HAA, MCA, and MX. Reductions in DBP formation with increasing alum dosage are shown in Figures 5.6 to 5.10. By using the alum dose closest to the enhanced coagulation target alum dose for each source water, DBP formation in this study can be compared with occurrence of these DBPs from a previous study (Krasner et al., 2006) as summarized in Table 5.5. DBP formation at enhanced coagulation target doses represent what may occur at full-scale treatment when operating under enhanced coagulation guidelines.

Table 5.5 - Comparison of DBP formation to Krasner et al. (2006)

\begin{tabular}{|c|c|c|c|c|c|}
\hline & \multicolumn{3}{|c|}{$\begin{array}{l}\text { Results from this study (formation at } \\
\text { alum dosage closest to target dose) }\end{array}$} & \multirow{2}{*}{$\begin{array}{c}\text { Krasner } \\
\text { et al. } \\
(2006)^{a}\end{array}$} \\
\hline & & $\begin{array}{c}\text { Ottawa } \\
\text { River }\end{array}$ & $\begin{array}{l}\text { Otonabee } \\
\text { River }\end{array}$ & $\begin{array}{l}\text { Lake } \\
\text { Simcoe }\end{array}$ & \\
\hline \multirow{2}{*}{$\begin{array}{l}\text { Alum dose } \\
\text { (mg/L) }\end{array}$} & Calculated target & 28.7 & 42.0 & 48.7 & \\
\hline & $\begin{array}{c}\text { Nearest jar tested } \\
\text { sample }\end{array}$ & 30.0 & 40.0 & 50.0 & \\
\hline \multirow{5}{*}{$\begin{array}{l}\text { Measured } \\
\text { DBPs }\end{array}$} & $\mathrm{AOX}\left(\mu \mathrm{g} / \mathrm{L}\right.$ as $\left.\mathrm{Cl}^{-}\right)$ & 149.3 & 228.4 & 161.8 & 178 \\
\hline & TTHM ( $\mu \mathrm{g} / \mathrm{L})$ & 100.1 & 128.2 & 45.4 & 31 \\
\hline & $\mathrm{HAA}_{9}(\mu \mathrm{g} / \mathrm{L})$ & 31.5 & 59.8 & 53.7 & 34 \\
\hline & MCA (ng/L) & 314.8 & 164.6 & 43.2 & $86.7^{b}$ \\
\hline & MX (ng/L) & 14.1 & 6.9 & 15.3 & $20^{\mathrm{c}}$ \\
\hline
\end{tabular}

${ }^{\mathrm{a}}$ Median concentrations from 12 drinking water treatment plant effluents in the U.S.

${ }^{b}$ Mean concentration of $\mathrm{MCA}_{\text {ring }}$ from 6 out of 12 plants; $\mathrm{MCA}_{\text {ring }}$ not detected in waters from the remaining 6 plants

${ }^{c} \mathrm{MX}$ not detected in samples from 4 out of 12 plants

Speciation of THMs and HAAs for each alum dose is given in the Appendices 8.2, 8.3, and 8.4. Speciation of THMs was similar for all three waters with chloroform (trichloromethane, TCM) formation comprising the majority of TTHM by mass and bromodichloromethane (BDCM) the second highest. These results are consistent with findings of past studies (Krasner et al., 2006; Richardson et al., 2007). Tribromomethane (TBM) was not detected in any samples from all three source waters. In terms of HAAs, dichloroacetic acid (DCAA) and trichloroacetic acid (TCAA) constituted the majority of $\mathrm{HAA}_{9}$ by mass, consistent with results presented by Edzwald \& Tobiason (1999) and Wassink (2011). Bromochloroacetic acid (BCAA) was the only brominated HAA observed in all three waters, at levels of 1.6, 2.7, and $3.5 \mu \mathrm{g} / \mathrm{L}$ for Ottawa River, Otonabee River, and Lake Simcoe waters respectively. The 
absence of brominated THMs and HAAs may be due to the low bromide concentrations in the waters.

MCA and MX formation were comparable to published occurrence data (Krasner et al., 2006; McDonald \& Komulainen, 2005). For all three source waters, MCA was present at much higher concentrations than MX. Both halogenated furanones showed a decrease in concentration with increasing alum dose. MX was not detected in Otonabee River water.

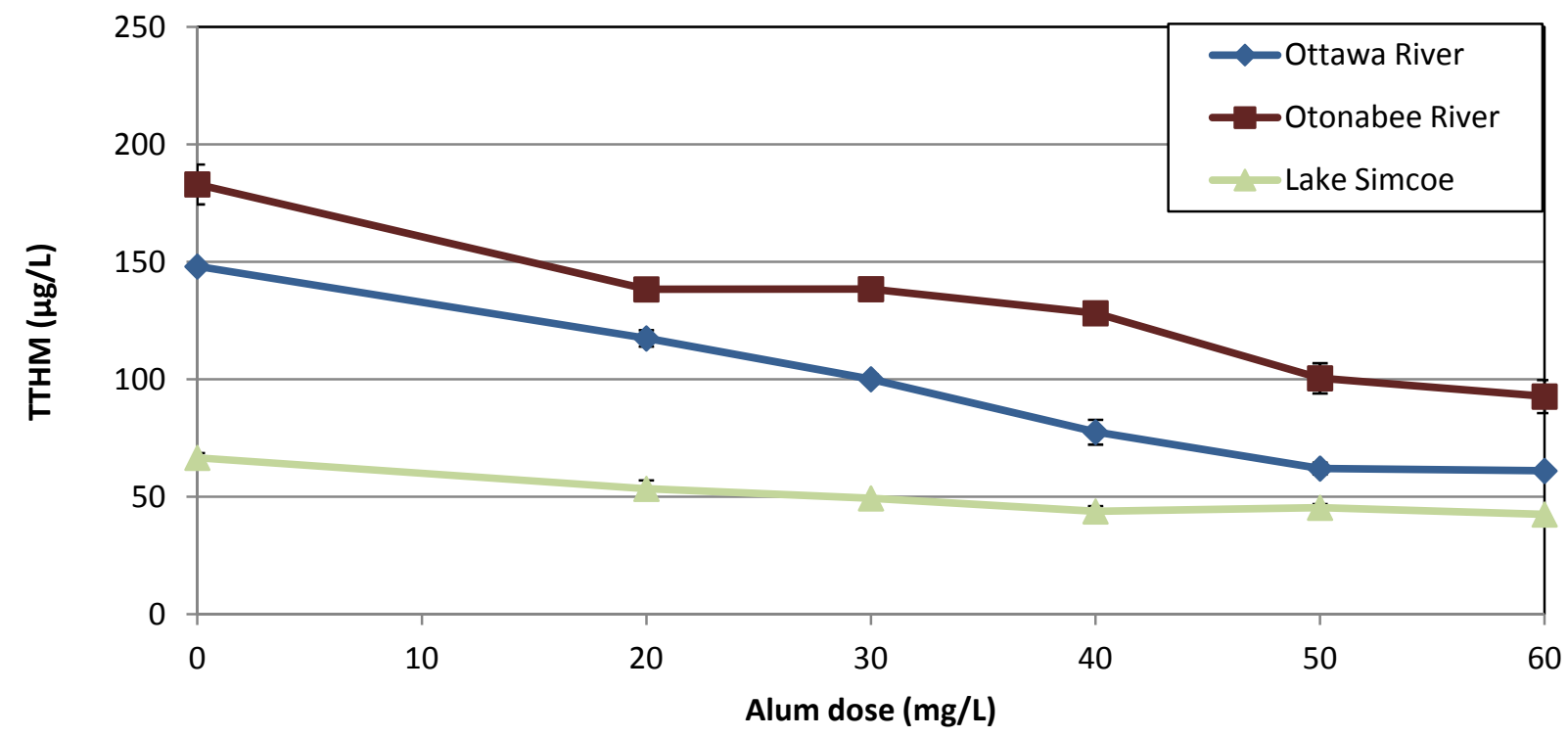

Figure 5.6 - Average concentration of TTHM, chlorinated under UFC.

Samples were analyzed in duplicate; error bars represent the maximum and minimum of duplicate samples. 


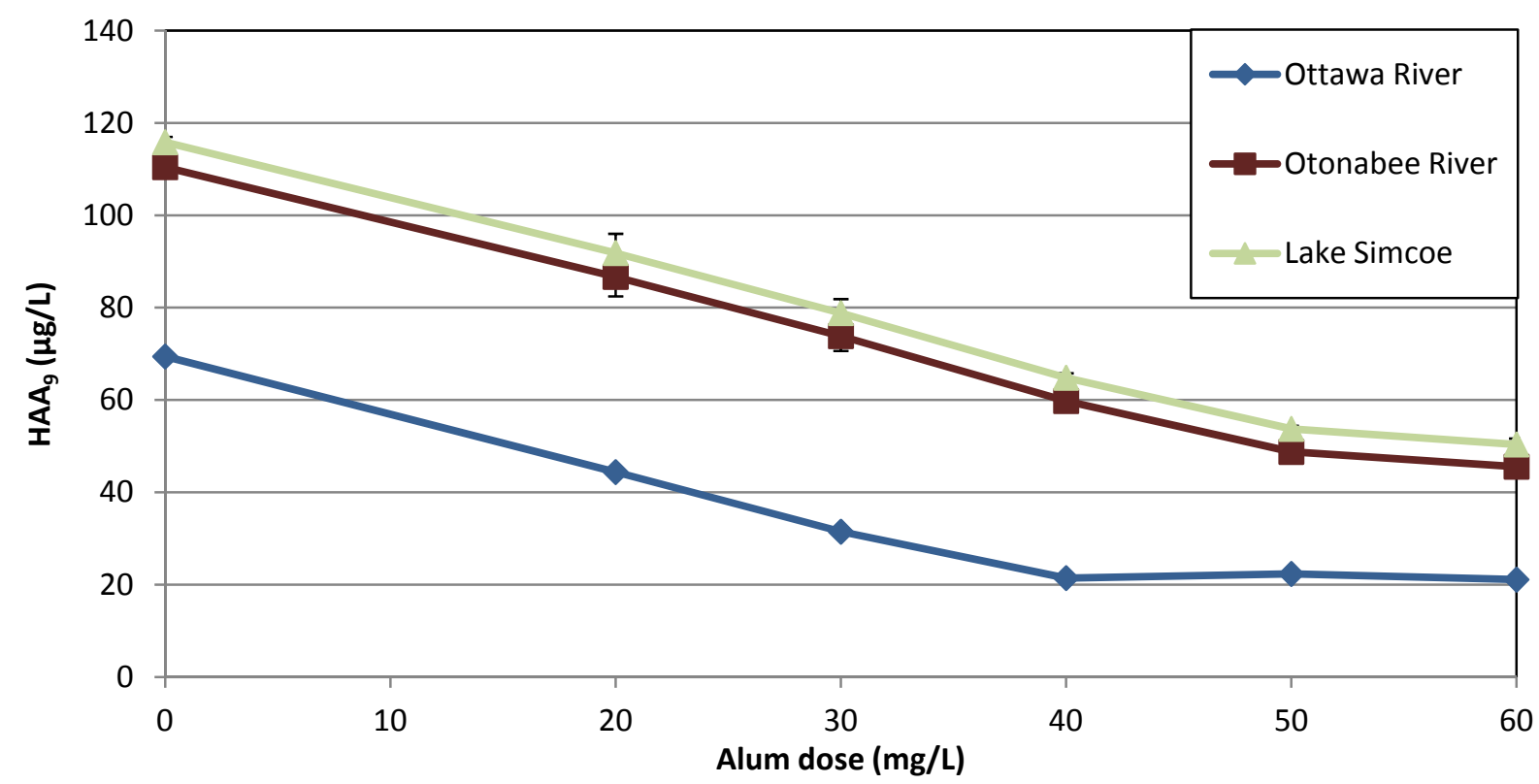

Figure 5.7 - Average concentration of $\mathrm{HAA}_{9}$, chlorinated under UFC.

Samples were analyzed in duplicate; error bars represent the maximum and minimum of duplicate samples.

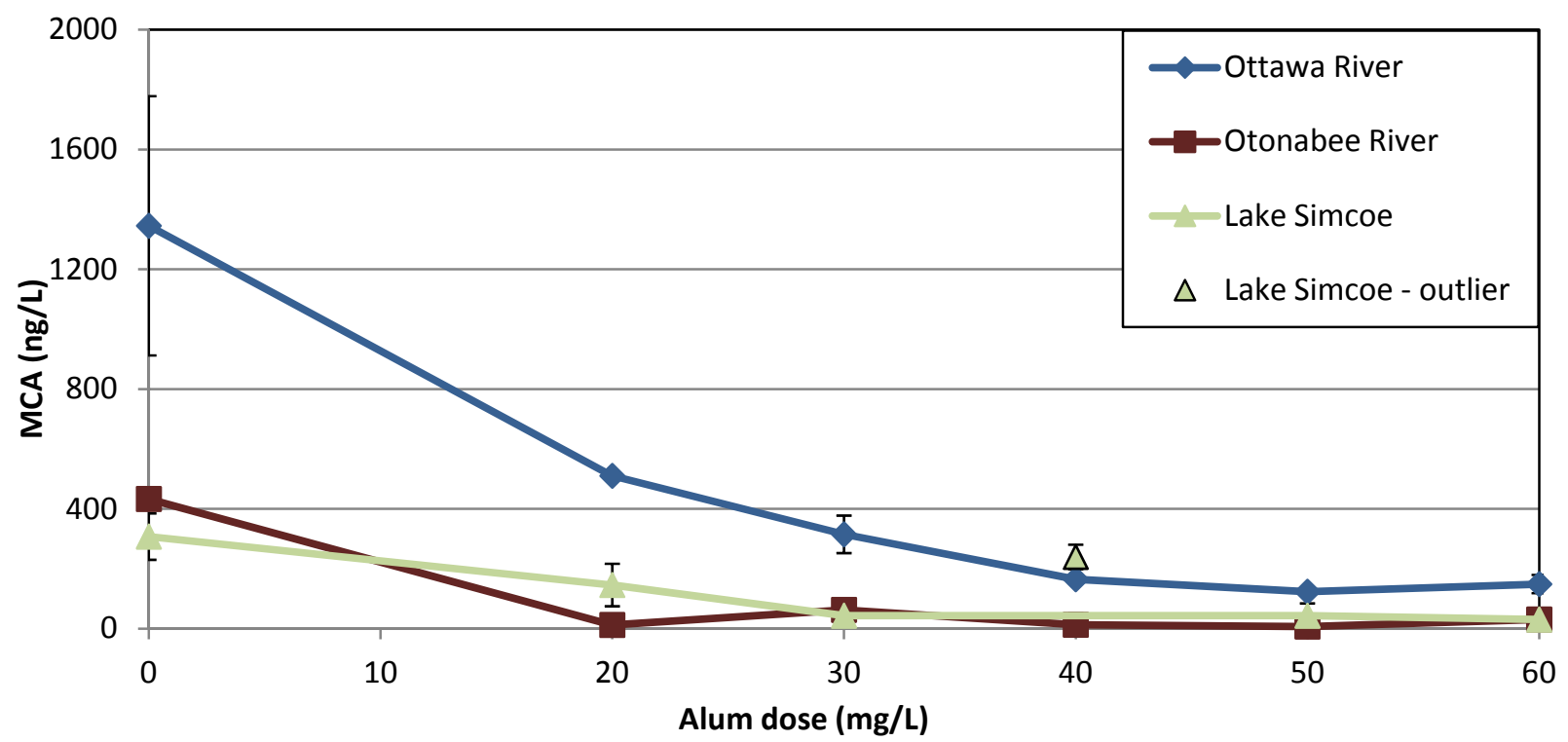

Figure 5.8 - Average concentration of MCA, chlorinated under UFC.

Samples were analyzed in duplicate; error bars represent the maximum and minimum of duplicate samples. 


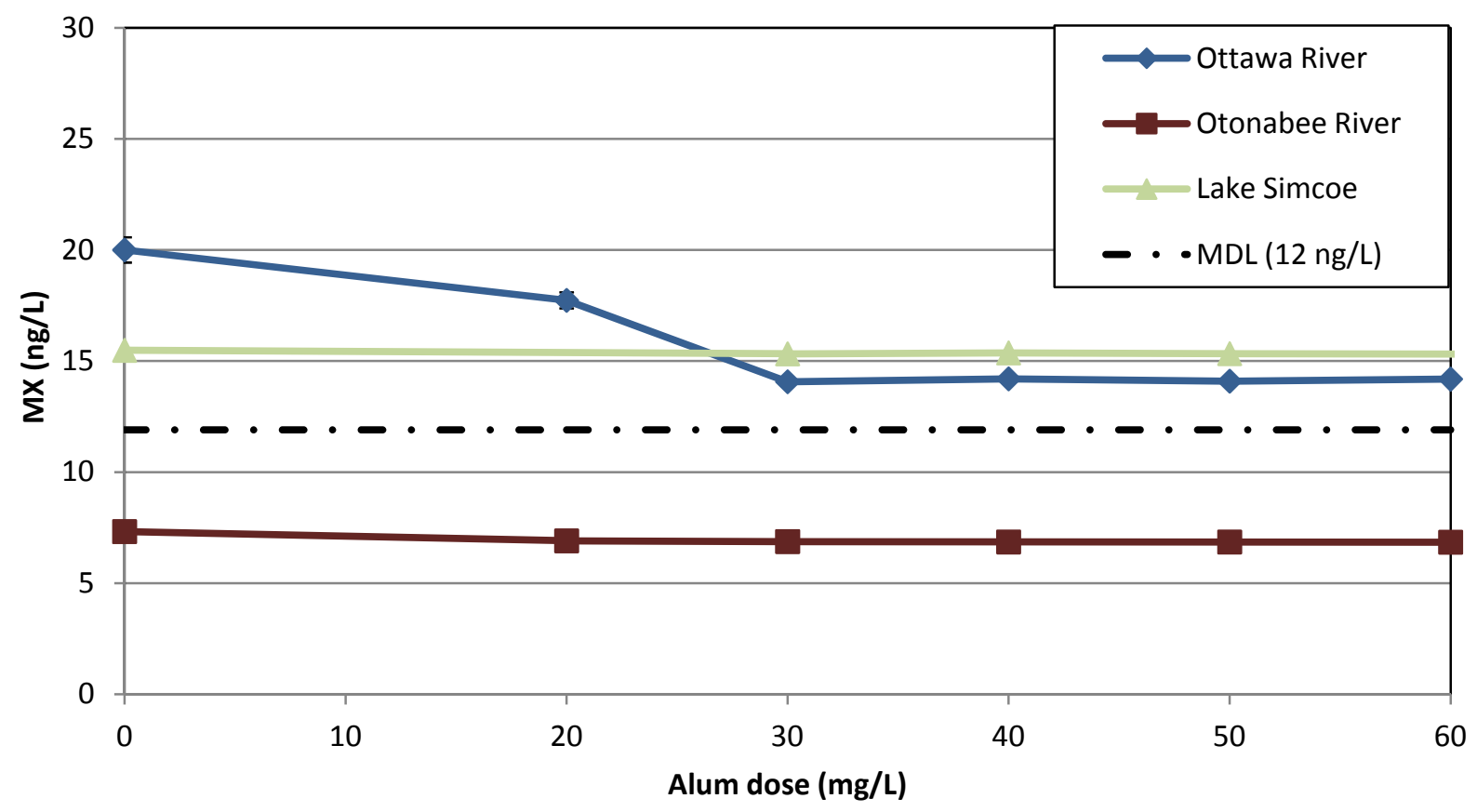

Figure 5.9 - Average concentration of MX, chlorinated under UFC.

Samples were analyzed in duplicate; error bars represent the maximum and minimum of duplicate samples.

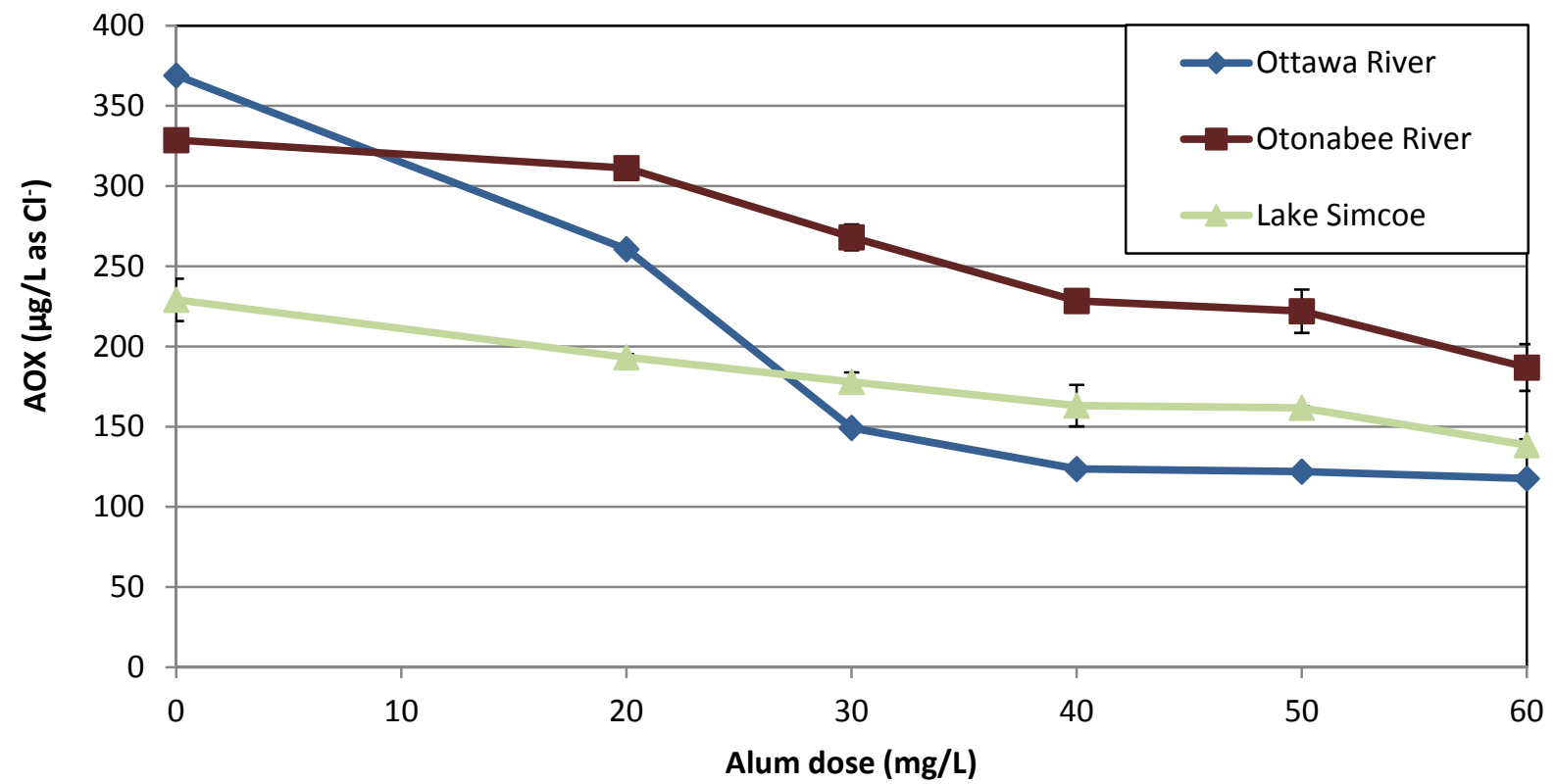

Figure 5.10 - Average concentration of AOX, chlorinated under UFC.

Samples were analyzed in duplicate; error bars represent the maximum and minimum of duplicate samples (Ottawa River samples were not analyzed in duplicate). 
AOX, a measure of total organic halides, was used as a measure of bulk DBP presence in a given sample. An unknown AOX fraction in each sample was calculated from the difference between AOX concentration and the sum of TTHM, HAA9, MCA, and MX (converted to $\mu \mathrm{g} / \mathrm{L}$ as $\left.\mathrm{Cl}^{-}\right)$. The composition of total AOX accounted for by measured and unknown DBPs is shown for each water source in Figure 5.11 to Figure 5.13. MCA and MX were not incorporated into the percent composition bar graphs, as their contributions were extremely low $\left(\mathrm{MCA}<0.1 \%\right.$ and $\mathrm{MX}<0.01 \%$ of $\mathrm{AOX}$ in $\mu \mathrm{g} / \mathrm{L}$ as $\mathrm{Cl}^{-}$) for all waters. In the three waters, unknown fractions made up for $34-60 \%$ of AOX measured for each sample. In an occurrence study by Krasner et al. (2006), 69.9\% of total organic halides were unknown fractions.

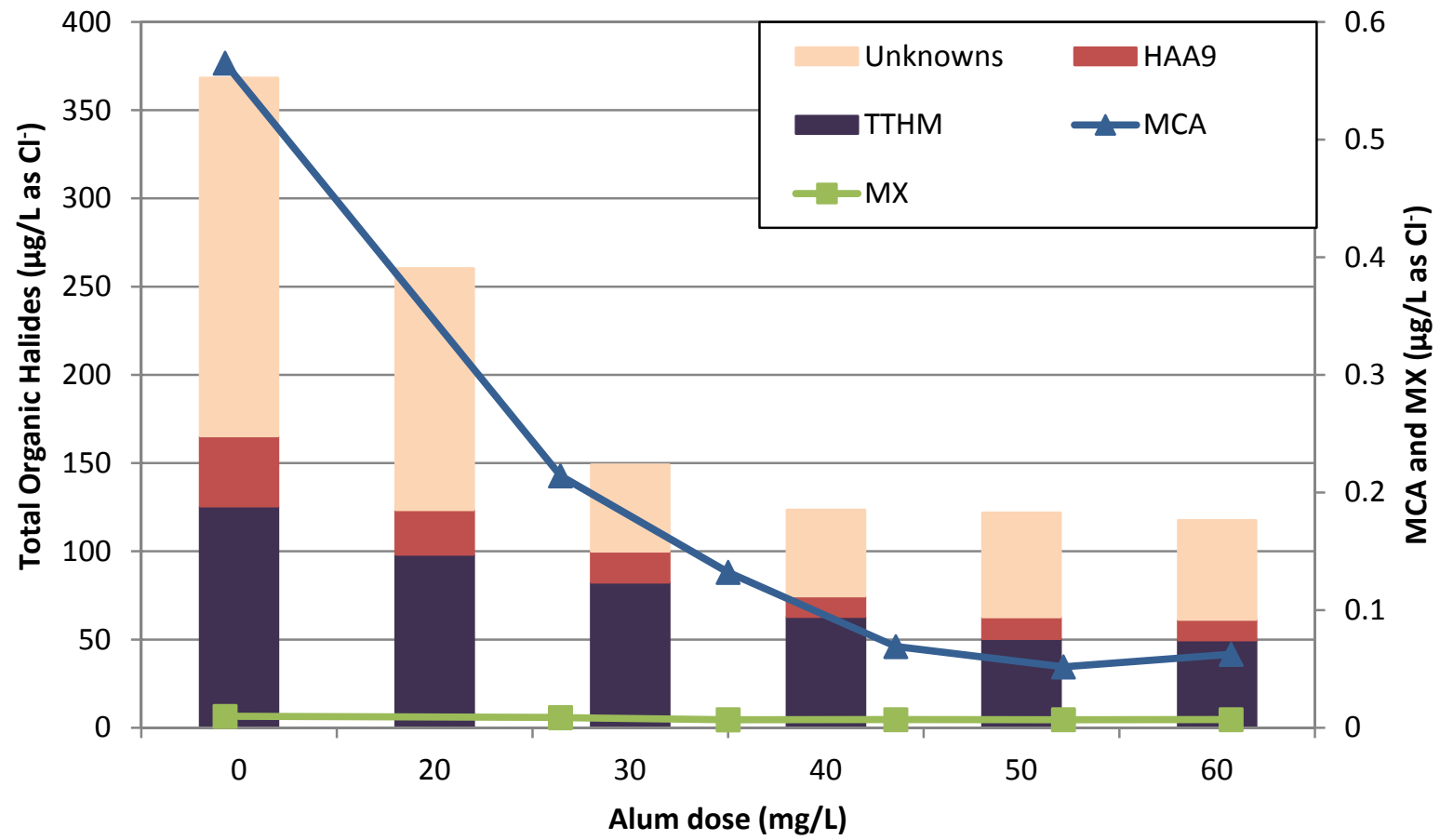

Figure 5.11 - Contributions to AOX: TTHM, HAA, MCA, and MX in Ottawa River water 


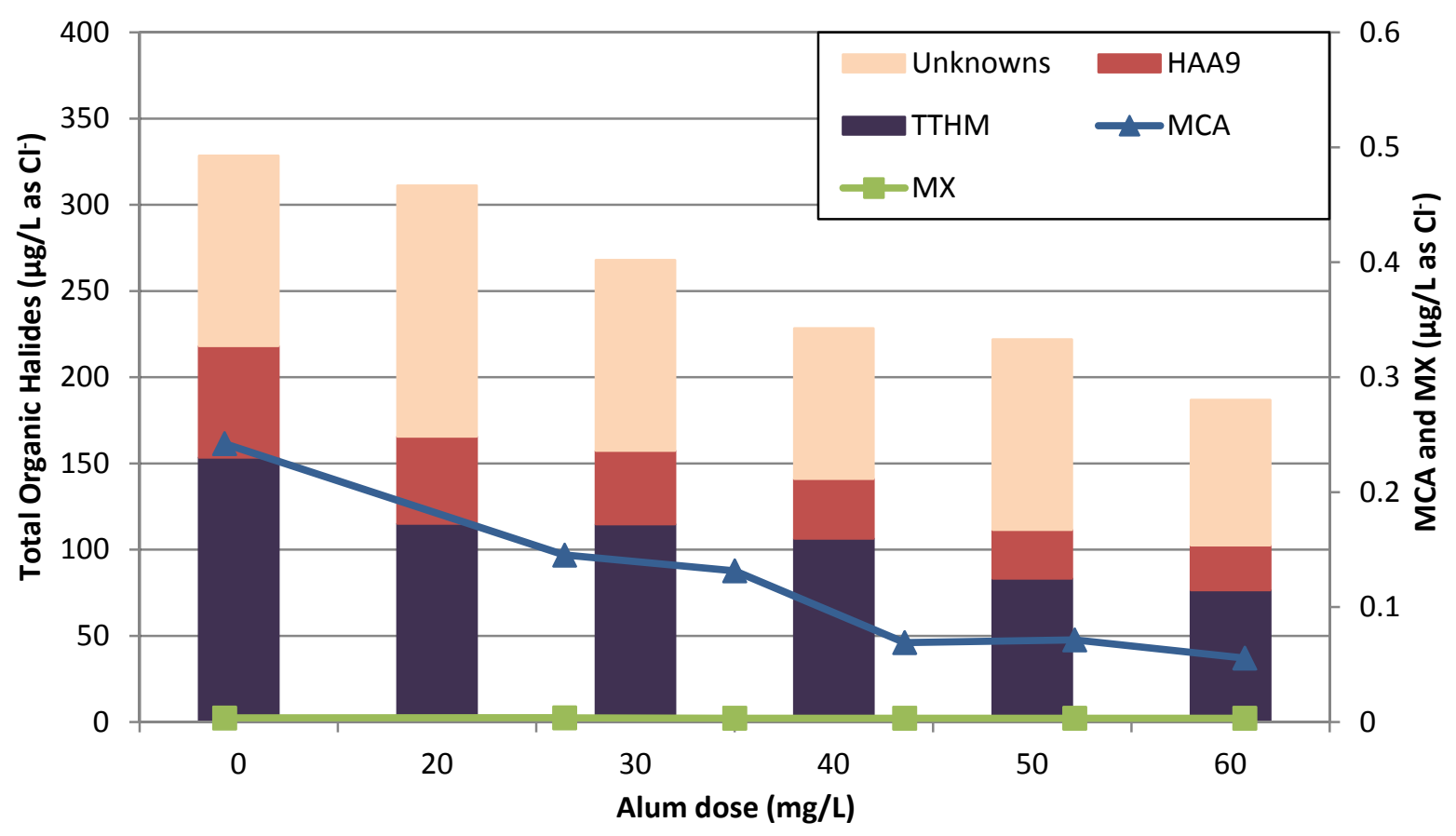

Figure 5.12 - Contributions to AOX: TTHM, HAA,, MCA, and MX in Otonabee River water

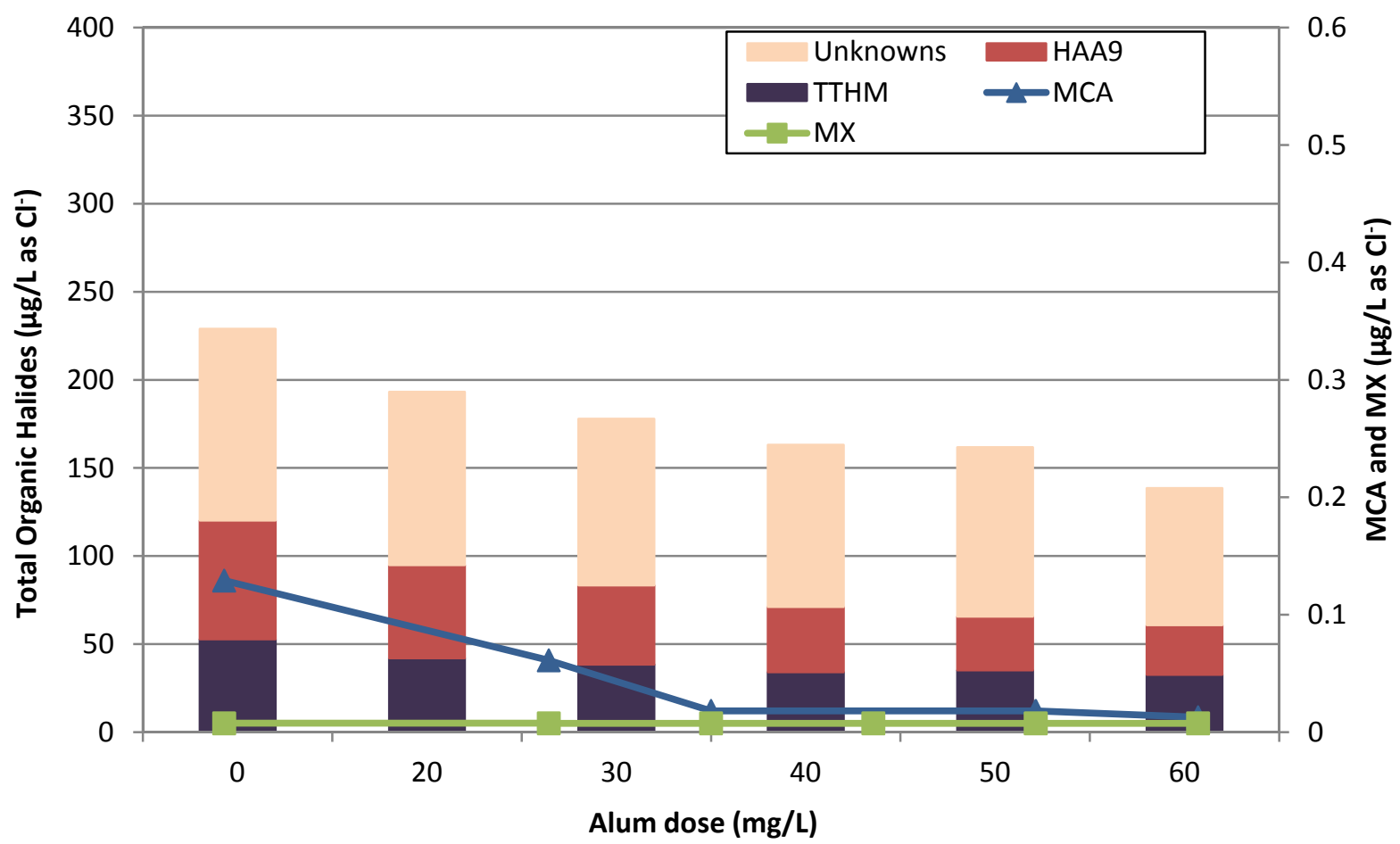

Figure 5.13 - Contributions to AOX: TTHM, HAA9, MCA, and MX in Lake Simcoe water 
Ottawa River had the highest initial TOC, DOC, $\mathrm{UV}_{254}$, and chlorine demand (in both raw and $20 \mathrm{mg}$ ) of the three waters (Figure 5.1 and Figure 5.2). Since the overall NOM content (as determined by TOC/DOC) at these two doses were the highest for the Ottawa River water, it was anticipated that DBP formation would be the highest as well. This was true for MCA and MX observed in the samples, but not for any of the other DBPs. In fact, Ottawa River showed the lowest concentration of HAAs (for all applied alum doses). Lake Simcoe water, which contained the lowest initial NOM content, had the highest concentrations of HAAs yet the lowest concentration of THMs. Otonabee River water had the highest concentrations of THMs but in contrast, the lowest amounts of MX $(<12 \mathrm{ng} / \mathrm{L}$ detection limit). These differing trends indicate that the removal of specific DBP precursors via coagulation is selective and varies by NOM composition. This could be attributed to interacting effects between the NOM fractions during coagulation, leading to selective removal that is dependent on the components of a specific water matrix.

\subsection{NOM Content and DBP Formation}

To determine the influence of each NOM fraction on the formation of individual groups of DBPs, correlations between NOM content/species and DBP concentrations were examined using multiple regression models. Past studies have reported positive correlations between NOM measurements (typically represented as DOC, TOC, $\mathrm{UV}_{254}$, and humic substances) and THM/HAA formation potential (Edzwald \& Tobiason, 1999; van Leeuwen et al., 2005; Wassink, 2010). In this study, NOM was separated into individual fractions and compared with the formation of AOX, THMs, HAAs, as well as MCA, MX and genotoxicity.

Chlorination experiments were completed in a batch system, with measured chlorine residuals of $1.0 \pm 0.5 \mathrm{mg} / \mathrm{L} \mathrm{Cl}_{2}$. Although these values are very close to the UFC guidelines $\left(1.0 \pm 0.4 \mathrm{mg} / \mathrm{L} \mathrm{Cl}_{2}\right)$, the fluctuations in measured chlorine residuals indicate variability in chlorine residuals between the samples. Since this could impact DBP formation, the measured chlorine residuals were taken into account during statistical analyses as a covariate to DBP formation in analysis of variance (ANOVA) tests. The coefficient of determination,

$\mathrm{R}^{2}$, is a measure of goodness of fit, in a regression model. $\mathrm{R}^{2}$ measures the proportion of 
variance or fluctuation of one variable (e.g. DBP concentration) that is predictable based on another variable (e.g. NOM presence). Correlations and $\mathrm{R}^{2}$ values between DBP formation and NOM content are shown in Table 5.6 to Table 5.8 for the Ottawa River, Otonabee River, and Lake Simcoe waters. Correlations with additional parameters such as TOC and LC-OCD measured DOC are provided in the Appendix 8.7.2, along with $\mathrm{p}$ values.

Based on analysis of variance (ANOVA) results, chlorine residual was shown to have no significant impact on DBP formation ( $p>0.01$; at a $99 \%$ confidence level), however the inclusion of this covariate improved the fit of some models (based on $\mathrm{R}^{2}$ values), and reduced Type I error (especially for correlations between DBPs and LMW acids and LMW neutrals). The interaction terms between each NOM parameter and chlorine residual were also observed to be insignificant ( $\mathrm{p}>0.01$ ) for all models with no contribution to fit, and were therefore not included in subsequent measures to simplify the models. Positive correlations indicate a statistical relationship between the reduction of DBP formation with that specific NOM parameter. As such, the correlations specify which NOM fractions are likely to serve as precursors to the DBPs measured.

Table 5.6 - Correlations $\left(\mathbf{R}^{2}\right)$ between DBP formation and water quality parameters Ottawa River water

\begin{tabular}{|c|c|c|c|c|c|c|c|c|c|c|}
\hline & & \multirow[b]{2}{*}{ 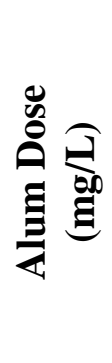 } & \multirow[b]{2}{*}{ 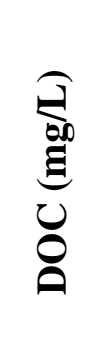 } & \multirow[b]{2}{*}{ 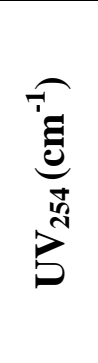 } & \multirow{2}{*}{ 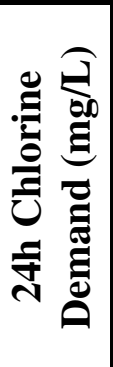 } & \multicolumn{5}{|c|}{$\begin{array}{c}\text { NOM Fractions - LC-OCD } \\
(\mathrm{mg} / \mathrm{L})\end{array}$} \\
\hline & & & & & & 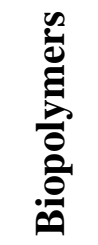 & 苗导导 & 曾 & $\begin{array}{l}\frac{n}{2} \\
\frac{Z}{4} \\
3 \\
\sum\end{array}$ & 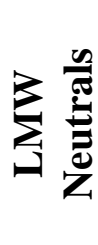 \\
\hline AOX $(\mu g / L)$ & $\mathbf{R}^{2}$ & 0.93 & 0.98 & 0.98 & 0.99 & 0.86 & 0.97 & 0.97 & 0.37 & 0.77 \\
\hline TTHM ( $\mu \mathrm{g} / \mathrm{L})$ & $\mathbf{R}^{2}$ & 0.97 & 0.98 & 0.96 & 0.96 & 0.92 & 0.96 & 0.96 & 0.33 & 0.88 \\
\hline HAA $_{9}(\mu \mathrm{g} / \mathrm{L})$ & $\mathbf{R}^{2}$ & 0.96 & 0.98 & 0.99 & 0.99 & 0.91 & 0.99 & 0.96 & 0.34 & 0.82 \\
\hline MCA (ng/L) & $\mathbf{R}^{2}$ & 0.88 & 0.90 & 0.92 & 0.88 & 0.89 & 0.91 & 0.85 & 0.38 & 0.81 \\
\hline MX (ng/L) & $\mathbf{R}^{2}$ & 0.97 & 0.93 & 0.93 & 0.97 & 0.78 & 0.92 & 0.96 & 0.40 & 0.66 \\
\hline $\begin{array}{l}\text { Genotoxicity } \\
\text { (TEQ4-NQO) }\end{array}$ & $\mathbf{R}^{2}$ & 0.73 & 0.80 & 0.79 & 0.88 & 0.60 & 0.77 & 0.92 & 0.27 & 0.48 \\
\hline
\end{tabular}

- Values in bold indicate correlations that are significant $(\mathrm{p}<0.01)$

- $\mathrm{n}=12$ for conventional NOM parameters, $\mathrm{n}=6$ for LC-OCD and AOX 
Table 5.7 - Correlations $\left(R^{2}\right)$ between DBP formation and water quality parameters Otonabee River water

\begin{tabular}{|c|c|c|c|c|c|c|c|c|c|c|}
\hline & \multirow{2}{*}{ 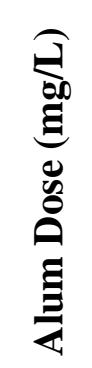 } & \multirow[b]{2}{*}{ 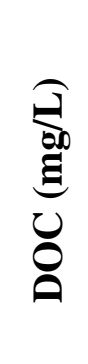 } & \multirow[b]{2}{*}{ 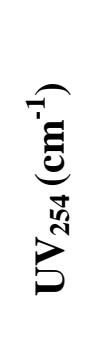 } & \multirow[b]{2}{*}{ 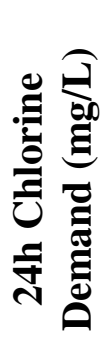 } & \multicolumn{5}{|c|}{$\begin{array}{c}\text { NOM Fractions - LC-OCD } \\
(\mathrm{mg} / \mathrm{L})\end{array}$} \\
\hline & & & & & & 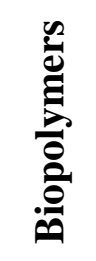 & 总 & 兽 & 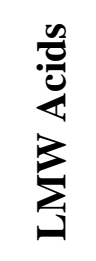 & 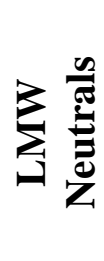 \\
\hline AOX $(\mu g / L)$ & $\mathbf{R}^{2}$ & 0.94 & 0.92 & 0.91 & 0.91 & 0.84 & 0.84 & 0.92 & 0.67 & 0.52 \\
\hline TTHM $(\mu \mathrm{g} / \mathrm{L})$ & $\mathbf{R}^{2}$ & 0.94 & 0.96 & 0.94 & 0.95 & 0.95 & 0.96 & 0.93 & 0.62 & 0.52 \\
\hline $\mathrm{HAA}_{9}(\mu \mathrm{g} / \mathrm{L})$ & $\mathbf{R}^{2}$ & 0.98 & 0.98 & 0.99 & 0.98 & 0.97 & 0.98 & 0.96 & 0.74 & 0.64 \\
\hline MCA (ng/L) & $\mathbf{R}^{2}$ & 0.96 & 0.96 & 0.95 & 0.95 & 0.92 & 0.94 & 0.94 & 0.71 & 0.67 \\
\hline MX (ng/L) & $\mathbf{R}^{2}$ & \multicolumn{9}{|c|}{ MX concentrations $<$ detection limit of $12 \mathrm{ng} / \mathrm{L}$} \\
\hline $\begin{array}{l}\text { Genotoxicity } \\
\text { (TEQ }\end{array}$ & $\mathbf{R}^{2}$ & 0.59 & 0.66 & 0.67 & 0.66 & 0.77 & 0.75 & 0.61 & 0.68 & 0.08 \\
\hline
\end{tabular}

- Values in bold indicate correlations that are significant $(p<0.01)$

- $\mathrm{n}=12$ for conventional NOM parameters, $\mathrm{n}=6$ for LC-OCD

Table 5.8 - Correlations $\left(\mathbf{R}^{2}\right)$ between DBP formation and water quality parameters Lake Simcoe water

\begin{tabular}{|c|c|c|c|c|c|c|c|c|c|c|}
\hline & \multirow{2}{*}{ 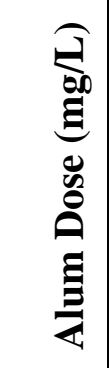 } & \multirow[b]{2}{*}{ 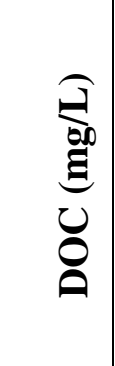 } & \multirow[b]{2}{*}{ 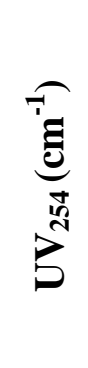 } & \multirow{2}{*}{ 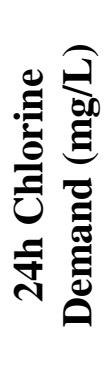 } & \multicolumn{5}{|c|}{$\begin{array}{c}\text { NOM Fractions - LC-OCD } \\
(\mathrm{mg} / \mathrm{L})\end{array}$} \\
\hline & & & & & & 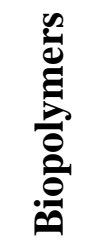 & 总 & 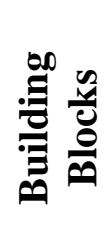 & 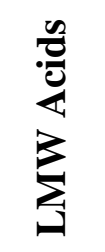 & 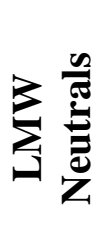 \\
\hline AOX $(\mu g / L)$ & $\mathbf{R}^{2}$ & 0.94 & 0.93 & 0.94 & 0.90 & 0.95 & 0.87 & 0.68 & 0.84 & 0.91 \\
\hline TTHM $(\mu \mathrm{g} / \mathrm{L})$ & $\mathbf{R}^{2}$ & 0.87 & 0.90 & 0.91 & 0.96 & 0.91 & 0.95 & 0.53 & 0.82 & 0.83 \\
\hline HAA $_{9}(\mu \mathrm{g} / \mathrm{L})$ & $\mathbf{R}^{2}$ & 0.99 & 0.99 & 0.99 & 0.93 & 0.99 & 0.88 & 0.78 & 0.79 & 0.90 \\
\hline MCA (ng/L) & $\mathbf{R}^{2}$ & 0.73 & 0.80 & 0.83 & 0.88 & 0.79 & 0.90 & 0.38 & 0.69 & 0.66 \\
\hline MX (ng/L) & $\mathbf{R}^{2}$ & 0.37 & 0.37 & 0.37 & 0.43 & 0.39 & 0.42 & 0.13 & 0.34 & 0.41 \\
\hline $\begin{array}{l}\text { Genotoxicity } \\
\text { (TEQ } \\
\text { 4-NQO) }\end{array}$ & $\mathbf{R}^{2}$ & 0.11 & 0.19 & 0.19 & 0.21 & 0.17 & 0.36 & 0.08 & 0.05 & 0.06 \\
\hline
\end{tabular}

- Values in bold indicate correlations that are significant $(\mathrm{p}<0.01)$

- $\mathrm{n}=12$ for conventional NOM parameters, $\mathrm{n}=6$ for LC-OCD 
TOC, DOC, and $\mathrm{UV}_{254}$ for all source waters were strongly correlated with AOX, TTHM, and $\mathrm{HAA}_{9}$ formation $\left(\mathrm{R}^{2}>0.9\right)$. Wassink (2010) reported linear correlations for TTHM and $\mathrm{HAA}_{9} 24 \mathrm{~h}$ formation potential to the same NOM parameters of $\mathrm{R}^{2}>0.84$ and $\mathrm{R}^{2}>0.94$ respectively. TOC, DOC, and $\mathrm{UV}_{254}$ also correlated well with MCA and MX formation $\left(\mathrm{R}^{2}>0.8\right.$, except for MX in Lake Simcoe samples).

Of the individual NOM fractions measured by LC-OCD, some differing trends were observed. For Ottawa River water, the reduction of all DBPs and genotoxicity was highly correlated with the reduction of humics and building blocks fractions, except for MCA, which was highly correlated with humics and biopolymers. For Otonabee River water, AOX reduction was associated with the reduction of building blocks; THMs, HAAs, and genotoxicity (though genotoxicity correlations were deemed insignificant, based on a $99 \%$ confidence level) were correlated with biopolymers and humics; and MCA with humics and building blocks. MX was not observed above the detection limit in Otonabee River samples. Correlations for Lake Simcoe water deviated from the results observed for Ottawa River and Otonabee River waters. For Lake Simcoe, AOX and HAA reductions were highly correlated with biopolymers and low molecular weight (LMW) neutrals; THMs and MCA with humics and biopolymers. Genotoxicity for Lake Simcoe samples was not correlated to any of the NOM parameters at the $99 \%$ confidence level. Wang et al. (2011) reported that although genotoxicity was not strongly correlated with TOC and $\mathrm{UV}_{254}$ in a study of chlorinated drinking waters in China, a positive relationship was found, which is consistent with correlations between genotoxicity and TOC/DOC/ $\mathrm{UV}_{254}$ observed in this study.

Overall, humic substances were strongly correlated with all DBPs measured in this study. This is consistent with the positive correlation found between humics and THM formation (Hua et al., 2007), as well as with HAA formation (Wassink, 2010). Of the remaining NOM fractions, biopolymers and building blocks were strongly correlated with DBP occurrence, indicating that these three fractions may serve as precursors to the DBPs measured. However, the variability amongst the three source waters, as evidenced by differences in DBP concentrations by type and correlation with other NOM fractions (e.g. LMW neutrals), suggests a complex interaction between NOM fractions that influences their removal by 
coagulation. A model of pooled results obtained from all three waters revealed a significant effect of water source on DBP formation, through an analysis of variance (ANOVA) test with Tukey's HSD post-hoc testing.

To assess the impact of the high (99\%) confidence imposed on the statistical relationships, confidence levels of $95 \%$ and $90 \%$ were also examined using $\mathrm{F}$ tests to evaluate correlation significance. Most relationships investigated were either very strongly correlated $(\mathrm{p}<0.01)$ or significantly not correlated $(\mathrm{p}>0.1)$; hence the reduction in confidence level did not noticeably influence conclusions.

\subsection{Comparison of Established DBPs (AOX/THMs/HAAs) with MX Compounds and Genotoxicity}

Correlations between NOM content and the formation of individual DBPs provided information concerning which NOM fractions may serve as precursors to specific DBPs. Humics, biopolymers, and building blocks provided the best correlations to the DBPs measured. Since detection and monitoring of DBPs in practice is often simplified to the measurement of THMs and HAAs (as surrogate DBPs), it is advantageous to identify additional correlations between other DBPs and THMs/HAAs. Detection of emerging DBPs (e.g. MCA and MX) is often costly, time consuming, and require extensive lab equipment. Thus, relating the formation of these DBPs to that of typically monitored DBPs can provide a means of predicting occurrence.

In this study, the level of fit was measured by the correlation coefficient, $R$ (Pearson product moment correlation coefficient) and validated by ANOVA hypothesis testing. $\mathrm{R}$ is used to measure the degree to which two variables are related. The use of $\mathrm{R}^{2}$ value was deemed not suitable when examining the statistical relationship between DBPs, as it implies a causal relationship (L. Duquette, personal communication, 2012). Correlations between the DBPs for each source water are shown in Table 5.9 to Table 5.11. Correlations were also analyzed 
by combining data obtained for all three sources. However, a given water source had a significant impact on correlations $(\mathrm{p}<0.01)$ and a combined data set was therefore not used.

Table 5.9 - Correlations (R) between specific DBPs formed - Ottawa River water

\begin{tabular}{|c|c|c|c|c|c|c|c|}
\hline & & $\begin{array}{c}\text { AOX } \\
(\mu \mathrm{g} / \mathrm{L})\end{array}$ & $\begin{array}{l}\text { TTHM } \\
(\mu \mathrm{g} / \mathrm{L})\end{array}$ & $\begin{array}{l}\mathbf{H A A}_{9} \\
(\mu \mathrm{g} / \mathrm{L})\end{array}$ & $\begin{array}{l}\text { MCA } \\
\text { (ng/L) }\end{array}$ & $\begin{array}{c}\text { MX } \\
\text { (ng/L) }\end{array}$ & $\begin{array}{l}\text { Genotoxicity } \\
\text { (TEQ }\end{array}$ \\
\hline AOX ( $(\mu \mathrm{g} / \mathrm{L})$ & $\mathbf{R}$ & & 0.94 & 0.99 & 0.99 & 0.99 & 0.94 \\
\hline TTHM( $(\mu \mathrm{g} / \mathrm{L})$ & $\mathbf{R}$ & 0.94 & & 0.96 & 0.88 & 0.90 & 0.87 \\
\hline $\mathrm{HAA}_{9}(\mu \mathrm{g} / \mathrm{L})$ & $\mathbf{R}$ & 0.99 & 0.96 & & 0.95 & 0.96 & 0.91 \\
\hline MCA (ng/L) & $\mathbf{R}$ & 0.99 & 0.88 & 0.95 & & 0.91 & 0.91 \\
\hline MX (ng/L) & $\mathbf{R}$ & 0.99 & 0.90 & 0.96 & 0.91 & & 0.95 \\
\hline $\begin{array}{l}\text { Genotoxicity } \\
\text { (TEQ }\end{array}$ & $\mathbf{R}$ & 0.94 & 0.87 & 0.91 & 0.91 & 0.95 & \\
\hline
\end{tabular}

- Values in bold indicate correlations that are significant $(\mathrm{p}<0.01)$

- $\mathrm{n}=12$ for TTHM, $\mathrm{HAA}_{9}, \mathrm{MCA}$, and MX; $\mathrm{n}=6$ for AOX and genotoxicity

Table 5.10 - Correlations (R) between species of DBPs formed - Otonabee River water

\begin{tabular}{|c|c|c|c|c|c|c|c|}
\hline & & $\begin{array}{c}\text { AOX } \\
(\mu g / L)\end{array}$ & $\begin{array}{l}\text { TTHM } \\
(\mu \mathrm{g} / \mathrm{L})\end{array}$ & $\begin{array}{l}\text { HAA9 } \\
(\mu \mathrm{g} / \mathrm{L})\end{array}$ & $\begin{array}{l}\text { MCA } \\
\text { (ng/L) }\end{array}$ & MX (ng/L) & $\begin{array}{l}\text { Genotoxicity } \\
\text { (TEQ4-NQO) }\end{array}$ \\
\hline AOX ( $(\mu \mathrm{g} / \mathrm{L})$ & $\mathbf{R}$ & & 0.89 & 0.95 & 0.92 & \multirow{4}{*}{ 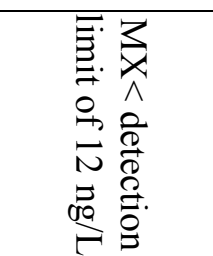 } & 0.28 \\
\hline $\begin{array}{l}\text { TTHM } \\
(\mu \mathrm{g} / \mathrm{L})\end{array}$ & $\mathbf{R}$ & 0.89 & & 0.95 & 0.94 & & 0.42 \\
\hline HAA $_{9}(\mu \mathrm{g} / \mathrm{L})$ & $\mathbf{R}$ & 0.95 & 0.95 & & 0.97 & & 0.27 \\
\hline MCA (ng/L) & $\mathbf{R}$ & 0.92 & 0.94 & 0.97 & & & 0.06 \\
\hline MX (ng/L) & $\mathbf{R}$ & \multicolumn{6}{|c|}{ MX concentrations $<$ detection limit of $12 \mathrm{ng} / \mathrm{L}$} \\
\hline $\begin{array}{l}\text { Genotoxicity } \\
\text { (TEQ4-NQO) }\end{array}$ & $\mathbf{R}$ & 0.28 & 0.42 & 0.27 & 0.06 & & \\
\hline
\end{tabular}

- Values in bold indicate correlations that are significant $(\mathrm{p}<0.01)$

- $\mathrm{n}=12$ for TTHM, $\mathrm{HAA}_{9}, \mathrm{MCA}$, and MX; $\mathrm{n}=6$ for AOX and genotoxicity

Table 5.11 - Correlations (R) between species of DBPs formed - Lake Simcoe water

\begin{tabular}{|c|c|c|c|c|c|c|c|}
\hline & & $\begin{array}{c}\text { AOX } \\
(\mu \mathrm{g} / \mathrm{L})\end{array}$ & $\begin{array}{l}\text { TTHM } \\
(\mu \mathrm{g} / \mathrm{L})\end{array}$ & $\begin{array}{l}\text { HAA9 }_{9} \\
(\mu \mathrm{g} / \mathrm{L})\end{array}$ & $\begin{array}{l}\text { MCA } \\
\text { (ng/L) }\end{array}$ & $\begin{array}{c}\text { MX } \\
\text { (ng/L) }\end{array}$ & $\begin{array}{l}\text { Genotoxicity } \\
\text { (TEQ } 4 \text {-NQO) }\end{array}$ \\
\hline AOX $(\mu \mathrm{g} / \mathrm{L})$ & $\mathbf{R}$ & & 0.92 & 0.95 & 0.85 & 0.74 & 0.01 \\
\hline TTHM $(\mu \mathrm{g} / \mathrm{L})$ & $\mathbf{R}$ & 0.92 & & 0.95 & 0.91 & 0.56 & 0.13 \\
\hline $\mathrm{HAA}_{9}(\mu \mathrm{g} / \mathrm{L})$ & $\mathbf{R}$ & 0.95 & 0.95 & & 0.86 & 0.59 & 0.05 \\
\hline MCA (ng/L) & $\mathbf{R}$ & 0.85 & 0.91 & 0.86 & & 0.39 & 0.60 \\
\hline MX (ng/L) & $\mathbf{R}$ & 0.74 & 0.56 & 0.59 & 0.39 & & 0.00 \\
\hline $\begin{array}{c}\text { Genotoxicity } \\
\text { (TEQ4-NQO) }\end{array}$ & $\mathbf{R}$ & 0.01 & 0.13 & 0.05 & 0.60 & 0.00 & \\
\hline
\end{tabular}

- Values in bold indicate correlations that are significant $(\mathrm{p}<0.01)$

- $\mathrm{n}=12$ for AOX, TTHM, HAA, MCA, and MX; $\mathrm{n}=6$ for genotoxicity 
For Ottawa River water, MCA and MX formation was highly correlated with AOX. As AOX is a measure of the total halide content of the water, it is expected to have a high correlation value with all DBPs as shown for both THMs and HAAs. MCA and MX were more highly correlated with HAAs than THMs. There was also a strong relationship between MCA and MX. Genotoxicity was only statistically correlated with AOX and MX formation, which validates findings for the genotoxicity test of individual DBPs (see Section 5.7). Takanashi et al. (2009) reported a positive correlation between genotoxicity and HAA concentrations in treated waters, but no correlations with THMs.

For Otonabee River water, the same high correlation trend of individual DBPs with AOX was observed. Similarly, MCA was most correlated with HAAs. MX was below the detection limit for Otonabee River samples. Genotoxicity was shown to be not correlated with AOX, THMs, or HAAs $(\mathrm{p}>0.01)$.

For Lake Simcoe samples, MX was well correlated with all other DBPs. AOX was again highly correlated to individual DBPs (other than MX). Interestingly, MCA was more highly correlated to THMs than HAAs, contrary to what was observed in the two other waters. Genotoxicity did not correlate with any DBPs.

\subsection{Genotoxicity Relationships}

Genotoxicity was analyzed using the SOS Chromotest. The effect of DNA damaging agents was quantified photometrically by the ratio of $\beta$-galactosidase ( $\beta$-gal) activity to alkaline phosphatase (AP) activity.

The serial, step-wise dilution (total of six dilutions for each sample) used in the SOS Chromotest bioassay defines equivalent concentrations (in eqmL/well) for each dilution. At a given equivalent concentration, IF values can be used to quantitatively compare the effects of different agents (water samples) on SOS response in the bioassay. IF values for jar tested waters from the three sources are presented in Figure 5.14, at an equivalent concentration of 16.5 eqmL/well. IF values greater than 2.0 are defined as genotoxic. Genotoxic potential 
decreased for alum dosages $\leq 40 \mathrm{mg} / \mathrm{L}$, signifying that coagulation was effective at removing genotoxicity precursors. However, a general parabolic trend in genotoxicity reduction was observed for both Ottawa River and Lake Simcoe waters. After a $40 \mathrm{mg} / \mathrm{L}$ dose, the genotoxic response was shown to increase. Otonabee River samples showed a general decrease in IF with increasing alum dosages.

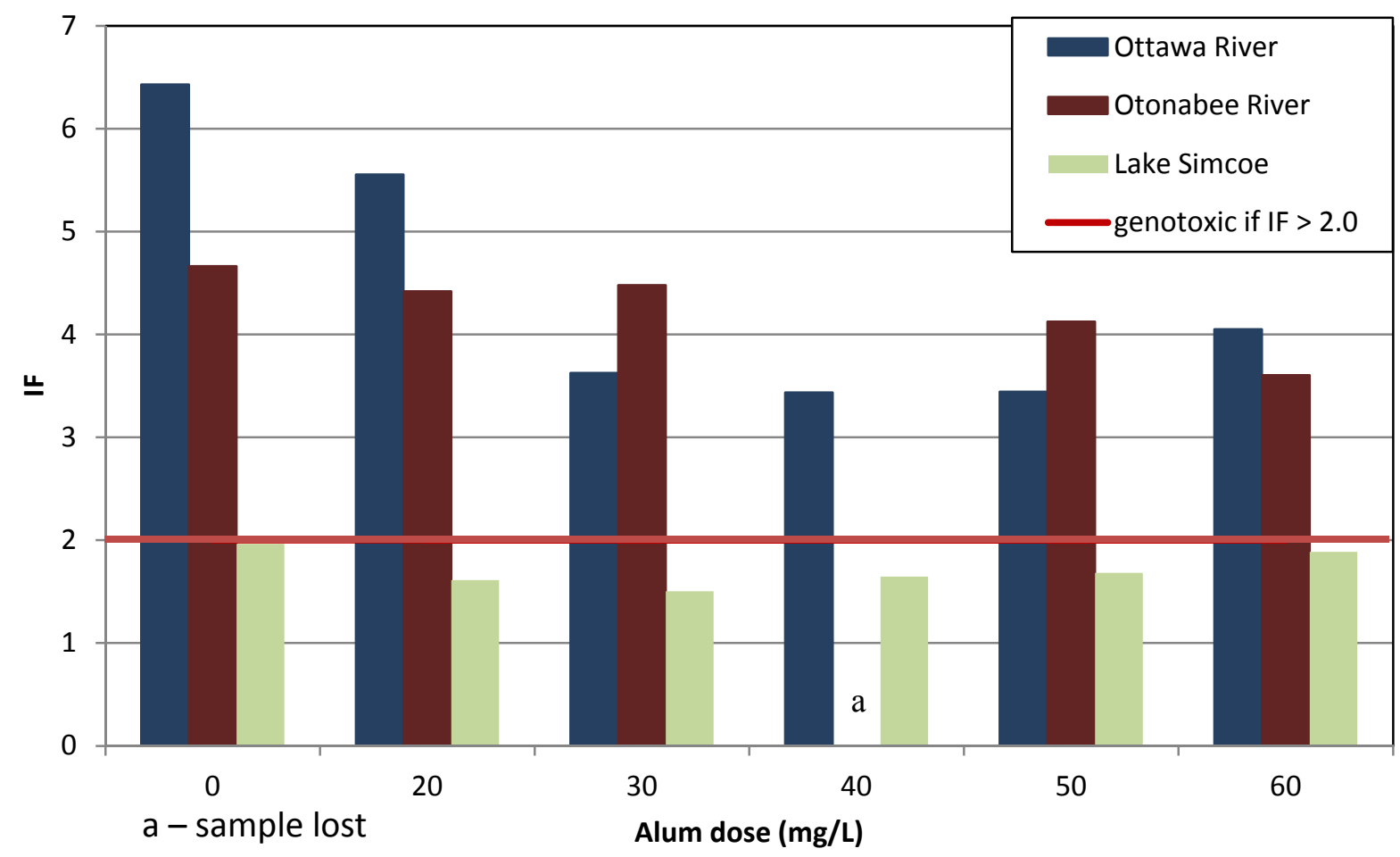

Figure 5.14 - SOS Chromotest IF values for three coagulated and chlorinated waters at an equivalent concentration of $16.5 \mathrm{eqmL} /$ well

A toxicity equivalent concentration $\left(\mathrm{TEQ}_{4-\mathrm{NQO}}\right)$ was calculated to provide additional insight regarding IF values. TEQ ${ }_{4-\mathrm{NQO}}$ represents the genotoxicity of each sample, relative to the genotoxicity of carcinogen 4-NQO. For example, if a sample was as genotoxic as 4-NQO, it would have a $\mathrm{TEQ}_{4-\mathrm{NQO}}$ value of 1.0. $\mathrm{TEQ}_{4-\mathrm{NQO}}$ values calculated following chlorination are presented in Figure 5.15. 


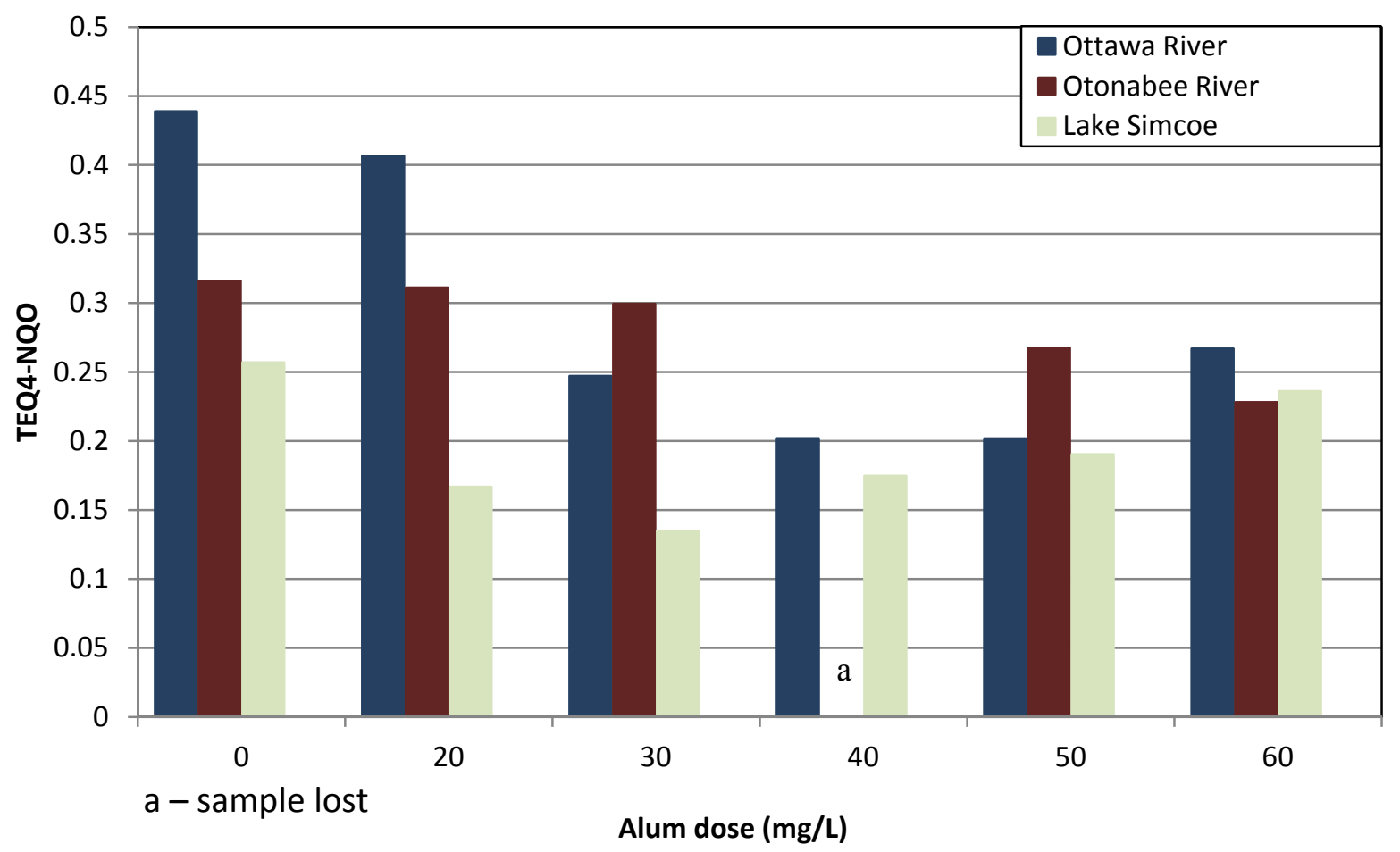

Figure 5.15 - Genotoxicity (TEQ 4 -NQo) of coagulated and chlorinated samples for three source waters. ( 1 TEQ $_{4-\mathrm{NQO}}$ is equivalent to toxicity of positive control 4-NQO at an equivalent concentration)

Ottawa River water had the highest $\mathrm{TEQ}_{4-\mathrm{NQO}}$ values, while Lake Simcoe had the lowest. In comparison to $4-\mathrm{NQO}$, all samples were $<0.5$ of the relative genotoxicity.

In addition to water extracts originating from coagulation and chlorination tests for the three source waters, individual DBPs were examined using the SOS Chromotest. DBP standards were prepared in dimethyl sulfoxide (DMSO) and tested using the bioassay. TTHM, HAA, and MCA were added at $8 \mathrm{mg} / \mathrm{L}, 8 \mathrm{mg} / \mathrm{L}$, and $500 \mathrm{ng} / \mathrm{L}$ respectively. $\mathrm{MX}$ was added at 10 , 25 , and $50 \mathrm{ng} / \mathrm{L}$. Concentrations are provided as an equivalent concentration in $2 \mathrm{~L}$ water samples. Interestingly, $\mathrm{MX}$ was the only compound with a positive $\beta$-gal activity level in the SOS Chromotest, indicating genotoxic potential. These results appear to confirm that the genotoxicity observed in the three chlorinated waters was not due to THMs, HAAs, or MCA. The sole DBP measured that contributed to genotoxicity was MX. 
The relationship between genotoxic response and spiked MX concentration was used to quantify the contribution of $\mathrm{MX}$ to the toxicity equivalent concentration (TEQ4-NQO) of each test sample (Table 5.12). The cause for the remaining genotoxic effect is unknown and may potentially be attributed to unidentified DBPs formed during disinfection. The contribution of $\mathrm{MX}$ to $\mathrm{TEQ}_{4-\mathrm{NQO}}$ can also be compared with the contribution of MX to AOX. Observed MX concentrations in samples were converted to $\mu \mathrm{g} / \mathrm{L}$ as $\mathrm{Cl}^{-}$and compared with the total AOX found. This procedure also allowed the unknown portion of AOX to be quantified. The contribution of MX and "unknown" portions to genotoxicity and AOX for the Ottawa River are shown in Table 5.12. Note that MX was not detected in Otonabee River samples.

Table 5.12 - Percent contributions of MX and unknown portions to toxicity equivalent concentration (TEQ $\left.{ }_{4-N Q O}\right)$ and $\mathrm{AOX}$ in Ottawa River water

\begin{tabular}{|c|c|c|c|c|c|}
\hline \multirow{2}{*}{$\begin{array}{c}\text { Alum dose } \\
(\mathbf{m g} / \mathbf{L})\end{array}$} & $\begin{array}{c}\text { Concentration } \\
\text { (ng/L) }\end{array}$ & \% TEQ $_{\text {4-NQO }}$ & \% AOX & \% TEQ & \multicolumn{2}{c|}{ Unknowns } & \% AOX \\
\hline $\mathbf{0}$ & 20 & 41 & 0.003 & 59 & 55.0 \\
\hline $\mathbf{2 0}$ & 18 & 40 & 0.003 & 60 & 52.5 \\
\hline $\mathbf{3 0}$ & 14 & 55 & 0.005 & 45 & 33.0 \\
\hline $\mathbf{4 0}$ & 14 & 67 & 0.006 & 33 & 39.7 \\
\hline $\mathbf{5 0}$ & 14 & 67 & 0.006 & 33 & 48.6 \\
\hline $\mathbf{6 0}$ & 14 & 51 & 0.006 & 49 & 47.9 \\
\hline
\end{tabular}

Although less than $0.010 \%$ of the total AOX present, MX accounted for $40-67 \%$ of the genotoxicity in Ottawa River water samples. This highlights its genotoxic potential, even at trace levels found in chlorinated drinking water. Unknown fractions of AOX comprised 33$55 \%$ of the total measured AOX and accounted for $32-49 \%$ of the genotoxicity.

This trend was also similar for Lake Simcoe water samples; however lower concentrations of MX (near detection limit of $12 \mathrm{ng} / \mathrm{L}$ ) may have introduced more variability and influenced the calculated contributions. As well, in samples associated with alum dosages of 20 and 60 mg/L, MX was not detected in Lake Simcoe samples. The contributions of MX and unknowns to TEQ 4 -NQO and AOX are shown in Table 5.13. 
Table 5.13 - Percent contributions of MX and unknown portions to toxicity equivalent concentration (TEQ $\left.{ }_{4-N Q O}\right)$ and AOX in Lake Simcoe water

\begin{tabular}{|c|c|c|c|c|c|}
\hline \multirow{2}{*}{$\begin{array}{c}\text { Alum Dose } \\
\text { (mg/L) }\end{array}$} & $\begin{array}{c}\text { Concentration } \\
(\mathbf{n g} / \mathbf{L})\end{array}$ & \% TEQ $_{\text {4-NQO }}$ & \% AOX & \% TEQ $4-$ QQo & \% AOX \\
\hline $\mathbf{0}$ & 15.5 & 57 & 0.003 & 43 & 47.5 \\
\hline $\mathbf{2 0}$ & n.d. & n.c. & n.c. & n.c. & 50.9 \\
\hline $\mathbf{3 0}$ & 15.3 & 107 & 0.004 & -7 & 53.1 \\
\hline $\mathbf{4 0}$ & 15.4 & 83 & 0.005 & 17 & 56.3 \\
\hline $\mathbf{5 0}$ & 15.3 & 76 & 0.005 & 24 & 59.4 \\
\hline $\mathbf{6 0}$ & n.d. & n.c. & n.c. & n.c. & 56.2 \\
\hline
\end{tabular}

n.d. $=$ not detected; n.c. $=$ not calculated 


\section{O CONCLUSIONS}

Coagulation jar tests using alum were conducted on three source waters (Ottawa River, Otonabee River, and Lake Simcoe). Samples were analyzed for NOM using conventional parameters (TOC, DOC, and $\mathrm{UV}_{254}$ ) and characterized for specific NOM fractions using LCCD. Following chlorination, the concentrations of DBPs (AOX, THMs, HAAs, MCA, and $\mathrm{MX}$ ) were determined as well as the potential to cause genotoxicity.

Bench-scale tests with the three source waters showed decreases in NOM content and DBP formation with increasing alum dosages. USEPA enhanced coagulation target doses were estimated and DBP formation at this dose was comparable to reported occurrence levels. Coagulation was more effective for overall NOM removal (measured by DOC removal) in higher DOC waters (Ottawa River, Otonabee River) compared with a lower DOC water (Lake Simcoe). When comparing DBP formation results for the three waters, it appeared that the reactivity of chlorine with NOM fractions was dependent on NOM speciation. Ottawa River water had the highest initial DOC, yet the lowest concentration of HAAs following chlorination. Lake Simcoe water, with the lowest initial DOC, had the highest concentration of THMs but the lowest concentration of HAAs.

Correlations between DBP formation and NOM content showed that humics, building blocks, and biopolymers (in descending order) were most correlated with all DBP formation. Correlations between MCA/MX and THM/HAA formation showed a possible relationship between MCA/MX occurrences with HAAs. NOM characteristics and possible interaction between fractions were observed to influence DBP formation patterns. ANOVA tests with Tukey's HSD post-hoc testing revealed the significance of water source characteristics on DBP formation.

Genotoxicity was observed to decrease with alum dosages up to $40 \mathrm{mg} / \mathrm{L}$. However, beyond this point the genotoxic response showed a slight increase. Individual DBPs were examined for genotoxic potential and it was found that of the measured DBPs, MX was the only significant contributor. To provide further insight, the contribution of individual DBPs measured (molar mass conversion) to AOX was also compared. MX comprised less than 
$0.001 \%$ of AOX content but accounted for $40-67 \%$ of the genotoxicity in Ottawa River water samples, leaving a portion of genotoxicity unaccounted for. Approximately $40 \%$ of AOX was attributed to undetermined DBPs, which may have been associated with the remaining genotoxicity measured.

\subsection{Recommendations for Future Work}

To expand on the results of this study and for further research, the following recommendations are made:

1. Improve the analytical methods for MCA and MX to allow for detection limits below $1 \mathrm{ng} / \mathrm{L}$. This is especially important for MX, which is often present at approximately low levels. Improved detection of MX compounds would allow for experiments that may reveal information on how these compounds are formed.

2. More sophisticated statistical analyses, such as principal component analysis (PCA), should be performed on data to help relate NOM content with DBP formation. This could lead to specific DBP precursor identification and provide additional information concerning formation pathways.

3. Water source was found to be a significant factor in DBP and NOM correlations. More information is needed regarding how these interactions influence specific DBP formation.

4. Genotoxicity results revealed the genotoxic effects of chlorinated waters. Further tests are required to establish additional causes of the genotoxicity. In vivo tests may provide more context to the effects observed. 


\section{O REFERENCES}

APHA, AWWA, \& WEF (2005) Standard Methods for the Examination of Water \& Wastewater, $21^{\text {st }}$ Edition. American Public Health Association: Washington, DC.

American Water Works Association (AWWA) (2000). Manual of Water Supply Practices: Operational Control of Coagulation and Filtration Processes $-2^{\text {nd }}$ Edition. Conwell, D.A. and Hiltebrand, D.J. (Eds). AWWA: Denver, CO.

Andrews, R. C., Daignault, S. A., Laverdure, C., Williams, D. T., \& Huck, P. M. (1990). Occurrence of the mutagenic compound ' $\mathrm{MX}$ ' in drinking water and its removal by activated carbon. Environmental Technology. 11(7), 685 - 694.

Bond, T.; Henriet, O.; Goslan, E.H.; Parsons, S.A.; \& Jefferson, B. (2009). Disinfection byproduct formation and fractionation behavior of natural organic matter surrogates. Environmental Science and Technology. 43, 5982-5989.

Brunborg, G.; Holme, J.A.; Soderlund, E.J.; Hongslo, J.K.; Vartiainen, T.; Lotjonen, S.; \& Becher, G. (1991). Genotoxic effects of the drinking water mutagen 3-chloro-4(dichloromethyl)-5-hydroxy-2 $(5 \mathrm{H})$-furanone $(\mathrm{MX})$ in mammalian cells in vitro and in rates in vivo. Mutation Research. 260(1), 55-64.

Budd, G.C.; Hess, A.F.; Shorney-Darby, H.; Neemann, J.J.; Spencer, C.M.; Bellamy, J.D. \& Hargette, P.H. (2004). Coagulation applications for new treatment goals. Journal AWWA. 96(2), 102-113.

Bull, R. (1993). Toxicity of disinfectants and disinfection byproducts. In G. Crawn (Ed.), Safety of Water Disinfection: Balancing Chemical and Microbial Risks (pp. 239-256). Washington, D.C.: ILSI Press.

Chow, C.W.K.; Fabris, R.; van Leeuwen, J.; Wang, D.; \& Drikas, M. (2008). Assessing natural organic matter treatability using high performance size exclusion chromatography. Environmental Science and Technology. 42, 6683-6689.

DeMarini, D. M., Abu-Shakra, A., Felton, C. F., Patterson, K. S., \& Shelton, M. L. (1995). Mutation spectra in Salmonella of chlorinated, chloraminated, or ozonated drinking water extracts: comparison to MX. Environmental and Molecular Mutagenesis. 26, 270-285.

Duan, J. \& Gregory, J. (2003). Coagulation by hydrolysing metal salts. Advances in Colloid and Interface Science. 100-102, 475-502.

Environmental Bio-Deterction Products Inc., EBPI .(2011). User's Manual for the SOSChromoTest $^{\mathrm{TM}}$ Basic Kit, Version 6.4. Mississauga, ON.

Escher, B. \& Leusch, F. (2011) Bioanalytical Tools in Water Quality Assessment. IWA Publishing: London, UK.

Edzwald, J.K. (1993) Coagulation in drinking water treatment: particles, organics and coagulants. Water Science and Technology. 27(11), 21-35. 
Edzwald, J.K. \& Tobiason, J.E. (1999) Enhanced coagulation: US requirements and a broader view. Water Science and Technology. 40(9), 63-70.

Fabris, R.; Chow, C.W.K.; Drikas, M.; \& Eikebrokk, B. (2008) Comparison of NOM character in selected Australian and Norwegian drinking waters. Water Research. 42, 4188-4196.

Fekadu, K.; Parzefall, W.; Kronbery, L.; Franzen, R.; Schulte-Hermann, R.; \& Knasmuller, S. (1994). Induction of genotoxic effects by chlorohydroxyfuranones, byproducts of water disinfection, E. coli K-12 cells recovered from various organs of mice. Environmental and Molecular Mutagenesis. 24(4), 317-324.

Gold, L.S.; Ames, B.N.; Bernstein, L.; Blumenthal, M.; Chow, K. et al. (2010) The Carcinogenic Potency Database Project (CPDB) - 3-chloro-4-(dichloromethyl)-5hydroxy-2(5H)-furanone. University of California, Berkeley. (Retrieved from: http://potency.berkeley.edu/chempages/3-CHLORO-4-(DICHLOROMETHYL)-5HYDROXY-2(5H)-FURANO.html on Dec 12, 2012)

Health Canada (2006). Guidelines for Canadian drinking water quality: Guideline Technical Document - Trihalomethanes. (Retrieved from: www.hc-sc.gc.ca/ewhsemt/pubs/water-eau/trihalomethanes/index-eng.php on May 14, 2011).

Health Canada (2008). Guidelines for Canadian drinking water quality: Guideline Technical Document - Haloacetic acids. (Retrieved from: www.hc-sc.gc.ca/ewhsemt/pubs/water-eau/haloaceti/index-eng.php on May 14, 2011).

Hemming, J., Holmbom, B., Reunanen, M., \& Kronberg, L. (1986). Determination of the strong mutagen 3-chloro-4-(dichloromethyl)-5-hydroxy-2(5H)-furanone in chlorinated drinking and humic waters. Chemosphere. 15(5), 549-556.

Holmbom, B. R., Voss, R. H., Mortimer, R. D., \& Wong, A. (1981). Isolation and identification of an Ames-mutagenic compound in kraft chlorination effluents. Taffi. 64, 172-174.

Holmbom, B., Voss, R. H., Mortimer, R. D., \& Wong, A. (1984). Fractionation, isolation, and characterization of Ames mutagenic compounds in kraft chlorination effluents. Environmental Science and Technology. 18(5), 333-337.

Holme, J.A.; Haddeland, U.; Haug, K.; \& Brunborg, G. (1999). DNA damage induced by the drinking water mutagen 3-chloro-4-(dichloromethyl)-5-hydroxy-2(5H)-furanone (MX) in mammalian cells in vitro and in mice. Mutation Research. 441(1), 145-153.

Hrudey, S.E. (2009). Chlorination disinfection by-products, public health risk tradeoff and me. Water Research. 43, 2057-2092.

Hua, G. \& Reckhow D.A. (2007). Characterization of disinfection byproduct formation based on hydrophobicity and molecular size. Environmental Science and Technology. 41, 3309-3315.

Huber, S.A. \& Frimmel, F.H. (1992). A liquid chromatographic system with multi-detection for the direct analysis of hydrophilic organic compounds in natural waters. Fresenius' Journal of Analytical Chemistry. 342, 198-200. 
Huber, S.A.; Balz, A.; \& Abert, M. (2011) Characterisation of aquatic humic and non-humic matter with size-exclusion chromatography-organic carbon detection-organic nitrogen detection (LC-OCD-OND). Water Research. 45, 879-885.

IARC (2004). International Agency for Research on Cancer Monographs on the Evaluation of Carcinogen Risks to Humans, Volume 84 Some Drinking Water Disinfectants and Contaminants, including Arsenic. Lyon, France. (Retrieved from: http://monographs.iarc.fr/ENG/Monographs/vol84/mono84-12.pdf on Dec 12, 2012)

Ishiguro, Y., LaLonde, R. T., Dence, C. W., \& Santodonato, J. (1987). Mutagenicity of chlorine-substituted furanones and their inactivation by reaction with nucleophiles. Environmental Toxicology \& Chemistry. 6(12), 935-946.

Jacangelo, J.G.; DeMarco, J.; Owen, D.M.; \& Randtke, S.J. (1995). Selected processes for removing NOM: an overview. Journal AWWA. 87 (1), 64-77.

Jarvis, P.; Jefferson, B; \& Parsons, S.A. (2004). Characterizing natural organic matter flocs. Water Science and Technology: Water Supply. 4(4), 79-87.

Jiang, J.Q. \& Graham, J.D. (1996). Enhanced coagulation using Al/Fe(III) coagulants: effect of coagulant chemistry on the removal of colour-causing NOM. Environmental Technology. 17, 937-950.

Karanfil, T., Krasner, S., Westerhoff, P., \& Xie, Y. (2008). Recent advances in disinfection by-product formation, occurrence, control, health effects, and regulations. In $\mathrm{T}$. Karanfil, S. W. Krasner, P. Westerhoff, \& Y. Xie (Eds.), Disinfection By-Products in Drinking Water, ACS Symposium Series 995 (pp. 2-19). Washington, D.C.: American Chemical Society.

Kocak, E.; Yetilmezsoy, K.; Gonullu, M.T.; \& Petek, M. (2010). A statistical evaluation of the potential genotoxic activity in the surface waters of the Golden Horn Estuary. Marine Pollution Bulletin. 60, 1708-1717.

Komulainen, H.; Kosma, V.-M.; Vaittinen, S.-L.; Vartiainen, T.; Kaliste-Korhonen, E.; Lotjonen, S.; Tuominen, R.K.; \& Tuomisto, J. (1997). Carcinogenicity of the drinking water mutagen 3-Chloro-4-(dichloromethyl)-5-hydroxy-2 $(5 \mathrm{H})$-furanone in the rat. Journal of the National Cancer Institute. 89(12), 848 - 856.

Krasner, S. W., Weinberg, H. S., Richardson, S. D., Pastor, S. J., Chinn, R., Sclimenti, M. J., et al. (2006). Occurrence of a new generation of disinfection byproducts. Environmental Science and Technology. 40 (23), 7175-7185.

Krasner, S. W. (2009). The formation and control of emerging disinfection by-products of health concern. Philosophical Transactions of the Royal Society A. 367, 4077-4095.

Kronberg, L., \& Franzen, R. (1993). Determination of chlorinated furanones, hydroxyfuranones, and butenedioic acids in chlorine-treated water and in pulp bleacking liquor. Environmental Science and Technology. 27 (9), 1811-1818.

Kronberg, L., Holmbom, B., Reunanen, M., \& Tikkanen, L. (1988). Identification and quantification of the Ames mutagenic compound 3-chloro-4-(dichloromethyl)-5hydroxy-2(5H)-furanone and of its geometric isomer (E)-2-chloro-3- 
(dichloromethyl)-4-oxobutenoic acid in chlorine-treated humic water and drinking water extract. Environmental Science and Technology. 22(9), 1097-1103.

Kubwabo, C., Stewart, B., Gauthier, S. A., \& Gauthier, B. R. (2009). Improved derivatization technique for gas chromatography-mass spectrometry determination of 3-chloro-4(dichloromethyl)-5-hydroxy-2(5H)-furanone in drinking water. Analytica Chimica Acta. 649, 222-229.

Matilainen, A.; Vepsalainen, M.; \& Sillanpaa, M. (2010). Natural organic matter removal by coagulation during drinking water treatment: a review. Advances in Colloid and Interface Science. 159, 189-197.

Meier, J., Knohl, R., Coleman, W., Ringhand, H., Munch, J., Kaylor, W., et al. (1987). Studies on the potent bacterial mutagen, 3-chloro-4-(dichloromethyl)-5-hydroxy$2(5 \mathrm{H})$-furanone: aqueous stability, XAD recovery and analytical determination in drinking water and in chlorinated humic acid solutions. Mutation Research. 189, 363373.

Mesdaghinia, A.; Rafiee, M.T.; Vaezi, F.; Mahvi, A.; Torabian, A. \& Ghasri, A. (2006). Control of disinfection by products formation potential by enhanced coagulation. International Journal of Environmental Science and Technology. 2(4), 335-342.

McDonald, T.A. \& Komulainen, H. (2005). Carcinogenicity of the chlorination disinfection by-product MX. Journal of Environmental Science and Health Part C, 23, 163-214.

Myllykangas, T.; Nissinen, T.K.; Maki-Paakkanen, J.; Kirvonen, A.; Vartiainen, T. (2003). Bromide affecting drinking water mutagenicity. Chemosphere. 53(7), 745-756.

Nikolaou, A.D. \& Lekkas, T.D. (2001). The role of natural organic matter during formation of chlorination by-products: a review. Acta hydrochimica et hydrobiologicam. 29(23), 63-77.

OEHHA (2001). No Significant Risk Level (NSRL) for the Proposition 65 Carcinogen MX (3-chloro-4-(dichloromethyl)5-hydroxy-2(5H)-furanone). Office of Environmental Health Hazard Assessment - Reproductive and Cancer Hazard Assessment Section, Californica Environmental Protection Agency, Oakland, CA. http://www.oehha.ca.gov/prop65/law/pdf_zip/MX_MSRL.pdf.

Onstad, G. D., \& Weinberg, H. S. (2005). Evaluation of the stability and analysis of halogenated furanones in disinfected drinking waters. Analytica Chimica Acta. 534, 281-292.

Onstad, G. D., Weinberg, H. S., \& Krasner, S. W. (2008). Occurrence of halogenated furanones in U.S. drinking waters. Environmental Science and Technology. 42(9), 3341-3348.

Plewa, M. J., Wagner, E. D., Richardson, S. D., Thruston, J. A., Woo, Y.-T., \& McKague, A. B. (2004). Chemical and Biological Characterization of Newly Discovered Iodoacid Drinking Water Disinfection Byproducts. Environmental Science and Technology. 38 (18), 4713-4722. 
Quillardet, P.; Huisman, O.; D'Ari, R.; \& Hofnung, M. (1982). SOS chromotest, a direct assay of inductionof an SOS function in Escherichia coli K-12 to measure genotoxicity. Proceedings of the National Academy of Sciences. USA. 79, 5971-5975.

Ramos, I., Llovaras, M., Solans, X., Huici, A., \& Messeguer, A. (2000). Brominated analogs of 3-chloro-4-(dichloromethyl)-5-hydroxy-2(5H)-furanone: preparation of 3-chloro-4(bromochloromethyl)-5-hydroxy-2(5H)-furanone and mutagenicity studies. Environmental Toxicology and Chemistry. 19(11), 2631-2636.

Rantakokko, P.; Yritys, M.; \& Vartiainen, T. (2004). Matrix effects in the gas chromatographic-mass spectrometric determination of brominated analogues of 3chloro-4-(dichloromethyl)-5-hydroxy-2(5H)-furanone. Journal of Chromatography A. $1028,179-188$.

Rezemini, A. L., Vaz, J. M., \& Carvalho, L. R. (2008). Solid-phase microextraction for the determination of 3-chloro-4-(dichloromethyl)-5-hydroxy-2(5H)-furanone in water. $J$. Braz. Chem. Soc. , 19 (5), 922-928.

Richardson, S.D. (2005). New Disinfection By-Product Issues: Emerging DBPs and Alternative Routes of Exposure. Global NEST Journal. 7(1), 43-60.

Richardson, S.D.; Plewa, M.J.; Wagner, E.D.; Schoeny, R.; \& DeMarini, D.M. (2007). Occurrence, genotoxicity, and carcinogenicity of regulated and emerging disinfection by-products in drinking water: A review and roadmap for research. Mutation Research. 636, 178 - 242.

Richardson, S.D.; Thruston Jr., A.D.; Krasner, S.W.; Weinberg, H.S.; Miltner, R.J.; Schenck, K.M.; Narotsky, M.G.; McKague, A.B.; \& Simmons, J.E. (2008). Integrated disinfection by-products mixtures research: comprehensive characterization of water concentrates prepared from chlorinated and ozonated/postchlorinated drinking water. Journal of Toxicology and Environmental Health, Part A: Current Issues. 71(17), 1165-1186.

Richardson, S.D. \& Postigo, C. (2012). Drinking Water Disinfection By-products. In Barcelo, D. (Ed.) Emerging Organic Contaminants and Human Health. (pp 93-137). The Handbook of Environmental Chemistry, Vol 20. Springer: New York.

Rook, J. (1974). Formation of haloforms during chlorination of natural waters. Water Treatmeant and Examination. 23, 234-243.

Sasaki, Y.F.; Nishidate, E.; Izumiyama, F.; Watanabe-Akanuma, M.; Kinae, N.; Matsusaka, N.; \& Tsuda, S. (1997). Detection of in vivo genotoxicity of 3-chloro-4(dichloromethyl)-5-hydroxy-2(5H)-furanone (MX) orally on three consecutive days. Mutation Research. 343 (2-3), 151-156.

Schenck, K., Meier, J., Ringhand, H., \& Kopfler, F. (1990). Recovery of 3-chloro-4(dichloromethyl)-5-hydroxy-2(5H)-furanone from water samples on XAD resins and the effect of chlorine on its mutagenicity. Environmental Science and Technology. 24, 863-867. 
Sharp, E.L.; Parsons, S.A.; \& Jefferson, B. (2006). Seasonal variations in natural organic matter and its impact on coagulation in water treatment. Science of the Total Environment. 363, 183-194.

Simmons, J.E.; Richardson, S.D.; Speth, T.F.; Miltner, R.J.; Rice, G.; Schenck, K.M.; Hunter III, E.S.; \& Teuschler, L.K. (2002). Development of a research strategy for integrated technology-based toxicological and chemical evaluation of complex mixtures of drinking water disinfection byproducts. Environmental Health Perspectives. 110(6), 1013-1024.

Simpson, K. L., \& Hayes, K. P. (1993). Occurrence and removal study of the highly mutagenic chlorinated furanone "MX" in disinfected drinking water. Australian Centre for Water Quality Research Report 1/93.

Summers, R.S.; Hooper, S.M.; Shukairy, H.M.; Solarik, G.; \& Owen, D. (1996). Assessing DBP yield: uniform formation conditions. Journal AWWA. 88, 6-80.

Suzuki, N., \& Nakanishi, J. (1995). The determination of strong mutagen, 3-chloro-4(dichloromethyl)-5-hydroxy-2(5H)-furanone in dirnking water in Japan. Chemosphere. 21(3), 387-392.

Takanashi, H.; Kishida, M.; Nakajima, T.; Ohki, A.; Akiba, M.; \& Aizawa, T. (2009). Surveying the mutagenicity of tap water to elicit the effects of purifications processes on Japanese tape water. Chemosphere. 77(3), 434-439.

Tikkanen, L. \& Kronberg, L. (1990). Genotoxic effects of various chlorinated butenoic acids identified in chlorinated drinking water. Mutation Research. 240, 109-116.

USEPA (1999). Enhanced Coagulation and Enhanced Precipitative Softening Guide. Office of Water. EPA 815-R-99-012.

USEPA (2008). The Occurrence of Disinfection By-Products (DBPs) of Health Concern in Drinking Water: Results of a Nationwide DBP Occurrence Study. Office of Research and Development, National Exposure Research Laboratory. Athens, GA: U.S. Environmental Protection Agency.

Vartiainen, T.; Lampelo, S.; \& Kauranen, P. (1990). Mutagenicity of drinking waters in Finland. Progress in Clinical and Biological Research. 340E, 1-9.

van Leeuwen, J.; Daly, R.; \& Holmes, M. (2005). Modeling the treatment of drinking water to maximize dissolved organic matter removal and minimize disinfection by-product formation. Desalination. 177, 81-89.

Wang, D.; Xu, Z.; Zhao, Y.; Yan, X.; \& Shi, J. (2011). Change of genotoxicity for raw and finished water: role of purification processes. Chemosphere. 83, 14-20.

Wassink, J.K. (2010). Coagulation Optimization to Minimize and Predict the Formation of Disinfection By-Products. M.A.Sc. thesis. Department of Civil Engineering, University of Toronto, Toronto, Ontario, Canada.

Wassink, J.K.; Andrews, R.C.; Peiris, R.H.; \& Legge, R.L. (2011). Evaluation of fluorescence excitation-emission and LC-OCD as methods of detecting removal of 
NOM and DBP precursors by enhanced coagulation. Water Science and Technology: Water Supply. 11(5), 621 - 630.

Wright, J.M.; Schwartz, J.; Vartiainen, T.; Maki-Paakkanen, J.; Altshul, L.; Harrington, J.J.; \& Dockery, D.W. (2002). 3-Chloro-4-(dichloromethyl)-5-hydroxy-2(5H)-furanone (MX) and mutagenic activity in Massachusetts drinking water. Environmental Heath Prospectives. 110(2), 157-164.

Zegura, B.; Heath, E.; Cernosa, A.; \& Filipic, M. (2009). Combination of in vitro bioassays for the determination of cytotoxic and genotoxic potential of wastewater, surface water and drinking water samples. Chemosphere. 75, 1453-1460.

Zou, H.; Lu, J.; Chen, J.; Yang, C.; Zhang, J.; \& Zhou, W. (2000). Screening the precursors of strong mutagen [3-Chloro-4-(dichloromethyl)-5-hydroxy-2(5H)-furanone] MX from chlorinated water. Water Research. 34, 225-229.

Zwiener, C. \& Kronberg, L. (2001). Determination of the strong mutagen 3-chloro-4(dichloromethyl)-5-hydroxy-2(5H)-furanone (MX) and its analogues by GC-ITD-MSMS. Fresenius' Journal of Analytical Chemistry. 371, 591-597. 


\subsection{APPENDICES}

\subsection{Alum Concentration Conversion Data}

Alum doses used in jar tests were reported as $\mathrm{mg} / \mathrm{L}$ (as solid alum). The alum used was supplied by General Chemical (Parsippany, NJ) with the following characteristics:

- Liquid alum form

- $\left(\mathrm{Al}_{2}\left(\mathrm{SO}_{4}\right)_{3} \cdot 14 \mathrm{H}_{2} \mathrm{O}\right.$

- $\quad 48.5 \%$ solid alum content (by weight)

- $\quad 4.4 \%$ aluminum content (by weight)

- $\quad$ Specific gravity of 1.335

Sample calculations, using alum dose of $20 \mathrm{mg} / \mathrm{L}$ :

As liquid alum:

$20 \frac{\mathrm{mg}}{\mathrm{L}}($ as solid alum $)=\frac{20 \frac{\mathrm{mg}}{\mathrm{L}}(\text { as solid alum })}{\left(\frac{0.485 \mathrm{mg} \text { solid alum }}{\mathrm{mg} \text { liquid alum }}\right)}=41.27 \frac{\mathrm{mg}}{\mathrm{L}}($ as liquid alum $)$

As aluminum:

$20 \frac{\mathrm{mg}}{\mathrm{L}}($ as solid alum $)=41.27 \frac{\mathrm{mg}}{\mathrm{L}}$ (as liquid alum)

$=41.27 \frac{\mathrm{mg}}{\mathrm{L}}$ (as liquid alum) $\times \frac{0.044 \mathrm{mg} \mathrm{Al}}{\mathrm{mg} \text { liquid alum }}=1.82 \frac{\mathrm{mg}}{\mathrm{L}}$ (as Al)

As volume added (of liquid alum) per 2L jar:

$20 \frac{\mathrm{mg}}{\mathrm{L}}($ as solid alum $)=\frac{20 \frac{\mathrm{mg}}{\mathrm{L}}(\text { as solid alum })}{\left(\frac{0.485 \mathrm{mg} \text { solid alum }}{\mathrm{mg} \text { liquid alum }}\right)} \times \frac{\mathrm{mL}}{1335 \mathrm{mg}} \times \frac{1}{2000 \mathrm{~mL}}$

$=61.8 \mu L$ (of liquid alum)

The volume of alum added per jar and conversion of concentrations as solid alum, liquid alum, and as $\mathrm{Al}$ are provided below: 
Table 8.1 - Conversion of alum concentrations for dosages used in jar tests

\begin{tabular}{|c|c|c|c|}
\hline $\begin{array}{c}\text { Alum dose (mg/L as } \\
\text { solid alum) }\end{array}$ & $\begin{array}{c}\text { Alum dose (mg/L as } \\
\text { liquid alum) }\end{array}$ & $\begin{array}{c}\text { Alum dose (mg/L } \\
\text { as Al) }\end{array}$ & $\begin{array}{c}\text { Volume of liquid alum } \\
\text { added to 2L jar }(\boldsymbol{\mu L})\end{array}$ \\
\hline 0 & 0 & 0.00 & 0 \\
\hline 5.0 & 10.32 & 0.45 & 15.5 \\
\hline 10.0 & 20.63 & 0.91 & 30.9 \\
\hline 20.0 & 41.27 & 1.82 & 61.8 \\
\hline 30.0 & 61.90 & 2.72 & 92.7 \\
\hline 40.0 & 82.53 & 3.63 & 123.6 \\
\hline 50.0 & 103.17 & 4.54 & 154.6 \\
\hline 60.0 & 123.80 & 5.45 & 185.5 \\
\hline
\end{tabular}

\subsection{Ottawa River Experiment Data}

Table 8.2 - Ottawa River jar test results - TOC/DOC/UV/SUVA/NOM fractions

\begin{tabular}{|c|c|c|c|c|c|c|c|c|c|c|c|}
\hline \multirow[b]{2}{*}{ 离 } & \multirow[b]{2}{*}{ 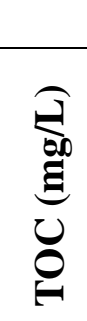 } & \multirow[b]{2}{*}{ 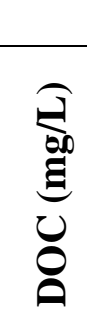 } & \multirow[b]{2}{*}{ 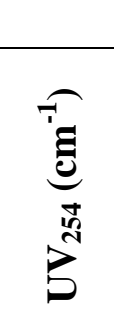 } & \multirow[b]{2}{*}{ 总 } & \multicolumn{7}{|c|}{ NOM Fractions - LC-OCD (mg/L) } \\
\hline & & & & & O & 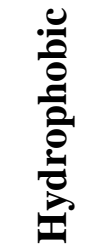 & 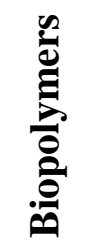 & 葛 & 量 & $\begin{array}{l}\sum_{0}^{n} \\
\sum_{j}^{2} \\
\sum_{j}\end{array}$ & 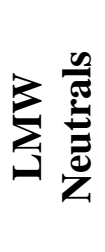 \\
\hline \multirow{2}{*}{$\mathbf{0}$} & 6.04 & 5.84 & 0.200 & 3.43 & 6.26 & 0.39 & 0.27 & 3.56 & 1.07 & 0.23 & 0.74 \\
\hline & 6.08 & 5.87 & 0.204 & 3.48 & n.m. & n.m. & n.m. & n.m. & n.m. & n.m. & n.m. \\
\hline \multirow{2}{*}{20} & 6.03 & 5.68 & 0.194 & 3.42 & 4.59 & 0.66 & 0.11 & 2.17 & 0.88 & 0.22 & 0.54 \\
\hline & 6.00 & 5.84 & 0.202 & 3.46 & n.m. & n.m. & n.m. & n.m. & n.m. & n.m. & n.m. \\
\hline \multirow{2}{*}{30} & 5.95 & 5.33 & 0.172 & 3.23 & 3.59 & 0.64 & 0.10 & 1.56 & 0.54 & 0.21 & 0.53 \\
\hline & 5.96 & 5.31 & 0.174 & 3.27 & n.m. & n.m. & n.m. & n.m. & n.m. & n.m. & n.m. \\
\hline \multirow{2}{*}{40} & 4.48 & 4.12 & 0.110 & 2.67 & 3.18 & 0.62 & 0.09 & 1.32 & 0.35 & 0.23 & 0.57 \\
\hline & 4.54 & 4.10 & 0.112 & 2.73 & n.m. & n.m. & n.m. & n.m. & n.m. & n.m. & n.m. \\
\hline \multirow{2}{*}{50} & 2.90 & 3.13 & 0.068 & 2.18 & 2.67 & 0.47 & 0.05 & 1.19 & 0.25 & 0.21 & 0.50 \\
\hline & 2.94 & 3.06 & 0.068 & 2.23 & n.m. & n.m. & n.m. & n.m. & n.m. & n.m. & n.m. \\
\hline \multirow{2}{*}{60} & 2.38 & 2.77 & 0.055 & 1.98 & 2.28 & 0.09 & 0.05 & 1.07 & 0.28 & 0.21 & 0.58 \\
\hline & 2.36 & 2.72 & 0.055 & 2.02 & n.m. & n.m. & n.m. & n.m. & n.m. & n.m. & 11..1. \\
\hline
\end{tabular}


Table 8.3 - Ottawa River chlorination results

\begin{tabular}{|c|c|c|c|c|c|c|c|c|c|}
\hline \multirow{3}{*}{ 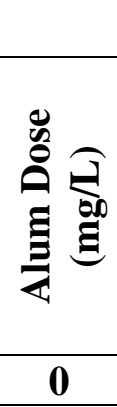 } & \multirow{3}{*}{$\begin{array}{l} \\
7.36 \\
\end{array}$} & \multirow{3}{*}{ 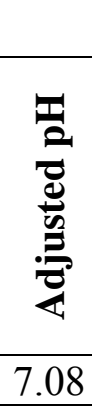 } & \multirow{3}{*}{ 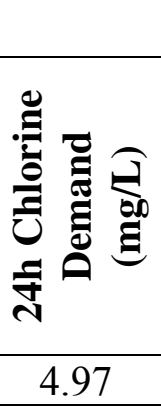 } & \multirow{3}{*}{ 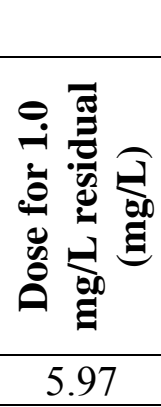 } & \multicolumn{5}{|c|}{ Measured 24h Residuals (mg/L) } \\
\hline & & & & & \multirow[t]{2}{*}{ 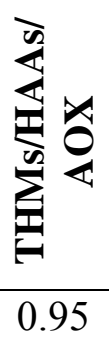 } & \multicolumn{2}{|c|}{$\sum_{\Sigma}^{x}$} & \multicolumn{2}{|c|}{ 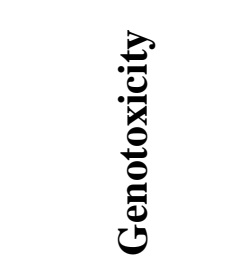 } \\
\hline & & & & & & 0.89 & 0.92 & 0.72 & 0.81 \\
\hline 20 & 7.02 & 7.02 & 4.05 & 5.05 & 1.4 & 1.46 & 1.5 & 1.31 & 2.00 \\
\hline 30 & 6.76 & 6.97 & 2.83 & 2.83 & 1.43 & 1.62 & 1.63 & 1.45 & 1.57 \\
\hline 40 & 6.42 & 7.05 & 2.03 & 3.03 & 1.27 & 1.32 & 1.29 & 1.22 & 1.17 \\
\hline 50 & 5.85 & 7.08 & 1.93 & 1.93 & 1.31 & 1.33 & 1.31 & 1.17 & 1.22 \\
\hline 60 & 5.16 & 7.06 & 1.63 & 1.63 & 0.99 & 0.97 & 0.95 & 0.89 & 0.87 \\
\hline
\end{tabular}

Table 8.4 - Ottawa River DBP formation results - AOX/THMs/HAAs/AOX/MCA/MX

\begin{tabular}{|c|c|c|c|c|c|c|}
\hline $\begin{array}{l}\text { Alum Dose } \\
\text { (mg/L) }\end{array}$ & $\begin{array}{c}\text { AOX } \\
(\mu g / L)\end{array}$ & $\begin{array}{l}\text { TTHM } \\
(\mu g / L)\end{array}$ & $\begin{array}{l}\text { HAA9 }_{9} \\
(\mu \mathrm{g} / \mathrm{L})\end{array}$ & $\begin{array}{l}\text { MCA } \\
\text { (ng/L) }\end{array}$ & $\begin{array}{c}\text { MX } \\
\text { (ng/L) }\end{array}$ & $\begin{array}{l}\text { Genotoxicity } \\
\text { (TEQ } 4 \text {-NQO) }\end{array}$ \\
\hline \multirow[b]{2}{*}{ O } & 369.0 & 147.3 & 68.9 & 1039 & 20 & \multirow{2}{*}{0.439} \\
\hline & n.m. & 148.9 & 69.9 & 1651 & 20 & \\
\hline \multirow{2}{*}{20} & 260.7 & 115.0 & 44.4 & 519 & 18 & \multirow{2}{*}{0.407} \\
\hline & n.m. & 120.0 & 44.4 & 502 & 18 & \\
\hline \multirow{2}{*}{30} & 149.3 & 101.5 & 32.0 & 271 & 14 & \multirow{2}{*}{0.247} \\
\hline & n.m. & 98.7 & 30.9 & 359 & 14 & \\
\hline \multirow{2}{*}{40} & 123.6 & 73.8 & 21.9 & 155 & 14 & \multirow{2}{*}{0.202} \\
\hline & n.m. & 81.3 & 21.0 & 174 & 14 & \\
\hline \multirow{2}{*}{50} & 122.0 & 60.3 & 22.1 & 119 & 14 & \multirow{2}{*}{0.202} \\
\hline & n.m. & 63.9 & 22.6 & 128 & 14 & \\
\hline \multirow{2}{*}{60} & 117.6 & 59.9 & 20.7 & 170 & 14 & \multirow{2}{*}{0.267} \\
\hline & n.m. & 62.2 & 21.5 & 127 & 14 & \\
\hline
\end{tabular}

n.m. $=$ not measured 
Table 8.5 - Ottawa River - TTHM by specific compounds

\begin{tabular}{|c|c|c|c|c|c|}
\hline $\begin{array}{c}\text { Alum Dose } \\
\text { (mg/L) }\end{array}$ & TCM $(\mu \mathrm{g} / \mathrm{L})$ & $\begin{array}{c}\text { DBMC } \\
(\mu \mathrm{g} / \mathrm{L})\end{array}$ & $\begin{array}{c}\text { DBCM } \\
(\mu \mathrm{g} / \mathrm{L})\end{array}$ & TBM ( $\mu \mathrm{g} / \mathrm{L})$ & $\begin{array}{l}\text { TTHM } \\
(\mu \mathrm{g} / \mathrm{L})\end{array}$ \\
\hline \multirow[t]{2}{*}{ 0 } & 121.8 & 23.5 & 2.0 & n.d. & 147.3 \\
\hline & 123.0 & 23.9 & 2.0 & n.d. & 148.9 \\
\hline \multirow[t]{2}{*}{20} & 89.5 & 23.4 & 2.1 & n.d. & 115.0 \\
\hline & 93.6 & 24.3 & 2.1 & n.d. & 120.0 \\
\hline \multirow[t]{2}{*}{30} & 74.2 & 24.9 & 2.4 & n.d. & 101.5 \\
\hline & 72.3 & 24.0 & 2.4 & n.d. & 98.7 \\
\hline \multirow[t]{2}{*}{40} & 51.3 & 20.1 & 2.4 & n.d. & 73.8 \\
\hline & 54.9 & 24.0 & 2.4 & n.d. & 81.3 \\
\hline \multirow[t]{2}{*}{50} & 41.8 & 16.1 & 2.5 & n.d. & 60.3 \\
\hline & 44.9 & 16.5 & 2.5 & n.d. & 63.9 \\
\hline \multirow[t]{2}{*}{60} & 41.5 & 16.1 & 2.4 & n.d. & 59.9 \\
\hline & 43.5 & 16.3 & 2.4 & n.d. & 62.2 \\
\hline
\end{tabular}

n.d. $=$ not detected

Table 8.6 - Ottawa River - HAA9 by specific compounds

\begin{tabular}{|c|c|c|c|c|c|c|c|c|c|c|}
\hline 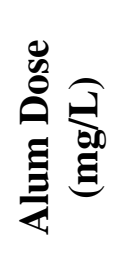 & 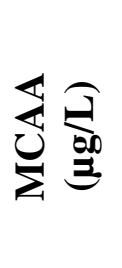 & 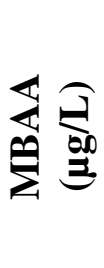 & 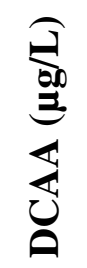 & 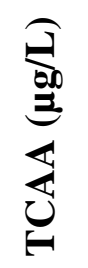 & 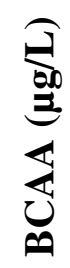 & 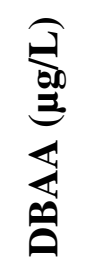 & 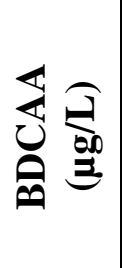 & 岁完 & 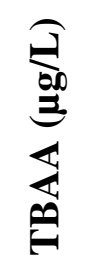 & $\frac{3}{300}$ \\
\hline \multirow{2}{*}{ 0 } & 2.9 & 0.1 & 41.5 & 22.9 & 1.6 & n.d. & n.d. & n.d. & n.d. & 68.9 \\
\hline & 3.0 & 0.1 & 42.0 & 23.3 & 1.5 & n.d. & n.d. & n.d. & n.d. & 69.9 \\
\hline \multirow{2}{*}{20} & 2.4 & 0.2 & 27.3 & 14.1 & 0.4 & n.d. & n.d. & n.d. & n.d. & 44.4 \\
\hline & 2.4 & 0.2 & 27.3 & 14.1 & 0.4 & n.d. & n.d. & n.d. & n.d. & 44.4 \\
\hline \multirow{2}{*}{30} & 2.2 & 0.6 & 20.0 & 8.5 & 0.6 & n.d. & n.d. & n.d. & n.d. & 32.0 \\
\hline & 2.0 & 0.6 & 19.5 & 8.3 & 0.6 & n.d. & n.d. & n.d. & n.d. & 30.9 \\
\hline \multirow{2}{*}{40} & 2.0 & 0.6 & 13.9 & 4.5 & 0.8 & n.d. & n.d. & n.d. & n.d. & 21.9 \\
\hline & 1.5 & 0.6 & 13.7 & 4.4 & 0.8 & n.d. & n.d. & n.d. & n.d. & 21.0 \\
\hline \multirow{2}{*}{50} & 1.8 & 0.7 & 13.9 & 5.2 & 0.6 & n.d. & n.d. & n.d. & n.d. & 22.1 \\
\hline & 1.8 & 0.7 & 14.2 & 5.3 & 0.6 & n.d. & n.d. & n.d. & n.d. & 22.6 \\
\hline \multirow{2}{*}{60} & 1.8 & 0.4 & 13.3 & 4.8 & 0.4 & n.d. & n.d. & n.d. & n.d. & 20.7 \\
\hline & 1.8 & 0.4 & 13.8 & 5.1 & 0.4 & n.d. & n.d. & n.d. & n.d. & 21.5 \\
\hline
\end{tabular}

n.d. $=$ not detected 
Table 8.7 - Ottawa River - SOS Chromotest IF values for water samples

\begin{tabular}{|c|c|c|c|c|c|c|c|c|c|c|c|c|}
\hline eqmL/well & \multicolumn{3}{|c|}{ Raw (no $\left.\mathrm{Cl}_{2}\right)$} & \multicolumn{3}{|c|}{0 mg/L alum } & \multicolumn{3}{|c|}{$20 \mathrm{mg} / \mathrm{L}$ alum } & \multicolumn{3}{|c|}{30 mg/L alum } \\
\hline 66 & 0.82 & 0.83 & 0.84 & 1.04 & 1.03 & 1.08 & 1.36 & 1.29 & 1.22 & 1.24 & 1.28 & 1.29 \\
\hline 33 & 0.84 & 0.85 & 0.88 & 1.23 & 1.27 & 1.26 & 1.50 & 1.51 & 1.33 & 3.49 & 3.23 & 3.34 \\
\hline 16.5 & 0.84 & 0.85 & 0.87 & 6.21 & 6.47 & 6.61 & 6.04 & 5.56 & 5.07 & 3.44 & 3.63 & 3.81 \\
\hline 8.25 & 0.90 & 0.88 & 0.85 & 4.59 & 4.74 & 4.75 & 3.64 & 3.47 & 3.46 & 2.19 & 2.32 & 2.41 \\
\hline 4.125 & 0.93 & 0.90 & 0.88 & 3.14 & 3.31 & 3.39 & 2.20 & 2.28 & 2.33 & 1.56 & 1.57 & 1.64 \\
\hline 2.0625 & 0.96 & 0.95 & 0.98 & 2.10 & 2.13 & 2.07 & 1.55 & 1.54 & 1.54 & 1.18 & 1.20 & 1.18 \\
\hline eqmL/well & \multicolumn{3}{|c|}{$40 \mathrm{mg} / \mathrm{L}$ alum } & \multicolumn{3}{|c|}{50 mg/L alum } & \multicolumn{3}{|c|}{$60 \mathrm{mg} / \mathrm{L}$ alum } & & & \\
\hline 66 & 1.55 & 1.55 & 1.56 & 1.55 & 1.51 & 1.56 & 1.69 & 1.65 & 1.63 & & & \\
\hline 33 & 5.10 & 5.16 & 4.96 & 5.48 & 5.38 & 5.04 & 6.57 & 6.36 & 6.06 & & & \\
\hline 16.5 & 3.57 & 3.55 & 3.20 & 3.54 & 3.45 & 3.34 & 4.12 & 4.04 & 3.99 & & & \\
\hline 8.25 & 2.31 & 2.18 & 2.29 & 2.31 & 2.22 & 2.19 & 2.41 & 2.45 & 2.37 & & & \\
\hline 4.125 & 1.67 & 1.69 & 1.74 & 1.70 & 1.73 & 1.65 & 1.68 & 1.80 & 1.82 & & & \\
\hline 2.0625 & 1.38 & 1.41 & 1.52 & 1.46 & 1.46 & 1.43 & 1.41 & 1.42 & 1.40 & & & \\
\hline
\end{tabular}

\subsection{Otonabee River Experiment Data}

Table 8.8 - Otonabee River jar test results - TOC/DOC/UV/SUVA/NOM fractions

\begin{tabular}{|c|c|c|c|c|c|c|c|c|c|c|c|}
\hline \multirow[b]{2}{*}{ 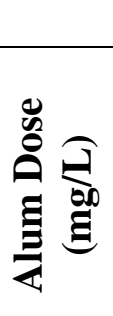 } & \multirow[b]{2}{*}{ 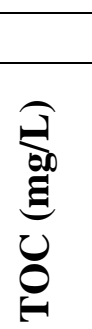 } & \multirow[b]{2}{*}{ 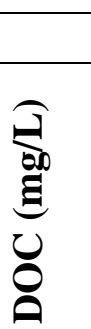 } & \multirow[b]{2}{*}{ 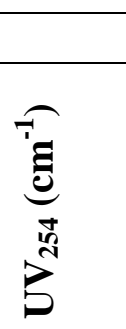 } & \multirow[b]{2}{*}{ 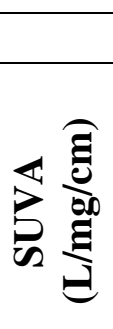 } & \multicolumn{7}{|c|}{ NOM Fractions - LC-OCD (mg/L) } \\
\hline & & & & & $\begin{array}{l}\text { O } \\
\text { ○ }\end{array}$ & 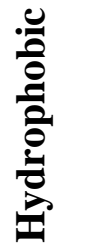 & 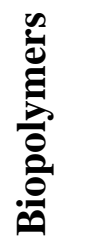 & 弟 & 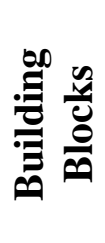 & $\begin{array}{l}\frac{0}{2} \\
\sum_{j}^{n} \\
\sum_{j}\end{array}$ & $\sum_{i} \frac{n}{\frac{n}{\pi}}$ \\
\hline \multirow[t]{2}{*}{$\mathbf{0}$} & 4.91 & 4.97 & 0.103 & 2.07 & 5.69 & 0.62 & 0.44 & 3.10 & 0.81 & 0.21 & 0.52 \\
\hline & 4.93 & 5.10 & 0.103 & 2.02 & n.m. & n.m. & n.m. & n.m. & n.m. & n.m. & n.m. \\
\hline \multirow[t]{2}{*}{20} & 4.18 & 4.08 & 0.076 & 1.86 & 4.66 & 0.77 & 0.29 & 2.16 & 0.80 & 0.19 & 0.45 \\
\hline & 4.32 & 4.13 & 0.078 & 1.89 & n.m. & n.m. & n.m. & n.m. & n.m. & n.m. & n.m. \\
\hline \multirow[t]{2}{*}{30} & 3.66 & 3.64 & 0.061 & 1.67 & 3.94 & 0.51 & 0.22 & 1.74 & 0.79 & 0.24 & 0.44 \\
\hline & 3.63 & 3.67 & 0.062 & 1.69 & n.m. & n.m. & n.m. & n.m. & n.m. & n.m. & n.m. \\
\hline \multirow[t]{2}{*}{40} & 3.31 & 3.36 & 0.053 & 1.58 & 3.56 & 0.46 & 0.20 & 1.55 & 0.74 & 0.20 & 0.42 \\
\hline & 3.28 & 3.36 & 0.053 & 1.58 & n.m. & n.m. & n.m. & n.m. & n.m. & n.m. & n.m. \\
\hline \multirow[t]{2}{*}{50} & 2.90 & 2.90 & 0.045 & 1.55 & 3.49 & 0.59 & 0.12 & 1.54 & 0.51 & 0.24 & 0.48 \\
\hline & 2.97 & 2.94 & 0.044 & 1.50 & n.m. & n.m. & n.m. & n.m. & n.m. & n.m. & n.m. \\
\hline \multirow[t]{2}{*}{60} & 2.64 & 2.56 & 0.043 & 1.68 & 3.51 & 0.83 & 0.13 & 1.51 & 0.38 & 0.25 & 0.41 \\
\hline & 2.67 & 2.51 & 0.041 & 1.63 & n.m. & n.m. & n.m. & n.m. & n.m. & n.m. & n.m. \\
\hline
\end{tabular}


Table 8.9 - Otonabee River chlorination results

\begin{tabular}{|c|c|c|c|c|c|c|c|c|c|}
\hline \multirow{3}{*}{ 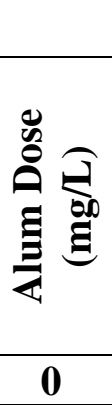 } & \multirow{3}{*}{$\begin{array}{l}\text { 吾 } \\
8.44\end{array}$} & \multirow{3}{*}{ 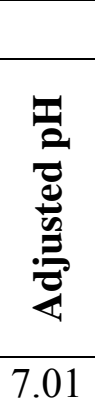 } & \multirow{3}{*}{ 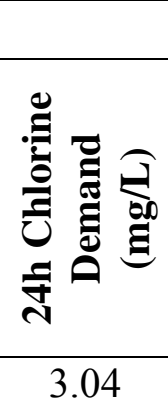 } & \multirow{3}{*}{ 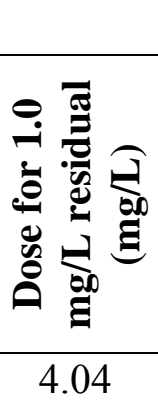 } & \multicolumn{5}{|c|}{ Measured 24h Residuals (mg/L) } \\
\hline & & & & & \multirow[t]{2}{*}{ 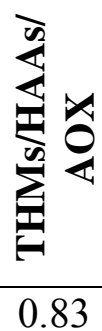 } & \multicolumn{2}{|c|}{$\sum$} & \multicolumn{2}{|c|}{ 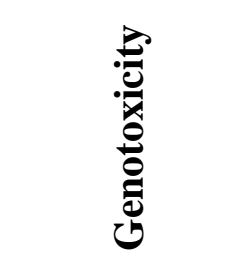 } \\
\hline & & & & & & 0.85 & 0.92 & 0.9 & 0.85 \\
\hline 20 & 7.76 & 6.97 & 2.62 & 3.62 & 0.97 & 1.18 & 1.18 & 1.11 & 1.19 \\
\hline 30 & 7.53 & 7.01 & 2.43 & 3.43 & 1.07 & 1.23 & 1.27 & 1.21 & 1.25 \\
\hline 40 & 7.40 & 7.02 & 2.28 & 3.28 & 1.07 & 1.32 & 1.3 & 1.27 & 1.32 \\
\hline 50 & 7.24 & 7.03 & 1.98 & 2.98 & 1.02 & 1.19 & 1.22 & 1.2 & 1.21 \\
\hline 60 & 7.18 & 7.02 & 1.84 & 2.84 & 1.03 & 1.17 & 1.12 & 1.14 & 1.16 \\
\hline
\end{tabular}

Table 8.10 - Otonabee River DBP formation results AOX/THMs/HAAs/AOX/MCA/MX

\begin{tabular}{|c|c|c|c|c|c|c|}
\hline $\begin{array}{c}\text { Alum Dose } \\
(\mathrm{mg} / \mathrm{L})\end{array}$ & $\begin{array}{c}\text { AOX } \\
(\mu g / L)\end{array}$ & $\begin{array}{l}\text { TTHM } \\
(\mu g / L)\end{array}$ & $\begin{array}{l}\mathrm{HAA}_{9} \\
(\mu \mathrm{g} / \mathrm{L})\end{array}$ & $\begin{array}{l}\text { MCA } \\
\text { (ng/L) }\end{array}$ & $\begin{array}{c}\text { MX } \\
\text { (ng/L) }\end{array}$ & $\begin{array}{l}\text { Genotoxicity } \\
\left(\text { TEQ }_{4-N Q O}\right)\end{array}$ \\
\hline \multirow{2}{*}{ 0 } & 325.9 & 177.0 & 110.9 & 560 & $<\mathrm{MDL}$ & \multirow{2}{*}{0.316} \\
\hline & 331.5 & 189.0 & 109.9 & 593 & $<\mathrm{MDL}$ & \\
\hline \multirow{2}{*}{20} & 310.7 & 135.4 & 89.7 & 323 & $<\mathrm{MDL}$ & \multirow{2}{*}{0.311} \\
\hline & 311.9 & 141.3 & 83.7 & 369 & $<\mathrm{MDL}$ & \\
\hline \multirow{2}{*}{30} & 273.8 & 138.4 & 71.6 & 302 & $<\mathrm{MDL}$ & \multirow{2}{*}{0.299} \\
\hline & 262.4 & 138.5 & 76.1 & 324 & $<\mathrm{MDL}$ & \\
\hline \multirow{2}{*}{40} & 229.3 & 126.4 & 59.0 & 137 & $<\mathrm{MDL}$ & \multirow{2}{*}{0.407} \\
\hline & 227.6 & 129.9 & 60.5 & 192 & $<\mathrm{MDL}$ & \\
\hline \multirow{2}{*}{50} & 212.5 & 105.0 & 49.3 & 165 & $<\mathrm{MDL}$ & \multirow{2}{*}{0.268} \\
\hline & 231.6 & 95.9 & 48.3 & 175 & $<\mathrm{MDL}$ & \\
\hline \multirow{2}{*}{60} & 197.2 & 97.7 & 46.5 & 152 & $<\mathrm{MDL}$ & \multirow{2}{*}{0.228} \\
\hline & 176.6 & 87.7 & 44.6 & 113 & $<\mathrm{MDL}$ & \\
\hline
\end{tabular}

MDL of MX $=12 \mathrm{ng} / \mathrm{L}$ 
Table 8.11 - Otonabee River - TTHM by specific compounds

\begin{tabular}{|c|c|c|c|c|c|}
\hline $\begin{array}{c}\text { Alum Dose } \\
(\mathbf{m g} / \mathbf{L})\end{array}$ & $\mathbf{T C M}(\mathbf{\mu g} / \mathbf{L})$ & $\begin{array}{c}\text { DBMC } \\
(\mathbf{\mu g} / \mathbf{L})\end{array}$ & $\begin{array}{c}\text { DBCM } \\
(\mathbf{\mu g} / \mathbf{L})\end{array}$ & $\mathbf{T B M}(\mathbf{\mu g} / \mathbf{L})$ & $\begin{array}{c}\text { TTHM } \\
(\mathbf{\mu g} / \mathbf{L})\end{array}$ \\
\hline \multirow{2}{*}{$\mathbf{0}$} & 139.9 & 35.1 & 2.1 & n.d. & 177.0 \\
\cline { 2 - 6 } & 148.1 & 38.8 & 2.1 & n.d. & 189.0 \\
\hline \multirow{2}{*}{$\mathbf{2 0}$} & 104.0 & 29.4 & 2.0 & n.d. & 135.4 \\
\cline { 2 - 6 } & 107.4 & 31.9 & 2.1 & n.d. & 141.3 \\
\hline \multirow{2}{*}{30} & 103.4 & 32.8 & 2.1 & n.d. & 138.4 \\
\cline { 2 - 6 } & 104.5 & 32.0 & 2.1 & n.d. & 138.5 \\
\hline \multirow{2}{*}{$\mathbf{4 0}$} & 95.1 & 29.2 & 2.1 & n.d. & 126.4 \\
\cline { 2 - 6 } & 98.7 & 29.2 & 2.1 & n.d. & 129.9 \\
\hline \multirow{2}{*}{50} & 78.9 & 24.1 & 2.1 & n.d. & 105.0 \\
\cline { 2 - 6 } & 72.0 & 21.9 & 2.0 & n.d. & 95.9 \\
\hline \multirow{2}{*}{$\mathbf{6 0}$} & 71.9 & 23.8 & 2.0 & n.d. & 97.7 \\
\cline { 2 - 6 } & 65.1 & 20.7 & 2.0 & n.d. & 87.7 \\
\hline
\end{tabular}

n.d. $=$ not detected

Table 8.12 - Otonabee River - HAA 9 by specific compounds

\begin{tabular}{|c|c|c|c|c|c|c|c|c|c|c|}
\hline 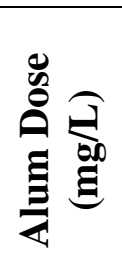 & 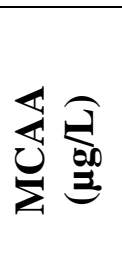 & 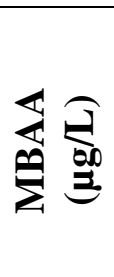 & 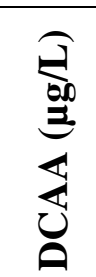 & 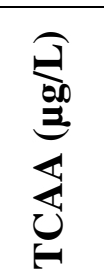 & $\frac{3}{\sum_{0}^{2}}$ & 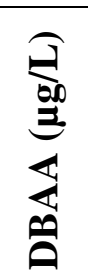 & 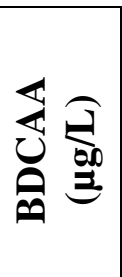 & 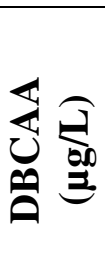 & 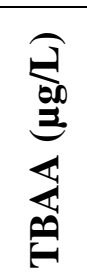 & 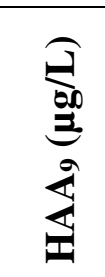 \\
\hline \multirow{2}{*}{ 0 } & 3.1 & 0.9 & 49.9 & 55.1 & 2.0 & n.d. & n.d. & n.d. & n.d. & 110.9 \\
\hline & 4.7 & 1.4 & 51.1 & 49.9 & 2.7 & n.d. & n.d. & n.d. & n.d. & 109.9 \\
\hline \multirow{2}{*}{20} & 3.6 & 1.6 & 41.6 & 40.5 & 2.4 & n.d. & n.d. & n.d. & n.d. & 89.7 \\
\hline & 3.1 & 1.2 & 39.1 & 38.8 & 1.5 & n.d. & n.d. & n.d. & n.d. & 83.7 \\
\hline \multirow{2}{*}{30} & 2.8 & 1.1 & 33.5 & 32.5 & 1.7 & n.d. & n.d. & n.d. & n.d. & 71.6 \\
\hline & 3.6 & 2.0 & 35.8 & 32.3 & 2.5 & n.d. & n.d. & n.d. & n.d. & 76.1 \\
\hline \multirow{2}{*}{40} & 2.1 & 0.7 & 28.9 & 26.4 & 0.9 & n.d. & n.d. & n.d. & n.d. & 59.0 \\
\hline & 2.5 & 1.3 & 29.1 & 26.5 & 1.2 & n.d. & n.d. & n.d. & n.d. & 60.5 \\
\hline \multirow{2}{*}{50} & 2.2 & 0.9 & 24.6 & 20.9 & 0.7 & n.d. & n.d. & n.d. & n.d. & 49.3 \\
\hline & 1.9 & 0.8 & 24.2 & 20.6 & 0.7 & n.d. & n.d. & n.d. & n.d. & 48.3 \\
\hline \multirow{2}{*}{60} & 2.5 & 0.9 & 23.8 & 17.8 & 1.5 & n.d. & n.d. & n.d. & n.d. & 46.5 \\
\hline & 2.1 & 0.6 & 23.1 & 17.4 & 1.4 & n.d. & n.d. & n.d. & n.d. & 44.6 \\
\hline
\end{tabular}

n.d. $=$ not detected 
Table 8.13 - Otonabee River - SOS Chromotest IF values

\begin{tabular}{|c|c|c|c|c|c|c|c|c|c|c|c|c|}
\hline eqmL/well & \multicolumn{3}{|c|}{ Raw (no $\left.\mathrm{Cl}_{2}\right)$} & \multicolumn{3}{|c|}{$0 \mathrm{mg} / \mathrm{L}$ alum } & \multicolumn{3}{|c|}{20 mg/L alum } & \multicolumn{3}{|c|}{30 mg/L alum } \\
\hline 66 & 0.87 & 0.91 & 0.77 & 1.03 & 1.06 & 1.06 & 1.06 & 1.07 & 1.05 & 0.97 & 1.01 & 1.11 \\
\hline 33 & 1.24 & 1.16 & 1.25 & 4.61 & 4.41 & 3.66 & 3.50 & 2.67 & 2.51 & 1.57 & 1.34 & 1.38 \\
\hline 16.5 & 1.02 & 0.94 & 1.10 & 4.41 & 4.68 & 4.90 & 4.61 & 4.50 & 4.15 & 4.45 & 4.42 & 4.57 \\
\hline 8.25 & 0.96 & 0.93 & 0.96 & 2.99 & 3.14 & 3.17 & 2.84 & 2.89 & 2.87 & 3.15 & 3.25 & 3.17 \\
\hline 4.125 & 0.93 & 0.90 & 0.91 & 1.92 & 1.98 & 1.97 & 1.82 & 1.86 & 1.84 & 2.02 & 2.24 & 2.10 \\
\hline 2.0625 & 0.88 & 0.86 & 0.91 & 1.50 & 1.53 & 1.56 & 1.31 & 1.33 & 1.36 & 1.48 & 1.48 & 1.58 \\
\hline eqmL/well & \multicolumn{3}{|c|}{$40 \mathrm{mg} / \mathrm{L}$ alum } & \multicolumn{3}{|c|}{$50 \mathrm{mg} / \mathrm{L}$ alum } & \multicolumn{3}{|c|}{$60 \mathrm{mg} / \mathrm{L}$ alum } & & & \\
\hline 66 & 1.11 & 1.49 & 1.43 & 1.41 & 1.71 & 1.60 & 1.54 & 3.05 & 2.94 & & & \\
\hline 33 & 1.38 & 4.82 & 4.65 & 4.50 & 6.40 & 6.35 & 6.48 & 5.96 & 5.49 & & & \\
\hline 16.5 & 4.57 & 5.73 & 5.72 & 5.59 & 4.16 & 4.13 & 4.09 & 3.61 & 3.55 & & & \\
\hline 8.25 & 3.17 & 3.46 & 3.51 & 3.54 & 2.56 & 2.41 & 2.55 & 2.38 & 2.34 & & & \\
\hline 4.125 & 2.10 & 2.27 & 2.22 & 2.21 & 1.80 & 1.81 & 1.75 & 1.82 & 1.71 & & & \\
\hline 2.0625 & 1.58 & 1.69 & 1.61 & 1.64 & 1.45 & 1.46 & 1.51 & 1.29 & 1.36 & & & \\
\hline
\end{tabular}

\subsection{Lake Simcoe Experiment Data}

Table 8.14 - Lake Simcoe jar test results - TOC/DOC/UV/SUVA/NOM fractions

\begin{tabular}{|c|c|c|c|c|c|c|c|c|c|c|c|}
\hline \multirow[b]{2}{*}{ 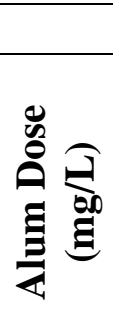 } & \multirow[b]{2}{*}{ 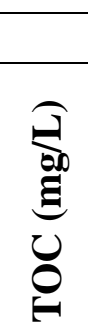 } & \multirow[b]{2}{*}{ 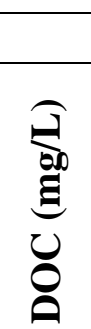 } & \multirow[b]{2}{*}{ 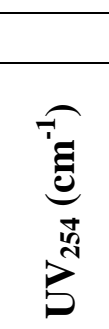 } & \multirow[b]{2}{*}{ 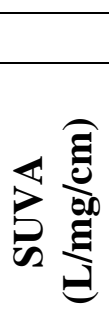 } & \multicolumn{7}{|c|}{ NOM Fractions - LC-OCD (mg/L) } \\
\hline & & & & & ๖ & 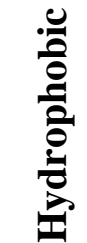 & & 总 & 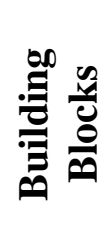 & 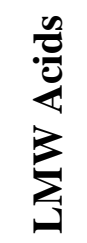 & $\sum_{1}^{3} \frac{n}{\tilde{c}}$ \\
\hline \multirow{2}{*}{$\mathbf{0}$} & 4.24 & 4.15 & 0.055 & 1.32 & 4.95 & 0.67 & 0.48 & 2.25 & 0.77 & 0.25 & 0.53 \\
\hline & 4.22 & 4.14 & 0.054 & 1.31 & n.m. & n.m. & n.m. & n.m. & n.m. & n.m. & n.m. \\
\hline \multirow{2}{*}{20} & 3.57 & 3.49 & 0.043 & 1.23 & 4.09 & 0.46 & 0.35 & 1.80 & 0.75 & 0.23 & 0.50 \\
\hline & 3.50 & 3.52 & 0.043 & 1.22 & n.m. & n.m. & n.m. & n.m. & n.m. & n.m. & n.m. \\
\hline \multirow{2}{*}{30} & 3.33 & 3.19 & 0.036 & 1.13 & 3.72 & 0.41 & 0.28 & 1.58 & 0.74 & 0.23 & 0.48 \\
\hline & 3.29 & 3.22 & 0.037 & 1.15 & n.m. & n.m. & n.m. & n.m. & n.m. & n.m. & n.m. \\
\hline \multirow{2}{*}{40} & 2.94 & 2.95 & 0.034 & 1.15 & 3.64 & 0.60 & 0.22 & 1.56 & 0.55 & 0.24 & 0.47 \\
\hline & 2.95 & 2.95 & 0.033 & 1.12 & n.m. & n.m. & n.m. & n.m. & n.m. & n.m. & n.m. \\
\hline \multirow{2}{*}{50} & 2.64 & 2.65 & 0.029 & 1.10 & 3.35 & 0.51 & 0.17 & 1.59 & 0.36 & 0.25 & 0.48 \\
\hline & 2.70 & 2.66 & 0.029 & 1.09 & n.m. & n.m. & n.m. & n.m. & n.m. & n.m. & n.m. \\
\hline \multirow{2}{*}{60} & 2.45 & 2.56 & 0.026 & 1.02 & 3.03 & 0.49 & 0.14 & 1.47 & 0.30 & 0.21 & 0.42 \\
\hline & 2.48 & 2.55 & 0.027 & 1.06 & n.m. & n.m. & n.m. & n.m. & n.m. & n.m. & n.m. \\
\hline
\end{tabular}


Table 8.15 - Lake Simcoe chlorination results

\begin{tabular}{|c|c|c|c|c|c|c|c|c|c|}
\hline \multirow{3}{*}{ 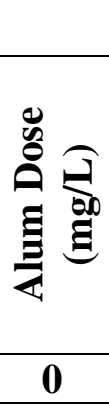 } & \multirow{3}{*}{$\begin{array}{l}\frac{\pi}{2} \\
8.47\end{array}$} & \multirow{3}{*}{ 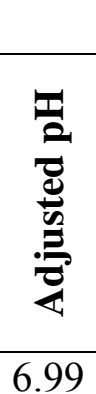 } & \multirow{3}{*}{ 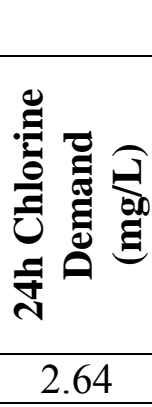 } & \multirow{3}{*}{ 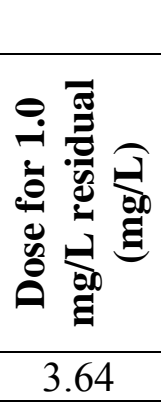 } & \multicolumn{5}{|c|}{ Measured 24h Residuals (mg/L) } \\
\hline & & & & & \multirow{2}{*}{ 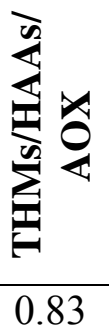 } & \multicolumn{2}{|c|}{$\sum_{\Sigma}^{\Sigma}$} & \multicolumn{2}{|c|}{ 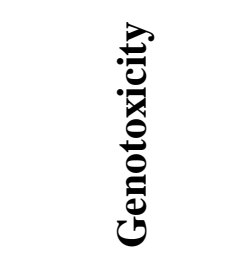 } \\
\hline & & & & & & 0.86 & 0.85 & 0.86 & n.m. \\
\hline 20 & 7.90 & 7.00 & 2.27 & 3.27 & 0.97 & 0.83 & 0.82 & 0.83 & n.m. \\
\hline 30 & 7.75 & 7.02 & 2.19 & 3.19 & 1.07 & 0.84 & 0.83 & 0.72 & n.m. \\
\hline 40 & 7.63 & 7.02 & 2.31 & 3.31 & 1.07 & 0.99 & 0.96 & 1.03 & n.m. \\
\hline 50 & 7.51 & 7.02 & 2.27 & 3.27 & 1.02 & 0.93 & 0.93 & 1.03 & n.m. \\
\hline 60 & 7.39 & 7.01 & 2.06 & 3.06 & 1.03 & 0.8 & 0.83 & 0.88 & n.m. \\
\hline
\end{tabular}

n.m. $=$ not measured

Table 8.16 - Lake Simcoe DBP formation results - AOX/THMs/HAAs/AOX/MCA/MX

\begin{tabular}{|c|c|c|c|c|c|c|}
\hline $\begin{array}{c}\text { Alum Dose } \\
\text { (mg/L) }\end{array}$ & $\begin{array}{c}\text { AOX } \\
(\mu g / L)\end{array}$ & $\begin{array}{l}\text { TTHM } \\
(\mu g / L)\end{array}$ & $\begin{array}{l}\text { HAA }_{9} \\
(\mu \mathrm{g} / \mathrm{L})\end{array}$ & $\begin{array}{l}\text { MCA } \\
\text { (ng/L) }\end{array}$ & $\begin{array}{c}\text { MX } \\
\text { (ng/L) }\end{array}$ & $\begin{array}{l}\text { Genotoxicity } \\
\text { (TEQ }\end{array}$ \\
\hline \multirow[b]{2}{*}{ O } & 219.8 & 68.1 & 116.6 & 362 & 15 & \multirow{2}{*}{0.257} \\
\hline & 238.4 & 65.1 & 115.0 & 253 & 16 & \\
\hline \multirow{2}{*}{20} & 191.8 & 56.0 & 94.8 & 95 & n.d. & \multirow{2}{*}{0.167} \\
\hline & 194.7 & 50.9 & 88.9 & 196 & n.d. & \\
\hline \multirow{2}{*}{30} & 182.1 & 49.7 & 76.7 & 43 & 15 & \multirow{2}{*}{0.135} \\
\hline & 173.7 & 49.0 & 81.0 & 43 & 15 & \\
\hline \multirow{2}{*}{40} & 172.4 & 42.1 & 64.1 & 210 & 15 & \multirow{2}{*}{0.175} \\
\hline & 154.0 & 45.4 & 65.5 & 268 & 15 & \\
\hline \multirow{2}{*}{50} & 162.5 & 44.3 & 54.2 & 38 & n.d. & \multirow{2}{*}{0.190} \\
\hline & 161.0 & 46.5 & 53.2 & 48 & 15 & \\
\hline \multirow{2}{*}{60} & 136.0 & 42.4 & 51.3 & 25 & n.d. & \multirow{2}{*}{0.236} \\
\hline & 141.1 & 42.6 & 49.5 & 36 & n.d. & \\
\hline
\end{tabular}

n.d. $=$ not detected; n.m. $=$ not measured 
Table 8.17 - Lake Simcoe - TTHM by specific compounds

\begin{tabular}{|c|c|c|c|c|c|}
\hline $\begin{array}{c}\text { Alum Dose } \\
(\mathbf{m g} / \mathbf{L})\end{array}$ & $\mathbf{T C M}(\mathbf{\mu g} / \mathbf{L})$ & $\begin{array}{c}\text { DBMC } \\
(\mathbf{\mu g} / \mathbf{L})\end{array}$ & $\begin{array}{c}\text { DBCM } \\
(\mathbf{\mu g} / \mathbf{L})\end{array}$ & $\mathbf{T B M}(\mathbf{\mu g} / \mathbf{L})$ & $\begin{array}{c}\mathbf{T T H M} \\
(\mathbf{\mu g} / \mathbf{L})\end{array}$ \\
\hline \multirow{2}{*}{$\mathbf{0}$} & 41.2 & 24.8 & 2.1 & n.d. & 68.1 \\
\cline { 2 - 6 } & 39.7 & 23.4 & 2.1 & n.d. & 65.1 \\
\hline \multirow{2}{*}{$\mathbf{2 0}$} & 33.0 & 20.8 & 2.2 & n.d. & 56.0 \\
\cline { 2 - 6 } & 29.0 & 19.9 & 2.0 & n.d. & 50.9 \\
\hline \multirow{2}{*}{30} & 27.7 & 19.9 & 2.0 & n.d. & 49.7 \\
\cline { 2 - 6 } & 27.0 & 19.9 & 2.1 & n.d. & 49.0 \\
\hline \multirow{2}{*}{$\mathbf{4 0}$} & 23.4 & 16.9 & 1.9 & n.d. & 42.1 \\
\cline { 2 - 6 } & 25.5 & 18.0 & 2.0 & n.d. & 45.4 \\
\hline \multirow{2}{*}{$\mathbf{5 0}$} & 23.8 & 18.4 & 2.1 & n.d. & 44.3 \\
\cline { 2 - 6 } & 25.3 & 19.1 & 2.1 & n.d. & 46.5 \\
\hline \multirow{2}{*}{$\mathbf{6 0}$} & 21.6 & 18.7 & 2.0 & n.d. & 42.4 \\
\cline { 2 - 6 } & 21.8 & 18.7 & 2.1 & n.d. & 42.6 \\
\hline
\end{tabular}

n.d. $=$ not detected

Table 8.18 - Lake Simcoe - HAA9 by specific compounds

\begin{tabular}{|c|c|c|c|c|c|c|c|c|c|c|}
\hline 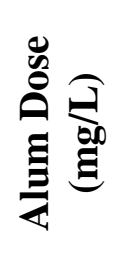 & 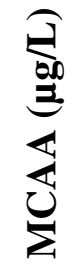 & 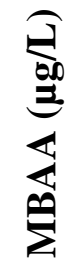 & 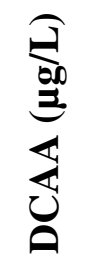 & 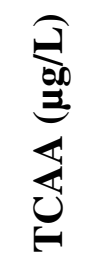 & 勇 & 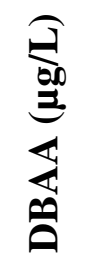 & 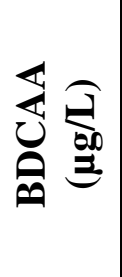 & 崖 & 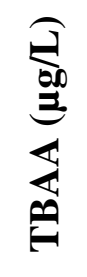 & 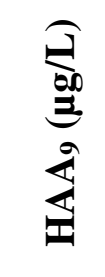 \\
\hline \multirow{2}{*}{ 0 } & 3.9 & 2.1 & 48.9 & 58.8 & 3.0 & n.d. & n.d. & n.d. & n.d. & 116.6 \\
\hline & 5.4 & 2.6 & 50.0 & 53.3 & 3.7 & n.d. & n.d. & n.d. & n.d. & 115.0 \\
\hline \multirow{2}{*}{20} & 4.3 & 2.8 & 40.9 & 43.3 & 3.4 & n.d. & n.d. & n.d. & n.d. & 94.8 \\
\hline & 3.9 & 2.3 & 38.5 & 4.5 & 2.5 & n.d. & n.d. & n.d. & n.d. & 88.9 \\
\hline \multirow{2}{*}{30} & 3.7 & 2.3 & 33.2 & 34.9 & 2.7 & n.d. & n.d. & n.d. & n.d. & 76.7 \\
\hline & 4.4 & 3.1 & 35.4 & 34.7 & 3.5 & n.d. & n.d. & n.d. & n.d. & 81.0 \\
\hline \multirow{2}{*}{40} & 3.1 & 2.0 & 28.8 & 28.4 & 1.9 & n.d. & n.d. & n.d. & n.d. & 64.1 \\
\hline & 3.4 & 2.4 & 29.0 & 28.5 & 2.2 & n.d. & n.d. & n.d. & n.d. & 65.5 \\
\hline \multirow{2}{*}{50} & 3.1 & 2.1 & 24.6 & 22.6 & 1.7 & n.d. & n.d. & n.d. & n.d. & 54.2 \\
\hline & 2.9 & 2.0 & 24.3 & 22.3 & 1.7 & n.d. & n.d. & n.d. & n.d. & 53.2 \\
\hline \multirow{2}{*}{60} & 3.4 & 2.1 & 23.9 & 19.3 & 2.5 & n.d. & n.d. & n.d. & n.d. & 51.3 \\
\hline & 3.0 & 1.9 & 23.2 & 19.0 & 2.4 & n.d. & n.d. & n.d. & n.d. & 49.5 \\
\hline
\end{tabular}

n.d. $=$ not detected 
Table 8.19 - Lake Simcoe - SOS Chromotest IF values

\begin{tabular}{|c|c|c|c|c|c|c|c|c|c|c|c|c|}
\hline eqmL/well & \multicolumn{3}{|c|}{ Raw $\left(\right.$ no $\left.\mathrm{Cl}_{2}\right)$} & \multicolumn{3}{|c|}{$0 \mathrm{mg} / \mathrm{L}$ alum } & \multicolumn{3}{|c|}{$20 \mathrm{mg} / \mathrm{L}$ alum } & \multicolumn{3}{|c|}{30 mg/L alum } \\
\hline 66 & 1.30 & 1.27 & 1.31 & 0.97 & 0.99 & 1.03 & 1.18 & 1.26 & 1.28 & 1.96 & 1.98 & 2.06 \\
\hline 33 & 1.10 & 1.11 & 1.10 & 2.36 & 2.47 & 2.54 & 2.42 & 2.36 & 2.32 & 2.16 & 2.14 & 2.04 \\
\hline 16.5 & 1.08 & 1.06 & 1.07 & 2.01 & 1.83 & 2.05 & 1.64 & 1.55 & 1.64 & 1.52 & 1.48 & 1.52 \\
\hline 8.25 & 1.03 & 1.03 & 1.04 & 1.42 & 1.42 & 1.36 & 1.27 & 1.27 & 1.26 & 1.22 & 1.22 & 1.20 \\
\hline 4.125 & 0.99 & 1.01 & 1.01 & 1.17 & 1.18 & 1.14 & 1.14 & 1.11 & 1.12 & 1.09 & 1.05 & 1.07 \\
\hline 2.0625 & 1.00 & 1.03 & 1.03 & 1.10 & 1.08 & 1.10 & 1.01 & 1.06 & 1.07 & 1.06 & 1.05 & 1.04 \\
\hline eqmL/well & \multicolumn{3}{|c|}{40 mg/L alum } & \multicolumn{3}{|c|}{50 mg/L alum } & \multicolumn{3}{|c|}{$60 \mathrm{mg} / \mathrm{L}$ alum } & & & \\
\hline 66 & 1.21 & 1.21 & 1.21 & 1.81 & 1.67 & 1.98 & 1.48 & 1.06 & 1.05 & & & \\
\hline 33 & 2.50 & 2.49 & 2.61 & 2.47 & 2.46 & 2.36 & 2.65 & 2.65 & 2.54 & & & \\
\hline 16.5 & 1.65 & 1.63 & 1.66 & 1.67 & 1.64 & 1.73 & 1.92 & 1.88 & 1.86 & & & \\
\hline 8.25 & 1.29 & 1.26 & 1.27 & 1.31 & 1.27 & 1.22 & 1.34 & 1.32 & 1.29 & & & \\
\hline 4.125 & 1.11 & 1.11 & 1.10 & 1.11 & 1.09 & 1.12 & 1.15 & 1.16 & 1.14 & & & \\
\hline 2.0625 & 1.06 & 1.06 & 1.05 & 1.04 & 1.03 & 1.04 & 1.07 & 1.08 & 1.11 & & & \\
\hline
\end{tabular}

\subsection{Contribution of Measured DBPs to AOX - Sample Calculations}

To calculate the contribution of the measured DBPs to AOX, mass balance calculations on halogens are used. In each DBP compound, the level of halogenation (number of halogen atoms per molecule) is determined. Then, the concentrations are converted into $\mu \mathrm{g} / \mathrm{L} \mathrm{as}^{-}$ with stoichiometric mass balances. The conversions for each DBP measured are provided below:

\begin{tabular}{|c|c|c|c|}
\hline \multicolumn{2}{|c|}{ DBPs measured } & MW (g/mol) & \# of halogens \\
\hline \multirow{4}{*}{ TTHM } & TCM & 119.5 & 3 \\
\cline { 2 - 4 } & BDCM & 163.9 & 3 \\
\cline { 2 - 4 } & DBCM & 208.3 & 3 \\
\cline { 2 - 4 } & TBM & 252.7 & 3 \\
\hline \multirow{4}{*}{ HAA 9} & MCAA & 94.5 & 1 \\
\cline { 2 - 4 } & MBAA & 138.9 & 2 \\
\cline { 2 - 4 } & DCAA & 129 & 3 \\
\cline { 2 - 4 } & TCAA & 163.5 & 2 \\
\cline { 2 - 4 } & BCAA & 173.4 & 2 \\
\cline { 2 - 4 } & DBAA & 217.8 & 3 \\
\cline { 2 - 4 } & BDCAA & 207.9 & 3 \\
\cline { 2 - 4 } & DBCAA & 252.3 & 2 \\
\cline { 2 - 4 } & TBAA & 296.7 & 3 \\
\hline \multirow{7}{*}{$\begin{array}{c}\text { Halogenated } \\
\text { furanones }\end{array}$} & MX & 169.0 & \\
\cline { 2 - 4 } & MCA & 217.5 & \\
\hline
\end{tabular}




\section{Sample calculation:}

The molecular weight (MW) of a chlorine ion is $35.5 \mathrm{~g} / \mathrm{mol}$.

Using the concentration of TCM measured in Lake Simcoe water at an alum dose of $40 \mathrm{mg} / \mathrm{L}$ $\left(1^{\text {st }}\right.$ replicate $\left.=23.4 \mu \mathrm{g} / \mathrm{L}\right)$,

- $\quad$ \# of halogens in TCM: 3

- $\quad \mathrm{MW}$ of $\mathrm{TCM}=119.5 \mathrm{~g} / \mathrm{mol}$

- $\quad \mathrm{MW}$ of $\mathrm{Cl}^{-}=35.5 \mathrm{~g} / \mathrm{mol}$

TCM concentration $\left(\frac{\mu \mathrm{g}}{\mathrm{L}}\right.$ as $\left.\mathrm{Cl}^{-}\right)=\left(\frac{23.4 \mu \mathrm{g} \mathrm{TCM}}{L}\right)\left(\frac{\mathrm{mol}}{119.5 \mathrm{gTCM}}\right)\left(\frac{3\left(35.5 \mathrm{gCl}^{-}\right)}{\mathrm{mol}}\right)$

TCM concentration $\left(\frac{\mu \mathrm{g}}{\mathrm{L}}\right.$ as $\left.\mathrm{Cl}^{-}\right)=20.8 \frac{\mu \mathrm{g}}{\mathbf{L}}$ as $\mathbf{C l}^{-}$

With this concentration, a percent contribution to the AOX of that sample can be determined:

- $\quad$ AOX in Lake Simcoe water at alum dose of $40 \mathrm{mg} / \mathrm{L}\left(1^{\text {st }}\right.$ replicate $)=163.18 \mu \mathrm{g} / \mathrm{L}$ as $\mathrm{Cl}^{-}$

$\%$ contribution of TCM to $A O X=\left(\frac{20.8 \frac{\mu \mathrm{g}}{\mathrm{L}} \mathrm{as} \mathrm{Cl}^{-}}{163.18 \frac{\mu \mathrm{g}}{\mathrm{L}} \text { as } \mathrm{Cl}^{-}}\right) \times 100 \%=\mathbf{1 2 . 7 5} \%$

\subsection{Genotoxicity TEQ Calculations}

Toxicity equivalent concentration to 4-NQO (TEQ 4 -NQO) are used to relate IF values of water samples to those of a known carcinogen, 4-NQO. TEQ 4 -NQO is adapted from Wang et al. (2011):

$$
T E Q_{\text {sample }}=\frac{\text { Slope }_{\text {sample }}}{\text { Slope }_{4-N Q O S O S I P}}
$$

Where: $\quad$ Slope $_{\text {sample }}=$ linear portion of IF vs. REF slope for each sample

Slope $_{4-\mathrm{NQO}}$ SOSIP $=$ linear portion of IF vs. pmol/well for 4-NQO samples, with SOSIP correction factor applied 


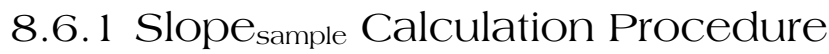

To relate IF values of water samples to those of a known carcinogen, 4-NQO, first the amount of sample in each step-wise dilution was quantified with a unit-less relative enrichment factor (Escher \& Leusch, 2011). A sample calculation is shown for the first dilution:

$R E F=\frac{\text { enrichment factor }_{\text {extraction }}}{\text { dilution factor } \text { fioassay }_{\text {fion }}}=\frac{\frac{2000 \mathrm{~mL}}{30 \mu L} \times \frac{1000 \mu L}{m L}}{\frac{1 \mu L}{205 \mu L}}=325.20$

Table 8.20 - Conversion of equivalent volumes (eqmL) to relative enrichment factors (REF) used in bioassay dilutions

\begin{tabular}{|c|c|c|c|}
\hline Step-wise dilution & $\begin{array}{c}\text { Volume of water } \\
\text { extract added }(\boldsymbol{\mu L})\end{array}$ & eqmL & REF \\
\hline 1 & 1 & 66 & 325.20 \\
\hline 2 & 0.5 & 33 & 162.60 \\
\hline 3 & 0.25 & 16.5 & 81.30 \\
\hline 4 & 0.125 & 8.25 & 40.65 \\
\hline 5 & 0.0625 & 4.125 & 20.33 \\
\hline 6 & 0.03125 & 2.0625 & 10.16 \\
\hline
\end{tabular}

Table 8.21 gives IF values for each dilution for samples from the three source waters. IF vs. REF is plotted, as shown in Figure for Ottawa River samples. The slope of the linear portion of each line ( Slope $_{\text {sample }}$ ) is calculated and given in Table 8.24.

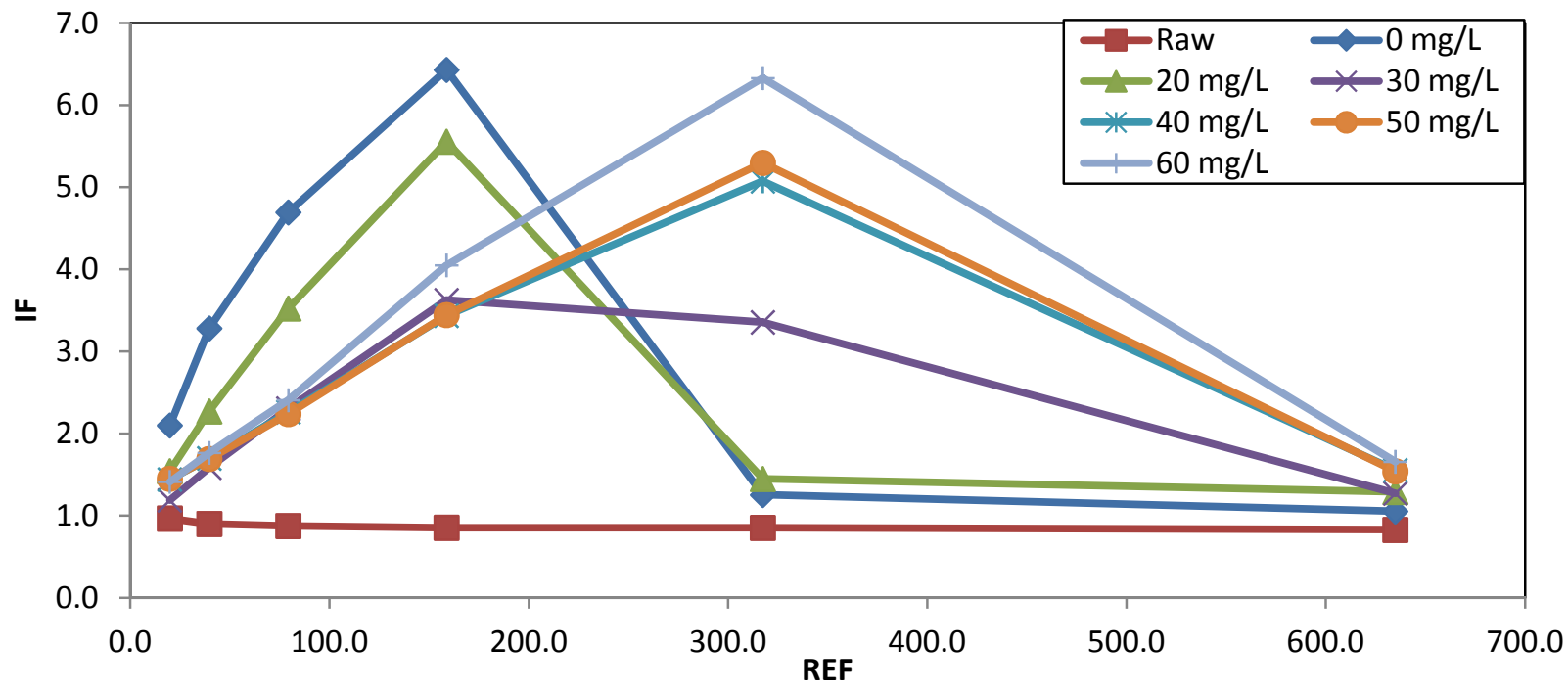

Figure 8.1 - IF vs. REF for Ottawa River samples 
Table 8.21 - IF values for each dilution in SOS Chromotest bioassays on the three source waters

\begin{tabular}{|c|c|c|c|c|c|c|c|c|}
\hline & & \multicolumn{7}{|c|}{ Ottawa River } \\
\hline REF & eqmL & $\begin{array}{l}\text { Raw - } \\
\text { no } \mathrm{Cl}_{2}\end{array}$ & $0 \mathrm{mg} / \mathrm{L}$ & $\begin{array}{c}20 \\
\mathrm{mg} / \mathrm{L}\end{array}$ & $\begin{array}{c}30 \\
\mathrm{mg} / \mathrm{L}\end{array}$ & $\begin{array}{c}40 \\
\mathrm{mg} / \mathrm{L}\end{array}$ & $\begin{array}{c}50 \\
\mathrm{mg} / \mathrm{L}\end{array}$ & $\begin{array}{c}60 \\
\mathrm{mg} / \mathrm{L}\end{array}$ \\
\hline 634.9 & 66 & 0.83 & 1.05 & 1.29 & 1.27 & 1.56 & 1.54 & 1.66 \\
\hline 317.5 & 33 & 0.85 & 1.25 & 1.45 & 3.36 & 5.07 & 5.30 & 6.33 \\
\hline 158.7 & 16.5 & 0.85 & 6.43 & 5.56 & 3.63 & 3.44 & 3.44 & 4.05 \\
\hline 79.4 & 8.25 & 0.88 & 4.69 & 3.53 & 2.30 & 2.26 & 2.24 & 2.41 \\
\hline 39.7 & 4.125 & 0.90 & 3.28 & 2.27 & 1.59 & 1.70 & 1.69 & 1.77 \\
\hline 19.8 & 2.0625 & 0.97 & 2.10 & 1.54 & 1.19 & 1.44 & 1.45 & 1.41 \\
\hline & & \multicolumn{7}{|c|}{ Otonabee River } \\
\hline REF & eqmL & $\begin{array}{l}\text { Raw - } \\
\text { no } \mathrm{Cl}_{2}\end{array}$ & $0 \mathrm{mg} / \mathrm{L}$ & $\begin{array}{c}20 \\
\mathrm{mg} / \mathrm{L}\end{array}$ & $\begin{array}{c}30 \\
\mathrm{mg} / \mathrm{L}\end{array}$ & $\begin{array}{c}40 \\
\mathrm{mg} / \mathrm{L}\end{array}$ & $\begin{array}{c}50 \\
\mathrm{mg} / \mathrm{L}\end{array}$ & $\begin{array}{c}60 \\
\mathrm{mg} / \mathrm{L}\end{array}$ \\
\hline 634.9 & 66 & 0.85 & 1.05 & 1.06 & 1.03 & 1.44 & 1.62 & 2.84 \\
\hline 317.5 & 33 & 1.22 & 4.23 & 2.89 & 1.43 & 4.66 & 6.41 & 5.73 \\
\hline 158.7 & 16.5 & 1.02 & 4.66 & 4.42 & 4.48 & 5.68 & 4.13 & 3.60 \\
\hline 79.4 & 8.25 & 0.95 & 3.10 & 2.87 & 3.19 & 3.50 & 2.51 & 2.34 \\
\hline 39.7 & 4.125 & 0.92 & 1.96 & 1.84 & 2.12 & 2.23 & 1.79 & 1.75 \\
\hline 19.8 & 2.0625 & 0.88 & 1.53 & 1.34 & 1.51 & 1.65 & 1.47 & 1.34 \\
\hline & & \multicolumn{7}{|c|}{ Lake Simcoe } \\
\hline REF & eqmL & $\begin{array}{l}\text { Raw - } \\
\text { no } \mathrm{Cl}_{2}\end{array}$ & $0 \mathrm{mg} / \mathrm{L}$ & $\begin{array}{c}20 \\
\mathrm{mg} / \mathrm{L}\end{array}$ & $\begin{array}{c}30 \\
\mathrm{mg} / \mathrm{L}\end{array}$ & $\begin{array}{c}40 \\
\mathrm{mg} / \mathrm{L}\end{array}$ & $\begin{array}{c}50 \\
\mathrm{mg} / \mathrm{L}\end{array}$ & $\begin{array}{c}60 \\
\mathrm{mg} / \mathrm{L}\end{array}$ \\
\hline 634.9 & 66 & 1.10 & 2.46 & 2.37 & 2.11 & 2.53 & 2.43 & 2.62 \\
\hline 317.5 & 33 & 1.07 & 1.97 & 1.61 & 1.50 & 1.65 & 1.68 & 1.89 \\
\hline 158.7 & 16.5 & 1.03 & 1.40 & 1.27 & 1.21 & 1.28 & 1.27 & 1.32 \\
\hline 79.4 & 8.25 & 1.00 & 1.16 & 1.12 & 1.07 & 1.11 & 1.11 & 1.15 \\
\hline 39.7 & 4.125 & 1.02 & 1.09 & 1.05 & 1.05 & 1.05 & 1.04 & 1.09 \\
\hline 19.8 & 2.0625 & 1.29 & 1.00 & 1.24 & 2.00 & 1.21 & 1.82 & 1.20 \\
\hline
\end{tabular}

8.6.2 Slope $_{4-\mathrm{NQO}}$ sosIP Calculation Procedure

A standard solution of $10 \mu \mathrm{g} / \mathrm{mL} 4-\mathrm{NQO}$ in DMSO is diluted step-wise in the bioassay along with the samples. The concentrations can be converted to from $\mu \mathrm{g} / \mathrm{mL}$ to pmol/well and are given in Table 8.22. The molecular weight of 4-NQO is $190.16 \mathrm{~g} / \mathrm{mol}$.

Sample calculation for the first dilution:

$\frac{10 \mu g}{m L} \times \frac{10 \mu L}{w e l l} \times \frac{m L}{1000 \mu L} \times \frac{1000 n g}{\mu g}=\frac{100 n g}{w e l l}$ 
$\frac{100 \mathrm{ng}}{\text { well }} \times \frac{\mathrm{mol}}{190.16 \mathrm{~g}} \times \frac{\mathrm{g}}{10^{9} \mathrm{ng}} \times \frac{10^{12} \mathrm{pmol}}{\mathrm{mol}}=525.87 \frac{\mathrm{pmol}}{\mathrm{well}}$

Table 8.22 - Concentrations of 4-NQO added to SOS Chromotest bioassay

\begin{tabular}{|c|c|c|c|c|}
\hline $\begin{array}{c}\text { Step-wise } \\
\text { dilution }\end{array}$ & $\begin{array}{c}\text { Volume of 10 } \mathbf{\mu g} / \mathbf{m L} \text { 4-NQO } \\
\text { added }(\boldsymbol{\mu L})\end{array}$ & ng/well & pmol/well & nmol/well \\
\hline 1 & 10 & 100 & 525.87 & 0.526 \\
\hline 2 & 5 & 50 & 262.94 & 0.263 \\
\hline 3 & 2.5 & 25 & 131.47 & 0.131 \\
\hline 4 & 1.25 & 12.5 & 65.73 & 0.066 \\
\hline 5 & 0.625 & 6.25 & 32.87 & 0.033 \\
\hline 6 & 0.3125 & 3.125 & 16.43 & 0.016 \\
\hline
\end{tabular}

IF values for each dilution of 4-NQO used for the three source waters are given in Table. IF vs. pmol/well is plotted for 4-NQO samples, and the linear portions of the slopes are calculated.

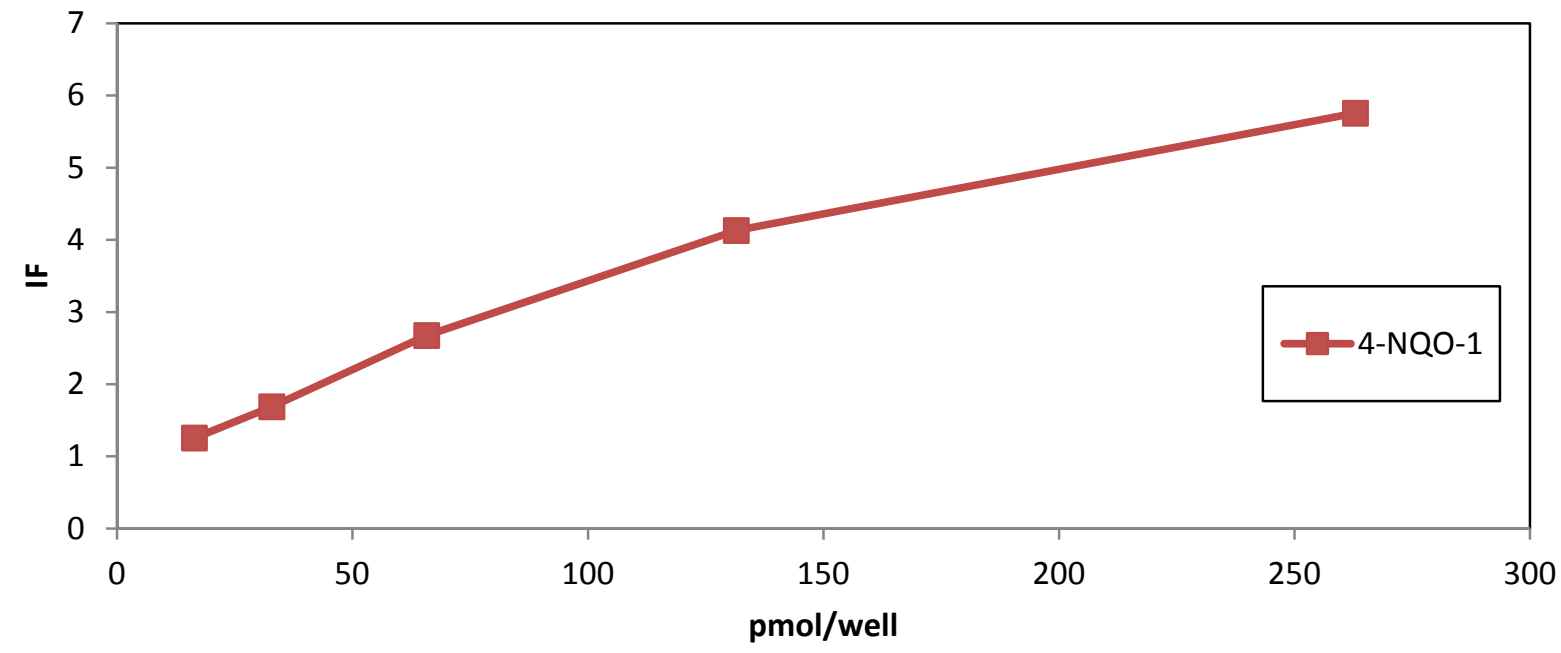

Figure 8.2 - IF vs. pmol/well for 4-NQO sample used in Ottawa River bioassays 
Table 8.23 - IF values for 4-NQO at each dilution in SOS Chromotest bioassays on the three source waters

\begin{tabular}{|c|c|c|c|c|}
\hline ng/well & pmol/well & Ottawa River & Otonabee River & Lake Simcoe \\
\hline 100 & 525.9 & 6.933 & 6.017 & 2.672 \\
\hline 50 & 262.9 & 5.756 & 5.467 & 3.942 \\
\hline 25 & 131.5 & 4.130 & 3.817 & 3.747 \\
\hline 12.5 & 65.7 & 2.674 & 2.357 & 2.926 \\
\hline 6.25 & 32.9 & 1.687 & 1.376 & 1.779 \\
\hline 3.125 & 16.4 & 1.254 & 1.062 & 1.280 \\
\hline
\end{tabular}

Potency factors with the SOS Chromotest (SOSIP) are unique to each compound and are calculated based on the linear portion of IF vs. concentration curves (Quillardet et al., 1982). The published SOSIP for 4-NQO is 71 (Quillardet et al., 1982) and this value can be used to account for reactivity discrepancies (e.g. changing incubation conditions, age of bacteria used, etc.) (EBPI, 2011). The SOSIP values for 4-NQO found in this study are normalized with 71 , to obtain a correction factor.

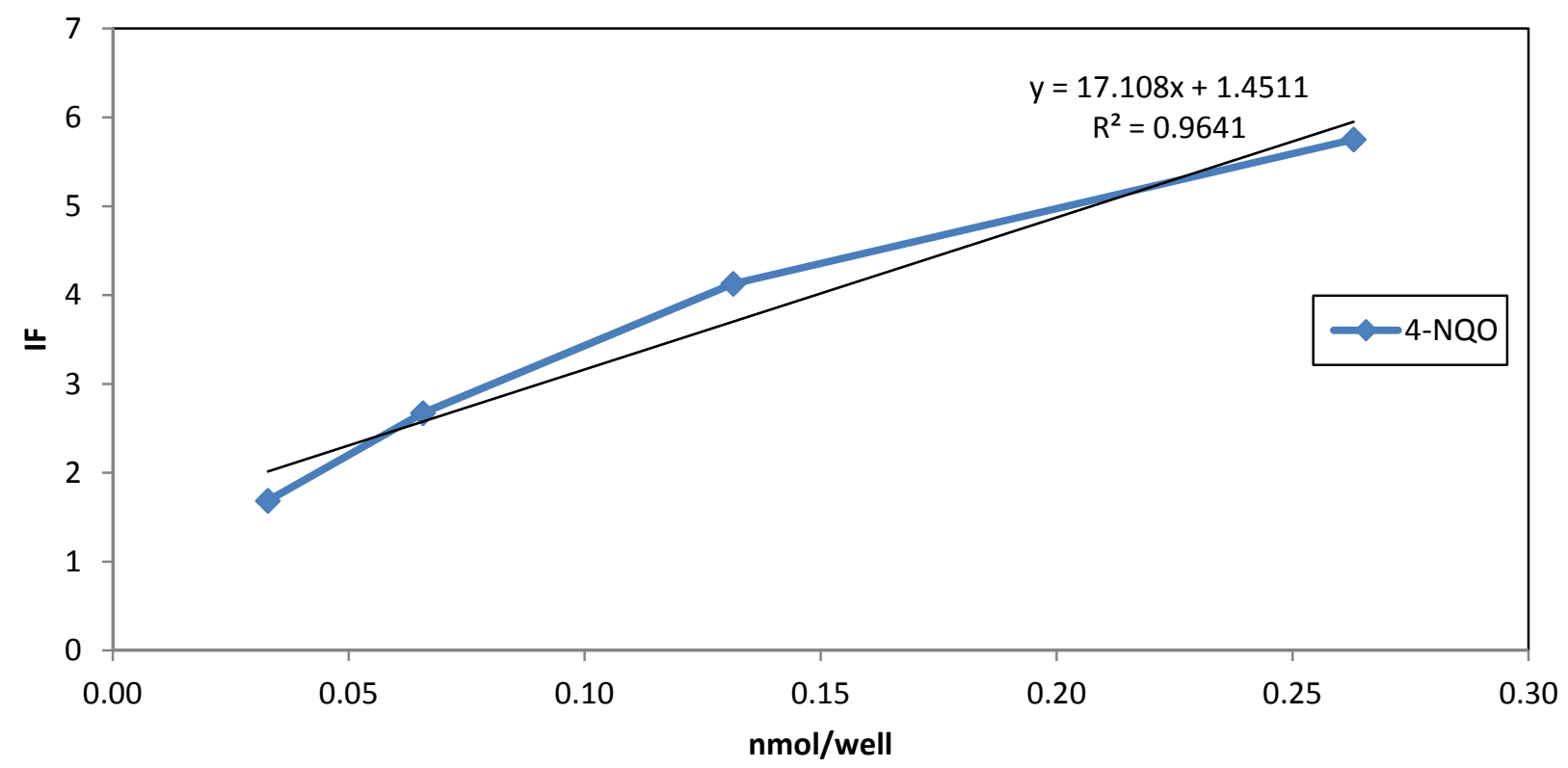

Figure 8.3 - IF vs. nmol/well for the determination of SOSIP 4 -NQO 
Correction factor $=\frac{\text { SOSIP }_{4-N Q O} \text { found in this study }}{\text { SOSIP }_{4-N Q O} \text { in Quillardet et al. }(1982)}=\frac{17.1}{71}=0.25$

This correction factor is applied to slopes found for IF vs. pmol/well (4-NQO samples) to obtain Slope 4 -NQO sosiP for 4-NQO samples and presented in Table 8.25.

8.6.3 TEQ $_{4-\mathrm{NQO}}$ Calculations

Finally, the toxicity equivalent concentration to 4-NQO (TEQ4-NQO) can be determined for the water samples. TEQ $4-\mathrm{NQO}$ is defined as:

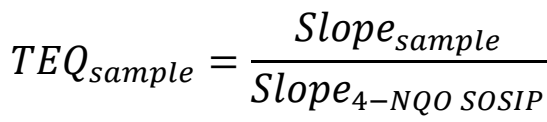

The calculation of $\mathrm{TEQ}_{4-\mathrm{NQO}}$ for Ottawa River water at a $0 \mathrm{mg} / \mathrm{L}$ alum dose is shown below; $\mathrm{TEQ}_{4-\mathrm{NQO}}$ values for all samples are presented in Table 8.26.

$T E Q_{0} \frac{m g}{L}$ alum, ottawa River $=\frac{\text { Slope }_{\text {sample }}}{\text { Slope }_{4-N Q O ~ S O S I P}}=\frac{0.0312}{0.071}=0.439$

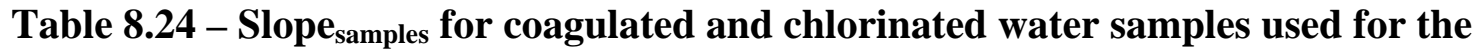
calculation of TEQ 4 -NQo values

\begin{tabular}{|c|c|c|c|}
\hline Alum dose (mg/L) & Ottawa River & Otonabee River & Lake Simcoe \\
\hline $\mathbf{0}$ & 0.0312 & 0.0226 & 0.00628 \\
\hline $\mathbf{2 0}$ & 0.0289 & 0.0222 & 0.00407 \\
\hline $\mathbf{3 0}$ & 0.0176 & 0.0214 & 0.00329 \\
\hline $\mathbf{4 0}$ & 0.0144 & 0.0291 & 0.00427 \\
\hline $\mathbf{5 0}$ & 0.0144 & 0.0191 & 0.00465 \\
\hline $\mathbf{6 0}$ & 0.0190 & 0.0163 & 0.00576 \\
\hline
\end{tabular}

Table 8.25 - SOSIP correction factors and Slope 4 -NQO sosIP for 4-NQO samples used for the calculation of TEQ $_{4-N Q O}$ values

\begin{tabular}{|c|c|c|c|}
\hline & Ottawa River & Otonabee River & Lake Simcoe \\
\hline Correction factor & 0.25 & 0.35 & 0.85 \\
\hline Slope $_{\text {4-NQO SOSIP }}$ & 0.071 & 0.071 & 0.023 \\
\hline
\end{tabular}


Table 8.26 - TEQ $_{4-\mathrm{NQO}}$ values

\begin{tabular}{|c|c|c|c|}
\hline & & & \\
Alum dose (mg/L) & Ottawa River & Otonabee River & Lake Simcoe \\
\hline $\mathbf{0}$ & 0.439 & 0.316 & 0.257 \\
\hline $\mathbf{2 0}$ & 0.407 & 0.311 & 0.167 \\
\hline $\mathbf{3 0}$ & 0.247 & 0.299 & 0.135 \\
\hline $\mathbf{4 0}$ & 0.202 & 0.407 & 0.175 \\
\hline $\mathbf{5 0}$ & 0.202 & 0.268 & 0.190 \\
\hline $\mathbf{6 0}$ & 0.267 & 0.228 & 0.236 \\
\hline
\end{tabular}

\subsection{Statistical Analyses Data and Sample Calculations}

\subsubsection{Two-way ANOVA for the Determination of Chlorine Residual Influence on DBP Formation}

For each measured DBP, the following ANOVA test was applied. Using alum dose as the main effect for DBP formation and measured chlorine residual as a secondary effect, the twoway ANOVA model is given by:

where: $\quad \begin{aligned} & \mu=\text { the grand mean of the observations } \\ & \mathrm{A}=\text { the effect of alum dose } \\ & \mathrm{B}=\text { the effect of measured chlorine residual } \\ & \mathrm{AB}=\text { the effect of interaction between A and } \mathrm{B} \\ & \varepsilon=\text { normally distributed random error (zero mean) } \\ & \mathrm{i}=\text { index of experimental units }(1,2) \\ & \mathrm{j}=\text { level of alum doses }(1-6)\end{aligned}$

The three null hypotheses tested to assess statistical significance on DBP formation were:

4. $\mathrm{H}_{0}$ : all $\mathrm{A}_{\mathrm{ij}}$ are zero (i.e. alum dose has no significant influence; $\mathrm{p}<\alpha$ )

5. $\mathrm{H}_{0}$ : all $\mathrm{B}_{\mathrm{ij}}$ are zero (i.e. chlorine residual has no significant influence; $p<\alpha$ )

6. $\mathrm{H}_{0}$ : all $(\mathrm{AB})_{\mathrm{ij}}$ are zero (i.e. the interaction between applied alum dose and measured chlorine residual has no significant influence; $p<\alpha$ )

A confidence level of $99 \%(\alpha=0.01)$ was chosen to be more restrictive on Type I errors (the false rejection of null hypotheses). This was to prevent compounding of error due to the different sources (e.g. error in each analytical technique). 
Table 8.27 - Two-way ANOVA for Ottawa River water

\begin{tabular}{|c|c|c|c|c|c|c|c|}
\hline & \multicolumn{2}{|c|}{ Alum effect } & \multicolumn{2}{|c|}{$\begin{array}{c}\text { Chlorine residual } \\
\text { effect }\end{array}$} & \multicolumn{2}{|c|}{ Interaction effect } & \multirow[t]{2}{*}{ MSE } \\
\hline & F Ratio & p-value & F Ratio & p-value & F Ratio & p-value & \\
\hline AOX $(\mu g / L)$ & 15.04 & 0.0605 & 3.086 & 0.221 & 0.287 & 0.646 & 16642.4 \\
\hline TTHM( & 495.87 & 0.0001 & 12.44 & 0.018 & 15.43 & 0.044 & 3908.75 \\
\hline HAA $_{9}(\mu \mathrm{g} / \mathrm{L})$ & 82.84 & 0.0001 & 17.13 & 0.033 & 0.389 & 0.551 & 1170.21 \\
\hline MCA (ng/L) & 19.27 & 0.0023 & 9.41 & 0.015 & 0.0012 & 0.973 & 715008 \\
\hline MX (ng/L) & 42.22 & 0.0002 & 15.31 & 0.015 & 2.943 & 0.125 & 20.0519 \\
\hline $\begin{array}{l}\text { Genotoxicity } \\
\text { (TEQ4-NQO) }\end{array}$ & 17.34 & 0.0531 & 5.48 & 0.144 & 4.85 & 0.159 & 0.0165 \\
\hline
\end{tabular}

- Values in bold indicate correlations that are significant $(p<0.01)$

Table 8.28 - Two-way ANOVA for Otonabee River water

\begin{tabular}{|c|c|c|c|c|c|c|c|}
\hline & \multicolumn{2}{|c|}{ Alum effect } & \multicolumn{2}{|c|}{$\begin{array}{c}\text { Chlorine residual } \\
\text { effect }\end{array}$} & \multicolumn{2}{|c|}{ Interaction effect } & \multirow{2}{*}{ MSE } \\
\hline & F Ratio & p-value & F Ratio & p-value & F Ratio & p-value & \\
\hline AOX $(\mu g / L)$ & 201.61 & 0.0001 & 13.80 & 0.0059 & 24.12 & 0.0212 & 10097.2 \\
\hline TTHM( $(\mu \mathrm{g} / \mathrm{L})$ & 199.90 & 0.0001 & 17.572 & 0.0030 & 20.03 & 0.0021 & 3476.77 \\
\hline $\mathrm{HAA}_{9}(\mu \mathrm{g} / \mathrm{L})$ & 162.45 & 0.0001 & 0.793 & 0.399 & 0.0113 & 0.918 & 2026.31 \\
\hline MCA (ng/L) & 64.18 & 0.0001 & 6.084 & 0.0389 & 0.2142 & 0.6558 & 91378.7 \\
\hline MX (ng/L) & \multicolumn{7}{|c|}{ MX not detected above detection limit $(<12 \mathrm{ng} / \mathrm{L})$} \\
\hline $\begin{array}{l}\text { Genotoxicity } \\
\text { (TEQ4-NQO) }\end{array}$ & 14.30 & 0.0633 & 46.006 & 0.0211 & 23.49 & 0.04 & 0.00576 \\
\hline
\end{tabular}

- Values in bold indicate correlations that are significant $(\mathrm{p}<0.01)$

Table 8.29 - Two-way ANOVA for Lake Simcoe water

\begin{tabular}{|c|c|c|c|c|c|c|c|}
\hline & \multicolumn{2}{|c|}{ Alum effect } & \multicolumn{2}{|c|}{$\begin{array}{c}\text { Chlorine residual } \\
\text { effect }\end{array}$} & \multicolumn{2}{|c|}{ Interaction effect } & \multirow[t]{2}{*}{ MSE } \\
\hline & F Ratio & p-value & F Ratio & p-value & F Ratio & p-value & \\
\hline AOX $(\mu g / L)$ & 68.38 & 0.0001 & 0.0664 & 0.803 & 0.0777 & 0.788 & 3176.19 \\
\hline TTHM( $\mu g / L)$ & 35.865 & 0.0003 & 0.0309 & 0.865 & 0.5933 & 0.4633 & 243.45 \\
\hline HAA $_{9}(\mu \mathrm{g} / \mathrm{L})$ & 616.62 & 0.0001 & 1.501 & 0.255 & 3.228 & 0.110 & 2075.61 \\
\hline MCA (ng/L) & 28.089 & 0.0018 & 3.038 & 0.132 & 3.305 & 0.119 & 33573 \\
\hline MX (ng/L) & 0.358 & 0.592 & 1.704 & 0.283 & 2.326 & 0.225 & 0.185 \\
\hline $\begin{array}{l}\text { Genotoxicity } \\
\text { (TEQ4-NQO) }\end{array}$ & 0.935 & 0.436 & 0.514 & 0.548 & 1.265 & 0.378 & 0.00144 \\
\hline
\end{tabular}

- Values in bold indicate correlations that are significant $(\mathrm{p}<0.01)$ 
8.7.2 Hypothesis Testing for Correlation Significance between NOM and DBP Formation

Table 8.30 - Correlations in Ottawa River water between DBP formation and water quality parameters

\begin{tabular}{|c|c|c|c|c|c|c|c|c|c|c|c|c|}
\hline & & & & & & & \multicolumn{6}{|c|}{ NOM Fractions - LC-OCD (mg/L) } \\
\hline & & 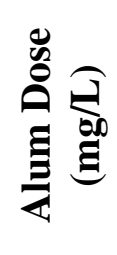 & 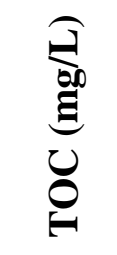 & 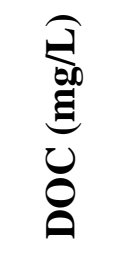 & 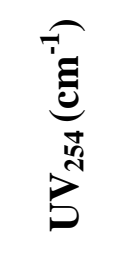 & 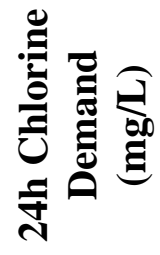 & $\begin{array}{l}0 \\
0 \\
0 \\
\text { 룸 }\end{array}$ & 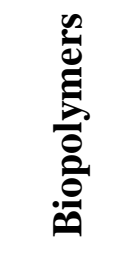 & 兰导 & 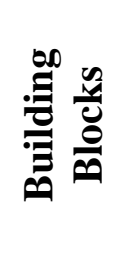 & 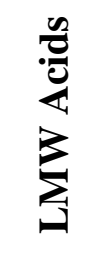 & 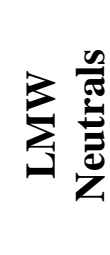 \\
\hline \multirow{2}{*}{$\operatorname{AOX}(\mu g / L)$} & $\mathbf{R}^{2}$ & 0.93 & 0.996 & 0.98 & 0.98 & 0.99 & 0.97 & 0.86 & 0.97 & 0.97 & 0.37 & 0.77 \\
\hline & $\mathbf{p}$ & 0.017 & 0.0003 & 0.0058 & 0.0035 & 0.0006 & 0.0052 & 0.053 & 0.0047 & 0.0041 & 0.494 & 0.108 \\
\hline \multirow{2}{*}{ TTHM( $\mu \mathrm{g} / \mathrm{L})$} & $\mathbf{R}^{2}$ & 0.97 & 0.96 & 0.98 & 0.96 & 0.96 & 0.98 & 0.92 & 0.96 & 0.96 & 0.33 & 0.88 \\
\hline & $\mathbf{p}$ & 0.0001 & 0.0001 & 0.0001 & 0.0001 & 0.0001 & 0.0001 & 0.0001 & 0.0001 & 0.0001 & 0.167 & 0.0001 \\
\hline \multirow{2}{*}{$\mathbf{H A A}_{9}(\mu \mathrm{g} / \mathrm{L})$} & $\mathbf{R}^{2}$ & 0.96 & 0.98 & 0.98 & 0.99 & 0.99 & 0.97 & 0.91 & 0.99 & 0.96 & 0.34 & 0.82 \\
\hline & $\mathbf{p}$ & 0.0001 & 0.0001 & 0.0001 & 0.0001 & 0.0001 & 0.0001 & 0.0001 & 0.0001 & 0.0001 & 0.156 & 0.0005 \\
\hline \multirow{2}{*}{ MCA (ng/L) } & $\mathbf{R}^{2}$ & 0.88 & 0.88 & 0.90 & 0.92 & 0.88 & 0.90 & 0.89 & 0.91 & 0.85 & 0.38 & 0.81 \\
\hline & $\mathbf{p}$ & 0.0001 & $\mathbf{0 . 0 0 0 1}$ & 0.0001 & 0.0001 & $\mathbf{0 . 0 0 0 1}$ & 0.0001 & 0.0001 & $\mathbf{0 . 0 0 0 1}$ & 0.0002 & 0.113 & $\mathbf{0 . 0 0 0 6}$ \\
\hline \multirow{2}{*}{ MX (ng/L) } & $\mathbf{R}^{2}$ & 0.97 & 0.97 & 0.93 & 0.93 & 0.97 & 0.92 & 0.78 & 0.92 & 0.96 & 0.40 & 0.66 \\
\hline & $\mathbf{p}$ & 0.0001 & 0.0001 & 0.0001 & 0.0001 & 0.0001 & 0.0001 & 0.0011 & 0.0001 & 0.0001 & 0.097 & 0.0079 \\
\hline \multirow{2}{*}{$\begin{array}{l}\text { Genotoxicity } \\
\text { (TEQ4-NQO) }\end{array}$} & $\mathbf{R}^{2}$ & 0.73 & 0.89 & 0.80 & 0.79 & 0.88 & 0.77 & 0.60 & 0.77 & 0.92 & 0.27 & 0.48 \\
\hline & $\mathbf{p}$ & 0.14 & 0.04 & 0.09 & 0.10 & 0.04 & 0.11 & 0.26 & 0.11 & 0.02 & 0.62 & 0.38 \\
\hline
\end{tabular}

- Values in bold indicate correlations that are significant $(\mathrm{p}<0.01)$ 
Table 8.31 - Correlations in Ottawa River water between specific DBPs formed

\begin{tabular}{|c|c|c|c|c|c|c|c|}
\hline & & $\begin{array}{l}\text { AOX } \\
(\mu g / L)\end{array}$ & $\begin{array}{c}\text { THM } \\
(\mu g / L)\end{array}$ & $\begin{array}{l}\text { HAA }_{9} \\
(\mu g / L)\end{array}$ & $\begin{array}{l}\text { MCA } \\
\text { (ng/L) }\end{array}$ & $\begin{array}{c}\text { MX } \\
(\mathbf{n g} / \mathrm{L})\end{array}$ & $\begin{array}{l}\text { Genotoxicity } \\
\left.\text { (TEQ }_{4-\mathrm{NQO}}\right)\end{array}$ \\
\hline \multirow{2}{*}{$\operatorname{AOX}(\mu \mathrm{g} / \mathrm{L})$} & $\mathbf{R}$ & & 0.94 & 0.99 & 0.99 & 0.99 & 0.94 \\
\hline & $\mathbf{p}$ & & 0.0052 & 0.0002 & 0.0002 & 0.0002 & 0.005 \\
\hline \multirow{2}{*}{ TTHM ( $\mu \mathrm{g} / \mathrm{L})$} & $\mathbf{R}$ & 0.94 & & 0.96 & 0.88 & 0.90 & 0.87 \\
\hline & $\mathbf{p}$ & 0.0052 & & 0.0001 & 0.0001 & 0.0001 & 0.03 \\
\hline \multirow{2}{*}{$\mathrm{HAA}_{9}(\mu \mathrm{g} / \mathrm{L})$} & $\mathbf{R}$ & 0.99 & 0.96 & & 0.95 & 0.96 & 0.91 \\
\hline & $\mathbf{p}$ & 0.0002 & 0.0001 & & 0.0001 & 0.0001 & 0.01 \\
\hline \multirow{2}{*}{ MCA (ng/L) } & $\mathbf{R}$ & 0.99 & 0.88 & 0.95 & & 0.91 & 0.91 \\
\hline & $\mathbf{p}$ & 0.0002 & 0.0001 & 0.0001 & & 0.0001 & 0.01 \\
\hline \multirow{2}{*}{ MX (ng/L) } & $\mathbf{R}$ & 0.99 & 0.90 & 0.96 & 0.91 & & 0.95 \\
\hline & $\mathbf{p}$ & 0.0002 & 0.0001 & 0.0001 & 0.0001 & & 0.003 \\
\hline \multirow{2}{*}{$\begin{array}{l}\text { Genotoxicity } \\
\left.\text { (TEQ }_{4-\mathrm{NQO}}\right)\end{array}$} & $\mathbf{R}$ & 0.94 & 0.87 & 0.91 & 0.91 & 0.95 & \\
\hline & $\mathbf{p}$ & 0.005 & 0.03 & 0.01 & 0.01 & 0.003 & \\
\hline
\end{tabular}

- Values in bold indicate correlations that are significant $(\mathrm{p}<0.01)$ 
Table 8.32 - Correlations in Otonabee River water between DBP formation and water quality parameters

\begin{tabular}{|c|c|c|c|c|c|c|c|c|c|c|c|c|}
\hline & & & & & & & \multicolumn{6}{|c|}{ NOM Fractions - LC-OCD (mg/L) } \\
\hline & & 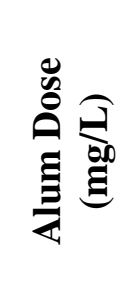 & 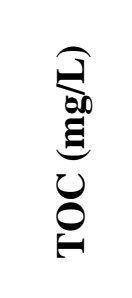 & 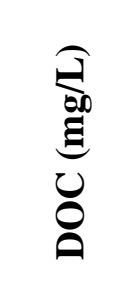 & 苗 & 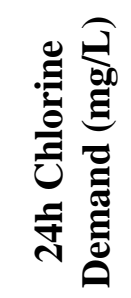 & 巳 & 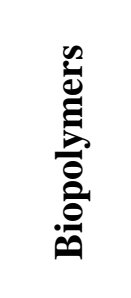 & 弟 & 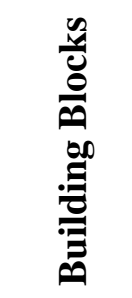 & $\begin{array}{l}\frac{n}{2} \\
\sum_{j}^{2} \\
\sum\end{array}$ & 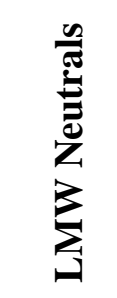 \\
\hline \multirow{2}{*}{$\operatorname{AOX}(\mu \mathrm{g} / \mathrm{L})$} & $\mathbf{R}^{2}$ & 0.94 & 0.95 & 0.92 & 0.91 & 0.91 & 0.91 & 0.84 & 0.84 & 0.92 & 0.67 & 0.52 \\
\hline & $\mathbf{p}$ & 0.0001 & 0.0001 & 0.0001 & 0.0001 & 0.0001 & 0.0001 & 0.0003 & 0.0003 & 0.0001 & 0.0065 & 0.0357 \\
\hline \multirow{2}{*}{$\begin{array}{l}\text { TTHM } \\
(\mu \mathrm{g} / \mathrm{L})\end{array}$} & $\mathbf{R}^{2}$ & 0.94 & 0.90 & 0.96 & 0.94 & 0.95 & 0.88 & 0.95 & 0.96 & 0.93 & 0.62 & 0.52 \\
\hline & p & 0.0001 & 0.0001 & 0.0001 & 0.0001 & 0.0001 & 0.0001 & 0.0001 & 0.0001 & 0.0001 & 0.0125 & 0.0375 \\
\hline \multirow{2}{*}{$\begin{array}{l}\mathrm{HAA}_{9} \\
(\mu \mathrm{g} / \mathrm{L})\end{array}$} & $\mathbf{R}^{2}$ & 0.98 & 0.98 & 0.98 & 0.99 & 0.98 & 0.99 & 0.97 & 0.98 & 0.96 & 0.74 & 0.64 \\
\hline & $\mathbf{p}$ & 0.0001 & 0.0001 & 0.0001 & 0.0001 & 0.0001 & 0.0001 & 0.0001 & 0.0001 & 0.0001 & 0.0023 & 0.0105 \\
\hline \multirow{2}{*}{ MCA (ng/L) } & $\mathbf{R}^{2}$ & 0.96 & 0.95 & 0.96 & 0.95 & 0.95 & 0.94 & 0.92 & 0.94 & 0.94 & 0.71 & 0.67 \\
\hline & $\mathbf{p}$ & 0.0001 & 0.0001 & 0.0001 & 0.0001 & 0.0001 & 0.0001 & 0.0001 & 0.0001 & 0.0001 & 0.0038 & 0.0068 \\
\hline MX (ng/L) & $\frac{\mathbf{R}^{2}}{\mathrm{D}}$ & \multicolumn{11}{|c|}{ MX below detection limit } \\
\hline \multirow{2}{*}{$\begin{array}{c}\text { Genotoxicity } \\
\text { (TEQ4-NQO) }\end{array}$} & $\mathbf{R}^{2}$ & 0.59 & 0.60 & 0.66 & 0.67 & 0.66 & 0.59 & 0.77 & 0.75 & 0.61 & 0.68 & 0.08 \\
\hline & p & 0.26 & 0.25 & 0.19 & 0.19 & 0.20 & 0.26 & 0.11 & 0.12 & 0.24 & 0.18 & 0.89 \\
\hline
\end{tabular}

- Values in bold indicate correlations that are significant $(\mathrm{p}<0.01)$ 
Table 8.33 - Correlations in Otonabee River water between species of DBPs formed

\begin{tabular}{|c|c|c|c|c|c|c|c|}
\hline & & $\begin{array}{l}\text { AOX } \\
(\mu g / L)\end{array}$ & $\begin{array}{l}\text { THM } \\
(\mu \mathrm{g} / \mathrm{L})\end{array}$ & $\begin{array}{l}\text { HAA }_{9} \\
(\mu \mathrm{g} / \mathrm{L})\end{array}$ & $\begin{array}{l}\text { MCA } \\
\text { (ng/L) }\end{array}$ & $\begin{array}{c}\text { MX } \\
\text { (ng/L) }\end{array}$ & $\begin{array}{l}\text { Genotoxicity } \\
\left.\text { (TEQ }_{4-\mathrm{NQO}}\right)\end{array}$ \\
\hline \multirow{2}{*}{$\operatorname{AOX}(\mu \mathrm{g} / \mathrm{L})$} & $\mathbf{R}$ & & 0.89 & 0.95 & 0.92 & \multirow{8}{*}{ 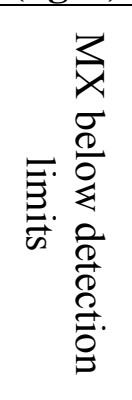 } & 0.28 \\
\hline & $\mathbf{p}$ & & 0.0001 & 0.0001 & 0.0001 & & 0.60 \\
\hline \multirow{2}{*}{ TTHM ( $\mu g / L)$} & $\mathbf{R}$ & 0.89 & & 0.95 & 0.94 & & 0.42 \\
\hline & $\mathbf{p}$ & 0.0001 & & 0.0001 & 0.0001 & & 0.41 \\
\hline \multirow{2}{*}{$\mathrm{HAA}_{9}(\mu \mathrm{g} / \mathrm{L})$} & $\mathbf{R}$ & 0.95 & 0.95 & & 0.97 & & 0.27 \\
\hline & $\mathbf{p}$ & 0.0001 & 0.0001 & & 0.0001 & & 0.61 \\
\hline \multirow{2}{*}{ MCA (ng/L) } & $\mathbf{R}$ & 0.92 & 0.94 & 0.97 & & & 0.06 \\
\hline & $\mathbf{p}$ & 0.0001 & 0.0001 & 0.0001 & & & 0.91 \\
\hline \multirow{2}{*}{ MX (ng/L) } & $\mathbf{R}$ & \multirow{2}{*}{\multicolumn{6}{|c|}{ MX below detection limits }} \\
\hline & $\mathbf{p}$ & & & & & & \\
\hline \multirow{2}{*}{$\begin{array}{l}\text { Genotoxicity } \\
\left.\text { (TEQ }_{4-\mathrm{NQO}}\right)\end{array}$} & $\mathbf{R}$ & 0.28 & 0.42 & 0.27 & 0.06 & & \\
\hline & $\mathbf{p}$ & 0.60 & 0.41 & 0.61 & 0.91 & & \\
\hline
\end{tabular}

- Values in bold indicate correlations that are significant $(\mathrm{p}<0.01)$ 
Table 8.34 - Correlations in Lake Simcoe water between DBP formation and water quality parameters

\begin{tabular}{|c|c|c|c|c|c|c|c|c|c|c|c|c|}
\hline & & & & & & & \multicolumn{6}{|c|}{ NOM Fractions - LC-OCD (mg/L) } \\
\hline & & 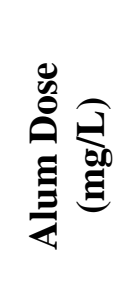 & 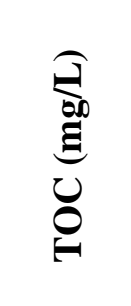 & 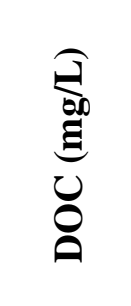 & 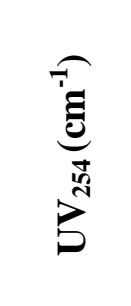 & 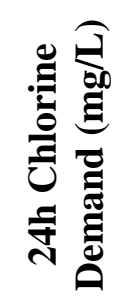 & 巳̆ & 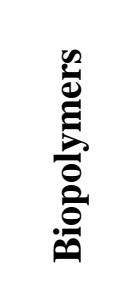 & ·䍖 & 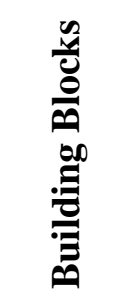 & $\begin{array}{l}\frac{n}{2} \\
\frac{2}{4} \\
\sum_{j}^{3}\end{array}$ & 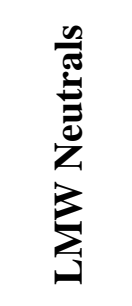 \\
\hline \multirow{2}{*}{$\operatorname{AOX}(\mu \mathrm{g} / \mathrm{L})$} & $\mathbf{R}^{2}$ & 0.94 & 0.94 & 0.93 & 0.94 & 0.90 & 0.94 & 0.95 & 0.87 & 0.68 & 0.84 & 0.91 \\
\hline & $\mathbf{p}$ & 0.0001 & 0.0001 & 0.0001 & 0.0001 & 0.0001 & 0.0001 & 0.0001 & 0.0001 & 0.0057 & 0.0003 & 0.0001 \\
\hline \multirow{2}{*}{$\operatorname{TTHM}(\mu \mathrm{g} / \mathrm{L})$} & $\mathbf{R}^{2}$ & 0.87 & 0.90 & 0.90 & 0.91 & 0.96 & 0.92 & 0.91 & 0.95 & 0.53 & 0.82 & 0.83 \\
\hline & $\mathbf{p}$ & 0.0001 & 0.0001 & 0.0001 & 0.0001 & 0.0001 & 0.0001 & 0.001 & 0.0001 & 0.0329 & 0.0005 & 0.0003 \\
\hline \multirow{2}{*}{$\mathrm{HAA}_{9}(\mu \mathrm{g} / \mathrm{L})$} & $\mathbf{R}^{2}$ & 0.99 & 0.99 & 0.99 & 0.99 & 0.93 & 0.99 & 0.99 & 0.88 & 0.78 & 0.79 & 0.90 \\
\hline & $\mathbf{p}$ & 0.0001 & 0.0001 & 0.0001 & 0.0001 & 0.0001 & 0.0001 & 0.0001 & 0.0001 & 0.001 & 0.001 & 0.0001 \\
\hline \multirow{2}{*}{ MCA (ng/L) } & $\mathbf{R}^{2}$ & 0.73 & 0.74 & 0.80 & 0.83 & 0.88 & 0.83 & 0.79 & 0.90 & 0.38 & 0.69 & 0.66 \\
\hline & $\mathbf{p}$ & 0.0105 & 0.0086 & 0.0035 & 0.0020 & 0.0006 & 0.0022 & 0.0042 & 0.0003 & 0.183 & 0.017 & 0.023 \\
\hline \multirow{2}{*}{ MX (ng/L) } & $\mathbf{R}^{2}$ & 0.37 & 0.37 & 0.37 & 0.37 & 0.43 & 0.40 & 0.39 & 0.42 & 0.13 & 0.34 & 0.41 \\
\hline & $\mathbf{p}$ & 0.39 & 0.397 & 0.39 & 0.40 & 0.33 & 0.36 & 0.38 & 0.34 & 0.75 & 0.44 & 0.35 \\
\hline \multirow{2}{*}{$\begin{array}{l}\text { Genotoxicity } \\
\text { (TEQ4-NQO) }\end{array}$} & $\mathbf{R}^{2}$ & 0.11 & 0.14 & 0.19 & 0.19 & 0.21 & 0.48 & 0.17 & 0.36 & 0.08 & 0.05 & 0.06 \\
\hline & $\mathbf{p}$ & 0.84 & 0.80 & 0.73 & 0.73 & 0.70 & 0.37 & 0.75 & 0.84 & 0.89 & 0.92 & 0.92 \\
\hline
\end{tabular}

\footnotetext{
- Values in bold indicate correlations that are significant $(p<0.01)$
} 
Table 8.35 - Correlations in Lake Simcoe water between species of DBPs formed

\begin{tabular}{|c|c|c|c|c|c|c|c|}
\hline & & $\begin{array}{c}\text { AOX } \\
(\mu g / L)\end{array}$ & $\begin{array}{c}\text { THM } \\
(\mu g / L)\end{array}$ & $\begin{array}{l}\text { HAA }_{9} \\
(\mu g / L)\end{array}$ & $\begin{array}{l}\text { MCA } \\
\text { (ng/L) }\end{array}$ & $\begin{array}{c}\text { MX } \\
\text { (ng/L) }\end{array}$ & $\begin{array}{l}\text { Genotoxicity } \\
\left.\text { (TEQ }_{4-\mathrm{NQO}}\right)\end{array}$ \\
\hline \multirow{2}{*}{$\operatorname{AOX}(\mu \mathrm{g} / \mathrm{L})$} & $\mathbf{R}$ & & 0.92 & 0.95 & 0.85 & 0.74 & 0.01 \\
\hline & $\mathbf{p}$ & & 0.0001 & 0.0001 & 0.002 & 0.06 & 0.90 \\
\hline \multirow{2}{*}{ TTHM ( $\mu \mathrm{g} / \mathrm{L})$} & $\mathbf{R}$ & 0.92 & & 0.95 & 0.91 & 0.56 & 0.13 \\
\hline & $\mathbf{p}$ & 0.0001 & & 0.0001 & 0.0003 & 0.19 & 0.47 \\
\hline \multirow{2}{*}{$\mathrm{HAA}_{9}(\mu \mathrm{g} / \mathrm{L})$} & $\mathbf{R}$ & 0.95 & 0.95 & & 0.86 & 0.59 & 0.05 \\
\hline & $\mathbf{p}$ & 0.0001 & 0.0001 & & 0.001 & 0.17 & 0.68 \\
\hline \multirow{2}{*}{ MCA (ng/L) } & $\mathbf{R}$ & 0.85 & 0.91 & 0.86 & & 0.39 & 0.60 \\
\hline & $\mathbf{p}$ & 0.002 & 0.0003 & 0.001 & & 0.52 & 0.29 \\
\hline \multirow{2}{*}{ MX (ng/L) } & $\mathbf{R}$ & 0.74 & 0.56 & 0.59 & 0.39 & & 0.00 \\
\hline & $\mathbf{p}$ & 0.06 & 0.19 & 0.17 & 0.52 & & - \\
\hline \multirow{2}{*}{$\begin{array}{l}\text { Genotoxicity } \\
\left.\text { (TEQ }_{4-\mathrm{NQO}}\right)\end{array}$} & $\mathbf{R}$ & 0.01 & 0.13 & 0.05 & 0.60 & 0.00 & \\
\hline & $\mathbf{p}$ & 0.90 & 0.47 & 0.68 & 0.29 & - & \\
\hline
\end{tabular}

- Values in bold indicate correlations that are significant $(\mathrm{p}<0.01)$ 


\subsubsection{Determination of Source Water Effect on DBP Formation Modeling}

An analysis of variance (ANOVA) test is used to determine effect of source waters on DBP formation. Tukey's Honestly Significant Difference (HSD) post-hoc testing was applied to determine if the sample sets (defined by source water) vary significantly from each other.

The three fractions of NOM determined to be most correlated with DBP formation: humics, biopolymers, and building blocks, are implemented as effects, as well as water source, in models of individual DBP formation (for each DBP measured). Tukey's HSD at a 95\% confidence interval was determined by comparing the Least Squares Means (LS Means) of each sample set (defined by source water). If difference in LS Means between sample sets exceeds the HSD (defined in Equation 3.9), then the sample sets are defined as significantly different from each other.

$$
H S D=q_{0.05,6} \sqrt{\frac{M S E}{n}}
$$

Where: $\quad \mathrm{q}=$ the studentized range statistic (table value)

$\mathrm{MSE}=$ mean square error (from ANOVA)

$\mathrm{n}=$ number of replicates in means

\section{Sample calculation:}

Performing a two-way ANOVA on TTHM formation $(\mu \mathrm{g} / \mathrm{L})$ with humics $(\mathrm{mg} / \mathrm{L})$ as the primary effect and water source as the secondary affect, the ANOVA model is given by:

$$
y_{i j}=\mu+A_{i j}+B_{i j}+(A B)_{i j}+\varepsilon_{i j}
$$

where: $\quad \mu=$ the grand mean of the TTHM concentration observations

$\mathrm{A}=$ the effect of humics $(\mathrm{mg} / \mathrm{L})$ content

$\mathrm{B}=$ the effect of water source

$\mathrm{AB}=$ the effect of interaction between $\mathrm{A}$ and $\mathrm{B}$

$\varepsilon=$ normally distributed random error (zero mean)

$\mathrm{i}=$ index of experimental units $(1,2)$

$\mathrm{j}=$ level of samples (1-6) 
The following F-ratios, p-values and MSE are obtained using JMP 9.0:

Table 8.36 - Two-way ANOVA

\begin{tabular}{|c|c|c|c|}
\hline & F-ratio & p-value & MSE \\
\hline Effect of humics (mg/L) & 6.909 & 0.013 & 259.96 \\
\hline Effect of water source & $\mathbf{1 2 2 . 1 9 7}$ & $\mathbf{0 . 0 0 0 1}$ & \\
\hline Effect of interaction & 1.909 & 0.166 & \\
\hline
\end{tabular}

- Values in bold indicate correlations that are significant $(\mathrm{p}<0.01)$

There was a significant effect of water source on TTHM formation at a 99\% confidence level for the three source waters. Post hoc comparisons using Tukey's HSD test was applied to determine where this significant effect between the source waters was.

$$
H S D=q_{0.05,6} \sqrt{\frac{M S E}{n}}=(2.465) \sqrt{\frac{259.96}{2}}=28.11
$$

The difference between source waters is significant if the difference between their least squares means (LS means) is greater than HSD.

Table 8.37 - Tukey's HSD - LS means of water sources

\begin{tabular}{|c|c|}
\hline Water Source & LS Means \\
\hline Ottawa River & 94.602 \\
\hline Otonabee River & 124.803 \\
\hline Lake Simcoe & 53.538 \\
\hline
\end{tabular}

Table 8.38 - Tukey's HSD - Difference between LS means

\begin{tabular}{|c|c|c|c|}
\hline & Ottawa River & Otonabee River & Lake Simcoe \\
\hline Ottawa River & & 30.200 & 41.064 \\
\hline Otonabee River & & & 71.265 \\
\hline Lake Simcoe & & & \\
\hline
\end{tabular}

Since the differences between LS means of all three source waters are greater than HSD, water source was determined to be a significant factor on TTHM formation in this study. 